\title{
All you need is ... home care : matches between home care needed, indicated and delivered; a study among chronic patients
}

Citation for published version (APA):

Algera, M. (2005). All you need is ... home care : matches between home care needed, indicated and delivered; a study among chronic patients. [Doctoral Thesis, Maastricht University]. Universiteit Maastricht. https://doi.org/10.26481/dis.20050429ma

Document status and date:

Published: 01/01/2005

DOI:

10.26481/dis.20050429ma

Document Version:

Publisher's PDF, also known as Version of record

Please check the document version of this publication:

- A submitted manuscript is the version of the article upon submission and before peer-review. There can be important differences between the submitted version and the official published version of record.

People interested in the research are advised to contact the author for the final version of the publication, or visit the DOI to the publisher's website.

- The final author version and the galley proof are versions of the publication after peer review.

- The final published version features the final layout of the paper including the volume, issue and page numbers.

Link to publication

\footnotetext{
General rights rights.

- You may freely distribute the URL identifying the publication in the public portal. please follow below link for the End User Agreement:

www.umlib.nl/taverne-license

Take down policy

If you believe that this document breaches copyright please contact us at:

repository@maastrichtuniversity.nl

providing details and we will investigate your claim.
}

Copyright and moral rights for the publications made accessible in the public portal are retained by the authors and/or other copyright owners and it is a condition of accessing publications that users recognise and abide by the legal requirements associated with these

- Users may download and print one copy of any publication from the public portal for the purpose of private study or research.

- You may not further distribute the material or use it for any profit-making activity or commercial gain

If the publication is distributed under the terms of Article $25 \mathrm{fa}$ of the Dutch Copyright Act, indicated by the "Taverne" license above, 


\section{All you need is... home care}

Matches between home care needed, indicated and delivered;

a study among chronic patients

\section{PROEFSCHRIFT}

ter verkrijging van de graad van doctor aan

de Universiteit Maastricht,

op gezag van de Rector Magnificus Prof. mr. G.P.M.F. Mols

volgens het besluit van het College van Decanen

in het openbaar te verdedigen

op vrijdag 29 april 2005 om 12.00 uur

door

Marco Algera 


\section{Promotor:}

Prof. dr. J. van der Zee

\section{Co-promotor:}

Mw. dr. A.L. Francke (Nivel)

Beoordelingscommissie:

Prof. dr. C. Spreeuwenberg

Mw. prof. dr. G.A.M. van den Bos (Universiteit van Amsterdam)

Dr. J. Hamers

Prof. dr. G.I.J.M. Kempen

Prof. dr. M.W. Ribbe (Vrije Universiteit Amsterdam)

The study presented in this book was funded by NWO-ZOB (Zorg, Opvang en Begeleiding; Netherlands Organisation of Scientific Research, programme Care and Support), the Netherlands. 


\section{Contents}

1. Overview 7

2. Home care needs of patients with long-term conditions:

literature review

3. 'New-style' needs assessment in the care chain; a study of the literature on the feasibility of the objectives of the 'new style' needs assessment and realising the care chain

4. An evaluation of the new home care needs assessment policy in the Netherlands

5. The match between Dutch chronic patients' felt need and demand for home care and subsequent needs assessment

6. Care indicated and home care delivered: do they match in Dutch chronic patients?

7. The match between Dutch chronic patients' felt need and home care delivered and its determinants

Summary

Samenvatting

Reference list

Dankwoord

Curriculum vitae 
1 Overview 


\subsection{What is this thesis about?}

This thesis regards the match between the chronic patients' felt need for care and the subsequent delivery of home care. It also investigates whether specific characteristics influence this need-delivery match. This needdelivery match is made up by two submatches: the match between the Dutch chronic patients' felt need and the care indicated by independent regional assessment agencies on the one hand and the match between care indicated and professional home care delivered on the other.

Factors that may influence the need-delivery match and its submatches that we investigated are characteristics of chronically ill patients, assessment agencies, and home care organisations. Concerning this match and its two submatches, we distinguish between the perceived matches (the patient's opinion) and the actual matches that we derived by record study. Figure 1.1 shows the research model.

We focus on chronic patients for whom home care is indicated. In 2001, assessment agencies assessed 520,000 cases, 75\% of which involved home care (Van Campen \& Van Gameren, 2003). More and more of this home care is to be delivered to the chronically ill.

We define 'needs assessment' as the result of a formalised process of objectively determining the need for care, and subsequently prescribing adequate care according to type, content, and amount of care (Nationale Raad voor de Volksgezondheid, 1994). In this context, the needs for care concern the patient's health-related care deficits. 
Figure 1.1 Research model: the matches between patient's felt need, care indicated, and home care delivered, and factors possibly influencing these matches

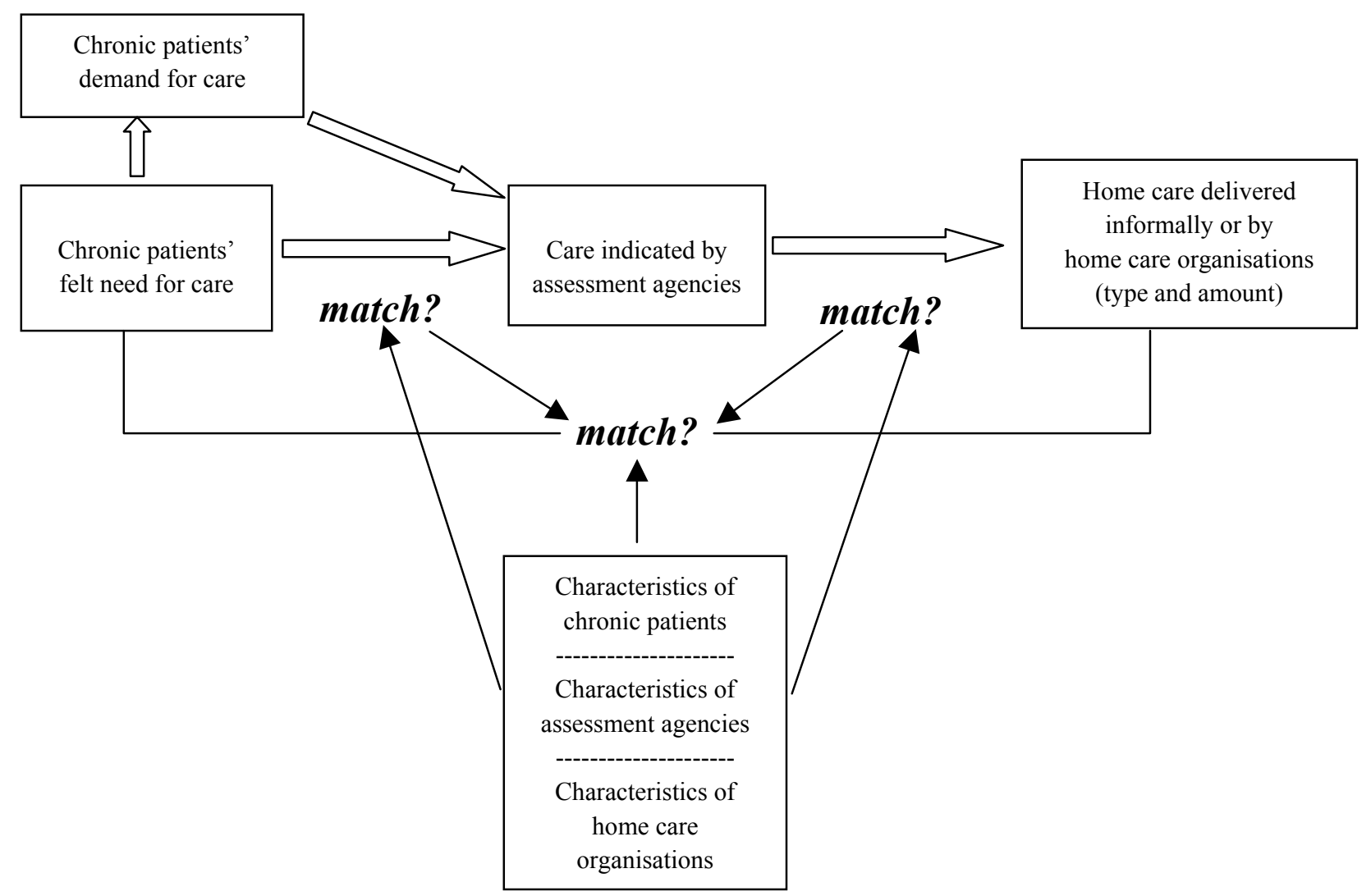


The research project encompassed several studies, all mentioned in Figure 1.2 .

Figure 1.2 Overview of the research project

\begin{tabular}{|c|c|}
\hline Studies & Methods \\
\hline $\begin{array}{l}\text { Literature study on: } \\
\text { Factors influencing match between the } \\
\text { patient's felt need and delivery of home } \\
\text { care (Chapter } 2 \text { ) }\end{array}$ & $\begin{array}{l}\text { Screening research papers on home care } \\
\text { use by the chronically ill and research } \\
\text { papers on unmet need }\end{array}$ \\
\hline $\begin{array}{l}\text { Feasibility of objectives of independent } \\
\text { needs assessment (Chapter } 3 \text { ) }\end{array}$ & $\begin{array}{l}\text { Screening research reports and 'quick } \\
\text { scans' on independent needs assessment in } \\
\text { the Netherlands }\end{array}$ \\
\hline $\begin{array}{l}\text { Study among assessment agencies and } \\
\text { home care organisations to gain insight } \\
\text { into their opinions on independent needs } \\
\text { assessment and factors influencing their } \\
\text { opinions (Chapter 4) }\end{array}$ & $\begin{array}{l}\text { Descriptive statistics and multiple } \\
\text { regression analyses of data gathered from } \\
\text { assessment agencies and home care } \\
\text { organisations on their evaluations of the } \\
\text { independent needs assessment }\end{array}$ \\
\hline $\begin{array}{l}\text { Study among chronically ill home care } \\
\text { users and record study to gain insight into: } \\
\text { Adequacy of the match between felt need } \\
\text { and demand for home care, and its } \\
\text { influencing factors (Chapter 5) } \\
\text { Adequacy of the match between felt need } \\
\text { and care indicated, and its influencing } \\
\text { factors (Chapter 5) } \\
\text { Adequacy of the match between care } \\
\text { indicated and professional home care } \\
\text { delivered and its influencing factors } \\
\text { (Chapter } 6 \text { ) } \\
\text { Adequacy of the match between felt need } \\
\text { and home care delivered, taking the two } \\
\text { composing submatches into account, and } \\
\text { its influencing factors (Chapter } 7 \text { ) }\end{array}$ & $\begin{array}{l}\text { Multi-level analyses and cross-tabulations } \\
\text { of } \\
\text { (a) data gathered from patients } \\
\text { (telephone interviews) on felt need, } \\
\text { home care received, and their } \\
\text { perception of matches } \\
\text { (b) data gathered from assessment } \\
\text { agencies' and home care } \\
\text { organisations' records on the } \\
\text { adequacy of the actual matches }\end{array}$ \\
\hline
\end{tabular}


This chapter gives an overview of the main findings of the entire research project. Subsequently, it answers the following questions (the numbers of the questions correspond with the numbers of the sections in this chapter):

1. What is this thesis about?

2. Why has attention for the need-delivery match intensified?

3. What factors influence the need-delivery match according to literature?

4. What are the objectives of the independent needs assessment as an intermediary in the need-delivery match?

5. Which actors are involved in the care chain holding their responsibilities in attaining a need-delivery match?

6. Are the objectives of the independent needs assessment feasible in practice?

7. What do the relevant organisations think of the independent needs assessment?

8. To what extent are the matches within the care chain adequate?

9. What characteristics influence the matches under study?

In each of the above mentioned sections, the answer to the question is discussed. After that, the value of the entire study is discussed in great length. It concerns the following aspects and sections:

10. Methodological issues and restrictions of the study;

11. Implications for practice;

12. Policy implications;

13. Implications for future research;

14. General conclusion. 


\subsection{Why has attention for the need-delivery match intensified?}

The need-care delivery match has received intensified attention from governments as well as patient organisations during the last decades. Societal developments and changing points of view in healthcare were at the base of this increased interest. They include:

- the ageing of Western societies and the inherent growth of the proportion of chronically ill;

- substitution of resident care for outpatient care (among which: home care);

- patient empowerment.

\subsubsection{People's ageing and the prevalence of chronic diseases}

Most industrialised Western countries are now facing the ageing of their populations. Currently, about $14 \%$ of all Dutch citizens are over 65 (Centraal Bureau voor de Statistiek, 2003a). In 2010, the percentage of the elderly in society is estimated to be almost $15 \%$ and this figure will be about $23 \%$ in 2040 (Sociaal Economische Raad, 1999; Centraal Bureau voor de Statistiek, 2003a). Not only does the proportion of senior citizens increase, the proportion of the old-old $(80+)$ increases as well (Van Oers, 2002; Centraal Bureau voor de Statistiek, 2003b). Because of better nutrition, education, and financial resources, but also because of ever-progressing healthcare, people tend to live longer. Although some diseases that were once lethal can be cured now, there are other diseases that cannot, while new chronic, lifestyle-related diseases are emerging. Although the disabilities caused by chronic diseases may be diminished by healthcare and/or assistive technology, more and more people suffer from a chronic disease or several chronic diseases concurrently (comorbidity) as a result of population ageing (Joung et al., 2001; Van Oers, 2002). Van der Windt et al. (2003) estimated that about $36 \%$ of those over 65 suffered from at least one chronic disease in 1990. In 2000, this had increased to $41 \%$ of the Dutch population and to $70 \%$ of Dutch senior citizens (Centraal Bureau voor de Statistiek, 2003b). In 2015 , the incidence and prevalence figures of various chronic diseases will have increased by $25-60 \%$ (Van Oers, 2002). In turn, the rapidly growing prevalence of suffering from one or more chronic diseases has led to an intensified demand for healthcare, especially home care and long-term care, and will continue to do so (Van der Windt et al., 2003). 


\subsubsection{Increased use of home care}

The demand for home care has been extended by another societal development as well: the substitution of resident or inpatient care (nursing home or home for the elderly) for home care (Degen \& Huijsman, 1999; Tweede Kamer der Staten-Generaal, 2000-2001a). The Dutch government promotes such substitution of care because most people want to live in their own homes as long as possible, and they do not want to be institutionalised if it can be avoided (Tweede Kamer der Staten-Generaal, 2000-2001b). The Dutch government also prefers outpatient care (among which: home care) to institutionalised care for economic reasons. Many other Western governments also see themselves faced with the necessity of cutting costs in healthcare. Rationing healthcare provision will be an inevitable consequence. However, the rationing of available resources should be done equitably (Degen \& Huijsman, 1999; Jörg, 2002). 'Cream skimming' in seeking to serve only the patients with the least costly needs was considered an injustice (Jörg, 2002). The Dutch patients' movement also voiced this criticism regarding home care: because the home care organisations controlled both the needs assessment and the delivery of home care, chronic patients in particular were to receive less care than they needed or they received the wrong type of care (Bellemakers, 1995; Dijkstra, 2001; Schrijvers, 2001). Needs assessment had been more of a political instrument for the care providers and financiers than an impetus to provide customised care (Degen \& Huijsman, 1999).

\subsubsection{Patient empowerment}

A concomitant societal development is the call for patient empowerment, on the macro-level in health policy and on the micro-level in the care provision. This concerns primarily chronic patients because of their greater and in many cases life-long dependency on healthcare facilities (Rijken \& Spreeuwenberg, 2004). Therefore, the focus on the patient's demand for care had to replace the traditional supply orientation of healthcare (Breed Indicatie Overleg, 1997; Ministerie van Volksgezondheid, Welzijn \& Sport, 1997, 2001; Tweede Kamer der Staten-Generaal, 1998-1999). It should be the patient who is the focal point in care provision, not the availability of care. Care delivered should be tailor-made in that the specific needs of the patient should be addressed, initially irrespective of the interests of the care provider. 
In summary, then, among the ongoing developments in society and in healthcare is the expected gradual but continuous increase of the proportion of the aged in society, which will lead to more suffering from chronic diseases. This will result in an extended need for home care. In addition, forced by economic scarcity, the Dutch government prefers home care to institutionalised care, i.e. substitution, whereas the patients themselves have grown more assertive in getting what they think is best for them (patient empowerment, tailor-made care, and demand-driven care policy).

All of these developments have increased the attention to the need-delivery match because the ever-increasing care requirement due to demographic developments should be addressed, despite limited budgets. Therefore, the government is interested in matching the delivery of care with the patient's needs in the most efficient way. Furthermore, the patients themselves oblige to be served adequately, as is exemplified by recent successful claims in Dutch courts for adequate home care delivery.

An independent style of needs assessment was introduced in 1998 in the Netherlands to fulfil the government's and patients' requirements (see Section 1.4).

\subsection{What factors influence the need-delivery match according to literature?}

The relevance of studying the factors influencing the need-delivery match seems obvious. In a literature study (see Figure 1.2), we investigated these factors focused on the need-delivery match for chronically ill home care users, as they will form the most relevant subpopulation in the near future (see Section 1.2).

Our main research question for the literature study was: Which patient or healthcare system characteristics influence the match between the chronic patient's need for care and their actual use of professional home care?

However, in the initial phase of our literature review, it became clear that there was little literature on the determinants of the match or mismatch between the chronic patient's need for care and home care delivery: only two 
studies were found. Since we assumed characteristics determining this match to be virtually identical to characteristics influencing the actual delivery of home care, we opted for including the latter factors as well. In this respect, we argue that 'home care delivery' and 'home care use' are interchangeable terms, toward which only the perspective is different (home care organisations' versus the patients').

As found in the classification in the Behavioural Model of Health Services Use (Andersen \& Newman, 1973; Andersen, 1995), we distinguished three categories of patient-related characteristics:

- predisposing characteristics, which refer to the characteristics of patients that may influence the likelihood of their using healthcare services. Examples of this kind of characteristics are age and sex;

- enabling resources, which concern the patient's opportunities to use the healthcare system. Income, education, and type of health insurance have often been noted as relevant factors here;

- need factors, which refer to the necessity for consuming healthcare services, often because of some illness. Need factors include the impediments to the instrumental activities of daily life, diagnoses, and comorbidity.

In the Andersen \& Newman model, patient and healthcare system characteristics were related to healthcare use. However, in our adapted model (see Chapter 2), as we just have noted, we assumed that these characteristics would not only influence use, but also the match between need and actual home care use.

Only 13 studies matched our inclusion criteria for review (see Chapter 2). The studies were all performed in the USA and in the Netherlands. Two of them focused on the match between need and home care use by the chronically ill. The other papers dealt with factors influencing whether the chronically ill make use of home care, or they were directed at factors influencing the amount of home care use.

In one study, a mismatch between need and use, i.e. unmet need, was significantly related to being younger or male (Scholte op Reimer, 1999), but this finding was not confirmed by the other study (Katz et al., 2000). Neither study was able to significantly associate either living arrangements (composition of the household), education, various health-related 
characteristics or healthcare system characteristics to unmet home care need.

With respect to studies focusing on just professional home care use (instead of its match with the patient's need), some studies revealed a significant influence of healthcare system characteristics, such as fewer nursing home beds (Kenney, 1993) or the general practitioner being informed of the chronic patient's discharge from hospital (De Haan et al., 1993).

Most studies of home care use included in our review aimed at patientrelated characteristics. With respect to age, most studies confirmed the expectations: the older the chronic patient, the more likely professional home care was used (De Haan et al., 1993; Kenney, 1993; Kane et al., 1994; Freiman \& Breen, 1997; Riemsma et al., 1998; Scholte op Reimer, 1999; London et al., 2001).

Most studies describing the effect of gender on home care use found that women use home care more often (De Haan et al., 1993; Kenney, 1993; Fleishman, 1997; Freiman \& Breen, 1997; Riemsma et al., 1998; London et al., 2001).

The studies reviewed seem to contradict each other on a third wellresearched predisposing characteristic: living arrangements. Some studies showed significantly more home care delivery when patients were living alone (De Haan et al., 1993; Riemsma et al., 1998; Scholte op Reimer, 1999), whereas others indicated that patients living with others use more (Ettner \& Weissman, 1994; Kane et al., 1994; Freiman \& Breen, 1997).

The influence of enabling resources such as insurance and income proved not to be unidirectional. However, since professional home care in the Netherlands is reimbursed by the Exceptional Medical Expenses Act (AWBZ; see Figure 1.3), in the Dutch setting these enabling resources seem less relevant. In addition, in most studies education and urbanisation proved not to be predictive of home care use.

Illness-related need factors were more frequently found to be significantly influential. Although the main diagnosis of chronic illness appeared not to influence home care use, comorbidity did. Riemsma et al. (1998) reported that comorbidity and longer disease duration generally lead to more use of 
home care. Furthermore, having physical or domestic impairments may increase the use of home care.

Finally, past inpatient healthcare use was significantly associated with professional home care use (London et al., 2001).

Figure 1.3 Features of the Dutch Exceptional Medical Expenses Act

\section{Dutch Exceptional Medical Expenses Act (AWBZ)}

- Collective insurance of all Dutch citizens

- Insurance for expenses for long-term care or home care use

- Accounting for about $40 \%$ of all healthcare expenditures in the Netherlands (Van Campen \& Van Gameren, 2003)

- Needs assessment by independent regional assessment agencies (since 1998) is considered to be the entrance ticket to benefit from the Exceptional Medical Expenses Act

\section{Discussion on characteristics influencing the need-delivery match according to the literature}

Reviewing the scarce literature on the match between need and professional home care delivery or on home care use separately, only a few platitudes were confirmed; age (older people using more), sex (women using more), and having impairments (higher use) are significantly influential on home care use. The influence of other characteristics proved either insignificant, the results of the studies were contradictory, or such influence was considered less relevant in the Dutch setting (Algera et al., 2004a).

Considering the importance of the subject, especially regarding near-future demographics and the inherent developments of the healthcare system, the lack of a vast body of knowledge on factors influencing the chronic patient's use of home care and its match with the patient's need is remarkable. Our empirical study (see Section 1.8 and Chapters 5-7) was designed to contribute to closing this gap in research. 


\subsection{What are the objectives of the independent needs assessment as an intermediary in the need-delivery match?}

According to the Dutch government, societal developments (see Section 1.2) made a revision of the Dutch Exceptional Medical Expenses Act (see Figure 1.3) inevitable, notwithstanding the lack of evidence-based knowledge about factors influencing the chronic patient's need-delivery match in home care. The modernisation of the Exceptional Medical Expenses Act aimed to address all of the aforementioned societal developments. It encompassed two main instruments for realising more updated legislation: (1) independent needs assessment in which need and delivery of care were better linked and (2) the care chain (see Section 1.5) (Tweede Kamer der Staten-Generaal, 1998-1999). The needs assessment by independent regional assessment agencies was to be located in the care chain.

In addition to the reasons for updating the Exceptional Medical Expenses Act (see Section 1.2), other developments prompted renewing the assessment procedures as well. One of these developments was the merger, in the 1990s, of organisations for home help with district nursing organisations into integrated home care organisations. In organisations for home help, it had been customary to separate the needs assessment and care planning from the actual delivery of care. After the merger, the needs assessment was taken out of the hands of the district nurse: separate intake offices were established within the home care organisations (Hutten \& Kerkstra, 2002). This process led the way to a further separation of needs assessment and care provision, but until 1998, both activities were still within the jurisdiction of the home care organisations.

Concurrently with the other developments mentioned, the Dutch government attempted to remove the financial and other barriers between the various healthcare facilities (Tweede Kamer der Staten-Generaal, 1998-1999). This was intended to lead to integrated care and a one-entry system for patients with a demand for more than one kind of care (Ministerie van Volksgezondheid, Welzijn \& Sport, 1997).

The general societal developments and those more closely related to the healthcare system became the motivation for new legislation, the Care Needs Assessment Decree of 1997 (in Dutch: Zorgindicatiebesluit) (Ministerie van 
Volksgezondheid, Welzijn \& Sport, 1997). This decree provided for establishing independent regional assessment agencies (see Section 1.5 for a more detailed description). In 2000, there were over 80 assessment agencies (Algera et al., 2003). In later years, there was a move toward large-scale economies and an eventual reduction to about 60 assessment agencies, still covering the entire country. In 2006, the needs assessment will be centralised into one national Centre for needs assessment in healthcare with local agencies.

Three objectives, or points of departure, for new-style needs assessment were outlined in the Care Needs Assessment Decree. These objectives were to achieve more independence, more objectivity, and an integrated approach to needs assessment for care (Breed Indicatie Overleg, 1997; Ministerie van Volksgezondheid, Welzijn \& Sport, 1997). The new-style needs assessment was considered a main tool for adequately bringing the patient's need and delivery of care together.

- Independence meant that the patient's real needs for care had to be determined separately from the availability of care. Not only should the needs assessment be independent of the capacity of the healthcare system and financial considerations, it should also be irrespective of the patient's demand for care, since felt need for care and demand for care do not always correspond (see Section 1.5) and since the patient's demand may be beyond the scope of reimbursable healthcare (Schippers, 2001). The assessor's professional decision about the care to be indicated to address the patient's need was intended to promote independence.

- Objectivity had to be obtained by separating the needs assessment, as far as possible, from the subjective opinions of the individual assessor. Subjectivity on the part of the assessor would be limited by making use of protocols and standardised assessment forms in order to reduce inequitable treatment. Until 2003, the use of the assessment forms was recommended, but not compulsory. In addition, objective needs assessment would facilitate adequate testing of assessment decisions (Breed Indicatie Overleg, 1997). Thus, the objectivity that was sought had primarily to do with uniformity.

- An integrated approach would promote assessments across the boundaries of the different types of care reimbursed by the Exceptional Medical Expenses Act and the Facilities for the Handicapped Act (in Dutch: Wet Voorzieningen Gehandicapten: $W V G)$. By the latter Act, 
home adaptations, assistive technology devices, and transport facilities are reimbursed. Assessing only care needs in the area of home care would not suffice. The same assessor should be able to assess the needs for additional day care, for specific adjustments to the house, or for admission to a home for the elderly or to a nursing home if the needs happen to relate to any of these areas. Primarily, coherence between the various types of care had to be sought. The idea was a one-stop shop. Differences in the type of funding (for example via the Exceptional Medical Expenses Act or the Facilities for the Handicapped Act) should no longer be a reason for a separate assessment of the patient's needs (Tweede Kamer der Staten-Generaal, 1998-1999). The intended needsled organisation of healthcare would most clearly be achieved in an integrated approach to the assessment of the patient's needs (Schrijvers \& Heinsbroek, 1998).

\subsection{Which actors are involved in the care chain holding their responsibilities in attaining a need-delivery match?}

The sequence from needing care through needs assessment to receiving home care is referred to as the 'care chain'. In this chain, patients, assessment agencies, health insurance agencies, and professional care providers, such as home care organisations, are actors with specific relationships to one another (Breed Indicatie Overleg, 1997; Ministerie van Volksgezondheid, Welzijn \& Sport, 1997; Tweede Kamer der StatenGeneraal, 1998-1999). The appropriate transfer of the patient from one link of the chain to the next was intended to be conditional on achieving an adequate match between the patient's felt need and subsequent use of home care or another type of care. Figure 1.4 illustrates the care chain. Below, the roles allotted by the government to each of the actors are briefly outlined. See Chapter 3 for a more detailed discussion of these roles. 
Figure 1.4 Care chain from needing care to receiving it

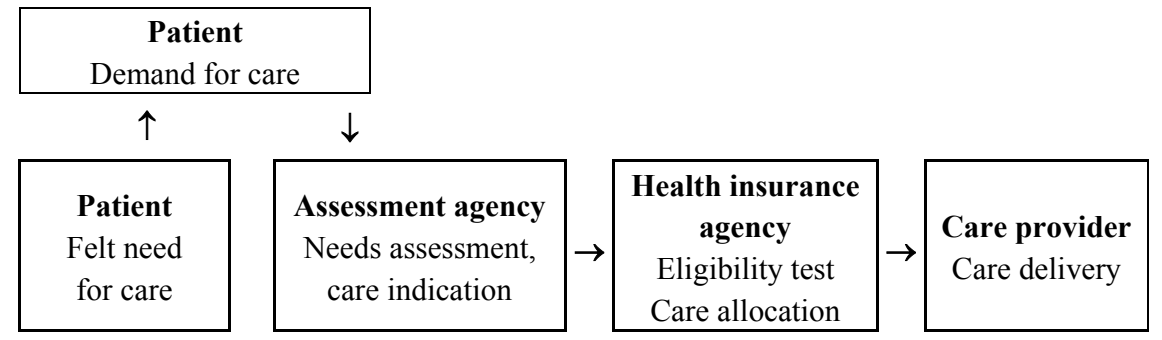

\subsubsection{The patient}

The patient is the starting point of the care chain. When a patient, or those around him/her, notice a need for care that can no longer be met by the patient alone or by the informal carers, this felt need for care is translated into a demand for care, which is subsequently reported to the assessment agency. Patients can present the demand for care themselves, as can informal carers or the general practitioner.

\subsubsection{The Regional Assessment Agency}

When the patient has presented the demand for care at the regional assessment agency (in Dutch: Regionaal Indicatie-Orgaan or RIO), or when a care provider has referred the patient to such an agency, then the second stage in the care chain has been reached (see Figure 1.4).

The needs assessor will take the patient's demand for care merely as a starting point. The assessment agency will investigate the patient's underlying need, whether or not felt by the patient.

Initially, assessment agencies addressed only demands for home care and admission to a home for the elderly or a nursing home (Ministerie van Volksgezondheid, Welzijn \& Sport, 1997). In the years that followed, the assessment agencies' domain expanded to a great extent. Now it also includes the needs assessment for mental care, for the mentally and physically handicapped, and for specific provisions in the area of the Facilities for the Handicapped Act (Ministerie van Volksgezondheid, Welzijn \& Sport, 1999, 2000). Next to these obligatory assessment fields, assessments of needs for a wide variety of social welfare facilities were optional.

Although need for home care is within the assessment agencies' mandatory 
domain, not all needs for home care have to be assessed by an assessment agency. According to the Care Needs Assessment Decree (Ministerie van Volksgezondheid, Welzijn \& Sport, 1997) assessment agencies may authorise home care organisations to assess evident, non-complex needs for home care (e.g. administering eye drops or putting on support stockings).

The assessment agencies' objectives - an independent, objective, and integrated approach to needs assessment and care indication - were described in the previous section.

\subsubsection{Health insurance agency}

The role of the health insurance agency (in Dutch: zorgkantoor) within the care chain is not very explicitly laid down in the Care Needs Assessment Decree (Tweede Kamer der Staten-Generaal, 1998-1999; Ministerie van Volksgezondheid, Welzijn \& Sport, 1999). This role concerns rather standard tests of the patient's eligibility for care. Furthermore, these organisations should mediate when there are waiting lists. However, with respect to home care, health insurance agencies hardly play a role in the care chain because assessment agencies usually send the assessment reports, i.e. the assessment agency's decision on the type and amount of care that the patient needs, directly to the home care organisation. That may also be the reason why, in many cases, health insurance agencies appear unable to give an opinion about the assessment agencies or independent needs assessment. Chapter 4 describes a study in which the health insurance agencies were involved. However, for the purposes of this overview, we opted not to discuss this link further.

\subsubsection{The care provider}

The last link in the care chain (the care provider) remained unchanged in its role of the provision of care. In the case of home care organisations, care providers formerly had the authority to determine the nature and scope of the care they themselves delivered. In realising the modernisation of the Exceptional Medical Expenses Act, they had to hand that authority over to the assessment agencies (Ministerie van Volksgezondheid, Welzijn \& Sport, 1997, 2000).

The care indicated by the assessment agency has a certain period of validity. Also, margins (bandwidths) are mentioned in the assessment report, within which the care provider is free to increase the amount of care to be delivered 
without consulting the assessment agency first.

In the Netherlands, professional home care consists of IADL-care (i.e. care concerning Instrumental Activities of Daily Life, also referred to as domestic care or home help), ADL-care (i.e. care concerning Activities of Daily Life, also referred to as physical or personal care, technical nursing care, and psychosocial care). Professionals deliver all these types of care at the patient's home (Hutten \& Kerkstra, 2002).

\subsubsection{Discussion on the organisation of the care chain}

In summary: after the patient has presented a demand for care at the assessment agency's office ('This is what I want'), an assessor usually makes a home visit to determine the care needed ('This is what you need'). Eventually, the care provider most eligible to deliver the allocated care starts giving care to the patient, initially on the basis of the assessment report ('This is what you will receive').

The assessment agency's 'evaluated need' does not always reflect the patient's felt need or demand for care, as is widely recognised in literature (Huijsman, 1990; Kerkstra et al., 1990; Beemsterboer, 2000; SGBO, 2000; Jörg, 2002; Van Campen \& Van Gameren, 2003). This incongruity may be caused by the patient's ignorance of the various possibilities of care provision, embarrassment about asking for help, distrust or dislike of the healthcare system, or out-of-scope demands (Jedeloo, 2002). In addition, awareness of waiting lists for care or other restraints for receiving care may inhibit asking for help at all (Parry-Jones \& Soulsby, 2001).

\subsection{Are the objectives of the independent needs assessment feasible in practice?}

In our second literature study (see Figure 1.2 and Chapter 3; Algera et al., 2002), the main research question was: What does already performed research indicate about the feasibility of the objectives of independent needs assessment? Five research reports and three quick scans were included in this literature study. The material focused mainly on the assessment agencies, but the subject of one research report was the home care organisations. All of them concerned descriptive studies. 
In addition, we gathered new data on this topic in an empirical study among assessment agencies and home care organisations (see Figure 1.2 and Chapter 4; Algera et al., 2003). One of our research questions was: Has the Dutch needs assessment process been implemented according to the main elements of the Care Needs Assessment Decree, as far as the objectives and the contents of the assessment report are concerned?

In 2000, all 85 assessment agencies and all 114 acknowledged home care organisations in the Netherlands were approached with a written questionnaire. The response rate of these organisations was high $(92 \%$ and $81 \%$, respectively) (Algera et al., 2003). Each questionnaire referred to the role that the specific type of organisation played in the procedures of the independent needs assessment, such as the activities of these organisations. Background information and evaluations of the independent needs assessment have also been gathered by means of the surveys. Experts in the respective fields judged the questionnaires on content validity.

In this section, the results of both of these studies - our literature study and our empirical study - will be used to provide insight into the feasibility of the objectives of the independent needs assessment.

In comparing the Care Needs Assessment Decree with the needs assessment in practice, we primarily considered its objectives. For starters, the establishment of over 80 assessment agencies in itself was a concrete realisation of the Care Needs Assessment Decree. By definition, the needs assessment in home care was separated from the delivery of it.

\subsubsection{Independence}

Our literature review (Algera et al., 2002) demonstrated that about one-third of the assessment agencies produced rather a-specific assessment reports (SGBO, 2000). This may threaten the independence of the needs assessment because home care organisations would still be able to effectuate the aspecific assessment reports in a way as is suitable for them regarding the availability of home care. The exception made in the Care Needs Assessment Decree with regard to authorisation arrangements for home care organisations in assessing non-complex home care needs (see Section 1.5) might also endanger the independence. Nonetheless, skipping one link in the 
chain from needing to receiving care may be more patient friendly and is certainly less bureaucratic, especially for non-complex home care needs. Although the handling of some of these needs is strictly protocolised, in many cases it is unclear whether a specific home care need should be classified as non-complex (STIP, 1999, 2000). Not only the complexity of individual care activities, but also the number of types of care may be aspects of the complexity of home care need. In some cases, the estimated duration of the care may play a role in the complexity.

In our empirical study among the relevant organisations (Algera et al., 2003), two out of three assessment agencies did not authorise, or no longer authorised, the assessment of non-complex home care needs to home care organisations. However, $9 \%(n=7)$ of the assessment agencies let the home care organisations perform these assessments, whereas another $24 \%(n=19)$ had arrangements with liaison nurses to assess home care needs for patients to be discharged from hospital. Conversely, three out of four home care organisations stated that they no longer had anything to do with needs assessment, while the others still were assessing non-complex home care needs.

\subsubsection{Objectivity}

Objectivity has to do with uniformity. Our literature review (Algera et al., 2002) showed that needs assessments and the resulting assessment reports were very diverse in terms of their periods of validity, urgency criteria, and bandwidths (the degrees of freedom within the assessment decision) (STIP, 1999). Some of these differences could be attributed to mere matters of definition (SGBO, 2000). For example, the categories for determining urgency were not uniform: in one assessment agency, 'very urgent' implied home care starting within a week, and in another, within three months (SGBO, 2000). In addition, appeal procedures for cases in which the patient is dissatisfied with the outcome of the needs assessment (the care indicated) were organised quite diversely (Schrijvers \& Ravelli, 2000). The SGBO makes the lack in uniformity more relative by stating that although between the assessment agencies there were major differences (and this was true for many areas), within the assessment agencies the needs assessment and its organisation was relatively uniform due to the use of assessment-agencybound protocols. However, Jörg's research (2002) into inter-assessor reliability showed that assessors, even of the same assessment agency, 
assessed identical cases (vignettes) completely differently. In the case of home care, this often resulted in a diverging amount of care indicated. These differences might promote an inequitable approach. An assessment by another agency might, as a result of the pluriform approach, yield a totally different care indication (SGBO, 2000). Dijkstra (2001) and Jörg (2002) stipulate that true objectivity is utopian, and even undesirable. They argue that not all patients with comparable needs should have the same type and amount of care indicated for them because extraneous individual circumstances should be taken into account as well. Objectivity should be achieved by offering patients with comparable needs the opportunity of receiving the same type and amount of care (Jörg, 2002).

Our empirical study (Algera et al., 2003) showed that most assessment agencies appeared to use the recommended assessment forms either completely $(45 \%, n=35)$ or partially $(41 \%, n=32)$. Half of the home care organisations authorised to assess home care needs did not use the national recommended assessment forms, but most of them $(62 \%, n=8)$ had based their own assessment forms on the national protocol, but had made some adjustments to suit their situation.

\subsubsection{Integrated approach}

The integrated approach to needs assessment has been materialised in assessment agencies' rather large domains (a domain consists of the many assessment fields a single assessment agency addresses). Part of the domain is obligatory, another part is optional. Our empirical study (Algera et al., 2003) showed a very diverse domain (Table 1.1). Other research reports confirm this observation (see Chapter 4). A broad domain may be conditional for a more integrated approach. However, a broad domain would imply that the assessment agency as a whole has a broad scope, but not necessarily so its individual assessors. Given the diverse professional backgrounds of needs assessors and the fact that the profession is in its initial phase, an integrated approach can hardly be expected at this time (SGBO, 2000; Schrijvers, 2001).

In addition, the integrated approach to needs assessment is limited by the authorisation arrangements for home care organisations because authorised home care organisations will only deal with demands in the area of home care. As a result, it is possible that other, latent or unexpressed needs for 
care, for example, day care, will not be included in the assessment (Beemsterboer, 2000).

Table 1.1 Domain of needs assessment by assessment agencies in $2000(\mathrm{n}=78)^{*}$

\begin{tabular}{lcc}
\hline Domain of needs assessment & Percentage & Number \\
\hline Compulsory & 100 & 78 \\
Nursing home & 100 & 78 \\
Home for the elderly & & \\
Home care: & 100 & 78 \\
$\quad$ Non-complex needs & 100 & 78 \\
$\quad$ Complex needs & 99 & 77 \\
Individual care budget & 27 & 21 \\
Expensive housing adjustments** & & \\
& & \\
Optional & 97 & 76 \\
Day care / night care & 55 & 43 \\
Sheltered home & 41 & 32 \\
Meals on wheels & 40 & 31 \\
Arousing public awareness & 39 & 30 \\
Other facilities for people with disabilities & 37 & 29 \\
Less-expensive housing adjustments & 33 & 26 \\
Nursing aids & 24 & 19 \\
Supplementary public transport &
\end{tabular}

* Multiple responses allowed

** Became obligatory during the survey

\subsubsection{Care chain}

The functioning of the care chain as a whole proved to be threatened by two features: communication difficulties between needs assessors and home care personnel, and apparently deficient assessment reports (Algera et al., 2002).

The communication between needs assessors and home care personnel was hampered by their use of different vocabularies (Vulto, 1999; Schrijvers, 2001). The level of abstraction on which they communicate about the home care to be delivered appeared to be divergent. In addition, electronic exchangeability of patient-related information between the organisations within the care chain was considered futuristic.

Our empirical study (Algera et al., 2003) considered in this respect the contents of the assessment reports. In these reports, both the type of care and 
the frequency of care to be delivered were always determined by the assessment agency. Most assessment agencies specified the duration of care to be delivered $(92 \%, n=72)$ as well as the validity limit of the report $(91 \%$, $n=71$ ). However, it appears that other specific topics referred to in the Care Needs Assessment Decree were not mentioned by every assessment agency (see Chapter 4). The less frequently mentioned items were the urgency with which care should be delivered, the expertise of the caregiver, a second best option in case the care required was not available, and margins within which the caregiver might expand the frequency or caring time without the need for a reassessment by the assessment agency. Authorised home care organisations' assessment reports, by and large, contained the same elements as the reports of assessment agencies.

\subsubsection{Discussion on feasibility of objectives of independent needs assessment}

In conclusion, it may be stated that, in general, the independent needs assessment process is organised in accordance with what is regulated by law (the Care Needs Assessment Decree) and that all structures to attain the three main objectives of the new-style needs assessment - independent, objective, and integrated needs assessment - seem to be present.

However, authorisation arrangements may endanger the independent and integrated approach to needs assessment, though it may be more patient friendly and is certainly less bureaucratic, especially concerning noncomplex needs for care. From our empirical research, we see that authorisation arrangements were present, but not on a large scale. It should be up to patients and their representing organisations to prioritise the independence of needs assessment versus patient friendliness.

The Dutch National Audit Office (in Dutch: Algemene Rekenkamer), which evaluates government policy, concluded without any reservation that assessment agencies still let the presence of waiting lists influence what the care indicated will be (Tweede Kamer der Staten-Generaal, 1999-2000). This institute viewed lack of independence in needs assessment as a reason for the mismatches within the care chain.

The recommended use of the national assessment forms was to promote the objectivity of needs assessment. Hence, in our empirical study, the use of these forms appeared to be rather widespread. Still, non-use of the 
recommended forms does not automatically imply that a needs assessment is not 'objective'. Only recently, the recommendation for using the assessment forms was changed to an obligation (Tweede Kamer der Staten-Generaal, 2001-2002). However, the many discrepancies between and within assessment agencies regarding individual needs assessments may reduce uniformity and therefore objectivity (Jörg, 2002). In addition, authorised home care organisations will probably not assess needs in a manner that is uniform with that of assessment agencies. This may be a source of pluriform needs assessments as well. Starting from 2005, all the assessment agencies are put under the jurisdiction of one governmental body in stead of being municipal organisations in order to achieve more direct managerial grip on needs assessment and to enhance the coercion of more objectivity (Ministerie van Volksgezondheid, Welzijn \& Sport, 2004).

Not only may authorisation arrangements may hamper an integrated approach to needs assessment, but also inadequate training of needs assessors may be a hindrance. Our empirical study shows that the broad domains of the assessment agencies would enhance an integrated approach, but we argue that a broad domain, though conditional, is not the equivalent of an integrated approach to needs assessment. The assessment agency as a whole may address needs of various kinds, but that does not mean that the individual needs assessor can oversee all the complexity of all the needs that a particular case may present.

Finally, electronic exchangeability of patient-related data would promote better communication and result in better functioning of the care chain as a whole, but it does not seem feasible at this time. Our empirical study reveals rather incomplete assessment reports that omit elements that are required by the Care Needs Assessment Decree. Again, this will leave the home care organisations to fill in the gaps to their liking.

\subsection{What do the relevant organisations think of the independent needs assessment?}

Guided by the following research questions, we tried to gain insight into the evaluation of the independent needs assessment by the relevant organisations in the year 2000 (see Figure 1.2; Algera et al., 2003). The items collecting 
the data about opinions of assessment agencies and home care organisations were integrated in the self-developed questionnaires that we used in the empirical study discussed in the previous section (see also Chapter 4).

1. How do assessment agencies and home care organisations judge the independent needs assessment for home care in comparison to the old needs assessment?

2. How practicable do home care organisations think assessment reports produced by assessment agencies are?

3. Which organisational characteristics of the assessment agencies and/or home care organisations may be related to home care organisations' judgements of assessment agencies?

In comparing the independent needs assessment with the old needs assessment by home care organisations, almost all (over 95\%) assessment agencies felt that the assessment had become more independent, objective, and comprehensive. In the opinion of assessment agencies, the match between home care needs and the assessment of these needs had improved, as had the transparency of the assessment procedure. In addition, the accessibility and efficiency of the assessment procedure had improved according to the assessment agencies. In contrast, respondents employed by home care organisations thoroughly disagreed with the viewpoints of assessment agencies' staff.

The pattern of positive assessment agencies and negative home care organisations also emerged when these organisations were asked about the advantages and disadvantages of the independent needs assessment. It is noteworthy that one quarter of all responding home care organisations did not see any gain from the independent needs assessment at all.

On average, the practicability of the assessment agencies' reports was evaluated by home care organisations as mediocre. While most assessment agencies $(87 \%, n=68)$ thought that they were producing usable (i.e. not too a-specific) assessment reports, only $16 \%(n=14)$ of the home care organisations who had to work with these reports seemed to agree with the assessment agencies' respondents. More strongly, $13 \%(n=11)$ of the home care organisations regarded the assessment agencies' reports as completely useless. Only about $20 \%(n=19)$ of all responding home care organisations judged complementary needs assessment on their own to be, generally, 
redundant. The others thought that the assessment report was not practicable and/or that the period between the needs assessment and the actual care provision was too long, so that the home care needs might have changed in the meantime.

Home care organisations' judgement of the independent needs assessment could not be significantly associated with the characteristics of home care organisations themselves. The only characteristic of assessment agencies that influenced home care organisations' judgement was the magnitude of the assessment agency's domain of needs assessments. No satisfactory explanation of this effect was found.

\section{Discussion on evaluation of independent needs assessment by relevant organisations}

The organisations involved in the care chain appeared to have different opinions about the independent needs assessment and its practical consequences. In general, the assessment agencies were more, or much more, positive about the independent needs assessment than were the home care organisations. The positive, respectively negative attitudes of assessment agencies and home care organisations are not very surprising. Assessment agencies have interests in positive evaluations of their own work and reasons for existence, and home care organisations might have interests in negative attitudes in trying to regain the authority of needs assessment. This may have strongly affected their responses. Of course, it may be that the realisation of independent needs assessment is as adequate as assessment agencies claim it to be or as inadequate as home care organisations assert it to be.

In the study just reported, we let the two main organisations within the care chain as far as home care is concerned, react to the independent needs assessment. This may be seen as an onset to the rest of the research project in which chronic patients are the central focus. To date, no research on the care chain as a chain (and not merely focusing on the separate organisations it includes) has been done. It is not clear, then, how these links connect in practice. Another issue is that only in the second instance the perspective of the patient - the person whom all this should be about - has been included in research on needs assessment (Schrijvers, 2001; Jedeloo, 2002; Jörg, 2002). 


\subsection{To what extent are the matches within the care chain adequate?}

Returning to the main subject of this thesis, we consider it relevant to study the need-delivery match all along the care chain. Our special interest was the matches involving the care indicated by assessment agencies: the match between the chronic patient's felt need and the care indicated on the one hand and the match between the care indicated and the home care delivered on the other. Our main research questions were:

1. To what extent does the home care delivered match the patient's felt need for care?

2. To what extent do submatches within the care chain influence the needdelivery match in home care?

3. What characteristics may influence the need-delivery match and the submatches under study? These characteristics comprise features of chronic patients, assessment agencies, and home care organisations.

The need-delivery match can be subdivided into four submatches, namely:

a. the match between the patient's felt need for care and the demand for home care (felt need-demand match);

b. the match between the patient's demand for home care and the care indicated by an assessment agency (demand-care indicated match);

c. the match between the patient's felt need for care and the care indicated by an assessment agency (felt need-care indicated match);

d. the match between the care indicated and the home care eventually delivered by a home care organisation (care indicated-delivered match).

For the purposes of this overview, we opted not to show the matches regarding the demand for home care because the function of the demand for home care is merely to notify the assessment agency. However, in Chapters 5 and 7, the matches concerning the patient's demand for home care, such as the match between the felt need and demand for home care, have been incorporated in the analyses.

In researching the match between felt need and delivery and its two submatches, we distinguished between patients' perceived matches on the one hand and actual matches derived by studying the patient records kept by assessment agencies and home care organisations on the other hand. In addition, where delivery of home care is concerned, we retrieved the match 
regarding the type of care as well as the amount of care.

Figure 1.1 already displayed the research model, which includes all the research questions under study.

\subsubsection{How was the study on matches designed?}

Below, the sample, the measuring instruments, the variables, and the analyses are explicated. However, not all the details are applicable to every submatch studied.

\section{Sample}

In 2000, 78 assessment agencies participated in the study (see Sections 1.6 and 1.7; Algera et al., 2003). These assessment agencies were asked to randomly select chronic patients who had presented a demand for home care at the assessment agency office. Of them, 49 were willing to participate in the present part of the study. Lack of time and staff and deficient data registration systems were reasons for the other 29 assessment agencies to refrain from further participation. A $t$-test was performed to determine systematic differences between participating and non-participating assessment agencies regarding their main organisational characteristics; none were found.

The patients selected had to meet the following inclusion criteria:

- they had suffered from a stroke, another chronic neurological disorder, chronic heart failure, diabetes mellitus, rheumatoid arthritis, and/or chronic disorders of the respiratory system;

- they were over 18 years of age;

- they were able to participate in a Dutch-language telephone interview;

- they had submitted an application for professional home care to the assessment agency;

- they were in receipt of a positive or negative decision on care allocation following needs assessment and the decision was noted in an assessment report; being on a waiting list was no exclusion criterion;

- they were in receipt of an assessment report made in the previous three months.

Not all assessment agencies were able to select patients by chronic disease criteria. A pilot project among three assessment agencies showed that, on 
average, every third randomly selected patient met the disease criterion. In addition, in other research in the Netherlands (Van Campen et al., 1997; Caris-Verhallen \& Kerkstra, 1998), the response rate among home care users who responded to a questionnaire was approximately $30 \%$. It was calculated that about 4000 selected patients would be needed to provide final data for analysis from 400 patients. The number of 400 cases was based on power analyses. Actually, 3814 patients were selected and this selection yielded 402 patient data sets in the end.

By way of the assessment agencies, an explanatory letter from the researcher, a consent form, and a stamp-addressed envelope were sent to patients whose needs had been assessed. Of the 3814 patients selected by the assessment agencies, 1611 patients (42\%) returned the consent form. Of this group, 983 refrained from participation, mostly because of age, health, or lack of interest. No additional information on non-responders was available. Therefore, non-response analyses were impossible. The remaining 628 patients (39\%) agreed to participate. Subsequently, 226 of these 628 patients were excluded because they did not meet the inclusion criteria after all. In the end, a telephone interview was held with 402 of the 628 chronically ill patients (64\%), whose needs had been assessed by an assessment agency or a authorised home care organisation.

The mean age of the respondents was 67 years (SD: 14); three out of four were women. About half of the respondents suffered from various diseases simultaneously (comorbidity); the proportion of respondents suffering from rheumatoid arthritis was the largest. In $85 \%$ of the cases, it was possible to have a telephone interview with the patients themselves; in the other cases spouses or other informal caregivers were interviewed on the patient's behalf. See Chapters 5-7 for more details.

\section{Design of the study}

Instruments Figure 1.2 already briefly showed the design of this part of the study. A structured interview scheme was set up to gather data by telephone about the patients' background characteristics and aspects of their felt need and home care delivery (either professionally or informally). Also, their views of the matches were asked (perceived matches). A draft of the interview scheme was content-validated by patients and experts. 
Written questionnaires for assessment agencies and home care organisations were initially distributed in a previous part of the study (see Section 1.6). In this patient study, the identified characteristics of assessment agencies and home care organisations were related to the matches under study. At the time of selecting the patients, the most relevant characteristics of the assessment agencies were actualised by means of a short written questionnaire.

In addition to these content-validated questionnaires, record study was performed to identify what care (type and amount) was indicated or delivered by the assessment agency or the home care organisation, respectively.

Variables The patient's felt need for care, the care indicated by the assessment agency, and the care delivered by the home care organisation or by informal caregivers were coded as IADL-care, ADL-care, technical nursing care, psychosocial care, or combinations of these types of care.

Actual matches between two specific links in the care chain were determined by cross-tabulating, for example, the type of need for care expressed by participants themselves during the telephone interviews, and what was noted in the assessment reports and in home care organisation's records when the information was suitable for the match or submatch at hand.

A 'perfect match' was observed when, for example, the type of care indicated was identical to the patient's felt need for care. Cases in which, for example, the delivery of care exceeded the felt need for care were coded as 'overdelivery'. 'Over-indication' was defined analogously. 'Underindication' was a case in which, for instance, the patient expressed a need for the combination of domestic care and personal care, but only domestic care was indicated by the assessor. 'Underdelivery' was defined analogously. Furthermore, a request for home care rejected by the assessment agency or the patient being put on a waiting list was coded as a 'mismatch', as were cases in which a totally different type of care was indicated or delivered than might have been expected on the basis of the patient's felt need or the care indicated, respectively. Computations of the correspondence in the amount of care only seemed meaningful when the match in the type of care was perfect or more-than-perfect because, for instance, receiving the appropriate number of hours of care according to the assessment report, but of an 
incongruent type of care was considered irrelevant.

Analyses When the influence of characteristics of patients, assessment agencies, and home care organisations was analysed, the dependent variable was 'match' (a combination of perfect match and 'over-indication' or 'overdelivery') or 'mismatch' (a combination of 'under-indication' or 'underdelivery' and 'mismatch').

Before the data were entered into the multi-level analyses (see Chapters 5, 6 and 7), multi-collinearity between the independent variables was determined. When a statistically significant correlation of more than 0.70 between two independent variables was detected, one of them was excluded. A multilevel approach to (logistic) regression analysis seemed appropriate in order to deal adequately with three methodological aspects in one analysis. First, it was expected that there would be a nesting of patients within assessment agencies or home care organisations. Secondly, the number of patients per assessment agency or per home care organisation in this study varied greatly. Thirdly because the independent variables were measured at two different levels (the patient's and the organisations'), statistical artefacts such as the ecological and atomistic fallacy had to be avoided.

\subsubsection{To what extent do matches occur along the care chain for home care?}

In our study, we made a distinction between perceived matches and actual matches. In the overall match between the patient's felt need for care and home care delivered, we distinguished several submatches.

Figure 1.5 shows the adequacy of the perceived match between felt need for care and professional home care delivered, as well as its submatches, namely, the patient's opinions about the match between felt need for care and the care indicated by the assessment agency on the one hand and the match between the care indicated and the professional home care delivered on the other.

From Figure 1.5 we can conclude that, in general, the patients perceived the matches as adequate. However, a partial match or mismatch between the felt need for care and the home care delivered did occur more often compared to the two submatches. 
Figure 1.5 Degree of perceived matches (in \%)

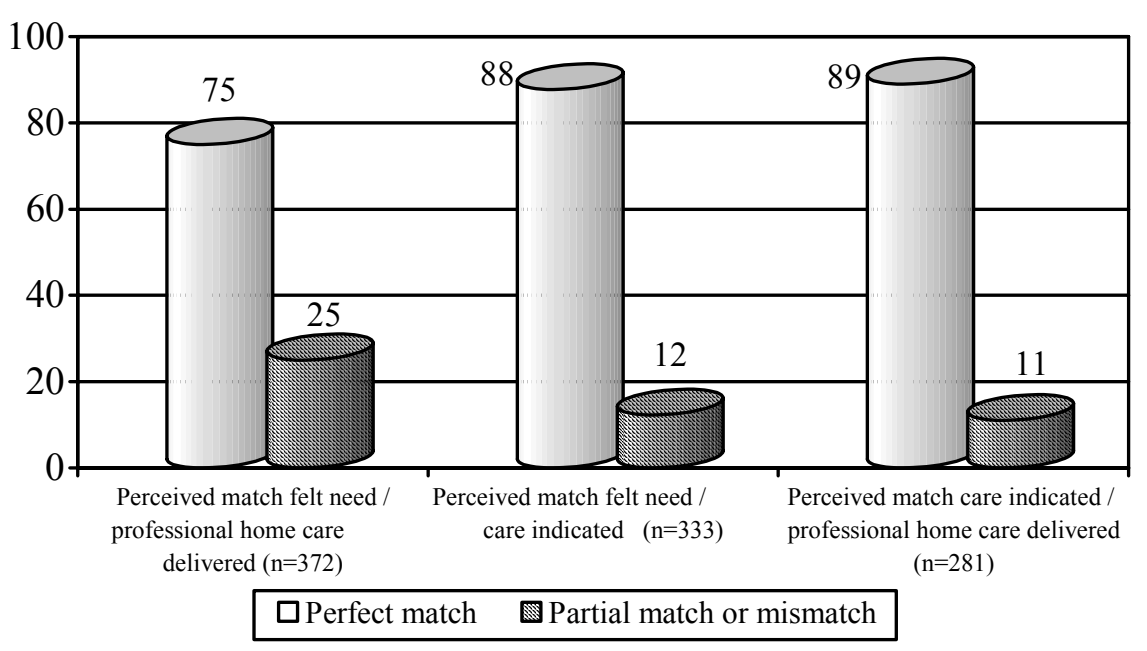

Regarding the actual matches, we scrutinised assessment agency reports and home care organisation records for the 402 participants of our patient study.

For the purposes of this overview, we present our findings in four ways:

1. Findings concerning the match between felt need for care and professional home care delivered;

2. Findings concerning the match according to the patient's descriptions;

3. Findings concerning both submatches;

4. Findings concerning matches all along the care chain.

Figure 1.6 and Table 1.2 contain the illustrative figures.

\subsubsection{Actual match between felt need for care and professional home care delivered}

Figure 1.6 shows that the actual match between felt need for care and professional home care delivered was poor: in only one-third $(32 \%)$ of the cases a perfect match occurred. Underdelivery in providing fewer types of care compared to the patient's expressed needs was very common; almost half $(48 \%)$ of the chronic patients involved in our study were confronted with a partial match. Mismatches were seen in almost one-fifth (18\%) of the cases; these patients did not receive professional home care at all (waiting 
list) or received a type of care completely different compared to their felt needs. Finally, overdelivery was rarely observed (3\%).

\subsubsection{Matches between felt need for care and professional and/or informal home care delivered according to the patient's description}

During the telephone interviews, we did not only ask about the patient's felt needs; we also asked about the type of care that was delivered to them. We asked chronic patients whether they actually had received a specific type of care to meet their needs, delivered either by professionals or by informal caregivers such as spouses or relatives. This is not the same as asking their opinion about the match. This information was gathered to be contrasted with the data from the home care organisations' records.

Figure 1.6 also holds the results in this respect. Perfect matches between felt need and home care delivered solely by professional home care were attained in about a quarter (29\%) of the cases. However, when adding the activities of informal caregivers, the number of perfect matches increased drastically: in well over three-quarters $(86 \%)$ of the cases, a perfect match was attained. In addition, mismatches were diminished to negligible numbers (2\%) when informal care was taken into account along with professional care. However, for professional care alone meeting the patient's felt needs, mismatches occurred in one-third $(34 \%)$ of the cases. Underdelivery diminished largely (from $37 \%$ to $12 \%$ ) due to the efforts of informal caregivers, which implies that professional home care and informal caregiving complemented each other in meeting the patient's felt needs. In many cases, informal caregivers provided the largest part of caregiving. 
Figure 1.6 Degree of actual matches (in \%)

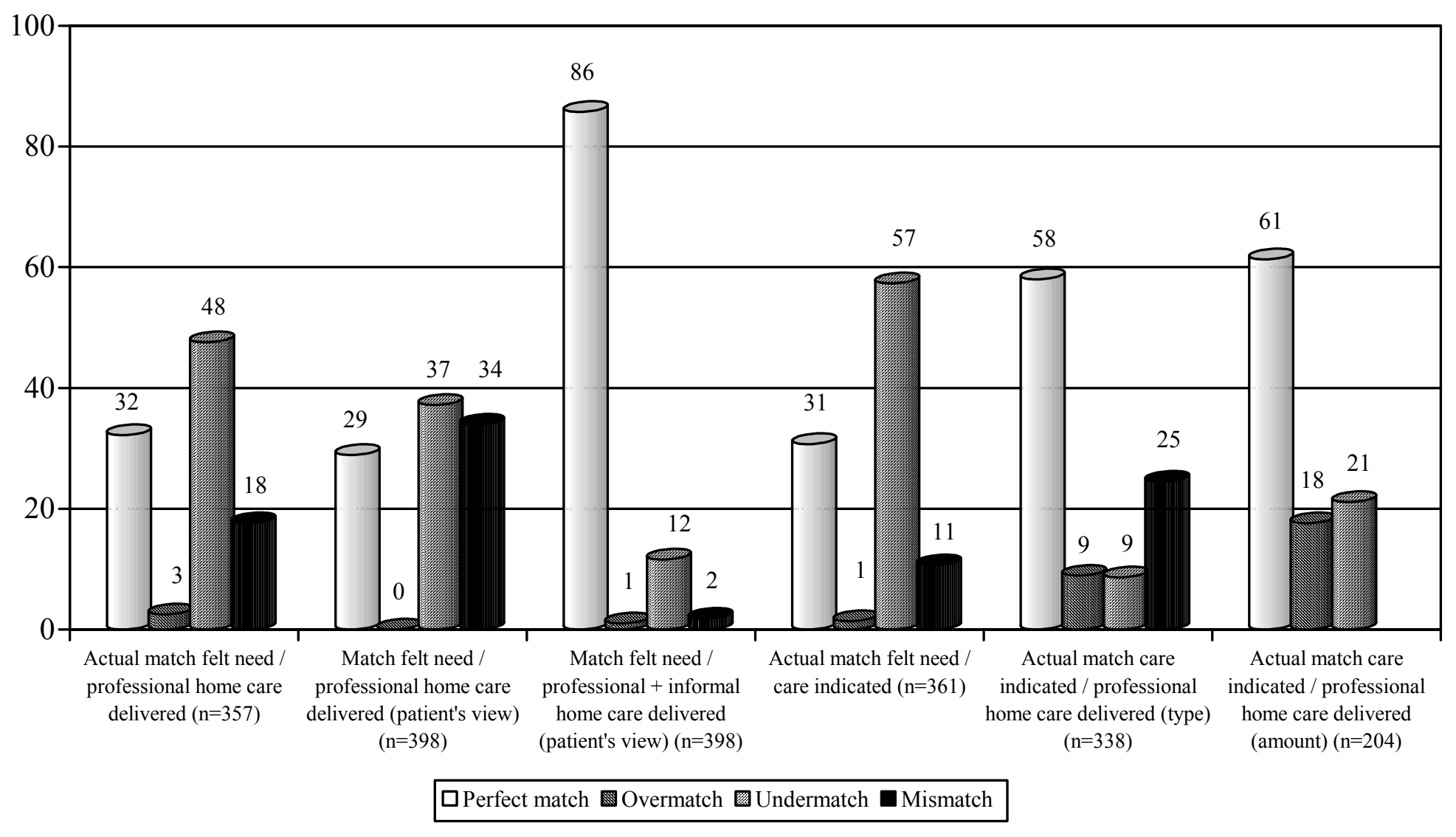




\subsubsection{Actual submatches}

Table 1.2 gives an overview of the adequacy of the matches found by the record study. The percentage is computed for each match separately, i.e. in this presentation of the actual matches, a deficient match earlier in the chain does not effect a following match.

Table 1.2 leads to several conclusions:

1. Under-indication of felt need for care was predominant $(57 \%$; fewer types of care were indicated by the assessment agency than were needed according to the chronic patient's felt needs), exceeding the percentage of perfect matches $(31 \%)$.

2. In one out of nine cases $(11 \%)$, there was a mismatch between the patient's felt need and the care indicated; in such cases, the patient's felt needs were not recognised by the needs assessor, which implies that the needs assessor thought other types of care necessary or that the patient's request for home care was denied altogether.

3. Over-indication compared to the patient's felt needs seems to occur seldom (1\%).

4. If the match between the patient's felt need and the care indicated was perfect, then in three out of four (74\%) cases the match between care indicated and the type of professional home care delivered was perfect as well. However, in the other cases, the home care organisation apparently decided to deliver more (4\%) or fewer $(7 \%)$ types of care or a different type (16\%). The last category includes patients put on a waiting list for a long time (the home care organisations' records were screened about a year after the needs assessment).

5. In cases in which the type of professional home care delivered matched or even exceeded the care indicated, two-thirds $(65 \%)$ of the patients received the indicated amount of that type of home care. In other instances, they received even more hours of home care (12\%). Thus, if the type of professional home care delivered matched the care indicated, so did the amount of care in $77 \%$ of the cases. Still others $(23 \%)$ received a smaller number of hours of the indicated type of care than was noted in the assessment report. 
Table 1.2 Overview of the actual matches between the patient's felt need, care indicated, and professional home care delivered

\begin{tabular}{|c|c|c|c|c|c|c|c|c|}
\hline $\begin{array}{l}\text { Actual ma } \\
\text { need and }\end{array}$ & $\begin{array}{l}\text { atch betwee } \\
\text { care indica }\end{array}$ & $\begin{array}{l}\text { felt } \\
\text { ted }\end{array}$ & $\begin{array}{r}\text { Actual mat } \\
\text { indicate } \\
\text { professio } \\
\text { de }\end{array}$ & $\begin{array}{l}\text { tch betwe } \\
\text { ed and typ } \\
\text { onal home } \\
\text { elivered }\end{array}$ & $\begin{array}{l}\text { en care } \\
\text { e of } \\
\text { care }\end{array}$ & $\begin{array}{r}\text { Actua } \\
\text { amoun } \\
\text { an } \\
\text { profes }\end{array}$ & $\begin{array}{l}\text { match bet } \\
\text { of care ind } \\
\text { amount } \\
\text { onal hom } \\
\text { elivered* }\end{array}$ & $\begin{array}{l}\text { een } \\
\text { cated } \\
\text { care } \\
\end{array}$ \\
\hline & Percentage & $n$ & & Percentage & $n$ & & Percentage & $n$ \\
\hline Perfect & 31 & 111 & Perfect & 74 & 78 & Perfect & 65 & 50 \\
\hline match & & & Over & 4 & 4 & Over & 12 & 9 \\
\hline & & & Under & 7 & 7 & Under & 23 & 18 \\
\hline & & & Mismatch & 16 & 17 & & & \\
\hline & & & Missing & & 5 & Missing & & 5 \\
\hline Overmatch & 1 & 5 & Perfect & 0 & 0 & Perfect & 0 & 0 \\
\hline$\widehat{\approx}$ & & & Over & 0 & 0 & Over & 0 & 0 \\
\hline z & & & Under & 100 & 5 & Under & 0 & 0 \\
\hline$\Xi$ & & & Mismatch & 0 & 0 & & & \\
\hline ગ્ & & & Missing & & 0 & Missing & & 0 \\
\hline$\stackrel{e}{e}$ Underrmatcl & 57 & 207 & Perfect & 54 & 105 & Perfect & 63 & 72 \\
\hline & & & Over & 10 & 20 & Over & 16 & 18 \\
\hline$\stackrel{\Xi}{=}$ & & & Under & 11 & 21 & Under & 22 & 25 \\
\hline 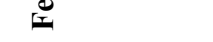 & & & Mismatch & 26 & 50 & & & \\
\hline & & & Missing & & 11 & Missing & & 10 \\
\hline Mismatch & 11 & 38 & Perfect & 30 & 9 & Perfect & 0 & 0 \\
\hline & & & Over & 7 & 2 & Over & 56 & 5 \\
\hline & & & Under & 7 & 1 & Under & 45 & 4 \\
\hline & & & Mismatch & 3 & 18 & & & \\
\hline & & & Missing & 60 & 8 & Missing & & 2 \\
\hline Missing & & 41 & & & & & & \\
\hline * & $\begin{array}{l}\text { Only con } \\
\text { professior }\end{array}$ & $\begin{array}{l}\text { ated i } \\
\text { home }\end{array}$ & $\begin{array}{l}\text { in case of ar } \\
\text { e care delive }\end{array}$ & $\begin{array}{l}\text { In adequat } \\
\text { ered accor }\end{array}$ & $\begin{array}{l}\text { e match } \\
\text { ding to ty }\end{array}$ & $\begin{array}{l}\text { between } \\
\text { ype }\end{array}$ & care indica & d and \\
\hline Perfect match: & perfect mat & & & & & & & \\
\hline Overmatch: & $\begin{array}{l}\text { more type } \\
\text { patient's fe } \\
\text { care organi }\end{array}$ & $\begin{array}{l}\text { of } c \\
\text { t neec } \\
\text { ation }\end{array}$ & $\begin{array}{l}\text { care were in } \\
d \text {, or more ty } \\
\text { than were in }\end{array}$ & $\begin{array}{l}\text { ndicated } \\
\text { types or ho } \\
\text { ndicated }\end{array}$ & $\begin{array}{l}\text { oy asses } \\
\text { ours of c }\end{array}$ & $\begin{array}{l}\text { sment a } \\
\text { care were }\end{array}$ & $\begin{array}{l}\text { ency comp } \\
\text { delivered } b\end{array}$ & $\begin{array}{l}\text { red to } \\
\text { home }\end{array}$ \\
\hline Undermatch: & $\begin{array}{l}\text { fewer type } \\
\text { patient's fe } \\
\text { care organi }\end{array}$ & $\begin{array}{l}\text { of } c \\
\text { t need } \\
\text { ation }\end{array}$ & $\begin{array}{l}\text { care were in } \\
d \text {, or fewer } t \\
\text { than were in }\end{array}$ & $\begin{array}{l}\text { indicated } \\
\text { types or h } \\
\text { ndicated }\end{array}$ & $\begin{array}{l}\text { by asses } \\
\text { ours of } c\end{array}$ & $\begin{array}{l}\text { sment a } \\
\text { care were }\end{array}$ & $\begin{array}{l}\text { ency comp } \\
\text { delivered } b\end{array}$ & $\begin{array}{l}\text { red to } \\
\text { home }\end{array}$ \\
\hline Mismatch: & $\begin{array}{l}\text { no care or } \\
\text { agency con } \\
\text { type of care }\end{array}$ & a con & $\begin{array}{l}\text { mpletely oth } \\
\text { d to patient's } \\
\text { delivered by }\end{array}$ & $\begin{array}{l}\text { her type o } \\
\text { s felt need } \\
\text { home car }\end{array}$ & $\begin{array}{l}f \text { care } \\
\text { or no c } \\
\text { e organis }\end{array}$ & $\begin{array}{l}\text { vas indic } \\
\text { are or a } \\
\text { sation tha }\end{array}$ & $\begin{array}{l}\text { ted by ass } \\
\text { mpletely } \\
\text { was indica }\end{array}$ & $\begin{array}{l}\text { sment } \\
\text { fferent } \\
\text { ed }\end{array}$ \\
\hline
\end{tabular}


6. Under-indication was present in $57 \%$ of the cases, as just reported. Subsequently, in most (64\%) cases, the home care organisation delivered the indicated type of care exactly or delivered even more types, but, in most cases, this home care delivery should be considered underdelivery in the light of the patient's underlying felt needs.

One out of nine $(11 \%)$ patients received fewer types of care from the home care organisation than were indicated by the assessment agency. Reasoning from the patient's perspective, in these cases the patient was disadvantaged twice: once by the assessment agency and once by the home care organisation.

In a quarter $(26 \%)$ of the cases in which under-indication occurred, patients received a completely different type of care. This does not necessarily mean the patient's felt needs are not addressed at all. For instance, if the patient's felt needs concern both domestic care and personal care and the assessment agency indicated only domestic care (under-indication), but the home care organisation judged delivery of personal care appropriate (mismatching the assessment report totally), then the patient's felt need would be partly addressed, though.

7. Almost two-thirds (63\%) of the patients confronted with underindication did get the amount of home care indicated, but still did not receive all the types of home care meeting their felt needs for care. In addition, $16 \%$ of the respondents in this subgroup received more hours of home care than indicated, but, nonetheless, not all the types of home care required based on their felt need for care were delivered. Furthermore, every fifth $(22 \%)$ patient in this group, which had an adequate match between the care indicated and the type of professional home care delivered, received fewer hours of that type of home care than was indicated.

8. With respect to the delivery of care following over-indication, we could only conclude that this is not very common. The five cases in which over-indication occurred all received fewer types of care compared to the assessment report.

9. As already reported, $11 \%$ of the patients were confronted with a mismatch between their felt need and the care indicated by the assessment agency. One-third (30\%) of the patients whose felt need was not recognised by the assessor at all did receive the indicated type of care, though. However, this was not matching their initial felt need for care. With regard to a subgroup of $60 \%$, neither the patient's felt needs 
were included in the needs assessment nor did the professional home care delivered match the assessment report. Nonetheless, in some cases the professional home care delivered may accidentally correspond with the needs felt by the patient.

10. The amount of professional home care delivered was more than adequate in over half $(56 \%)$ of the cases in which the home care organisation realised the indication of the assessment report, but the assessment report itself mismatched the patient's initial felt needs.

\subsubsection{Actual matches along the care chain}

As reported earlier (see Figure 1.6), only one-third of the patients enjoyed a perfect actual match between the felt need and the professional home care delivered. In such cases, the patients got care from the home care organisation corresponding with their felt need for care, irrespective of what type(s) of care the assessment agency indicated. However, it would be interesting to compute the match between patient's felt need, the assessment report, and the professional home care delivered, thus taking the assessment agency's indication into account. Tracking patients along the care chain, we found that 59 patients were lost to analyses due to incomplete records. Of the remaining 343,82 patients $(23 \%)$ had a perfect match or even a more-thanperfect match (1\%) all along the care chain. The felt needs were adequately assessed or even more types of home care were indicated than the patient's felt needs led to believe, and, subsequently, the adequate, or more-thanadequate, type(s) of professional home care were delivered. In contrast, almost half $(46 \% ; n=157)$ of the patients involved in our study were confronted with only partial matches. Either fewer types of home care were indicated than could be expected on the basis of their felt needs or the types of care indicated outnumbered the types of professional home care delivered. Finally, 30\% $(n=104)$ of the respondents had a mismatch somewhere along the care chain (see Figure 1.7). 
In the case a perfect or more-than-perfect match all along the care chain could be observed $(n=82)$, we further studied patient records and retrieved the matches between the amount of care indicated and delivered. Due to incomplete records, another 11 patients were lost to this analysis, leaving 71 records to be studied. In addition to adequate preceding matches, four out of five patients $(79 \%, n=56)$ received the appropriate or even a larger number of hours of professional home care. These 56 patients had every reason to be fully satisfied all along the care chain. Since there were 332 (402-59-11) patient data sets available for this analysis, this group represents only $17 \%$ of the population studied.

Figure 1.7 Degree of actual matches all along the care chain (in \%)

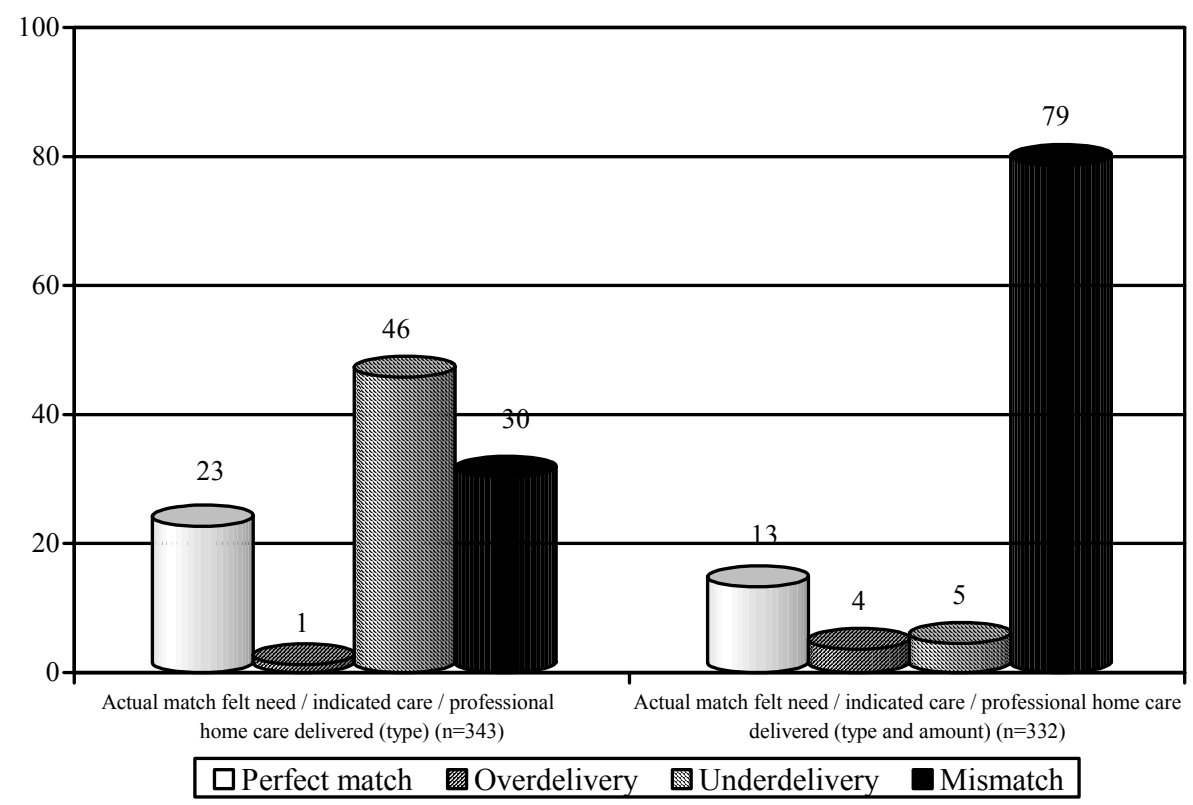

\subsubsection{Discussion on matches and mismatches}

Based on record study of the match between the patient's felt need and the professional home care delivered, underdelivery of professional home care is predominant. From what patients say about from whom they had received need-matching home care, we can conclude that it is informal care delivered by people in the patient's social network who meet the patient's felt needs rather than professional home care. The proportion of informal care that fulfils the patient's felt need is substantial, but it is understandable because 
assessment agencies have to take the capabilities and incapabilities of informal carers into account in determining the type and amount of care they indicate in the assessment report. Therefore, at forehand, in many cases professional home care will not be sufficient to meet all the patient's felt needs. Undermatches between felt need for care and care indicated are inherent to the assessment procedures, then.

Considering the matches all along the care chain, we see that many chronic patients are confronted with some kind of a mismatch. In our sample, only every sixth patient had reason to be fully satisfied with the matches. Their needs were adequately assessed (in accordance with the patient's felt needs) and the assessment report was carried out integrally by the home care organisation with respect to the type and amount of care to be delivered. In contrast, in almost half of the cases, the patient got only part of what he/she wanted. Finally, a substantial proportion of the patients did not obtain the professional care in order to meet their felt needs. Most mismatches can be attributed to under-indication of the patient's felt needs. In general, it can be stated that home care organisations are not responsible for 'breaking the chain': by and large they deliver the types and amounts of care as indicated. In contrast, the needs assessment resulting in the care indicated appears to be the most critical link within the care chain.

The patient movement directed criticisms to home care organisations' tendency to minimise the patient's needs in order to serve as many patients as possible within the constraints of money and available staff (Nationale Raad voor de Volksgezondheid, 1994). Indeed, in our study, about 10\% (34 of 337) of the chronic patients were confronted with underdelivery compared to the indicated type of professional home care (see Table 1.2). Another $22 \%$ (47 of 218) did get the indicated type of professional home care, but received a smaller amount of it than was indicated. In contrast, our study also shows that about $8 \%$ (26 of 337) of the patients received more types of care than indicated and about 15\% (32 of 218) received more hours of care from home care organisations than was indicated. In some of these cases, the home care organisation may have decreased or increased the number of types or hours of care to be delivered due to changed circumstances of health condition or availability of informal care. However, as we only analysed cases in which the type of care was delivered as indicated by the assessment agency, no patients on waiting lists (11\%) were included. Because no professional home 
care was delivered within a reasonable term, these patients should be added to those confronted with a mismatch. Therefore, our finding of $22 \%$ underdelivery of the amount of care is, in fact, an underestimation.

In general, these findings suggest that the non-equitable allocation of scarce care - one of the initial reasons for the Care Needs Assessment Decree - yet remains after the introduction of the new assessment procedures. It can also be concluded that home care organisations are still checking the adequacy of the care indicated by the assessment agency, and are still delivering care according to their own complementary assessment. This is in line with home care organisations' self-claimed necessity to do so because of deficient assessment reports (see Section 1.7).

Some explanations for inadequate submatches may be the following. It may be that under-indication occurred because the needs assessor did not recognise all the patient's needs. If that was the case, the assessors' incapability and lack of skills disadvantaged these patients. However, underindication may also occur because informal care did part of the caring job, as we concluded earlier. In this sense, in promoting the role of informal care, the government might stimulate under-indicating home care needs. If the patient refrained from specific care because he/she would not accept it from the home care organisation, the assessment report would list fewer types of care than necessary to meet the patient's felt needs. Effectively, it was the patient who chose under-indication, then. We cannot deduce from the assessment reports which needs were recognised by the assessor, which needs would be met by informal care, which care would be delivered professionally, and, finally, which felt needs the patient did not wish to be met.

On the subject of the match or mismatch between care indicated and professional home care delivered, the adequacy of the records of home care organisations can be questioned. Since May 2000 (before our record study), home care organisations no longer register the type of care delivered in the patient's record, but the type of care provider who delivered it (PricewaterhouseCoopers/Nivel, 2002). For example, if a highly qualified nurse washes a patient, this act is noted as 'nursing care', but if an auxiliary nurse does the same job, it is registered as 'personal care'. It is unknown to what extent matches or mismatches may be attributed to this corruption of 
the types of care actually delivered.

In order to determine the actual matches and mismatches, we compared assessment reports and records of home care organisations. It is unknown to what extent home care organisations made use of the degrees of freedom (bandwidths) that the assessment reports allowed for the amount of care to be delivered. Perhaps home care organisations 'corrected' the assessment agencies' under-indications. In addition, the records described types of care in a rather abstract way (domestic care or personal care). They did not specify the underlying concrete activities. It is therefore possible, that, for example, only one of the three indicated domestic chores was delivered. In fact, this would be underdelivery, but due to the registration of just the main type of care, in our research project this would remain undetected. If that is the case, then the magnitude of underdelivery and overdelivery may even be larger.

Observing the figures on perceived and actual matches (see Figures 1.5 and 1.6), we can conclude that perceived matches (based on the patient's perceptions) were present in about $75 \%$ to $89 \%$ of the cases, whereas actual matches (based on record study) vary from $31 \%$ to $61 \%$. (The $86 \%$ match in Figure 1.6 includes the activities of informal carers and therefore should not be seen as an actual match attained by just professional input.) Notwithstanding the moderate actual matches found in the record study, the patient generally perceives the matches in the various links within the care chain as adequate. Apparently, the patient's opinions about the matches are only partly determined by whether an actual match had occurred. General high satisfaction with home care received, very common in most satisfaction research (e.g. Caris-Verhallen, 1999; PricewaterhouseCoopers/Nivel, 2002) may be one of the explanations. Furthermore, the efforts of informal caregivers might be largely responsible for chronic patients being positive despite the apparent shortcoming professional care (Algera et al., 2004d).

Other studies (Sixma et al., 1998; Schrijvers, 2001; Jörg, 2002) made it clear that, if patients are dissatisfied with the care delivered at all, they are usually dissatisfied with the number of hours of care indicated by the assessment agency rather than the type of care. Our study confirms this in our analysis of the patient's perceived match between felt need for care and the care indicated (see Chapter 5; Algera et al., 2004b). No data about the actual 
matches regarding the amount of care could be gathered because we deemed it impossible for most patients to realistically estimate the number of hours of care they might need.

The patient's perceptions of the matches were asked approximately three months after the assessment report was written. Almost a third of them had not received professional home care by then. It might be expected that the patient's perceived matches would be influenced negatively by these waiting lists. Perceived matches could be expected to be outnumbered by actual matches since the actual matches were computed almost a year later, and most patients received at least some home care in the meantime. However, in practice, the contrary was observed. This result even supports our finding that, irrespective of mediocre actual matches, patients generally perceive the matches as adequate.

The patients' opinions about the match between the felt need for care and home care delivered match were rather positive ( $75 \%$ of the patients), though smaller than the two submatches within the process of receiving professional home care. With respect to the match between the felt need for care and the care indicated and the match between care indicated and professional home care delivered, $87 \%$ and $89 \%$ of the opinions were positive, respectively. However, these being submatches, both are conditional for attaining an adequate overall match. Therefore, the figures should be multiplied in predicting the perceived overall match. By multiplying the percentages of these submatches ( $89 \%$ times $87 \%)$, the percentage of patients experiencing the overall match between felt need and delivery as positive approaches 75 . The explanation for this reduction may be rather common: the longer a sequence to be evaluated (in this case the process from needing home care to receiving it), the more chance there is of complications along the way, which lead to a less positive evaluation. One of those complications was expected to be the existence of waiting lists for home care, but no statistical supporting evidence was found (see Section $1.9)$.

Most of the explanations mentioned point in the direction of strengthening our results, others would weaken them. However, we argue that our main conclusion - in most cases there is no perfect match, but patients are nonetheless positive about the matches under study - still stands firmly. 


\subsection{What characteristics influence the matches under study?}

Table 1.3 presents the characteristics of patients, assessment agencies, and home care organisations that significantly influence the various matches under study. For these analyses, 'perfect matches' and 'overmatches' were combined, as were 'undermatches' and 'mismatches' (see Section 1.8).

Keeping in mind the wide variety of independent variables entered into the analyses (Figures 5.2, 6.2 and 7.2) and comparing them with the statistical significance of these characteristics as shown in Table 1.3, we can conclude that only a few patient-related characteristics appeared to be influential, hardly any features of assessment agencies, and none concerning home care organisations.

\section{Discussion on characteristics influencing matches under study}

Only a few patient characteristics appear to contribute to the matches under study. Patients under the age of 65 more often perceived a match between felt need and the care indicated. In addition, younger patients also actually had such a match significantly more often. In part, the latter finding will probably cause the former. Although, in healthcare research, satisfaction is often associated with older age (Sixma et al., 1998; Caris-Verhallen, 1999; Jedeloo, 2002), it is argued that younger patients are more assertive in getting what they want and more eloquent in expressing it (Jörg, 2002).

Men perceived a better match between the care indicated and the professional home care delivered than women, and they also actually had a better match of that kind. However, the literature (Algera et al., 2004a) suggests that women are heavier home care users. We argue that whenever men seek help, home care organisations pursue better matches for men than for women. It is possible that men's needs are more intense or that men are judged more dependent on domestic care in particular, which leads to a better match more often, as also Jörg (2002) found. 
Table 1.3 Overview of significant characteristics of patients and assessment agencies on better matches *

\begin{tabular}{|c|c|c|c|c|c|c|c|}
\hline Characteristic & $\begin{array}{l}\text { Perceived } \\
\text { match felt } \\
\text { need and } \\
\text { professional } \\
\text { home care } \\
\text { delivered }\end{array}$ & $\begin{array}{l}\text { Actual match } \\
\text { felt need and } \\
\text { professional } \\
\text { home care } \\
\text { delivered: } \\
\text { type }\end{array}$ & $\begin{array}{l}\text { Perceived } \\
\text { match felt } \\
\text { need and care } \\
\text { indicated }\end{array}$ & $\begin{array}{l}\text { Actual match } \\
\text { felt need and } \\
\text { care indicated }\end{array}$ & $\begin{array}{l}\text { Perceived match } \\
\text { care indicated } \\
\text { and professional } \\
\text { home care } \\
\text { delivered }\end{array}$ & $\begin{array}{l}\text { Actual match } \\
\text { care indicated } \\
\text { and professional } \\
\text { home care } \\
\text { delivered: type }\end{array}$ & $\begin{array}{l}\text { Actual match } \\
\text { care indicated } \\
\text { and professional } \\
\text { home care } \\
\text { delivered: } \\
\text { amount } \\
\end{array}$ \\
\hline Age & & & Under 65 & Under 65 & & & \\
\hline Sex & & & & & Male & Male & \\
\hline $\begin{array}{l}\text { Patients presenting demand for } \\
\text { home care themselves }\end{array}$ & \# & $\#$ & $\#$ & Yes & $\#$ & $\#$ & $\#$ \\
\hline Patient's evaluation of house call & \# & \# & Positive & \# & \# & \# & \# \\
\hline $\begin{array}{l}\text { Patient's satisfaction with amount } \\
\text { of professional and informal care } \\
\text { received }\end{array}$ & High & \# & $\#$ & \# & High & \# & $\#$ \\
\hline $\begin{array}{l}\text { Already receiving professional } \\
\text { home care }\end{array}$ & $\#$ & \# & $\#$ & No & \# & $\#$ & $\#$ \\
\hline $\begin{array}{l}\text { Complexity of care indicated } \\
\text { Authorisation arrangements }\end{array}$ & Complex & & & $\begin{array}{l}\text { Complex } \\
\text { Yes }\end{array}$ & Non-complex & Non-complex & \\
\hline Use of assessment forms & \# & & & No & \# & & \\
\hline $\begin{array}{l}\text { Perceived match between } \\
\text { felt need for care and care } \\
\text { indicated }\end{array}$ & Adequate & $\#$ & $\#$ & $\#$ & $\#$ & $\#$ & $\#$ \\
\hline $\begin{array}{l}\text { Actual match between } \\
\text { felt need for care and care } \\
\text { indicated }\end{array}$ & & Adequate & & \# & Adequate & Adequate & \\
\hline $\begin{array}{l}\text { Perceived match between care } \\
\text { indicated and home care delivered }\end{array}$ & Adequate & \# & \# & \# & $\#$ & $\#$ & $\#$ \\
\hline $\begin{array}{l}\text { Actual match between care } \\
\text { indicated and professional home } \\
\text { care delivered }\end{array}$ & & Adequate & $\#$ & \# & & $\#$ & $\#$ \\
\hline Empty cells mean no & ificant as & ion & & & & & \\
\hline
\end{tabular}


If the patients presented their demands for professional home care to the assessment agency themselves, an actual match between felt need and care indicated would occur more often. Patients notifying the assessment agency themselves are probably better able to word their felt needs than are informal carers or general practitioners. It can be argued that non-patients notifying the assessment agency may prioritise the patient's need, resulting in a partial match or a mismatch, as seen from the patient's perspective.

A positive evaluation of the assessor's house call may humour the patient with respect to the perceived match between felt need and care indicated. Similarly, if the patient was more satisfied with the amount of professional and informal care received, the perception of the match between felt need and the professional home care delivered was positive as was the perception of the match between the care indicated and the professional home care delivered. It can be argued that satisfaction with the total amount of care received may erase the effect on the patient's perception of any mismatches concerning professional home care delivery. This emphasises once again the importance of informal care. Professional caregivers and informal carers will resolve the patient's felt needs best in a joint effort (see Section 1.8). However, the patients judged the type of professional home care delivered only as matching their felt need, if they thought the amount of professional and informal home care received was sufficient. Considering the large proportion of informal care in satisfying the patient's felt need (see Section 1.8), this finding suggests that chronic patients may give the credit for informal carers' work to home care organisations. This may imply an underestimation of informal carers' position in meeting the patient's felt needs.

Patients who were already receiving professional home care at the moment the assessment agency was notified were more often confronted with an actual mismatch between their felt need and the care indicated. If patients are already receiving professional home care, possibly the assessor is likely to under-indicate yet unmet needs. This may be the case in reassessments, which usually take place once a year. Jörg (2002) found comparable results for admission to a nursing home.

Non-complexity of the care indicated appeared to be a predictor of a perceived match as well as of an actual proper match between the care 
indicated and the type of professional home care delivered. Apparently, if the care indicated comprises just one type of home care (exclusively domestic care in many cases), the home care organisation more often agrees with the assessor that the type of care chosen is the solution to the patient's care deficits. Conversely, if the care indicated is more diverse, there may be underdelivery. This finding is in line with our record study of the adequacy of the actual matches (see Section 1.8). If we disregard, for a moment, the possibility that needs assessors may have been too generous in their assessment reports, one reason for underdelivery may be that home care organisations are unable or unwilling to provide all the indicated types of care. If that is the case, then despite possible independent needs assessment, the final delivery of care will remain supply oriented and not needs-led.

In contrast, if the care indicated by the assessment agency was complex, the patient would be more satisfied with the match between the felt need and the professional home care delivered. Also, an indication for multiple types of care led to a better actual match between the felt need and the care indicated. Here, an explanation may be that assessment agencies try 'a bit harder' in complex cases to achieve a match. Assessment agencies may not be well equipped for or interested in simple needs assessments like domestic care. However, these findings seem to contradict our result that the matches are better for cases in which the type of felt need for care is non-complex (see Section 1.8; Algera et al., 2004b). With regard to the perceived better match between felt need for care and professional home care delivered, a clear statistical explanation cannot be given because the complexity of the type of felt need for care is involved here. Due to multi-collinearity, the complexity of the type of felt need could often not be analysed in conjunction with the complexity of the type of care indicated (see Chapters 5 to 7). However, it does show a direct association between the outcome of the needs assessment and the perceived match between felt need for care and professional home care delivered.

With regard to our finding that de actual match between felt need for care and the care indicated is more adequate if the care indicated is complex, the following explanation may be valid. In the case of determining the adequacy of the match between felt need and care indicated, underdelivery was predominant (57\%; see Table 1.2 and Figure 1.6). This means that the felt need for care encompassed more types of care than the assessment agency 
recognised. Therefore, in many cases of underdelivery, the type of care indicated was non-complex (just one type of care). Non-complex care indicated can therefore be linked to underdelivery with respect to the match between felt need for care and care indicated. Conversely, complex care indicated can be linked to a better match between felt need and care indicated.

The characteristics of the organisations involved in the care chain (see Figures 1.1 and 1.4) had hardly any influence on the matches under study. Only two characteristics of assessment agencies were significantly related to a match, namely, the actual match between felt need for care and care indicated.

First, if assessment agencies authorised home care to assess non-complex needs in home care, there was a better actual match. This seems to strengthen our inference that patients are better off when non-complex home care needs are not handled by assessment agencies. Authorisation arrangements are allowed for in the Care Needs Assessment Decree (Ministerie van Volksgezondheid, Welzijn \& Sport, 1997), but they were negated more and more often in practice after the assessment agencies had been in operation for more than a year or so. However, in trying to make assessment procedures less bureaucratic, authorising the indication of care to home care organisations may be valuable. Although in theory this might endanger the independence and comprehensiveness of the needs assessment (Algera et al., 2002, 2003), reasoning from the patient's perspective, it proves to lead to better indication of care, as long as non-complex care is concerned.

Second, if assessment agencies used the national standardised assessment forms, the actual match between felt need and care indicated was worse. The use of the forms was considered to generate uniformity leading to objectivity in needs assessment, objectivity being one of the objectives of the Care Needs Assessment Decree. We argue that promoting objectivity in needs assessment by making use of these forms, does not lead to all the patient's felt needs being recognised in the assessment report. The use of these forms may hamper the assessor's receptivity to the patient's real needs. However, the patient may be too demanding, and the use of these assessment forms may help the assessor to indicate reimbursable care to complement the 
available informal care. Seen from the patient's perspective, this is underindication; seen from the macrosocietal viewpoint, this is objective indication of care. Assessors have to deal with the tension between these views.

In addition to inadequate matches between felt need and care indicated that result from the use of these assessment forms, home care organisations appear to be dissatisfied with them as well (see Section 1.7 and Chapter 4). They gave clues to an explanation of the impracticability of the assessments reports made up based on the assessment forms. They mentioned that assessment agencies' level of abstraction in determining the care indicated did not fit the vocabulary of the home care organisations. Furthermore, the assessment reports could not be used by home care organisations to start their home care because they lack the necessary information for doing so. Even the designers of these forms criticised them because of lack of validation of these assessment forms (Breed Indicatie Overleg, 1997).

The match between felt need for care and the professional home care delivered proved to be codetermined by the two submatches: the match between the felt need for care and the care indicated, and the match between care indicated and professional home care delivered. This was the case both actually and in the patient's perception. In addition, an adequate actual match between felt need for care and care indicated was followed by a better actual match between care indicated and the type of professional home care delivered. Patients perceived these matches accordingly. Thus, adequate matches earlier in the care chain appear to be conditional for subsequent matches, either in the patient's perception or determined through record study. Since the perceived matches are far better than we could expect on the basis of the actual matches, we hypothesised that other determinants must also be responsible for the patient's perception. Our multi-level analyses confirmed this hypothesis. Other patient characteristics not included in the analyses may also have an influence. The limited sample size did not allow to compute further significant associations of specific variables.

Recent studies that investigated the patient characteristics influencing the chance of having indicated or delivered a certain type or amount of home care (Jörg, 2002; Van Campen \& Van Gameren, 2003), did not focus on the influence of these characteristics on the matches described in our study. The 
influence of patient-related characteristics we measured proved to be limited. For instance, contrary to our expectations, comorbidity was not related to any of the matches under study. We expected that the complexity of felt need would also influence the match between felt need and the care indicated. For statistical reasons, we could not analyse this (Algera et al., 2004b).

The sheer absence of statistical significance of organisational characteristics is in line with the findings of Jedeloo (2002), who, in her study on needs assessment for assistive devices, was unable to differentiate by the assessment agencies' characteristics whether adequate indication occurred. Circumstantial aspects such as waiting lists and shortage of home care personnel were supposed to block correspondence between the care indicated and the professional home care delivered to the patient. However, we found no statistical evidence to support our expectations (see Section $1.10)$.

\subsection{Methodological issues and restrictions of the study}

The value of our project was enhanced by the inclusion of the patient's perspective on the matches under study. In addition, we consulted various sources of information to retrieve the actual matches (triangulation): the patients themselves, assessment reports of the assessment agencies and records of the home care organisations. Following patients all through the care chain made it possible to pinpoint the crucial position of needs assessment and the care indication for the chronically ill in need of home care. Most other studies have dealt with just one link of the care chain. We also highlighted the importance of informal care in a rather quantitative way. Making use of multi-level analyses for eliminating the effects of nesting of patients within assessment agencies or home care organisations (Snijders \& Bosker, 1999) strengthened our results.

Analysis of the patient's perspective on the match between their felt need for care and the care indicated on the one hand and the match between the care indicated and the home care delivered on the other - the submatches showed that most patients had positive opinions. Subsequently, the vast majority of the respondents judged the match between felt need and 
delivered home care was adequate. It may be argued that the linking pin between the patient's felt need and home care delivered, which is the needs assessment and subsequent care indication, yields positive opinions from the patient. However, if the patient would have been assessed with the 'old style' needs assessment (home care organisations assessing the patient's needs themselves) which was abolished in 1998, the opinions might be just as positive. Since authorisation arrangements (comparable to the 'old style' needs assessment) did not significantly influence the perceived matches under study, it seems plausible that the perceived match would not be any different now than it was then. As the actual match between felt need and care indicated is positively influenced by authorisation arrangements, there is some evidence that the old style was not as bad as the patient organisations claimed it to be. However, since the old style needs assessment was not well-researched (Jörg, 2002), a full comparison of both styles is impossible.

In discussing the finding that so many patients were positive about the matches under study, we noticed the well-known validity problem of measuring patient satisfaction that generally results in high to very high satisfaction scores (Sixma et al., 1998). In addition, the procedure of selecting patients for this study (by means of the assessment agencies) has to be taken into account. This procedure may have led to a systematic bias in that patients, whose request for care was denied by the assessment agency, may have been excluded from the sample, even though this was explicitly not an exclusion criterion. In our study, assessors judged that patients were not eligible for professional home care at all in only six cases. In addition, 28 cases once selected by the assessment agencies appeared not retrievable for home care organisations. We assume that these cases received a negative indication by the assessor. When tallied, this leads to about $8 \%$ of the patients receiving a negative indication for care. In other studies, it appeared that this group might encompass about $6 \%$ of all requests for care registered at an assessment agency office (Schrijvers, 2001; Van Campen \& Van Gameren, 2003). By definition, this group was excluded from analyses of the matches for home care delivered, leaving the relatively more satisfied cases to be analysed.

We consider it not very likely that we have overlooked patients who could not find the entrance to the care chain (i.e. the assessment agency), which 
was suggested in research among patients in need of facilities for disabled people (Jedeloo, 2002; Van Campen \& Van Gameren, 2003). We believe so because home care is a well-known healthcare facility and because home care organisations will refer patients to the assessment agency if they want to present their request for care at the home care organisation's office.

For determining the actual matches between felt need and care indicated and professional home care delivered in times of waiting lists, we recommend sluggishness in conducting record studies in order to prevent many missing values in the data sets. Had we conducted the telephone interview and the record study concurrently, we would have had missing cases at a rate of about $30 \%$ of our sample.

Some mismatches or partial matches may be artefacts and should be attributed to the time elapsed between the needs assessment and the date of the telephone interview. For instance, patients were asked to report their felt needs for care retrospectively and score them on a structured needs list, no matter whether they received professional or informal help to address these needs. Because home care was being delivered in two-thirds of the cases at the time of the telephone interview, it is possible that some needs for care were already being met, which would result in a seeming partial match in case the patients did not remember their initial needs. Letting patients score on a scale measuring felt need for care and asking patients about their needs assessment and its inherent indication of care should preferably be separate from actually already receiving the allocated care. In research, too, these moments should be separated. This might yield fewer cases of overindication and overdelivery as well. A prospective study design might facilitate this. However, since the chronic patient's needs are usually rather stable, we argue that our retrospective design sufficed.

We might have found more influence of the assessment agencies on the matches studied in this project if we had focussed on the characteristics of the individual needs assessor rather than on the characteristics of the assessment agency as an organisation. Jörg (2002), in demonstrating a lack of objectivity of needs assessment, found the person of the needs assessor to be a major factor for predicting an adequate match between felt need and care indicated. 
We have had difficulty including the characteristics of home care organisations in the analyses because over a quarter of the cases were lost. This was mainly because home care was not delivered to some of the patients and there was also a lack of co-operation on the part of some of the home care organisations to participate in our study. The fact that we did not detect any significance does not automatically mean that the characteristics of home care organisations actually have no influence. We may just have lacked the statistical power for detecting it.

Power analyses suggested that gathering data on 400 cases would suffice for demonstrating statistical associations. In practice, however, the number of cases in the analyses dropped due to incomplete data sets (no professional home care delivered; conditional matches, whereby matches in type of home care delivered were conditional for computing matches with amount of home care delivered; lack of co-operation or consent of patients, assessment agencies, and home care organisations). Lack of co-operation of assessment agencies was not statistically linked to some characteristic of these organisations, and only two home care organisations did not want to cooperate in our study (of course, resulting in a loss of more than two cases). In the light of the generally complete patient interview data sets, we tend to conclude that bias due to systematic loss of cases was minimal.

In relation to the topic of incomplete data sets, we were unable to include all the independent variables in the analyses that we would have liked. The number of variables did not balance the number of cases adequately. Small effects could not be traced. Had we had more cases, these extra, possibly influential, variables could have been studied. In fact, in our multi-variate analyses we only included the variables from which we theoretically or bivariate statistically expected the largest influence. Therefore, we recommend that future research try to use larger samples and to minimise the loss of cases in advance.

Finally, we have some remarks about using records as an instrument of data gathering. In record studies, researchers are dependent on the accuracy of what is recorded (Van Campen \& Van Gameren, 2003). In our case, we had to rely on the validity of assessment agency reports and records of home care organisations. There was no absolute certainty about whether the home care delivered according to the home care organisation was always the care 
belonging to the needs assessment studied in the preceding part of the research project or belonging to the needs expressed during the telephone interview. The fact that the home care organisations occasionally deficiently recorded dates or type of care delivered, made adequate retrieval of patientbound data questionable in some cases. Furthermore, because there were two files from different organisations (assessment reports and home care organisation's records) for each patient to be connected, just one deficient file caused the deletion of the whole case.

At the very first beginning of this study (mid-1999), we were surprised to discover that hardly any research on the functioning of the needs assessment that included the patient's perspective had been set up or conducted. Not only that, hardly any evidence-based information on factors that might have an effect on the match between the need for and use of professional home care by chronic patients was available. Despite this, both topics (the patient's perspective on care delivered to them and factors determining the match between need and delivery) even then already had had the government's interest for over a decade. Our study anticipated these gaps in empirical knowledge.

\subsection{Implications for practice}

Our literature study (Algera et al., 2003; see Chapter 3) suggests that, in the light of attaining the objectives described in the Care Needs Assessment Decree, authorisation arrangements allowing for delegation of assessments of non-complex needs for home care should be abolished. Such authorisation arrangements may threaten the objectives of independence of and the integrated approach to needs assessment and lead to only partial matches, as also the Dutch National Audit Office stipulated (Tweede Kamer der StatenGeneraal (1999-2000). However, authorisation arrangements did not show any significant associations with the adequacy of the matches in our patient study, except for one positive association. This concerned the actual match between felt need for care and care indicated which was better in the case of authorising non-complex needs assessments to home care organisations. Other reasons should be taken into account for valuing authorisation arrangements as well. Patient friendliness, efficiency, and reducing bureaucracy come to mind (see Chapter 4; Algera et al., 2003). 
Authorisation arrangements cause one link in the chain between needing and receiving care to be omitted; this may be considered more patient friendly and is definitely less bureaucratic. Certainly this may be the case for patients with non-complex home care needs which may include about $85 \%$ of all demands for care (Van Campen \& Van Gameren, 2003). The fact that waiting lists for needs assessment exist within assessment agencies favours authorising assessments for non-complex home care needs to home care organisations all the more. Thus, there seems to be a paradox in the independent needs assessment. The driving force behind constructing the new procedures of assessing home care needs was to give the patient a stronger position and to provide adequate care (a better match between need and delivery; see Section 1.2). However, by this, the route to home care has been lengthened. This will probably be unprofitable from the patient's perspective, especially in the case of evident, non-complex home care needs. Assessment agencies and home care organisations as well as health insurance agencies, policymakers, and - last but not least - patient organisations should seek consensus in setting priorities. In doing so, especially assessment agencies and home care organisations should primarily pursue the interests of their clientele: the users of care. Our research project yields evidence that authorising does not affect the matches at hand negatively (no significance of authorising on most matches). Indeed, the actual match between felt need for care and care indicated would improve.

The independence of needs assessment may be hampered by the rather incomplete reports assessment agencies tend to produce (see Section 1.6). Incomplete assessment reports may give home care organisations too much freedom to fill in the gaps to their liking, and this is not necessarily in the patient's interest. Since mid-2003, assessment agencies have to formulate the care indicated as one or more of seven so-called functions of care: domestic care, personal care, nursing care, supporting care, activating care, treatment, and resident care (Tweede Kamer der Staten-Generaal, 2002-2003). Considering this very a-specific indication of care to be delivered, more complementary needs assessments by home care organisations may be expected. However, in our patient study, the extent to which home care organisations judge the assessment reports to be unusable, did not influence the matches under study. 
Partial matches and mismatches between care indicated and professional home care delivered can be attributed to assessment agencies as well as to home care organisations. For example, Jörg's (2002) study of vignettes (patient cases described on paper) demonstrated that assessors would grant over three-quarters of the patients domestic care, while in practice only about one-third of this group enjoyed this service. Mismatches may have been caused here by assessment agencies indicating care too generously or by home care organisations rationing the available home care. Assessment reports and professional home care delivery should be periodically and retrospectively scrutinised for adequacy in individual cases in order to study the origin of these mismatches and subsequently prevent them from recurring.

Concerning the objectivity of needs assessment, we would like to underscore Dijkstra's (2001) and Jörg's (2002) conclusion that objectivity should not be defined as mere uniformity of care indicated but rather as standardisation of opportunities of acquiring an indication for a specific type and amount of care. For instance, regarding several perceived and actual matches, our study shows that chronically ill women and older patients were disadvantaged relative to men or patients younger than 65 . Assessors should be aware of this discrimination and act accordingly in order to avoid inequality among patients and, proactively, pursue more perceived and actual matches in these subgroups of growing significance.

In conclusion, we would like to make a case for defining objectivity in needs assessment as assessing the patient's needs within the context of the patient's specific situation and desires. As a consequence, needs assessment would not be needs-oriented or demand-driven, but rather patient-led. In many cases, these three phrases will be synonyms in that patients recognise their own needs and make a request for solving their healthcare deficits. In other cases, however, patients will not accept help for all of their felt needs and will not request the care that needs assessors may find necessary. In such cases, patient-led needs assessment would be more restrictive at the patient's own request than needs-led or demand-driven needs assessment would have been. However, patient-led needs assessment should not be confused with giving the patient his/her way automatically; needs assessors must apply their professional standards in indicating the care needed to meet the patient's needs he/she wishes to be met. 
The extended magnitude of the domain of the assessment fields should not be seen as synonymous with an integrated approach to needs assessment. Specific training is needed for assessors if they are to be able to oversee the various facilities reimbursed by the Exceptional Medical Expenses Act and Facilities for the Handicapped Act. Especially because assessing needs is a young profession, training seems crucial to us. Specific training for needs assessors should make them also more sensitive to the patient's real needs, even when these are unexpressed or latent, while superfluous demands for home care are not created.

Our study shows that only one out of six respondents received the appropriate type and amount of care according to their care indication which, in turn, corresponded with their felt needs adequately. The process of obtaining home care can go wrong at several points along the care chain. Fortifying the crucial link of needs assessment would facilitate more actual matches. Intensified training for needs assessors in the area of noticing older people's and women's needs might be an instrument for strengthening the needs assessment link as employing more needs assessors would be. The latter would reduce waiting lists and therefore mismatches due to time elapsed. Another option would be clarifying the patient's and assessment agencies' expectations for both parties.

Just recently, new regulations are dispersed among assessment agencies in which standardised assessment reports are promoted for assessing evident, non-complex needs for care (Ministerie van Volksgezondheid, Welzijn \& Sport, 2004). With two or three 'smart questions', the care indicated to meet the patient's need is determined. Although this development might speed up the assessment procedure, investigating all of the patient's needs is not possible in these cases. Therefore, the comprehensiveness of the needs assessment is threatened by this initiative.

We argue that if health insurance agencies played a more dominant role in the management of home care in the care chain, financial incentives might strengthen the assessment agencies' position within care chain. They could reimburse only the home care delivered that was indicated in the assessment report. Overdelivery would probably be a thing of the past because home care organisations would have to pay for that themselves. The assessment agencies would be more important, provided that the quality of the 
assessment reports meets certain standards such as providing clear, relevant information that is not too general. Health insurance agencies could check the quality of the assessment reports periodically.

Other studies (Schrijvers, 2001; Jedeloo, 2002) showed large percentages in which the patient's demand for home care was confirmed by the assessment agency: $95 \%$ of the assessment reports reflected the patient's demands for a specific type of home care perfectly. However, our study found a considerably smaller percentage (see Chapter 5; Algera et al., 2004b). On the basis of their figures, Schrijvers and Jedeloo suggested that assessment agencies should not play a role before home care delivery. In most cases, home care was delivered as patients requested, so why bother? From this point of view, assessment agencies as an extra link within the care chain are redundant in far most cases. However, this suggestion ignores the fact that felt need for care and demand for home care are far from identical (see Chapter 5; Algera et al., 2004b). Furthermore, a positive decision does not mean that a perfect match between felt need and professional home care delivery will ensue. In addition, Holtkamp (2002) discovered the largest number of discrepancies in needs assessment versus delivery of care concerning the psychosocial care of nursing home residents, while physical needs were recognised by the assessor and addressed by the nurses. Another study found that psychosocial care was rarely incorporated into the indication for care (Van Campen \& Van Gameren, 2003). In conclusion, checking assessment reports just retrospectively would leave home care organisations to determine once again the amount of care to match their capacity. Home care delivery according to availability, 'cream-skimming' by serving the cheapest patients, and inequitable allocation of care would then be encouraged.

\subsection{Policy implications}

Hardly any characteristic of the assessment agencies had a significant effect on the matches under study. However, the use of assessment forms did. If an assessment agency used these forms, the actual match between the patient's felt need and the care indicated tended to be worse. These assessment forms were recommended for use at the time of the study. In later years, their use was made compulsory. It is questionable whether chronically ill patients will 
benefit from the government's obliging assessment agencies to use these forms (see Chapter 3). The government meant this requirement to achieve more objectivity, but the patient appear to suffer the negative consequences, and home care organisations have already voiced their own objections to the use of these forms. We note, however, that the contents of the assessment forms have changed since we gathered our data (Tweede Kamer der StatenGeneraal, 2002-2003), and it is unknown whether the current assessment forms will still influence the actual match between felt need and care indicated negatively. However, as we argued before, real objectivity should not be expected from standardised assessment forms. Probably, making all assessment agencies resort under one governmental body directly linked to the Ministry of Health, starting from 2005 (Ministerie van Volksgezondheid, Welzijn \& Sport, 2004), will help in reducing the differences between the assessment agencies. This might lead to more objectivity in the way we redefined it earlier. In addition, the merge into just one nation-wide centre for needs assessments and care indication may enhance the quality of the needs assessment, although the efficiency may be threatened by the large economies of scale.

Based on our study, we do not advocate using nationally uniform assessment forms. For policy reasons, however, it would be convenient if assessment reports customarily included a distinction in indicating care for addressing the patient's felt need. We recommend that after a skilled needs assessor has determined all the patient's needs (obvious or latent), he should note who is going to deliver the care and to what extent: informal caregivers, professional home care, or nobody (if the patient chooses to refrain from care). Such a division would be helpful in determining mismatches and who to hold accountable for them. To date, the patient's real needs (all of them) are not made explicit because informal caregivers meet part of them. In addition, the opportunity of quantifying the valuable position of informal caregivers by means of assessment reports has yet been lost.

Distinguishing the needs to be met and by whom would also provide the government with valuable information about the gap between needing care and receiving it. From the contemporary assessment reports, the government can only deduce how much professional home care is necessary to meet the patient's need. This is a supply-oriented view. Further, this gap is blurred by new guidelines for assessment agencies, according to which assessors now 
have to be restraint in indicating domestic or physical home care (Ministerie van Volksgezondheid, Welzijn \& Sport, 2004). Despite the tendency toward out-patient care (see Section 1.2), regulations are now in preparation to eliminate reimbursable domestic care altogether (Ministerie van Volksgezondheid, Welzijn \& Sport, 2004)

If we redefine the egalitarian principle intrinsic in the Care Needs Assessment Decree in the fashion we have suggested, patients will be given equal chances of receiving home care. Our study shows underdelivery of home care with respect the indicated number of hours in $22 \%$ of the cases. However, concurrently, overdelivery of the amount of home care was observed in $15 \%$ of the cases as well. There may be logical explanations for some of these cases, but we argue that the inequitable allocation of scarce care facilities is rather common. Rationing home care not only makes the gap between the need for care and the availability of care facilities invisible, it also proves to be ineffective. Indeed, a substantial number of patients received more hours of care than were indicated, whereas rationing of home care was meant to lead to serve more patients by limiting the amount of professional home care delivered to all patients.

Communication problems between needs assessors and home care personnel arose because they make use of different vocabularies (Vulto, 1999; Schrijvers, 2001). As already mentioned, for some time needs assessors have to formulate the care indicated in terms of so-called functions of care. In practice, the typology used in all the Exceptional Medical Expenses Act sectors could be traced back to these functions of care in $99 \%$ of the cases (Van Campen \& Van Gameren, 2003). A conversion table has been drawn up. Although home care organisations should recognise the three functions of domestic care, personal care, and nursing care as their core business, we still expect conflicting jargon between assessment agencies and home care organisations. With regard to the independence of needs assessment, these very indistinct functions may give home care providers yet again more opportunities to consider the assessment report as merely a hint of what type of care should be delivered. The term 'indication of care needed' is, then, interpreted too liberally. Most likely, providing for compatible software for exchanging patient-related data within the care chain would not only speed up procedures, but may also improve communication, especially when the conversion table is built in into the software. 
Our study shows that chronically ill home care users generally held very positive opinions about the matches, notwithstanding the finding that the actual matches were often limited. Apparently, the patient's opinions about these matches are not just based on whether there was an actual match. Our study presents some evidence that the efforts of informal caregivers in providing home care may be largely responsible for these positive opinions. Continuing and even expanding legislative support of informal caregivers by facilitating care leaves and sabbaticals will probably help reduce the pressure for professional home care. In addition, expanding facilities for semiinstitutionalised day care would give informal carers more respite.

We have suggested that assessment agencies, home care organisations, health insurance agencies, and the Dutch government should try to achieve consensus in setting priorities regarding the paradox of the assessment agencies. These agencies were established for the patient's sake, but they also constitute an extra bureaucratic layer or even a barrier to getting care to the detriment of the same patient.

In policy, the assessment agencies are the hinges within the care chain, but in practice, their role is seriously criticised, mainly for organisational reasons. It would probably be wise to enhance authorisation arrangements for noncomplex home care needs as a shortcut through the care chain. This would resolve the assessment agencies' waiting lists and their shortage of personnel and free them to deal only with needs assessments for the complex cases. Such authorisation arrangements would imply that the home care organisations will regain authority over more than three-quarters of all home care needs assessments, thus giving them more control over the contents of their own work. In addition, home care organisations would no longer need to perform complementary needs assessments because of the elapsed time between a request for care and delivery. Communication problems in understanding the assessment reports would diminish. Health insurance agencies could retrospectively check the quality of the needs assessments of the home care organisation and perhaps give certificates or other status awards for adequate needs assessment if a certain level of actual and perceived matches is attained. As a consequence, the extent to which actual and perceived matches in needs assessment occur could play a role in financial negotiations in determining the amount of care to be reimbursed by health insurance agencies. On a macro scale, needs assessment would be 
more transparent, efficient, and less bureaucratic, all magic words for today's Dutch government. As icing on the cake: the care indicated would actually match the patient's felt need significantly better.

And the chronically ill patients? Except for the actual need-care indicated match, neither the other actual matches nor their perceived matches would be affected by authorisation arrangements in any way, as our study shows. Until tomorrow's more eloquent elderly are the clientele of assessment agencies and home care organisations, the patient will probably continue to be as satisfied as ever, no matter how the needs assessment is organised...

\subsection{Implications for future research}

In the methodological section we discussed some methodological issues and the restrictions of the study. In this section, we would like to give some recommendations for topics for further research. Future research into the topic of this thesis may probe into specifying our results or generalising them.

Our study shows that, in many cases, the perceived matches under study were rather good, whereas the actual matches appeared to be poor of mediocre. However, in our study the focus was on chronically ill patients with a demand for home care. Although assessment agencies' clientele to a large degree consists of this category of patients, also other categories are served by the assessment agencies. It is unknown whether comparable results on the matches involved would occur for these other patient groups. Therefore, we would like to recommend investing in further research into the needs assessment and care indication for other care facilities and expanding the scope towards other patient groups as well. Some research concerning other patient groups or other facilities has already been performed (Jedeloo, 2002; Jörg, 2002), but the research designs used did not incorporate following patients all through their individual care chain.

In our study, the use of the national assessment forms appeared to be of no influence on the matches we investigated, except for a negative association with the actual match between felt need and care indicated. Mid-2003, a new set of the assessment forms were introduced (Tweede Kamer der Staten- 
Generaal, 2002-2003). Assessment agencies are compelled to use these forms. However, it is unknown whether these new forms would enhance or worsen the matches under study.

In addition, since the functions of care (see Section 1.11), traditionally belonging to home care organisations, can now be delivered by other longterm care providers (such as nursing homes), it is interesting to investigate these matches non-home care organisations would achieve in delivering home care.

New legislation (Act for Societal Support; in Dutch: Wet Maatschappelijke Ondersteuning: WMO), scheduled for 2006, would locate the needs assessment for domestic care at the municipalities (Ministerie van Volksgezondheid, Welzijn \& Sport, 2004). Our study demonstrates that in many cases matches concerning just domestic care needs usually were quite adequate (Algera et al., 2004b, 2004c, 2004d). It would be interesting to study the extent of these matches when the local authorities compose the assessment reports. Whether the matches included in our study have improved with the implementation of the independent needs assessment in 1998 could not be quantified because the old style of needs assessment was not well-researched (see Section 1.10). However, our study provides data that may be considered as a pre-test, conducted before the planned centralisation of the needs assessment (see Section 1.6) and also before the shifting of the needs assessment for domestic needs to the municipalities. Hence the matches in domestic needs assessment by the assessment agencies and the matches in domestic needs assessment by the municipalities can be compared in a pre-test/post-test design.

In the methodological section (Section 1.10) we discussed the systematic exclusion of patients who failed to receive a positive indication of care from analyses of the matches for professional home care delivered, leaving the relatively more satisfied cases to be analysed. Further research among this small, but most probably very dissatisfied group, will be very highly informative. 


\subsection{General conclusion}

Matching delivery of care with the patient's need has the attention of the policymakers in Western countries. However, hardly any research on the influence of characteristics of chronic patients or the healthcare system on this match could be traced in the literature on home care.

In the Netherlands, some organisations are forming a so-called care chain: ideally an assessment agency assesses the patient's felt needs and indicates the care required to meet those needs, and a care-giving organisation delivers the care accordingly. Along with the care chain, a new style of needs assessment and indication of care has been introduced. These new procedures were intended to lead to independent, objective, and comprehensive needs assessment.

By and large, the independent needs assessment seems to be organised in accordance with the Care Needs Assessment Decree (Ministerie van Volksgezondheid, Welzijn \& Sport, 1997). In principle, in 2000/2001all the necessary structures have been established for assessing needs for home care in an independent, objective, and comprehensive fashion.

Nonetheless, studying assessment reports and home care organisations' records revealed imperfect matches between felt need, care indicated, and type and/or amount of professional home care delivered on a rather large scale. In most cases, these imperfect matches consisted of under-indication of care needed to meet the patient's felt needs or underdelivery of professional home care, but, in contrast, in a substantial number of cases, over-indication or overdelivery of professional home care was observed as well. This may be an example of the inequitable distribution of scarce care resources, even though the independent needs assessment was intended to overcome that particular criticism from the patient organisations. However, overdelivery (and underdelivery to a lesser extent) may also be a result of home care organisations correcting for what they judge to be assessment agencies' flaws in needs assessment.

Record study has shown that the actual matches between felt need for care and the care indicated on the one hand and between the care indicated and the professional home care delivered on the other were quite moderate. 
Further, the overall match between felt need for care and professional home care delivered was rather poor. Still, the chronic patients themselves generally reported positive opinions about how the assessment report reflected their felt needs and how it was put into practice by the home care organisation.

When patients seem positive irrespective the actual match, the question arises whether it will be worth the assessment agencies' and home care organisations' while to try to improve these matches. Although pragmatism may inhibit such initiatives, taking patient-led needs assessment and according professional home care delivery as points of departure, improvement attempts will be inevitable. Improved matches would probably evoke even greater satisfaction rates among the chronically ill.

Regarding the matches under study, we notice some significant patient characteristics (age and sex). Of course, these characteristics are beyond the realm of assessment agencies' management. In practice, women and younger chronically ill patients appeared to run the risk of being disadvantaged. Therefore, they should be kept in mind in training and working procedures.

Almost no characteristics of assessment agencies and home care organisations were significantly associated with adequate matches. Our study offers only two specific findings to policymakers for ameliorating the independent needs assessment. Both have to do with the objectives of the independent needs assessment. First, authorisation arrangements are promoted both directly (because the actual match between felt need and care indicated would improve) and indirectly (because neither the other actual nor none of the perceived matches are disadvantaged by authorising of noncomplex needs assessments) as much is to gain from authorisation arrangements in the area of reduction of bureaucracy, for instance.

The match between felt need and care indicated as well as the match between the care indicated and the professional home care delivered, both concerning the link of needs assessment and indication of care, turned out to be predictors of the overall match between the patient's felt need for care and professional home care delivered. We therefore conclude that the needs assessment and as its result: the care indication appear to be crucial in the sequence from needing to obtaining home care. This was the case in the 
patient's perception of the adequacy of matches as well as in the actual matches based on comparison of records. The objective of the operation to modernise the Exceptional Medical Expenses Act by making the needs assessment the linking pin between need for care and the professional supply of care therefore seems to be attained. By improving the submatches concerning needs assessment and indication of care, policymakers would have an instrument that would help them to attain better overall matches between the patient's felt needs and the professional home care delivered. However, policymakers should not neglect the value of informal care. The care chain is held together by informal caregiving. Our study quantitatively shows its importance in meeting the patient's felt need along with professional care. 


\section{References}

Algera M, Francke AL \& Van der Zee J (2002). Zorg-indicatiestelling 'nieuwe stijl' binnen de zorgketen: een literatuurstudie naar de haalbaarheid van de doelstellingen van de indicatiestelling 'nieuwe stijl' en de realisering van de zorgketen. ['New-style' needs assessment in the care chain; a study of the literature on the feasibility of the objectives of the 'new-style' needs assessment and realising the care chain.] Verpleegkunde, Nederlands-Vlaams Wetenschappelijk Tijdschrift voor verpleegkundigen; 17 (3): 140151.

Algera M, Francke AL, Kerkstra A \& Van der Zee J (2003). An evaluation of the new home care needs assessment policy in the Netherlands. Health \& Social Care in the Community; 11 (3): 232-241.

Algera M, Francke AL, Kerkstra A \& Van der Zee J (2004). Home care needs of patients with long-term conditions: literature review. Journal of Advanced Nursing; 46 (4): 417-429.

Algera M, Francke AL, Spreeuwenberg P, Kerkstra A \& Van der Zee J (2004). The match between Dutch chronic patients' felt need and demand for home care and subsequent needs assessment. Submitted.

Algera M, Francke AL, Spreeuwenberg P, Kerkstra A \& Van der Zee J (2004). Care indicated and home care delivered: do they match in Dutch chronic patients? Submitted.

Algera M, Francke AL, Spreeuwenberg P, \& Van der Zee J (2004). The match between Dutch chronic patients' felt need and home care delivered and its determinants. Submitted.

Andersen RM (1995). Revisiting the Behavioral Model and access to medical care: does it matter? Journal of Health and Social Behavior; 36: 1-10.

Andersen R \& Newman JF (1973). Societal and individual determinants of medical care utilization in the United States. The Milbank Memorial Fund Quarterly Health and Society; 51: 95-124.

Beemsterboer WGM (2000). De ratio van de RIO's: meerwaarde van onafhankelijke, objectieve en integrale indicatiestelling. [The ratio of the regional assessment agencies: the extra worth of independent, objective, and comprehensive needs assessment.] Tijdschrift voor Gezondheidswetenschappen; 78 (4): 238-243.

Bellemakers C (1995). Patiënt en indicatiestelling. [Patient and needs assessment.] NRV Magazine; 2 (1): 9.

Breed Indicatie Overleg (1997). Modelprotocol geïntegreerde indicatiestelling voor het terrein van wonen, welzijn en zorg. [Model protocol for integrated needs assessment in the area of living, welfare and care.] Gouda: BIO.

Caris-Verhallen WMCM (1999). Nurse-patient communication in elderly care: an observation study into verbal and nonverbal communication in nursing practice. Utrecht: Nivel/University Utrecht (thesis). 
Caris-Verhallen W \& Kerkstra A (1998). Cliënten op de wachtlijst voor een verpleeghuis of verzorgingshuis en hun ervaring met de continuiteit van zorg. [Patients on a waiting list for a nursing home or a home for the elderly and their experience with the continuity of care.] Utrecht: Nivel.

Centraal Bureau voor de Statistiek (2003). Statistisch jaarboek. [Statistical yearbook.] Voorburg/Heerlen: CBS.

Centraal Bureau voor de Statistiek (2003). Vademecum gezondheidstatistieken. [Vademecum health statistics.] Den Haag: CBS.

Degen JJEC \& Huijsman R (1999). Schakelen in de keten tussen vraag en aanbod: regionale indicatie-organen in de ouderenzorg. [Gearing in the chain between demand and supply: regional assessment agencies in care for the elderly.] Maarssen/Zoetermeer: Elsevier/De Tijdstroom/STIMO.

De Haan R, Limburg M, Van der Meulen J \& Van den Bos GAM (1993). Use of health care services after stroke. Quality in Health Care; 2: 222-227.

Dijkstra GJ (2001). De indicatiestelling voor verzorgingshuizen en verpleeghuizen. [Needs assessment for homes for the elderly and nursing homes.] Groningen: Noordelijk Centrum voor Gezondheidsvraagstukken (thesis).

Ettner SL \& Weissman J (1994). Utilization of formal and informal home care by AIDS patients in Boston: a comparison of intravenous drug users and homosexual males. Medical Care; 32: 459-470.

Fleishman JA (1997). Utilization of home care among people with HIV infection. Health Services Research; 32: 155-175.

Freiman MP \& Breen N (1997). The use of home care by cancer patients: a multi-variate analysis. Home Health Care Services Quarterly; 16: 3-19.

Holtkamp CCM (2002). Effects of the Resident Assessment Instrument on quality of care and quality of life in nursing homes. Utrecht: Nivel (thesis).

Huijsman R (1990). Model van voorzieningen voor ouderen. [Model of facilities for the elderly.] Zeist: Kerckebosch BV (thesis).

Hutten JBF \& Kerkstra A (2002). Home care is what people want. In: Van Rooij EHC, Droyan Kodner L, Rijsemus AH \& Schrijvers AJP (Ed.). Health and health care in the Netherlands: a critical self-assessment of Dutch experts in medical and health sciences. Maarssen: Elsevier Gezondheidszorg; p. 101-110.

Jedeloo S (2002). Quality of needs assessment and the provision of assistive devices and services for people with a functional disability. Utrecht: Universiteit Utrecht (thesis).

Jörg F (2002). Objectivity in individual needs assessment for access to long-term care. Utrecht: University Utrecht (thesis). 
Joung IMA, Kunst AE, Van Imhoff E \& Mackenbach JP (2001). Sociaal-demografische variabelen toekomstige gezondheid. Effecten op gezondheid en gebruik van gezondheidszorgvoorzieningen 1996-2015. [Social-demographic variables future health. Effects on health and use of healthcare facilities 1996-2015.] Tijdschrift voor Gezondheidswetenschappen; 1: 21-26.

Kane RL, Finch M, Chen Q, Blewett L, Burns R \& Moskowitz M (1994). Post-hospital home health care for Medicare patients. Health Care Financing Review; 16: 131-153.

Katz MH, Cunningham WE, Mor V, Andersen RM, Kellogg T, Zierler S, Crystal SC, Stein MD, Cylar K, Bozzette SA \& Shapiro MF (2000). Prevalence and predictors of unmet need for supportive services among HIV-infected persons: impact of case management. Medical Care; 38: 58-69.

Kenney GM (1993). How access to long-term care affects home health transfers. Journal of Health Politics, Policy and Law; 18: 937-965.

Kerkstra A, Verheij RA, Foets M \& Van der Velden J (1990). Behoefte aan nazorg en verleende nazorg na ontslag uit het ziekenhuis. [Need for aftercare and provided aftercare following discharge from hospital.] Tijdschrift voor Sociale Gezondheidszorg; 68 (8): 346-354.

London AS, Fleishman JA, Goldman DP, McCaffrey DF, Bozzette SA, Shapiro MF \& Leibowitz AA (2001). Use of unpaid and paid home care services among people with HIV infection in the USA. AIDS Care; 13: 99-121.

Ministerie van Volksgezondheid, Welzijn \& Sport (1997). Zorgindicatiebesluit (Besluit van 2 oktober 1997, houdende regels met betrekking tot het werkterrein, de samenstelling en werkwijze van indicatie-organen). [Care Needs Assessment Decree (White Paper of October, 2 1997, regarding field of activities, the formation, and the operation of Regional Needs Assessment Agencies).] Staatsblad van het Koninkrijk der Nederlanden. Den Haag: Sdu, 447.

Ministerie van Volksgezondheid, Welzijn \& Sport (1999). Brief d.d. 25 maart 1999 over Ontwikkelingen indicatiestelling 'nieuwe stijl'. [Letter of March, 251999 on developments new-style needs assessment.] Den Haag: Ministerie van Volksgezondheid, Welzijn \& Sport.

Ministerie van Volksgezondheid, Welzijn \& Sport (2000). Brief d.d. 31 mei 2000 over Indicatiestelling 'nieuwe stijl'. [Letter of May, 312000 on new-style needs assessment.] Den Haag: Ministerie van Volksgezondheid, Welzijn \& Sport.

Ministerie van Volksgezondheid, Welzijn \& Sport (2000). Brief d.d. 15 januari 2001 over Robuuste RIO's. [Letter of January, 152001 on robust regional assessment agencies.] Den Haag: Ministerie van Volksgezondheid, Welzijn \& Sport. 
Ministerie van Volksgezondheid, Welzijn \& Sport (2004). Op weg naar een bestendig stelsel voor langdurige zorg en maatschappelijke ondersteuning. [Heading towards a longlasting system for long-term care and societal support.] Den Haag: Ministerie van Volksgezondheid, Welzijn \& Sport.

Nationale Raad voor de Volksgezondheid (1994). Indicatiestelling en zorg op maat: advies van de Nationale Raad voor de Volksgezondheid en het College voor Ziekenhuisvoorzieningen. [Needs assessment and customised care: recommendations by the National Council for Public Health and the Council for Hospital Facilities]. Zoetermeer: Nationale Raad voor de Volksgezondheid.

Parry-Jones B \& Soulsby J (2001). Needs-led assessment: the challenges and the reality. Health and Social Care in the Community, 9(6): 414-428.

PricewaterhouseCoopers/Nivel (2002). Benchmarkonderzoek 2000 verscherpt inzicht in prestaties en bedrijfsvoering thuiszorginstellingen: resultaten benchmarkonderzoek op sectorniveau. Eindrapport. [Benchmark project 2000 gives more insight into achievements and management of home care organisations: results of a benchmark study on the level of the sector. Final report.] Almere/Utrecht: PricewaterhouseCoopers/Nivel.

Riemsma RP, Klein G, Taal E, Rasker JJ, Houtman PM, Van Paassen HC \& Wiegman O (1998). The supply of and demand for informal and professional care for patients with rheumatoid arthritis. Scandinavian Journal of Rheumatology; 27: 7-15.

Rijken PM \& Spreeuwenberg P (2004). Patiëntenpanel Chronisch Zieken. Kerngegevens Zorg 2003. [Patient Panel Chronically Ill. Core data Care 2003.] Utrecht: Nivel.

Schippers A (2001). Indicatiestelling voor wonen, zorg en welzijn. [Needs assessment for living, care and welfare.] In: Veldheer VC, Van den Nieuwenhuizen PJCM, Schoorl AHA, Sprinkhuizen AMM \& Stevens PGJJ (Ed.). Handboek Lokaal Sociaal Beleid. Den Haag: Elsevier Bedrijfsinformatie bv; p. D 7.1.1 - D 7.1.24.

Scholte op Reimer WJM (1999). Long-term care after stroke: studies on care utilisation, quality of care and burden of caregiving. Amsterdam: University of Amsterdam (thesis).

Schrijvers AJP (2001). RIO, het jongste kind groeit op; eindrapport van de evaluatie van het Zorgindicatiebesluit van 1998. [The assessment agency, the youngest child grows to maturity; final report on the evaluation of the Care Needs Assessment Decree of 1998.] Utrecht: Julius Centrum voor Huisartsgeneeskunde en Patiëntgebonden onderzoek.

Schrijvers AJP \& Heinsbroek NQM (1998). Veel op het spel: over het hoe en waarom van verbreding van geïntegreerde indicatiestelling voor mensen met een functiebeperking. [Much to lose: regarding the reason for expanding integrated needs assessment for people with a functional disability.] Utrecht: Stichting Dienstverleners Gehandicapten. 
Schrijvers AJP \& Ravelli DP (2000). RIO, het jongste kind; tussenverslag van de evaluatie van het Zorgindicatiebesluit. [Regional assessment agency: the youngest child; preliminary report on the evaluation of the Care Needs Assessment Decree.] Utrecht: Juliuscentrum voor Huisartsgeneeskunde en Patiëntgebonden onderzoek.

SGBO (2000). Werkwijze van Regionale Indicatie-Organen; Onderzoek onder 7 RIO's. [Working procedures of regional assessment agencies; research among 7 regional assessment agencies.] Den Haag: SGBO.

Sixma HJ, Kerssens JJ, Van Campen C \& Peters L (1998). Quality of care from the patients' perspective: from theoretical concept to a new measuring instrument. Health Expectations; 1: 82-95.

Snijders TAB \& Bosker RS (1999). Multi-level analysis: an introduction to basic and advanced multi-level modeling. London: Sage Publications.

Sociaal Economische Raad (1999). Gezondheidszorg in het licht van de toekomstige vergrijzing. [Healthcare in the light of the future ageing.] Den Haag: Sdu.

STIP (1999). Informatiebulletin; $n r .5$. [Information bulletin, nr. 5.] Enschede: STIP.

STIP (2000). Periodieke inventarisatie indicatie-organen: de stand van zaken in mei 2000. [Periodical inventarisation assessment agencies: state of affairs in May 2000.] Enschede: STIP.

Tweede Kamer der Staten-Generaal (1998-1999). Nota Zicht op Zorg: plan van aanpak modernisering AWBZ. [White Paper Vision on Care: planning the modernisation of the Exceptional Medical Expenses Act.] Kamerstukken 26.631, nr. 1. [White Paper.] Den Haag: Staatsuitgeverij.

Tweede Kamer der Staten-Generaal (1999-2000). Planning en indicatie AWBZvoorzieningen. [Planning and assessment of facilities on behalf of the Exceptional Medical Expenses Act.] Kamerstukken 27.180 nr. 2. Den Haag: Sdu Uitgevers.

Tweede Kamer der Staten-Generaal (2000-2001). Kamerstukken 26.631 nr.10. [White Paper.] Den Haag: Sdu Uitgevers.

Tweede Kamer der Staten-Generaal (2000-2001). Kamerstukken 26.631 nr.12. [White Paper.] Den Haag: Sdu Uitgevers.

Tweede Kamer der Staten-Generaal (2001-2002). Kamerstukken 26.631 nr.22. [White Paper.] Den Haag: Sdu Uitgevers.

Tweede Kamer der Staten-Generaal (2002-2003). Kamerstukken 26.631 nr.46. [White Paper.] Den Haag: Sdu Uitgevers.

Van Campen C, Sixma HJ, Kerssens JJ \& Peters L (1997). Assessing non-institutionalised asthma and COPD patients' priorities and perceptions of quality of health care: the development of the QUOTE-CNSLD instrument. Journal of Asthma; 34: 531-538.

Van Campen C \& Van Gameren E (2003). Vragen om hulp; vraagmodel verpleging en verzorging. [Asking for help; model for demand in nursing and caring.] Den Haag: Sociaal en Cultureel Planbureau. 
Van der Windt W, Calsbeek H, Talma H \& Hingstman L (2003). Feiten over verpleegkundige en verzorgende beroepen in Nederland 2003. [Facts on nursing and caring professions in the Netherlands 2003.] Maarssen/Utrecht: Elsevier gezondheidszorg / Landelijk Expertisecentrum Verpleging \& Verzorging.

Van Oers (2002). Gezondheid op koers?: Volksgezondheid Toekomst Verkenning 2002. [Health on track?: Exploration of future health of the population 2002.] Bilthoven/Houten: Rijksinstituut voor Volksgezondheid en Milieu / Bohn Stafleu Van Loghum.

Vulto, M (1999). Indicatiestelling in de thuisverzorging; knelpuntenanalyse. [Needs assessment in home care; analysis of bottlenecks.] Utrecht: Vulto. 

Home care needs of patients with long-term
conditions: literature review 


\section{Abstract}

Background There is a widely felt need to improve the match between longterm patients' care needs and actual use of home care. As this match is not always adequate, it is important to know what factors influence it.

Aim The aim of this paper is to provide insight into long-term patients' need and actual use of home care, and the factors influencing these.

Method A literature review was carried out, based on database searches in PubMed, CINAHL and the Nivel online library catalogue. A total of 114 papers were retrieved, but only 13 clearly dealt with use of professional home care (rather than informal home care or residential care) by people with long-term conditions.

Results There is a dearth of publications on factors influencing the match between care need and actual use of professional home care among people with long-term conditions. Most of the 13 publications reviewed concerned determinants of professional home care use, rather than the match between patients' felt needs and the home care delivered. From these studies, a profile of people with long-term conditions who use home care emerged. In general, older, non-white women, with multiple chronic diseases and impairments, and who had recently had inpatient care, tend to make more use of professional home care.

Conclusion Future research in this field is recommended, particularly into system- and patient-related characteristics that may be responsible for the mismatch between care need and use.

Keywords chronic illness, long-term illness, literature review, home care, care needs, utilisation of care, nursing 


\section{Summary}

What is already known about this topic:

- People with long-term conditions are heavy users of home care.

- In practice, home care provision does not always match the needs of people with long-term conditions.

What this paper adds:

- Insight into determinants of the use of home care by people with longterm conditions.

- Insight into 'the state of the art' in research on determinants of the match between care needs and use by people with long-term conditions.

\section{Background}

Until the mid-1990s, in the Netherlands and many other Western European countries, health care organisations were supply-centred: delivery of care was determined to a large extent by availability (Adam \& Hutten, 2001). However, under the influence of movements for patient empowerment and emancipation, there has been an increase in the attention paid to patients' health care needs by decision-makers and society at large. This has resulted in an emphasis on 'tailor-made care' with its implicit match between patients' need for care and care used. Nevertheless, in real life, 'tailor-made care' is not always supplied. Consequently, it is important for health care professionals and policy-makers to gain insight into the factors that account for the care need/use mismatch. The primary aim of this paper is to provide this insight with regard to people with long-term conditions who need home care. Although a good match is essential for every group of patients, it is particularly important for this patient group. Because of the enduring, often complex, character of their illnesses, many of these patients are largely dependent on health care organisations and professionals for much of their lives, and many are heavy consumers of home care (Steel et al., 1998). This focus on long-term illness is also relevant because, in the West, increasing numbers of people suffer from such diseases, a fact closely related to the ageing of the population (Philp, 2001).

Despite the increasing importance of long-term illness and home care use in health policy, no systematic review of determinants of the need/use match in professional home care was found. This prompted the review presented in this paper, in which 'need for care' means patient-perceived need for care because of health-related deficits (Bradshaw, 1972). 'Professional home 
care', in the context of this paper, means care delivered by nursing or caring professionals in patients' homes. This may include several types of care: care relating to instrumental activities of daily life (IADL-care), also called domestic care; care relating to activities of daily living (ADL-care), also called physical care or personal care; nursing care (often involving technical interventions); and psychosocial care.

\begin{abstract}
Aims
It was expected that the need/use match in professional home care would be related to characteristics of both people with long-term illness and the health care system.

The primary research question addressed in this review of the literature was:

What patient characteristics and what health care system characteristics influence the match between need for care in people with long-term conditions and their actual use of professional home care?
\end{abstract}

However, in the initial phase of the review it became clear that there was very little literature on determinants of the match (or mismatch) between these patients' needs for home care and home care use. As it was expected that characteristics determining this match would be virtually identical to characteristics influencing home care use, a secondary research question was formulated:

What patient and health care system characteristics influence use of professional home care in patients' with long-term conditions?

\title{
Research model
}

In developing a model that could structure the review of the literature presented, various concepts were derived from the Behavioural Model of Health Services Use (Andersen \& Newman, 1973; Andersen, 1995). In this well-known model, and the adapted model used in our study (see Figure 2.1), the characteristics of health care systems and patients are considered to be the main determinants of use of care. Health care system characteristics may be those of the organisations or the professionals who deliver care. In accordance with Andersen (1995), patient characteristics are differentiated into three categories:

- predisposing characteristics, such as age and gender, that may influence likelihood of using health care services;

- enabling resources, or patients' opportunities to use the health care 
system. Income, education, and type of health insurance have been noted as the most relevant factors in this respect;

- need factors, or the necessity of consuming health care services, often due to illness. Examples include impediments to instrumental activities of daily life, and pain and fatigue.

Figure 2.1 Characteristics influencing the use of home care and the match between need and use of home care

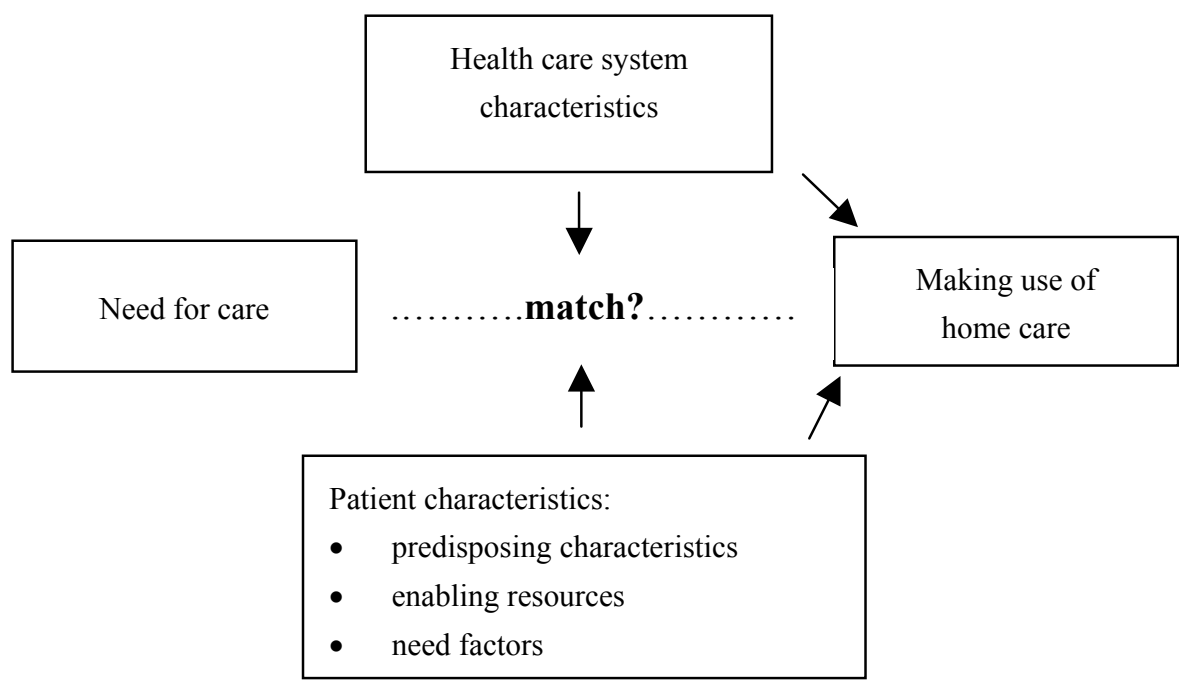

In the Andersen \& Newman model, patient and health care system characteristics impact on health care use. However, in our adapted model, it is assumed that these characteristics influence not only use, but also the match between need and actual use of home care (see Figure 2.1).

\section{Search methods}

In the review, a data search was carried out in the online catalogue of the Netherlands Institute for Health Services Research (Nivel) for the period 1980-2002, PubMed (1980-2002), and CINAHL (1982-2002). Key search terms entered for question 1 were 'home care services', 'health services needs and demand', 'utilisation', 'needs assessment', 'unmet need' and 'case management'. Key search terms entered for question 2 were: 'home care services', 'chronic disease', 'health services needs and demand' and 'utilisation'. In both cases combinations of key words were entered. 
The keywords and initial searches of the online databases produced a total of 862 potentially useful references. Subsequently, the abstracts and titles of these references were screened and only literature which met the following inclusion criteria was considered appropriate for review:

1. the literature (published reports, papers or books) contains empirical research on (a) factors influencing the match between need and use of professional home care in patients with long-term conditions or (b) factors influencing use of professional home care in this patient group;

2. it has a specific focus on people with long-term somatic conditions; and

3. it is written in English, Dutch, German or French.

A total of 114 publications seemed to meet the inclusion criteria. However, after close reading of these, only 11 clearly met the criteria. After searching the reference lists of these, two further relevant publications were identified and included in the review, making a total of 13 (see Tables 2.1 and 2.2).

The main reasons for the ineligibility of many potentially useful references were that distinctions were not made between professional and nonprofessional care or home care and inpatient care (e.g. Van den Bos, 1989; Mor et al., 1992), and between data from people with long-term conditions and data from other patient groups (e.g. Coulton \& Frost, 1982; Evashwick et al., 1984; Kempen \& Suurmeijer, 1991; Kerkstra \& Vorst-Thijssen, 1991; Shaughnessy et al., 1994; Tennstedt et al., 1994).

\section{Results}

\section{Description of the studies reviewed \\ Focus of the studies}

Studies reviewed focused on determinants of the match between need and use of home care among people with long-term conditions (Table 2.1), or determinants of home care use in this patient group (Table 2.2). One study addressed both types of determinants (Scholte op Reimer, 1999) and is, thus, included in both Tables 2.1 and 2.2.

Types of professional home care included in the analyses varied among the studies. Some studies distinguished between several types of home care (e.g. IADL-care or ADL-care) or made a distinction based on type of home care provider involved (e.g. home care nursing or home help). Other publications reviewed, however, were not explicit about the kind of professional home 
Four studies focused on determinants of use (or lack of use) of some kind of home care, and six publications only reported determinants of the amount or intensity of home care utilisation (Table 2.2). Two studies (Fleishman, 1997; Freiman \& Breen, 1997) encompassed both focuses.

A wide range of chronic patient groups was included in the studies reviewed. The most frequently investigated patient groups were those with chronic heart failure (five studies), chronic obstructive pulmonary disease (COPD) (four studies), and diabetes mellitus, stroke and HIV/AIDS (three studies). Only one study focused on cancer, and one study on rheumatoid arthritis.

\section{Origin}

Ten of the 13 studies reviewed were carried out in the United States of America (USA), and three were conducted in the Netherlands (Tables 2.1 and 2.2).

\section{Methodological properties and qualities}

Eleven of the 13 studies featured quantitative analysis of survey data, sometimes combined with analysis of patient records (Tables 2.1 and 2.2). One study was based on records only (Adams \& Kramer, 1996). One study had a nonrandomised control group design and focused on the influence of a collaborative intervention by primary care professionals (Sommers et al., 2000).

The methodological quality of the two studies addressing the first research question (Table 2.1) was beyond dispute. Large research samples were used $(\mathrm{n}=2832$ and 328) and the analysis methods (logistic regression analyses) seemed adequate.

However, methodological quality of the studies on the second research question varied as far as sample sizes were concerned. Most of these studies had fairly large research samples, while three had smaller ones $(n<150)$ (Table 2.2). In most of the studies, multiple logistic regression analyses were used; these appeared to be adequate for answering questions on the determinants of home care use. 


\section{Characteristics influencing the match between need and use of professional home care}

An adequate match between chronic patients' need and use of care indicates that a care need was well met, while a poor match means that the need was not sufficiently met. This is coherent with the two relevant studies found, which described a mismatch in terms of 'unmet needs' (Scholte op Reimer, 1999; Katz et al., 2000).

However, these two studies devoted their attention to the influence of patient characteristics and did not explore the influence of health care system characteristics. Both studies investigated the influence of predisposing characteristics such as age, gender and living arrangements (Table 2.1). The findings of these two studies did not, however, point in a clear direction. In Scholte op Reimer's study it was found that younger or male stroke patients had a larger probability of unmet home care needs, while in Katz et al.'s work age and gender did not appear to be influential (Table 2.1). In addition, in both studies, living arrangements (composition of the household) proved to have no significant influence.

In addition, both studies investigated the influence of education, an 'enabling resource'. In this regard, the studies did have comparable findings: neither found a significant relationship between education and unmet home care needs.

Both studies also explored whether there was a relationship between various need factors and unmet home care needs. However, the two studies did not include the same need factors, and so their results cannot be compared. For the influence of characteristics that were only considered in one of the two studies see Table 2.1.

\section{Health care system characteristics influencing use of professional home care}

Literature on the influence of health care system characteristics on use of home care by people with long-term conditions was also scarce. The few relevant studies focused on diverse characteristics and patient groups (De Haan et al., 1993; Kenney, 1993; Sommers et al., 2000). Kenney described the influence of a broad variety of health care system characteristics on use of home care by patients with COPD, chronic heart failure or stroke, and 
found that the chance of using it increased when there were fewer nursing home beds or more health staff available per insured person. In addition, use of home care was greater if there were fewer hospital-based long-term care arrangements or more hospital-owned home health agencies. All but one of these relationships appeared to be significant in patients with COPD and chronic heart failure (Table 2.2), whereas, in patients who had experienced stroke, only the relationship between a smaller number of nursing home beds per insured person and home care use appeared to be significant.

In the De Haan et al. (1993) study, it was found that if a general practitioner was notified about a stroke patient's discharge from hospital, the chance of home help use increased.

In a study involving a number of different diagnoses (Table 2.2), Sommers et al. (2000) detected no significant relationship between extent to which primary health care professionals (physicians, home care nurses and social workers) worked together and frequency of home care visits.

\section{Predisposing patient characteristics influencing use of professional home care}

Most of the studies reviewed considered the influence of the predisposing characteristics of people with long-term conditions on home care utilisation (Table 2.2). The influence of age, gender, and living arrangements, in particular, were usually explored. As far as age was concerned, the results were almost unidirectional and tended to confirm expectations: the older the patient, the more likely it was that professional home care would be used (De Haan et al., 1993; Kenney, 1993; Kane et al., 1994; Freiman \& Breen, 1997; Riemsma et al., 1998; Scholte op Reimer, 1999; London et al., 2001). For instance, in a longitudinal study, Scholte op Reimer reported that the odds on receiving IADL- or ADL-care five years after stroke was 8.4 times higher among patients over the age 72 than among younger respondents. Other studies, however, did not find unidirectional effects of age on home care use (Bull, 1994; Freiman \& Breen, 1997).

Most studies describing the effect of gender on home care utilisation found that women used home care more often (De Haan et al., 1993; Kenney, 1993; Fleishman, 1997; Freiman \& Breen, 1997; Riemsma et al., 1998; London et al., 2001). For instance, in a study of HIV patients, being female 
increased the odds of professional home care by $61 \%$ (London et al., 2001). However, in a minority of studies, no significant relationship was found between gender and use of home care. For example, in Kane et al.'s (1994) study of chronic heart failure, COPD and stroke, and Scholte op Reimer's (1999) study of stroke, gender was not influential.

Living arrangements, as a predisposing characteristic for people with longterm conditions using home care, have been well researched. However, the studies reviewed seemed to contradict one another. Some studies showed significantly greater home care use when patients were living alone (De Haan et al., 1993; Riemsma et al., 1998; Scholte op Reimer, 1999), whereas others indicated that patients living with others used home care more (Ettner \& Weissman, 1994; Kane et al., 1994; Freiman \& Breen, 1997). Scholte op Reimer, for instance, calculated probability of receiving ADL- or IADL-care in patients who had experienced stroke and found that those living alone were at least five times more likely to use care than those living with other people. On the other hand, Ettner \& Weissman showed that patients with AIDS living with a partner received an average of 26.8 hours more professional home care than those living alone. Other studies have found no significant effects of living arrangements on home care utilisation (Fleishman, 1997; Freiman \& Breen, 1997; London et al., 2001).

Several studies also included ethnicity as a characteristic which might influence home care utilisation (Table 2.2). Most of these studies indicated that being non-white increased the chance of using home care, although this relationship seemed also to be dependent on the diagnosis. For instance, in Kane et al.'s (1994) study, non-white people with COPD made 32\% more use of home care facilities than white people, but among patients with heart failure or stroke patients no relationship was found. In another study, being non-white increased the chance of using home care in patients with COPD and stroke, but not in patients with heart failure (Kenney, 1993).

For use of home care according to other, infrequently investigated, predisposing characteristics see Table 2.2.

Enabling resources influencing use of professional home care

A relatively large number of studies explored the influence of enabling resources (such as type of insurance, income, availability of facilities, 
educational level and degree of urbanisation) on home care use.

In studies carried out in the USA type of insurance was one of the independent variables. Three main types of insurance could be distinguished: (1) Medicaid insurance for people below a certain level of income; (2) Medicare insurance for older people; and (3) insurance through membership of a Health Maintenance Organisation (HMO) (Health Insurance Association of America; HIAA, 1999). These studies produced ambiguous results. In some studies type of insurance made no difference (Ettner \& Weissman, 1994; Adams \& Kramer, 1996), while in others the influence of insurance type appeared to be dependent on the specific type of home care (Fleishman, 1997; Freiman \& Breen, 1997; London et al., 2001).

In most studies investigating the influence of income on use of home care, no significant relationships were found (De Haan et al., 1993; Bull, 1994; Ettner \& Weissman, 1994; Freiman \& Breen, 1997; London et al., 2001). However, two studies showed a significant but contradictory relationship (Fleishman, 1997; Riemsma et al., 1998). Riemsma et al. (1998) reported that patients with rheumatoid arthritis who had a low income made more use of professional home care. In contrast, Fleishman (1997) found that a higher income was associated with use of a home help in people who were HIV positive.

Another enabling resource included in a great deal of research on home care utilisation is educational level. In these studies, education proved not to be predictive of use of home care. Patient samples on which this conclusion was based, involved patients with AIDS or HIV (Fleishman, 1997; London et al., 2001), stroke (Scholte op Reimer, 1999), and rheumatoid arthritis (Riemsma et al., 1998).

Three studies also investigated urbanisation as a possible predictor of use of home care. Two of these studies indicated that urbanisation did not have any significant relationship with use or intensity of home care among patients with cancer and rheumatoid arthritis respectively (Freiman \& Breen, 1997; Riemsma et al., 1998). In contrast, in Kenney's (1993) study a higher level of urbanisation appeared to be related to increased use of home care among patients with COPD and heart failure. 
Some additional enabling resources and their relationships with home care use are displayed in Table 2.2; all these variables were only mentioned once in the literature reviewed.

\section{Need factors influencing use of professional home care}

As already stated, need factors refer to patient characteristics which are often illness-related and make use of professional care necessary (Andersen, 1995). A high proportion of the studies considered the influence of need factors on use of home care by people with long-term conditions (Table 2.2).

Four major categories of need factors emerged from the literature reviewed. The first category relates to the conditions experienced by patients. In some studies, the main diagnosis only was subject to analysis; in others comorbidity was also studied. In studies that included only the principle diagnosis, no significant results were reported; this was the case in a study that compared different types of home care (Adams \& Kramer, 1996) and one on the difference between non-users and heavy users of home care (Freiman \& Breen, 1997). However, in a number of studies in which comorbidity was involved, several significant effects on home care use were revealed. For instance, De Haan et al. (1993) found, in patients who had experienced stroke, that those who also had dementia appeared to make use of home help more often than those not diagnosed with dementia. Riemsma et al. (1998) reported that, in general, comorbidity and also longer disease duration led to more use of home care. Kenney (1993), on the other hand, found no relationship between comorbidity and home care use among patients suffering from multiple illnesses.

The second category of need factors concerns impairments in terms of ADL or IADL. The results of most of the studies reviewed pointed in the same direction: having impairments may increase the use of home care. Significant relationships between impairments and utilisation of home care were reported in the case of patients with heart failure (Bull, 1994), diabetes mellitus (Bull, 1994), COPD (Bull, 1994), stroke (De Haan et al., 1993; Scholte op Reimer, 1999), AIDS (Ettner \& Weissman, 1994), HIV (Fleishman, 1997), and cancer (Freiman \& Breen, 1997). Most studies found that having more impairments increased the chance of using home care facilities (Table 2.2). For instance, Scholte op Reimer (1999) noted that, in stroke patients, inability to perform IADL and severe handicap led to a rise 
in the use of IADL- and ADL-care by a factor of six to twelve.

A third category of need factors relates to patients' perceptions of their own health status. Some research on this topic has been undertaken by Scholte op Reimer (1999) and De Haan et al. (1993). In both research projects, no significant effects of self-assessed health or emotional distress on use of home care were found. Riemsma et al. (1998), however, found that low selfefficacy expectations in respect of coping with rheumatoid arthritis, poor self-reported health, fatigue and feelings of loneliness were associated with greater use of home care.

The fourth category of need factors contains aspects of past care use. London et al. (2001) showed that HIV-positive patients who had recently received residential care made greater use of home care; the odds for the firstmentioned group were 3.2 times higher than those for the group who had not received such care during the past six months. Kenney (1993) found that post-surgery stroke patients used home care more often than patients who had not had surgery, while among patients with COPD and heart failure these relationships were not found. In their study on people with cancer, Freiman \& Breen (1997) concluded that number of hospitalisations was associated with the use/lack of use of home care, but not with intensity of use. Fleishman (1997) had comparable findings when relating recent hospitalisation to use and frequency of home help. For details about the influence of less frequently investigated factors see Table 2.2. 
Table 2.1 Studies on factors influencing the match between need and use of professional home care by people with longterm conditions

\begin{tabular}{|c|c|c|c|c|}
\hline $\begin{array}{l}\text { Author \& year } \\
\text { Methodological characteristics } \\
\text { Country }\end{array}$ & $\begin{array}{l}\text { Health care system } \\
\text { characteristics }\end{array}$ & $\begin{array}{l}\text { Predisposing } \\
\text { characteristics }\end{array}$ & Enabling resources & Need factors \\
\hline $\begin{array}{l}\text { Katz et al. }(2000) \\
\text { Multiple logistic regression } \\
\text { analysis on survey data on } \\
2832 \text { HIV-infected patients } \\
\text { USA }\end{array}$ & -- & $\begin{array}{l}\text { Unmet home care need } \\
\text { Age (NS) } \\
\text { Gender (S) } \\
\text { Ethnicity (NS) } \\
\text { HIV risk group (NS) } \\
\text { Past drug use (NS) } \\
\text { Living arrangements (NS) } \\
\text { Not living in own house (S) }\end{array}$ & $\begin{array}{l}\text { Unmet home care need } \\
\text { Education (NS) } \\
\text { Income (NS) } \\
\text { Insurance (NS) } \\
\text { Not having a case manager (S) }\end{array}$ & $\begin{array}{l}\text { Unmet home care need } \\
\text { Sum of needs (NS) } \\
\text { Higher lymphocyte count (S) }\end{array}$ \\
\hline $\begin{array}{l}\text { Scholte op Reimer (1999) } \\
\text { Logistic regression analysis on } \\
\text { longitudinal survey data and } \\
\text { record data on } 382 \text { stroke } \\
\text { patients } \\
\text { The Netherlands }\end{array}$ & -- & $\begin{array}{l}\text { Unmet IADL- and ADL-need } \\
\text { Younger age (S) } \\
\text { Male (S) } \\
\text { Living arrangements (NS) } \\
\text { Living independently (S) }\end{array}$ & $\begin{array}{l}\text { Unmet IADL- and ADL-need } \\
\text { Education (NS) } \\
\text { Degree of urbanisation (NS) }\end{array}$ & $\begin{array}{l}\text { Unmet IADL- and ADL- need } \\
\text { No dementia (S) } \\
\text { Less impaired (S) } \\
\text { Perceived health (NS) } \\
\text { Less emotional distress (S) }\end{array}$ \\
\hline
\end{tabular}

IADL = Instrumental Activities of Daily Life; ADL = Activities of Daily Life; S = statistically Significant; NS = Not statistically Significant 
Table $2.2 \quad$ Studies on factors influencing use of professional home care by people with long-term conditions

\begin{tabular}{|c|c|c|c|c|}
\hline $\begin{array}{l}\text { Author \& year } \\
\text { Methodologicalcharacteristics } \\
\text { Country }\end{array}$ & $\begin{array}{l}\text { Health care system } \\
\text { characteristics }\end{array}$ & $\begin{array}{l}\text { Predisposing } \\
\text { characteristics }\end{array}$ & Enabling resources & Need factors \\
\hline $\begin{array}{l}\text { Adams \& Kramer (1996) } \\
\text { Analysis of variance on record } \\
\text { study data on } 100 \text { CHF, DM } \\
\text { patients } \\
\text { USA }\end{array}$ & -- & -- & $\begin{array}{l}\text { Intensity of use of home nursing } \\
\text { Type of insurance (NS) } \\
\text { Intensity of use of home help } \\
\text { Type of insurance (NS) }\end{array}$ & $\begin{array}{l}\text { Intensity of use of home nursing } \\
\text { Diagnosis (NS) } \\
\text { Intensity of use of home help } \\
\text { Diagnosis (NS) }\end{array}$ \\
\hline \multirow[t]{2}{*}{$\begin{array}{l}\text { Bull (1994) } \\
\text { Multiple logistic regression } \\
\text { analysis on survey data on } 185 \\
\text { CHF, COPD, DM patients } \\
\text { USA }\end{array}$} & -- & $\begin{array}{l}\text { Intensity of use of home } \\
\text { nursing care } \\
\text { Age (NS) }\end{array}$ & $\begin{array}{l}\text { Intensity of use of home nursing care } \\
\text { Income (NS) } \\
\text { Education (NS) } \\
\text { Age of informal caregiver (NS) } \\
\text { Education of informal caregiver (NS) } \\
\text { Job commitments of informal caregiver (NS) } \\
\text { Number of hours of informal care given (NS) }\end{array}$ & $\begin{array}{l}\text { Intensity of use of home nursing care } \\
\text { Physical health (NS) } \\
\text { More predischarge ADL impairment (S) }\end{array}$ \\
\hline & & $\begin{array}{l}\text { Intensity of use of home } \\
\text { health aid } \\
\text { Older age (S) }\end{array}$ & $\begin{array}{l}\text { Intensity of use of home health aid } \\
\text { Income (NS) } \\
\text { Education (NS) } \\
\text { Age of informal caregiver (NS) } \\
\text { Education of informal caregiver (NS) } \\
\text { Greater job commitments of informal } \\
\text { caregiver (S) } \\
\text { Number of hours of informal care given (NS) }\end{array}$ & $\begin{array}{l}\text { Intensity of use of home health aid } \\
\text { Physical health (NS) } \\
\text { More predischarge ADL impairment (S) }\end{array}$ \\
\hline $\begin{array}{l}\text { De Haan et al. (1993) } \\
\text { Multi-variate logistic regression } \\
\text { analysis on cross sectional survey } \\
\text { data on } 128 \text { stroke patients } \\
\text { The Netherlands }\end{array}$ & $\begin{array}{l}\text { Making use of home help } \\
\text { Referring GP informed } \\
\text { about discharge from } \\
\text { hospital (S) }\end{array}$ & $\begin{array}{l}\text { Making use of home } \\
\text { help } \\
\text { Older age (S) } \\
\text { Female (S) } \\
\text { Living alone (S) }\end{array}$ & $\begin{array}{l}\text { Making use of home help } \\
\text { Income (NS) }\end{array}$ & $\begin{array}{l}\text { Making use of home help } \\
\text { Having dementia (S) } \\
\text { ADL impaired (NS) } \\
\text { Having severe handicap (S) } \\
\text { Feeling unhealthy (NS) } \\
\text { Emotional distress (NS) }\end{array}$ \\
\hline
\end{tabular}


Table 2.2 Continued I

\begin{tabular}{|c|c|c|c|c|}
\hline $\begin{array}{l}\text { Author \& year } \\
\text { Methodological characteristics } \\
\text { Country }\end{array}$ & $\begin{array}{l}\text { Health care system } \\
\text { characteristics }\end{array}$ & $\begin{array}{l}\text { Predisposing } \\
\text { characteristics }\end{array}$ & Enabling resources & Need factors \\
\hline $\begin{array}{l}\text { Ettner \& Weissman (1994) } \\
\text { Multiple regression analysis on } \\
\text { survey data on } 231 \text { AIDS } \\
\text { patients } \\
\text { USA }\end{array}$ & -- & $\begin{array}{l}\text { Intensity of use of formal } \\
\text { home care } \\
\text { Not living alone (S) }\end{array}$ & $\begin{array}{l}\text { Intensity of use of formal home care } \\
\text { Type of insurance (NS) } \\
\text { Income (NS) }\end{array}$ & $\begin{array}{l}\text { Intensity of use of formal home care } \\
\text { More nursing needs (S) } \\
\text { Worse physical functioning (S) }\end{array}$ \\
\hline \multirow[t]{3}{*}{$\begin{array}{l}\text { Fleishman (1997) } \\
\text { Multiple regression analysis on } \\
\text { record and survey data on } 1727 \\
\text { HIV-infected patients } \\
\text { USA }\end{array}$} & -- & $\begin{array}{l}\text { Making use of home nursing } \\
\text { care } \\
\text { Gender (NS) } \\
\text { Living arrangements (NS) } \\
\text { Being white (S) } \\
\text { No drug use (S) }\end{array}$ & $\begin{array}{l}\text { Making use of home nursing care } \\
\text { Being insured (S) } \\
\text { Type of insurance (NS) } \\
\text { Income (NS) } \\
\text { Education (NS) }\end{array}$ & $\begin{array}{l}\text { Making use of home nursing care } \\
\text { Having diagnosis of AIDS (S) } \\
\text { Fatigue (S) } \\
\text { Pain (NS) } \\
\text { Having ADL impairment (S) } \\
\text { Having functional limitation (S) } \\
\text { Hospitalisation (NS) }\end{array}$ \\
\hline & & $\begin{array}{l}\text { Making use of home help } \\
\text { Female (S) } \\
\text { Living arrangements (NS) } \\
\text { Not being Hispanic (S) } \\
\text { Drug use (NS) }\end{array}$ & $\begin{array}{l}\text { Making use of home help } \\
\text { Being publicly insured (S) } \\
\text { Higher income (S) } \\
\text { Education (NS) }\end{array}$ & $\begin{array}{l}\text { Making use of home help } \\
\text { Having diagnosis of AIDS (S) } \\
\text { Fatigue (NS) } \\
\text { Pain (NS) } \\
\text { Having ADL impairment (S) } \\
\text { Having functional limitation (S) } \\
\text { Recent hospitalisation (S) }\end{array}$ \\
\hline & & $\begin{array}{l}\text { Intensity of home nursing } \\
\text { care } \\
\text { Gender (NS) } \\
\text { Living arrangements (NS) } \\
\text { Being from an ethnic } \\
\text { minority (S) } \\
\text { No drug use (S) }\end{array}$ & $\begin{array}{l}\text { Intensity of home nursing care } \\
\text { Type of insurance (NS) } \\
\text { Income (NS) } \\
\text { Education (NS) }\end{array}$ & $\begin{array}{l}\text { Intensity of home nursing care } \\
\text { Diagnosis of AIDS (NS) } \\
\text { Fatigue (NS) } \\
\text { Pain (NS) } \\
\text { ADL impairment (NS) } \\
\text { Functional limitation (NS) } \\
\text { Hospitalisation (NS) }\end{array}$ \\
\hline
\end{tabular}


Table 2.2 Continued II

\section{Author \& year \\ Methodological characteristics Country}

Fleishman (1997) Continued Multiple regression analysis on record and survey data on 1727 HIV-infected patient

Freiman \& Breen (1997) Probit modelling and multiple regression analysis on survey data on 490 cancer patients USA

\begin{tabular}{l}
$\begin{array}{l}\text { Health care system } \\
\text { characteristics }\end{array}$ \\
\hline
\end{tabular}

Predisposing

Intensity of home help Female (S)

Living arrangements (NS)

Drug use (NS)

Type of istome help

Type of insurance (NS)

Income (NS)

Education (NS)

Making use of home care

Older age (S)

Female (S)

Not living alone (S)

Making use of home care

Type of insurance (NS)

Income (NS)

Availability of facilities (NS)

Intensity of use of home care

Age (NS)

Living arrangements (NS)
Intensity of use of home care

Medicare insured (NS)

Not being uninsured or Medicaid only

Not being enrolled in HMO (S)

Income (NS)

Availability of facilities (NS)

Need factors

Intensity of home help

Diagnosis of AIDS (NS)

Fatigue (NS)

Being in pain (S)

ADL impairment (NS)

Functional limitation (NS)

Hospitalisation (NS)

Making use of home care

Diagnosis (NS)

ADL impairment (NS)

More IADL impairment (S)

Larger number of hospitalisations (S)

Intensity of use of home care

Diagnosis (NS)

ADL impairment (NS)

IADL impairment (NS)

Number of hospitalisations (NS) 


\begin{tabular}{|c|c|c|c|c|}
\hline $\begin{array}{l}\text { Author \& year } \\
\text { Methodological } \\
\text { characteristics } \\
\text { Country }\end{array}$ & $\begin{array}{l}\text { Health care system } \\
\text { characteristics }\end{array}$ & $\begin{array}{l}\text { Predisposing } \\
\text { characteristics }\end{array}$ & Enabling resources & Need factors \\
\hline $\begin{array}{l}\text { Kane et al. (1994) } \\
\text { Multi-variate logistic } \\
\text { regression analysis on record } \\
\text { and survey data on } 1837 \text { CHF, } \\
\text { COPD, stroke patients } \\
\text { USA }\end{array}$ & -- & $\begin{array}{l}\text { Making use of home care } \\
\text { Older age (stroke: S; } \\
\text { CHF/COPD: NS) } \\
\text { Gender (all: NS) } \\
\text { Not living alone (all: S) } \\
\text { Being non-white (COPD: S; } \\
\text { CHF/stroke: NS) }\end{array}$ & -- & $\begin{array}{l}\text { Making use of home care } \\
\text { Less ADL impairment at discharge } \\
\text { from hospital (stroke: S; CHF/COPD: } \\
\text { NS) } \\
\text { More IADL and ADL impairment } \\
\text { prior to hospital admission (stroke: S) } \\
\text { Less IADL and ADL impairment } \\
\text { prior to hospital admission (CHF: S) } \\
\text { IADL and ADL impairment prior to } \\
\text { hospital admission (COPD: NS) } \\
\text { Having speech problems (stroke: S; } \\
\text { CHF/COPD: NS) } \\
\text { Not having hearing problems (stroke: } \\
\text { S; CHF/COPD: NS) }\end{array}$ \\
\hline $\begin{array}{l}\text { Kenney (1993) } \\
\text { Tobit regression analysis on } \\
\text { record and survey data on } \\
12115 \text { CHF, COPD, stroke } \\
\text { patients } \\
\text { USA }\end{array}$ & $\begin{array}{l}\text { Making use of home care } \\
\text { Less hospital long-term care } \\
\text { arrangements (COPD/CHF: S; } \\
\text { stroke: NS) } \\
\text { More hospital-owned home health } \\
\text { agencies (COPD/CHF: S; stroke: } \\
\text { NS) } \\
\text { Smaller number of nursing home } \\
\text { beds per Medicare insured person } \\
\text { (all: S) } \\
\text { Larger number of home health } \\
\text { staff per Medicare insured person } \\
\text { (COPD/CHF: S; stroke: NS) }\end{array}$ & $\begin{array}{l}\text { Making use of home care } \\
\text { Older age (stroke/COPD: S; } \\
\text { CHF: NS) } \\
\text { Female (COPD: S; } \\
\text { stroke/CHF: NS) } \\
\text { Being non-white } \\
\text { (stroke/COPD: S; CHF: NS) }\end{array}$ & $\begin{array}{l}\text { Making use of home care } \\
\text { Higher level of } \\
\text { urbanisation (COPD/CHF: } \\
\text { S; stroke: NS) } \\
\text { Not being admitted from } \\
\text { skilled nursing facility } \\
\text { (all: S) }\end{array}$ & $\begin{array}{l}\text { Making use of home care } \\
\text { Having had surgery (stroke: S; } \\
\text { COPD/CHF: NS) } \\
\text { Comorbidity (all: NS) }\end{array}$ \\
\hline
\end{tabular}


Table 2.2 Continued IV

\begin{tabular}{|c|c|c|c|c|}
\hline $\begin{array}{l}\text { Author \& year } \\
\text { Methodological } \\
\text { characteristics } \\
\text { Country } \\
\end{array}$ & $\begin{array}{l}\text { Health care system } \\
\text { characteristics }\end{array}$ & $\begin{array}{l}\text { Predisposing } \\
\text { characteristics }\end{array}$ & Enabling resources & Need factors \\
\hline $\begin{array}{l}\text { London et al. (2001) } \\
\text { Multi-variate logistic } \\
\text { regression analysis on survey } \\
\text { data on } 611 \text { HIV-infected } \\
\text { patients } \\
\text { USA }\end{array}$ & -- & $\begin{array}{l}\text { Making use of home care } \\
\text { Older age }(50+)(\mathrm{S}) \\
\text { Female (S) } \\
\text { Living arrangements (NS) } \\
\text { Ethnicity (NS) } \\
\text { No nonprescribed drug use } \\
\text { (S) } \\
\text { Heavy alcohol use (NS) } \\
\text { Sexual orientation (NS)) }\end{array}$ & $\begin{array}{l}\text { Making use of home care } \\
\text { Being insured by Medicaid } \\
\text { only (S) } \\
\text { Medicare only (NS) } \\
\text { Being insured by both } \\
\text { Medicaid and Medicare (S) } \\
\text { HMO membership (NS) } \\
\text { Income (NS) } \\
\text { Education (NS }\end{array}$ & $\begin{array}{l}\text { Making use of home care } \\
\text { AIDS diagnosis (NS) } \\
\text { Having CMV diagnosis (S) } \\
\text { Number of symptoms (NS) } \\
\text { Physical functioning (NS) } \\
\text { Hospitalised recently (NS) } \\
\text { Having received residential care } \\
\text { recently (S) }\end{array}$ \\
\hline $\begin{array}{l}\text { Riemsma et al. (1998) } \\
\text { Multiple regression analysis on } \\
\text { survey data on } 229 \text { RA patient } \\
\text { The Netherlands }\end{array}$ & -- & $\begin{array}{l}\text { Intensity of use of } \\
\text { professional home care } \\
\text { Age (NS) } \\
\text { Gender (NS) } \\
\text { Living alone (S) }\end{array}$ & $\begin{array}{l}\text { Intensity of use of } \\
\text { professional home care } \\
\text { Income (NS) } \\
\text { Education (NS) } \\
\text { Urbanisation (NS) } \\
\text { Number of informal } \\
\text { caregivers living nearby } \\
\text { (NS) }\end{array}$ & $\begin{array}{l}\text { Intensity of use of professional } \\
\text { home care } \\
\text { Comorbidity (NS) } \\
\text { Pain (NS) } \\
\text { Fatigue (NS) } \\
\text { Disease duration (NS) } \\
\text { Poor health (S) } \\
\text { Self-efficacy expectations in } \\
\text { coping with RA (NS) } \\
\text { Higher degree of loneliness (S) } \\
\text { Problematic social support (S) } \\
\text { Degree of social interaction (NS) }\end{array}$ \\
\hline
\end{tabular}


Table 2.2 Continued V

Author \& year

Health care system

characteristics

Predisposing

Enabling resources

Need factors

Methodological

Intensity of use of IADL- and ADL care

Older age (NS)

Gender (NS)

Thity of use of $I A D L$ - and

Scholte op Reimer

$--$

Living alone (S)

ADL care

Multi-variate logistic

regression analysis on

longitudinal survey

Education (NS)

Intensity of use of $I A D L$ - and $A D L$

data and on record

data on 110 stroke

patients

The Netherlands

Sommers et al. (2000) Intensity of use of home health

Nonrandomised

controlled intervention Collaboration among primary care

study on 465 cancer, professionals (NS)

CHF, COPD, stroke,

DM patients

USA

$\mathrm{CHF}=$ congestive heart failure; $\mathrm{COPD}=$ chronic obstruction pulmonary disease; $\mathrm{DM}=$ =diabetes mellitus; $\mathrm{RA}=$ rheumatoid arthritis; $\mathrm{CMV}=$ cytomegalovirus

$\mathrm{HMO}=$ health maintenance organisation; IADL = Instrumental Activities of Daily Life; ADL = Activities of Daily Life

$\mathrm{S}=$ statistically Significant; NS = Not statistically Significant 


\section{Discussion}

This review of the literature has focused on factors influencing the match between perceived care need and use of home care in people with long-term conditions. No published studies on the influence of health care system characteristics on this match were identified, and only two relevant studies that considered the influence of the characteristics of people with long-term conditions were found. The limited number of studies found, differences between the specific patient groups involved, and the sometimes contradictory findings inhibit bold conclusions. In light of the attention paid to tailor-made and needs-led care by decision makers and society as a whole, it is surprising that so few empirical data exist on determinants of the match between need and use of home care.

Because of the scarcity of studies on the need/use match, a secondary aim of our review was to identify factors relating to home care use by people with long-term conditions. This was based on the assumption that the same determinants may influence home care use and the match between need for and use of home care. Again, few studies were identified, and most of these only paid attention to the influence of patient characteristics, rather than health care system characteristics. Nevertheless, on the basis of Kenney's (1993) research, it might be expected that health care system characteristics, such as availability of other care facilities, affect patients' use of home care. It seems probable that these characteristics can also impact on whether or not chronic patients' needs for care are met.

Based on the studies on patient characteristics, a profile of patients with long-term conditions who are likely to use home care is beginning to emerge. Some reservation should be made because these studies involved a variety of diagnosis-related groups, did not always have unanimous findings and were sometimes based on small samples. Nonetheless, the emerging profile may be summarised as follows: in general, older non-white women, with a number of simultaneous chronic illnesses, impaired in both instrumental and physical activities, and having recently made use of inpatient care tend to make more use of home care.

The effects of living arrangements, type of insurance and urbanisation on home care use appeared to diverge considerably. A plausible reason for the contradictory findings on living arrangements may be as follows: on the one 
hand, people with long-term conditions who live alone may use professional home care because informal care may be unavailable; on the other hand, the presence of a partner or other informal caregiver may increase likelihood of using home care because they may help to arrange and co-ordinate it. Ettner \& Weissman (1994) argue that fellow residents may also share the costs of professional home care, thus making use possible.

Remarkably enough, 10 of the 13 studies reviewed were conducted in the USA and three in the Netherlands. This is all the more remarkable in light of the use of several international literature databases, and the application of a selection criterion indicating that, in addition to English and Dutch, publications in German or French could be included. The finding that the majority of relevant studies were of USA origin may indicate that, in the USA, research on this topic is performed more frequently and more highly developed. However, it may also point to a publication bias. For instance, Dickersin (1990) suggests that, when a manuscript is submitted to an English language journal and the author's native language is not English, bias may occur. Publication of 'second language' papers may be especially problematic if no significant findings are being reported.

\section{Limitations of the study}

This literature review was conducted as part of a broader research project in which the match between the felt care needs of people with long-term conditions, their care needs as identified by an assessment agency, and the home care delivered was studied. When searching the literature for possible determinants of this match, the research questions had to be strict, and papers in which results could not be clearly attributed to use of professional home care had to be discarded. This could be because results for professional home care were combined with those on informal home care or residential care. An even greater number of studies did not differentiate between chronic and acute diseases, and, thus, were not included. If the research questions addressed in this review had not been 'dictated' by the broader research project, more papers, especially those on home care use in acute conditions, could have been included, making the profile of 'the' home care user more solid. 


\section{Implications for nursing}

The results of this study are informative for professionals engaged in home nursing and give insight into patient characteristics that are associated with the use of home care. A profile of 'the' home care user emerged which describes, in general terms, the persons who are likely to make use of professional home care. However, the profile also draws the attention of nurses, policymakers in nursing, and needs assessors who do not match this profile. It is not surprising that patients who do not satisfy the need-related determinants of home care use make less use of professional home care. However, younger and/or white men appear to have difficulty in making use of home care at all or in making intense use of it, and these groups of patients should be given extra attention in meeting their home care needs. In regions in which certain features of the health care system - such as extended inpatient care facilities - are not present, the availability of home care should be given priority. This may be the case for some chronic Diagnosis Related Group rather than the other.

The professional standards of both home care staff and needs assessors should lead to needs-led home care provision, in that professional home care provision should meet patients' need. However, to date, determinants of the match between need and professional home care delivery are not evidencebased.

\section{Conclusion}

This review of literature has disclosed several gaps in existing knowledge. These gaps are greatest with respect to factors responsible for an adequate/poor match between felt need for and use of home care in people with long-term conditions. In addition, little is known about the specific influence of health care system characteristics on home care use in this patient group.

In the broader research project, of which this literature review is the first phase, efforts will be made to fill the knowledge gap on factors that influence the match between need for and actual use of professional home care. Attention will also be paid to the influence of characteristics of the health care system and, more specifically, to the characteristics of assessment agencies and home care organisations in relation to those of patients with long-term conditions. 


\section{Acknowledgement}

This research project was funded by Netherlands Organisation of Scientific Research (NWO-ZOB) - research programme on care and social support for chronically ill patients. 


\section{References}

Adam SGM \& Hutten JBF (2001). The Netherlands. In: Philp I (Ed.).Family Care of Older People in Europe. Amsterdam/Berlin/Oxford/Tokyo/Washington DC: IOS Press; p.135160.

Adams CE \& Kramer S (1996). Home health resource utilization: Health Maintenance Organization versus fee-for-service subscribers. Journal of Nursing Administration; 6: 20-27.

Andersen RM (1995). Revisiting the Behavioral Model and access to medical care: does it matter? Journal of Health and Social Behavior; 36: 1-10.

Andersen R \& Newman JF (1973). Societal and individual determinants of medical care utilization in the United States. The Milbank Memorial Fund Quarterly Health and Society; 51: 95-124.

Bradshaw J (1972). A taxonomy of social need. In: MacLachlan G (Ed.). Problems and progress in Medical care. Oxford: University Press; p. 69-82.

Bull MJ (1994). Use of formal community services by elders and their family caregivers 2 weeks following hospital discharge. Journal of Advanced Nursing; 19: 503-508.

Coulton C \& Frost AK (1982). Use of social and health services by the elderly. Journal of Health and Social Behavior; 23: 330-339.

De Haan R, Limburg M, Van der Meulen J \& Van den Bos, GAM (1993). Use of health care services after stroke. Quality in Health Care; 2: 222-227.

Dickersin K (1990). Existence of publication bias and risk factors for its occurrence. Journal of the American Medical Association; 263: 1385-1389.

Ettner SL \& Weissman J (1994). Utilization of formal and informal home care by AIDS patients in Boston: a comparison of intravenous drug users and homosexual males. Medical Care; 32: 459-470.

Evashwick C, Rowe G, Diehr P \& Branch L (1984). Factors explaining the use of health care services by the elderly. Health Services Research; 19: 357-382.

Fleishman JA (1997). Utilization of home care among people with HIV infection. Health Services Research; 32: 155-175.

Freiman MP \& Breen N (1997). The use of home care by cancer patients: a multi-variate analysis. Home Health Care Services Quarterly; 16: 3-19.

Health Insurance Association of America (1999). Source Book of Health Insurance Data. Washington DC: HIAA.

Kane RL, Finch M, Chen Q, Blewett L, Burns R \& Moskowitz M (1994). Post-hospital home health care for Medicare patients. Health Care Financing Review; 16: 131-153. 
Katz MH, Cunningham WE, Mor V, Andersen RM, Kellogg T, Zierler S, Crystal SC, Stein MD, Cylar K, Bozzette SA \& Shapiro MF (2000). Prevalence and predictors of unmet need for supportive services among HIV-infected persons: impact of case management. Medical Care; 38: 58-69.

Kempen GIJM \& Suurmeijer ThPBM (1991). Professional home care for the elderly: an application of the Andersen-Newman model in the Netherlands. Social Science \& Medicine; 33: 1081-1089.

Kenney GM (1993). How access to long-term care affects home health transfers. Journal of Health Politics, Policy and Law; 18: 937-965.

Kerkstra A \& Vorst-Thijssen T (1991). Factors related to the use of community nursing services in the Netherlands. Journal of Advanced Nursing; 16: 47-54.

London AS, Fleishman JA, Goldman DP, McCaffrey DF, Bozzette SA, Shapiro MF \& Leibowitz AA (2001). Use of unpaid and paid home care services among people with HIV infection in the USA. AIDS Care; 13: 99-121.

Mor V, Allen SM, Siegel K \& Houts P (1992). Determinants of need and unmet need among cancer patients residing at home. Health Services Research; 27: 337-360.

Philp I (2001). Family Care of Older People in Europe. Amsterdam/Berlin/ Oxford/Tokyo/ Washington DC: IOS Press.

Riemsma RP, Klein G, Taal E, Rasker JJ, Houtman PM, Van Paassen HC \& Wiegman O (1998). The supply of and demand for informal and professional care for patients with rheumatoid arthritis. Scandinavian Journal of Rheumatology; 27: 7-15.

Scholte op Reimer WJM (1999). Long-term care after stroke: studies on care utilisation, quality of care and burden of caregiving. Amsterdam: University of Amsterdam (thesis).

Shaughnessy PW, Schlenker RE \& Hittle DF (1994). Home health care outcomes under capitated and fee-for-service payment. Health Care Financing Review; 16: 187-222.

Sommers LS, Marton KI, Barbaccia JC \& Randolph J (2000). Physician, nurse, and social worker collaboration in primary care for chronically ill seniors. Archives of Internal Medicine; 160: 1825-1833.

Steel K, Leff B \& Vaitovas B (1998). A home care annotated bibliography. Journal of the American Geriatrics Society; 46: 898-909.

Tennstedt S, McKinlay J \& Kasten L (1994). Unmet need among disabled elders: a problem in access to community long-term care? Social Science \& Medicine; 38: 915-924.

Van den Bos GAM (1989). Zorgen van en voor chronisch zieken. (Concerns of and caring for the chronically ill.) Utrecht: Bohn, Scheltema \& Holkema. 
'New-style' needs assessment in the care
chain; a study of the literature on the
feasibility of the objectives of the 'new-style'
needs assessment and realising the care chain

[Zorgindicatiestelling 'nieuwe stijl' binnen de zorgketen; een literatuurstudie naar de haalbaarheid van de doelstellingen van de indicatiestelling 'nieuwe stijl' en de realisering van de zorgketen]

Algera M, Francke AL \& Van der Zee J

Verpleegkunde - Nederlands-Vlaams Wetenschappelijk Tijdschrift voor verpleegkundigen (2002); 17 (3): 140-151 


\begin{abstract}
A number of developments in Dutch society prompted the needs assessment for care to change. The Care Needs Assessment Decree (Ministerie van Volksgezondheid, Welzijn \& Sport, 1997) specified that needs assessment, funded via the Exceptional Medical Expenses Act (AWBZ), should no longer be carried out by the care providers themselves. In addition, needs assessment and the subsequent care indication were to become more objective and not to be restricted to a particular sector. The establishment of regional assessment agencies was the solution envisaged. These agencies are part of the 'care chain' together with health insurers and care providers.
\end{abstract}

On the basis of an investigation of the literature, indicators were reviewed which revealed that in practice the objectives of the new-style needs assessment (independence, objectivity and comprehensiveness) were being achieved and the care chain was being realised.

Possible obstacles to the achievement of these objectives may be: authorisation arrangements in that care providers carry out the assessment of specific care demands as well as the very divergent definitions of some of the characteristics in the assessment agencies' reports. The operation of the care chain could be negatively influenced by the change of roles among the parties involved in it, whereas the role of the health insurers is hardly specified.

Thus far there has been no available research on the adequacy of the matches between the parties in the care chain. Although the patient is the starting point in the new-style needs assessment, in most of the already performed research, the patient perspective is conspicuous by its absence.

\title{
Introduction
}

\section{Modernisation of the AWBZ}

A broad range of societal changes in the Netherlands brought about the modernisation of the Exceptional Medical Expenses Act (AWBZ). Demanddriven care (with the patients in the focal position at the macro level of policy development) leading to demand-oriented care (with the patient central in the micro level of care) had to replace the age-old orientation towards the provision of care (Kerkstra et al., 1990; Donker, 1996; BIO, 1997; Ministerie van Volksgezondheid, Welzijn \& Sport, 1997; Tweede 
Kamer der Staten-Generaal, 1998-1999; Ministerie van Volksgezondheid, Welzijn \& Sport, 2001a). The patient had to be 'empowered.' In addition, there was a necessity to remove the barriers between the various sectors of care. At the same time, the requirement for outpatient care and the absence of customised care became ever more glaring. Another reason for bringing the AWBZ up to date was the desire to make an inventory of the actual need for care on the part of the insured and the size of the gap, i.e.: the discrepancy at an aggregated level between care needed and care supplied (Tweede Kamer der Staten-Generaal, 1998-1999).

In the 'Care in Sight' policy document (Zicht op Zorg; Tweede Kamer der Staten-Generaal, 1998-1999) an explanation was given of how the AWBZ was to be modernised. One of the instruments in the 'Care in Sight' policy document is what came to be called the 'care chain'.

Another instrument is the new style of needs assessment, as an explicit part of the care chain. The new-style needs assessment relates to a new approach to an objective establishment of the need for care, followed by a specification in terms of the type of care, its scope and content (Nationale Raad voor de Volksgezondheid, 1994).

Both instruments will be dealt with below.

\section{Care chain}

The care chain involves to linking the players who are concerned with patient demand and meeting that demand by means of the provision of care. The care chain should not be confused with similar terms referring to the continuity of care, in moving from one setting to another. The care chain links four parties who have a specific relationship with one another (BIO, 1997; Ministerie van Volksgezondheid, Welzijn \& Sport, 1997; Tweede Kamer der Staten-Generaal, 1998-1999). Figure 3.1 illustrates the care chain. Below, an overview of the roles allotted by government to each of the players, is further specified.

\section{Patient}

The patient is the starting point of the care chain. When patients, or those in their environment, experience a need for care, which can no longer be (fully) met by the patients themselves or their informal carers, this need for care is 
interpreted as a demand for care, which is subsequently presented to a Regional Assessment Agency. The patients can present their demand for care themselves, as can their informal carers or GP. Demands for care were initially intended for home care, homes for the elderly or nursing homes (Ministerie van Volksgezondheid, Welzijn \& Sport, 1997). Between 2000 and 2002, the domain of the assessment agencies was enlarged to include the needs assessment for specific facilities in the area of the Provision for the Handicapped Act (WVG) and for sensory, intellectually and physically handicapped patients (Ministerie van Volksgezondheid, Welzijn \& Sport, 1999, 2000). Although the patient registers a demand for care, the need for care is investigated by the assessment agency. The 'expressed need' in Andersen's terms (1995) does not always reflect the underlying need for care, patient's 'felt need' (Huijsman, 1990; Kerkstra et al., 1990; Beemsterboer, 2000; SGBO, 2000).

Figure 3.1 Care chain from needing care to receiving it

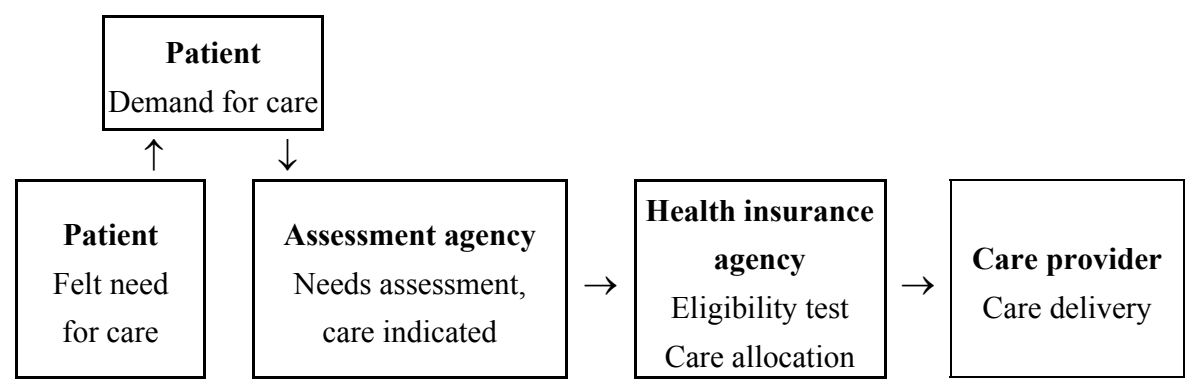

\section{Regional assessment agency}

When patients know that their demand for care is to be registered with the assessment agency or a provider refers them, then the second stage in the care chain is reached. Assessment agencies are responsible for assessing need. These independent organisations had been established by 1998, either with or without inter-municipal co-operative association (article 9a, paragraph 1 AWBZ). In 2002, there were 84 assessment agencies. Currently, the move is towards economies of scale and to an eventual reduction to about 60 agencies. The methodology for determining need is subject to a number of requirements in the Care Needs Assessment Decree (Ministerie van Volksgezondheid, Welzijn \& Sport, 1997). All the players in the care chain have thus far drawn up a model protocol for indications in the area of living, welfare and care (BIO, 1997). Later in the present paper, we will look 
at the developments in needs assessment and the objectives of the new-style needs assessment.

\section{Health Insurance Agency}

The health insurer, with the largest number of insured persons in a specific legally circumscribed region, operates the health insurance agency. The role of these agencies within the care chain is twofold (Tweede Kamer der Staten-Generaal, 1998-1999; Ministerie van Volksgezondheid, Welzijn \& Sport, 1999). The first thing the agency does is to carry out the legitimacy test. This test looks at the entitlement in respect of the assessment from two points of view:

- entitlement to insurance cover. The formal establishment that the applicant, on whose behalf the assessment decision is made, is insured pursuant to the AWBZ;

- the test in respect of the claim. The assessment, in terms of whether the applicant who has been assessed positively, pursuant to the AWBZ, has the right to the care specified.

The second task for these agencies in the care chain relates to the allocation of care. On the basis of the assessment report that is sent to the health insurance agency, the agency looks for the most suitable provider for the care indicated. The term 'allocation of care' appears to be interpreted in many different ways. With the positioning and development of the parties within the care chain the concept is interpreted in a different way. Where, initially, allocation of care was on the basis of the care products indicated, the term has now evolved into that of a waiting list manager.

\section{Care Provider}

The last link in the care chain, the care provider, has not changed in its role of the provision of care, although the initial authority on indicating the type and amount of this care has become the responsibility of the assessment agency. In the case of home care organisations, however, they had, in the past, made the assessment themselves (Ministerie van Volksgezondheid, Welzijn \& Sport, 1997, 2000).

\section{New-style needs assessment}

In the old-style needs assessment (before the Care Needs Assessment Decree of 1997), the district nurse took the histories herself, as far as home care was 
concerned, and on the basis of it, set up a care plan and implemented it. In this care plan, the required care (both objectives and interventions) were described. Indications for a nursing home or a home for the elderly were determined by separate municipal assessment committees (Dijkstra, 2001).

Although the reasons for renewing the assessment procedures were, in part, the same as those for the updating of the AWBZ, there were a number of other developments which underlay the need for a new approach to needs assessment and the subsequent indicating of care. One of those reasons was being the merger in the 90's of family care with district nursing to form home care organisations. In family care, it had been usual to separate the needs assessment and care planning from the delivery of home care. After the merger, the district nurse was also removed from the needs assessment and separate intake bureaus were established within the home care organisations (Dijkstra, 2001; Hutten \& Kerkstra, 2002). This process led the way to a further separation between assessment and care delivery.

A second development related to the desire, as expressed by the organisations representing the handicapped and the chronically sick (Slingerland \& Van Amelsvoort, 1993; Dijkstra, 2001; Schrijvers, 2001), to make a separation between the organisation which determined the care indicated and the organisation that actually delivered the care. The patient organisations advocated this separation because the care provider could have an interest in delivering a particular product or not delivering it. Furthermore, the providers could often themselves decide to whom which care to provide. In times of scarcity this could result in unequal treatment of patients or unmet need (Gorter et al., 1989, Bellemakers, 1995; Degen \& Huijsman, 1999). Needs assessment was more of a political instrument for the care providers and financiers than an impetus to provide customised care (Degen \& Huijsman, 1999).

A third development, which influenced the assessment policy, related to the government policy to provide outpatient care (Tweede Kamer der StatenGeneraal, 1973-1974, 1979-1980, 1987-1988). In previous years, all sorts of extramural and transmural care innovation projects had been started, both on financial grounds, and also because of the requests of an increasingly assertive and eloquent clientele who wanted to receive care at home whenever possible. Many of these projects allowed the boundaries between 
institutional care and home care to become vague (SGBO, 2000). Needs assessment was therefore no longer to be sector-specific but was to form an integrated whole.

\section{Objectives of the new-style needs assessment}

The general societal developments, and those more closely related to the care system sketched above, were the motivation for the new legislation, the Care Needs Assessment Decree of 1997 (Ministerie van Volksgezondheid, Welzijn \& Sport, 1997). In this decree, three objectives or points of departure for new-style needs assessment, were worked out. These objectives were to achieve more independence, objectivity and an integrated approach to needs assessment for care (BIO, 1997; Ministerie van Volksgezondheid, Welzijn \& Sport, 1997; Degen \& Huijsman, 1999; Beemsterboer, 2000; Schippers, 2001; Schrijvers, 2001).

- Independence meant that the patient's real needs for care were determined, as far as possible separately from the availability of care. Independence makes the care assessment process more transparent for the patient and promotes equitable treatment in the allocation of scarce care resources and assistive devices to patients (BIO, 1997; Ministerie van Volksgezondheid, Welzijn \& Sport, 1997; Schrijvers \& Heinsbroek, 1998).

- Objectivity meant separating the needs assessment, as far as possible from the assessor who makes the assessment. Subjectivity, on the part of the assessor, can be limited by forcing to make the assessor's normative considerations more explicit. In addition, protocols should reduce inequitable treatment. Furthermore, objective needs assessment allows adequate testing of assessment decisions (BIO, 1997). So, the objectivity that is sought has primarily to do with uniformity.

- An integrated approach takes the assessment across the boundaries of the disciplines. There is not only an assessment of care needs in the area of home care. The same assessor can also make an assessment, for example, for additional day care, for specific adjustments to the house, for a home for the elderly or admission to a nursing home, if the needs happen to relate to any of these areas. Primarily, the coherence between the disciplines must be sought. The idea is a one-stop shop. Differences in the type of funding (for example via the AWBZ or the WVG) should no longer be a reason for a separate assessment of needs (SGBO, 2000). 
The proposed comprehensiveness in needs assessment is most clearly achieved in an integrated approach to the assessment of needs (Schrijvers \& Heinsbroek, 1998).

\section{Objective and research questions}

The objective of this investigation of the literature is to determine, on the part of research that has already been done, what the prospects are for the achievement of the three objectives of the new-style needs assessment. In addition, the objective of this study is to give insight into the extent to which the care chain, envisioned in the Care Needs Assessment Decree (Ministerie van Volksgezondheid, Welzijn \& Sport, 1997), has actually taken shape in practice. This is important because the care chain is the context in which the new-style needs assessment actually takes place.

In the meantime, a number of studies have been carried out among those who play a role in the care chain. The majority of these studies focus on the assessment agencies because they are the most crucial elements in the implementation of the new-style needs assessment and indication of care.

It ensues from what we have said above that the principal research question in the present paper can be phrased as follows:

Evaluating, what can be said on the basis of research carried out among the players in the care chain about:

1. the prospect of the achievement of the objectives of new-style needs assessments or failure to achieve them?

$2 . \quad$ the realisation of the care chain in practice?

Answering this research question is important for nurses because they are confronted with new-style needs assessment in an increasing number of sectors in which they are active. This investigation of the literature offers nurses the opportunity of forming a judgement themselves about the new style of assessing needs, independent of any difficult situations in which they might find themselves.

\section{Methods}

In order to provide an answer to the sub-parts of the question indicated above, research reports and quick scans of the status quo on the functioning of the players within the care chain were investigated. These sources have, in part, been found in reports in the STIP-bulletin (a periodical which deals 
with the implementation of the new-style needs assessment) and in part via the snowball method, in which references in one source lead to another source in which yet other references are used. In answering the research questions, we only took into account research publications that were not directed at just one assessment agency. Eventually six research reports and three quick scans were incorporated in the investigation of the literature. Two reports (Schrijvers \& Ravelli, 2000; Schrijvers, 2001) relate to the formal evaluation of the Care Needs Assessment Decree (Ministerie van Volksgezondheid, Welzijn \& Sport, 1997) initiated by the Ministry of Health and cover virtually all of the assessment agencies. Two other reports (SGBO, 1999, 2000) which cover the cost of home care assessment and the methods of assessment agencies, respectively, contain results based on a limited number of assessment agencies. The two remaining reports concern the home care organisations (Bureau voor Toegepaste Economische en Ruimtelijke Planning BV, 1999) and the health insurers (Commissie Toezicht Uitvoeringsorganisatie, 2001). In the three periodical quick scans (STIMO, 1998; STIP, 1999b, 2000b) virtually all of the assessment agencies were asked in broad terms about the current status of the development of each assessment agency at that time.

\section{Results}

\section{Independence}

The independence of needs assessment means that the care indicated is not determined with a view to the available care. There are a number of assessment agencies who have delegated the actual needs assessment to home care organisations or to municipal health care services (GGD'en). The number of authorising assessment agencies varies through time and also in terms of the specific study: from 14\% in 1998 (STIMO, 1998), through 3\% in 1999 to $5 \%$ in 2000 (STIP, 2000b) or to $31 \%$ (Schrijvers \& Ravelli, 2000). The latter piece of research reveals that $39 \%$ of the agencies that do not authorise home care organisations to perform noncomplex home care needs had such arrangements in the past (Schrijvers \& Ravelli, 2000). Reasons for their no longer using authorisation arrangements are, however, not given.

As far as the authorisation the needs assessment to home care organisations is used for noncomplex needs for home care, it is allowed by the legislation (Ministerie van Volksgezondheid, Welzijn \& Sport, 1997, 2000). Exactly 
what noncomplex needs for care are is, however, not clearly defined (STIP, 1999a, 2000a). Not only the complexity of individual care activities, but also the number of care products, are aspects of this, whereas, in some cases, the estimated duration of the care plays a role as well. In over $10 \%$ of the assessment agencies, there appears to be a policy of entirely outsourcing the needs assessment (both in noncomplex, singular needs for care and complex, multiple needs for care) to other organisations like the GGD (see Table 3.1).

A second aspect relating to independence is the character of the assessment report, which is produced by the assessment agencies. The assessment report should be, in concrete terms, about the nature, content and amount of the care, so that there is sufficient information available to start with the care, without the requirement for additional intake information by the care provider. About one-third of all of the assessment agencies, however, produce hardly concrete needs assessments and, as a result of this, the independence of the assessments can be questioned because the care provider is still able to relate the decision on care indicated to the available care supply, making it no longer demand-oriented (SGBO, 2000). On the other hand, many assessment agencies appear to make fairly detailed descriptions of care deficits (69\% of all assessment agencies, according to Schrijvers \& Ravelli (2000)), expressing assessment reports in terms of a specific product instead of the required functions, which are general specifications of type of care (SGBO, 2000; Schrijvers, 2001). The assessment agencies gave as the reason for this the fact that the needs assessment is otherwise too global for the care provider and also that the patients are not satisfied with a global indication. Although the independence of the assessment is not violated, yet the functionally-oriented needs assessment is not put in practice.

\section{Objectivity}

The objectivity of needs assessment is enhanced by a protocol and uniformity. Going through the assessment process is developed in the national assessment agency protocol, but the protocol has to be put into concrete terms at a regional level (BIO, 1997). At the same time, use of the protocol is not compulsory, but is merely recommended by the authorities (Ministerie van Volksgezondheid, Welzijn \& Sport, 1999). 
Table 3.1 Assessment agencies authorising tasks and being authorised tasks (depth) and other tasks performed (breadth)

\begin{tabular}{|c|c|c|c|c|}
\hline Tasks & $\begin{array}{c}1998 \\
\text { (STIMO, 1998) }\end{array}$ & $\begin{array}{c}1999 \\
\text { (STIP, 2000b) }\end{array}$ & $\begin{array}{c}2000 \\
\text { (STIP, 2000b) }\end{array}$ & $\begin{array}{c}2000 \\
\text { (Schrijvers \& } \\
\text { Ravelli, 2000) }\end{array}$ \\
\hline \multicolumn{5}{|c|}{ Authorisation of care provider by assessment agency } \\
\hline $\begin{array}{l}\text { Assessment of } \\
\text { noncomplex needs }\end{array}$ & $14 \%$ & $3 \%$ & $5 \%$ & $31 \%$ \\
\hline $\begin{array}{l}\text { Assessment of } \\
\text { noncomplex and } \\
\text { complex needs }\end{array}$ & $14 \%$ & $12 \%$ & $11 \%$ & $\begin{array}{c}\text { not } \\
\text { investigated }\end{array}$ \\
\hline \multicolumn{5}{|c|}{ Authorisation of assessment agency by health insurance agency (depth of assessment agency) } \\
\hline Eligibility test & $12 \%$ & $25 \%$ & $31 \%$ & $53 \%$ \\
\hline Care allocation & $13 \%$ & $12 \%$ & $9 \%$ & $1 \%$ \\
\hline $\begin{array}{l}\text { Registration on } \\
\text { waiting lists }\end{array}$ & $\begin{array}{c}\text { Not } \\
\text { investigated }\end{array}$ & $26 \%$ & $36 \%$ & $26 \%$ \\
\hline $\begin{array}{l}\text { Mediating on waiting } \\
\text { lists }\end{array}$ & $\begin{array}{c}\text { Not } \\
\text { investigated }\end{array}$ & $22 \%$ & $21 \%$ & $18 \%$ \\
\hline \multicolumn{5}{|c|}{ Breadth of assessment agency } \\
\hline $\begin{array}{l}\text { Facilities for the } \\
\text { Handicapped Act }\end{array}$ & $25 \%$ & $33 \%$ & $54 \%$ & $67 \%$ \\
\hline Sheltered housing & $15 \%$ & $55 \%$ & $58 \%$ & $60 \%$ \\
\hline $\begin{array}{l}\text { Care for the } \\
\text { handicapped }\end{array}$ & $2 \%$ & $0 \%$ & $0 \%$ & $3 \%$ \\
\hline
\end{tabular}

The assessments reports that are produced are very diverse in terms of their periods of validity, urgency criteria and bandwidths (the margins within the assessment report) (STIP, 1999a). In part, these differences can be traced back to matters of definition (SGBO, 2000). Does the validity of an assessment report commence when it is issued or when care actually starts? What categories of urgency are used? How broad are the bandwidths within which the provider is allowed to provide more care than was assessed? Broad validity terms and bandwidths do make a difference in the follow-up or reassessment, but reduce the value of the assessment report. As a result of this, up to a certain level, it is left to the care provider to determine how long and how much care will be provided, whereas the objective was precisely to 
indicate these features separate from the availability of care (independence). An additional disadvantage of broad bandwidths is that the assessment agencies' records cannot be brought up to date. The care provider has freedom, within the margins, without the assessment agency having any idea of the amount of care that is actually provided. For planning purposes, the government is very interested in the gap between the need for care (formally determined by the assessment agency) and the delivery of care (Tweede Kamer der Staten-Generaal,, 1998-1999, 1999-2000). However, this gap will stay unclear if the assessment agency does not know the amount of care actually delivered. In addition, the categories to determine urgency are not uniform. Very urgent implies home care starting within a week with one agency and with another within three months (SGBO, 2000).

If an assessment is made and the patient doesn't agree with the content, the patient can make an official objection to it. In practice, what happens more often is, that the patient asks for reconsideration rather than starting a formal appeals procedure. The reconsideration can be via an informal complaint procedure within the assessment agency or can be on the basis of a second opinion. On average, there is, per assessment agency, less than one appeal annually as against six of the complaint procedures and six requests for a second opinion (Schrijvers \& Ravelli, 2000). The procedures for a second opinion are varied. Not only does the amount of information to be freshly gathered vary (everything including the personal data or just the care content), but another issue is who is to give the second opinion, a colleague assessor of the same assessment agency or from a neighbouring assessment agency.

\section{Integrated approach}

The Care Needs Assessment Decree (Ministerie van Volksgezondheid, Welzijn \& Sport, 1997) stated that the assessment agencies, in any event, had to assess the need for home care, nursing home care or homes for the elderly. Since April 2000 and January 2002, the domain has been expanded in law to cover part of the WVG and the handicapped sector (Ministerie van Volksgezondheid, Welzijn \& Sport, 1999, 2000). The domain of the assessment agency may, optionally, even expand to providing assessments for other types of care, whether they are financed by the AWBZ or not. Examples of these types of care are included in Table 3.1. Most assessment agencies appear in practice to have a broader domain than legally prescribed 
(STIP, 1999b; SGBO, 2000), but the degree of expansion varies (see Table $3.1)$.

In principle, authorisation arrangements limit an integrated approach to needs assessment because only specific requests for care are addressed by the authorised organisation, for instance only needs for home care. As a result of this, there is a possibility that other needs for care, for example day care, will not be included in the assessment (Beemsterboer, 2000).

In addition to this, the route chosen for assessing need can either aid an integrated approach or hinder it. There is, among the assessment agencies, some variation on the path to be followed to a needs assessment. In this respect, the path implies the way in which the assessment agency gets in touch with a patient to make the assessment. With some assessment agencies the policy is to make a home visit to determine the assessment, whereas others do this by telephone or in writing. The sort of demand (simple, complex, urgent or not urgent), the degree of standardisation in dealing with particular care demands by use of protocols and the amount of information already available from the first request or reassessment are some of the considerations that have to be taken into account, in the choice of path in making the assessment (BIO, 1997; Ministerie van Volksgezondheid, Welzijn \& Sport, 1997). If a telephone or written assessment is made, the integrated approach to the assessment can be negatively influenced. The assessor does not have, in such cases, the option, for example, of observing the domestic situation or talking to informal carers and would not be able to include possible needs that patient do not express themselves in the assessment. The likelihood then is that the assessment of an adequate, coherent care package will be much smaller (Beemsterboer, 2000; SGBO, 2000).

Giving shape to the intention of integrated needs assessment comes into conflict in practice with the expertise and experience of the needs assessors. Many assessors have a background in the care sector as district nurses or social workers (Schrijvers \& Ravelli, 2000) and now they have to adopt an integrated approach. It is not the care supply, but the patient who is central in this. This requires not only new knowledge about other sectors of care but also about another way of thinking (STIP, 1999a; Schrijvers \& Ravelli, 2000; SGBO, 2000; Schrijvers, 2001). 


\section{The Care Chain}

The roles of the players in the care chain (see Figure 3.1) are not always exclusively reserved to that particular player. Authorisation constructions within the care chain can in practice cause a change of role from one to the other link in the chain. Where this concerns assessment agencies, one speaks in this regard of the 'depth' of the assessment agencies. As shown in Table 3.1 , the needs assessment is the primary role of the assessment agency, but in practice both the legitimacy tests and the allocation of care by the health insurance agency can be delegated to the assessment agency in a formal or informal way. Some assessment agencies are concerned with registering patients on waiting lists, others occupy themselves with mediating on waiting lists (Schrijvers \& Ravelli, 2000; SGBO, 2000; STIP, 1999b, 2000b). Mediation on waiting lists is also often delegated by the health insurance agency either to the provider or to a regional multi-sectoral care allocation team (Schrijvers \& Ravelli, 2000; SGBO, 2000). Table 3.1 includes these changes from and to the assessment agencies and the percentages of the degree to which they occur according to research that has been undertaken by others. Changes of role among the other players in the care chain are not expressed numerically in these research publications.

If the quality of a series of processes is evaluated, it is often said that a chain is as strong as its weakest link. SGBO (2000) also concludes this in its report, by indicating the influence of cohesion within the care chain on the adequate functioning of the assessment agencies. A break in the chain means that other links have to provide ad hoc solutions. An example of this is regional waiting list management. When the health insurance agency cannot of will not carry out this task properly, the assessment agencies or care providers are faced with the consequences. These organisations regard themselves as morally obliged to the patients not to let them become victims of this situation, and they carry out the activities themselves, although there are no financial or staffing budgets to cover it (SGBO, 2000).

Vulto (1999) and Schrijvers (2001) indicated problems in the communication between needs assessor and the home care organisation. The home care organisations make use of the care products described in the 'Home Care Product Book'. Its concrete activities in the area of home care are directed at making the care provided transparent. The needs assessor, on the other hand, describes the care indicated in conformity with the 
formulation of the national protocol and approaches the provision of care at a higher level of abstraction and focuses on determining the necessary care.

There has been a great deal of consultation between the assessment agencies and the care providers, but the actual form of the links between assessment agency/insurer/ and insurer/provider are still unclear (SGBO, 2000). The report of the Supervisory Committee of Insurance Agencies (Commissie Toezicht Uitvoeringsorganisatie, 2001) looks at the role of the health insurance agencies in home care. This report is not at all positive about the way in which the health insurance agencies actually equip themselves for their task in practice. The report confirms the findings of SGBO (2000) and Schrijvers (2001) that this role has scarcely been developed. They, in part, as a result of their being restricted by all sorts of laws and regulations, are scarcely able to carry out real negotiations about the amount of care to be provided and other managerial options often remain unused because of an inadequate exchange of information with the preceding or subsequent link in the chain (the assessment agency or the home care organisation, respectively). Furthermore, monitoring activities, e.g. randomly checking of the assessment agencies' reports, have a low priority (Commissie Toezicht Uitvoeringsorganisatie, 2001). Since the players in the care chain within most regions are being computerised, and have differing, incompatible, software packages, efficiency within the care chain is rendered impossible. Assessment agencies should be able to supply assessment data to the care providers online and the agency should also be able to provide information on the needs assessment online. Also information should be available on their waiting lists (Tweede Kamer der Staten-Generaal, 1999-2000; SGBO, 2000).

As far as is known, there has only been one national investigation into care providers' satisfaction with the assessment agencies. This related to research by Bureau voor Toegepaste Economische en Ruimtelijke Planning BV (1999) for the National Association of Home Care. This research reveals, that in the view of the home care organisations, the quality of the needs assessment would have been reduced. The direct usability of the assessment reports would be in many cases minimal. The methods would be not uniform and too slow and the assessors would have too little insight into the supply of care (Bureau voor Toegepaste Economische en Ruimtelijke Planning BV, 1999). 


\section{Discussion}

The objectives of new-style needs assessment are: more independence, more objectivity and an integrated approach to the determination of the required type and amount of care. Research literature shows, in practice, that there are various factors that impede the achievement of these objectives. Independence of needs assessment can be endangered when authorisation arrangements are applied in which home care organisations themselves have to assess specific needs for home care. The far from clear definition, both of the concept of singular demands for care and also of authorisation, also seem to be to blame for the differences in research into the degree of the presence of authorisation arrangements. In addition, part of the variation in the research can perhaps also be attributed to the ongoing development within the assessment agencies. A number of assessment agencies initially authorised specific needs assessments to provide themselves with the opportunity to set up a solid organisation. About one year after the Care Needs Assessment Decree came into effect, the number of authorising assessment agencies dropped sharply which could indicate that the assessment agencies had got sufficient organisational potential. The tendency towards yet an increasing amount of authorisation arrangements in the research by Schrijvers \& Ravelli (2000) could be explained by the fact that some of the assessment agencies felt that having the agency itself deal with noncomplex needs for home care can be patient unfriendly, bureaucratic or inefficient (Ministerie van Volksgezondheid, Welzijn \& Sport, 1999; SGBO, 2000). Less detailed assessment reports can compel the care provider, to a certain degree, to determine the concrete delivery of care themselves (SGBO, 2000).

Objectivity of needs assessment should among other things be guaranteed by using the national assessment protocol that provides guidance in forming an assessment report. This protocol does have to be shaped to fit the requirements in the various regions, which does lead to differences. Hence, there are assessment agency bound or regional agreements on validity terms, urgency criteria and bandwidths. What strikes one here is that the definitions used for these terms are often divergent. There is also diversity in respect of the use of the complaints procedure.

The following conclusion by SGBO makes the lack in uniformity more relative by stating that although between the agencies there are major 
differences (and this is true of many areas), within the agencies the assessments are rather uniformly made up due to the use of protocols. The differences between the assessment agencies not only make it difficult to request a second opinion from another agency, they also promote an inequitable approach. A needs assessment by another agency could, as a result of the pluriform approach, lead to a totally different type or amount of care indicated (SGBO, 2000). Schrijvers' research (2001) into inter-assessor reliability shows that identical cases (vignettes) are assessed entirely differently. It is unclear whether these differences can be attributed to structural characteristics of the assessment agencies or to personal differences in assessment among the assessors attached to the assessment agencies.

The integrated approach to assessment relates to a comprehensive multidisciplinary approach to the needs for care. In this respect, we have already noted that the scope of the domain varies from one agency to another. Related to this, an integrated approach may be limited by the authorisation arrangements and the route chosen for the assessment. In both cases, there is the possibility that the assessment will be made narrower to meet what the authorised care provider has to offer, or what the demander asks for. As a result of this, other unknown needs for care will not be included in the final assessment. Thus, the assessment for other forms of care or for coherence in care is reduced. Another aspect is that the assessors are not always expert enough to perform an integrated assessment. For example because of their background as district nurses, they cannot just give a WVG assessment (Beemsterboer, 2000; SGBO, 2000).

The new-style needs assessment is embedded in the care chain, pursuant to the Care Needs Assessment Decree (Ministerie van Volksgezondheid, Welzijn \& Sport, 1997) and the policy document 'Care in Sight' (Tweede Kamer der Staten-Generaal, 1998-1999). The chain begins with the registration of a request for care by patients or by someone in their direct vicinity and leads to a needs assessment and subsequently to care indicated by an assessment agency. Subsequently the health insurance agency checks the eligibility and allocates the care, if necessary dealing with waiting lists. Finally, the care provider delivers the allocated care. It is striking that, in illustrating the care chain, no mention is made of the second aspect of the role of the patient which is that of the care receiver, a role which makes the 
care chain a cyclical whole.

The differing range of the depth (number of activities performed) of the assessment agencies is a result of all sorts of delegation systems. It can largely be ascribed to the definition of the various concepts. Here too, there are gaps in time between the studies concerned.

Research reports show that the link of the health insurance agencies is weak because both the agencies themselves and the assessment agencies have insufficient information on the responsibilities of health insurance agencies within the care chain. The provision of information between those parties is, as a result, difficult also as a result of shortcoming computerisation and incompatible software. As far as the health insurance agencies are concerned, it appears that their principal roles are not regulated by law, pursuant to the Care Needs Assessment Decree (STIMO, 1997), although they have responsibilities for the legitimacy test and the allocation of care pursuant to the AWBZ. This omission in the Care Needs Assessment Decree is perhaps the basis of the unclear position of these agencies within the care chain (Tweede Kamer der Staten-Generaal, 1998-1999; Ministerie van Volksgezondheid, Welzijn \& Sport, 1999; SGBO, 2000). In any event, the health insurance agencies should only be concerned with assessments in the area of the AWBZ; the implementation of the other laws included in the WVG is not their responsibility. The part to be played by the health insurance agency in the care chain is purely AWBZ-oriented (Ministerie van Volksgezondheid, Welzijn \& Sport, 1997).

Research into the new-style needs assessment is often limited to inventory studies of the organisation of just one link within the care chain, generally the assessment agency, or to responses from, for example, the home care organisations to developments. The co-operation between other links within the care chain remains virtually out of sight. It is striking that in research into (the players within) the care chain, which, after all, was designed to be patient-oriented and to implement empowerment, the patient perspective is virtually absent. Research by Schrijvers (2001) forms an exception to this observation.

SGBO concludes in its report (2000) that no model method for the assessment agencies can be determined. The most adequate method used by 
them is largely determined, among other things, by the domain and depth of the assessment agency, the procedure and route for registration of demands for care, the complaints procedure, all in which assessment agencies can vary. It may be provocative, but it could be said that there are not only 84 assessment agencies, but yet 84 different assessment agencies. We stated earlier in this paper that, in any event, a number of these differences could lead to inequitable treatment of patients.

Long before the new-style needs assessment was developed, Huijsman (1990) warned about these variations and the danger that the various local assessment systems will strongly diverge from one another, so it would perhaps be more efficient to develop a national system. Although BIO (1997) clearly stated that its model protocol required further specifications at a local and/or regional level, one could expect advantages from this objective assessment model such as promoting customised care, adequate decision making in allocating provision, legal security and a certain degree of predictability of outcomes and furthermore equal access to care and efficiency. Further, a national protocol could increase the expertise of the needs assessment and make adequate control possible (BIO, 1997). The question is whether these objectives can be achieved despite the far-reaching diversity at the assessment agencies. The Secretary of State of the Ministry of Health also recognises this problem and is striving for greater uniformity with more regulations and protocols (Ministerie van Volksgezondheid, Welzijn \& Sport, 2000). The Secretary of State is confronted as a result of the great variety among the assessment agencies with the impossibility of calculating a cost price for each assessment that is indispensable in establishing properly funded budgets (SGBO, 1999; Ministerie van Volksgezondheid, Welzijn \& Sport, 2000). A number of principal topics in government policy are, in this context, improving internal management of assessment agencies and the reducing the number of assessment agencies and transmission of nonrelated tasks, such as waiting list management and registration. Further, the government focuses on more protocols, training of assessors, expansion of the domain of the assessment agencies and getting rid of the backlog at the assessment agencies. The final result of these efforts should be the formation of what are called robust assessment agencies.

In conclusion, it can be stated that it is mainly the authorisation arrangements which are the major threat, both to the objectives envisioned 
for the 'new-style' care assessment and for the proper functioning of the care chain. There is too little clarity in the research on the degree of the use of these authorisation arrangements, whereas the care chain as a whole, including the patient's point of view, has scarcely been the subject of research. There can, as a result, be no funded statements on the matches between the various links in the care chain; nor on how the patient views the trajectory from need for care to the care eventually delivered.

A note on our investigation into the literature is that there has also been little targeted research into the degree of achievement of an independent, objective and integrated needs assessment. The presence of particular structural characteristics (domain, depth, authorisation arrangements and the use of assessment protocols) of assessment agencies has, however, been monitored continually. On the basis of the evaluation of the Care Needs Assessment Decree (Schrijvers, 2001) or other studies carried out, it cannot be concluded that, as regards content, the needs assessment is now independent, objective, or presents an integrated approach; any more than the old-style needs assessment.

To great extent, the absence of research into the objectives achieved using the new style of needs assessment and into the care chain can be attributed to the relatively recent establishment of the assessment agencies and of the care chain. SGBO states that the assessment agencies have by no means been fully developed (SGBO, 2000). Within the assessment agencies, the professional discussion about the preferred method for needs assessment is still ongoing and also the national developments are following one another at a high speed, so the pressure of work increases and there is less time for consolidation (Ministerie van Volksgezondheid, Welzijn \& Sport, 2000; STIP, 2000b; Schrijvers, 2001). The pluriform approach to needs assessment is a problem from a research point of view. Making sub-groups for comparisons is difficult because there is so much variation in the other essential characteristics. Various studies have been disrupted by this, among them SGBO (1999).

The objectives of the new-style needs assessment were intended to give the patient a stronger position and to provide care more adequately. Paradoxically enough, it appears that the match between patients' felt need for care and the actual care delivered is in more danger because of this; 
since, with the agencies, there is an extra link in the care chain and it is not clear whether the assessment agencies have a positive or negative role in this match. The authors are currently carrying out research in this area. In this research all of the players within the care chain, including the patients, are involved. This research project mismatches in patients' is being conducted to determine the degree to which passing all along the care chain may be attributed to, among others, the characteristics of the assessment agencies.

\section{Acknowledgement}

This research project was funded by Netherlands Organisation of Scientific Research (NWO-ZOB) - research programme on care and social support for chronically ill patients. 


\section{References}

Andersen RM (1995). Revisiting the Behavior Model and access to medical care: does it matter? Journal of Health and Social Behavior; 36: 1-10.

Beemsterboer WGM (2000). De ratio van de RIO's: meerwaarde van onafhankelijke, objectieve en integrale indicatiestelling. [The ratio of the regional assessment agencies: the extra worth of independent, objective, and comprehensive needs assessment.] Tijdschrift voor Gezondheidswetenschappen; 78 (4): 238-243.

Bellemakers C (1995). Patiënt en indicatiestelling. [Patient and needs assessment.] NRV Magazine; 2 (1): 9.

Breed Indicatie Overleg (1997). Modelprotocol geïntegreerde indicatiestelling voor het terrein van wonen, welzijn en zorg. [Model protocol for integrated needs assessment in the area of living, welfare and care.] Gouda: BIO.

Bureau voor Toegepaste Economische en Ruimtelijke Planning BV (1999). Uitwerking enquête Landelijke Vereniging voor Thuiszorg: naar de effecten van de overheveling van de indicatiestelling. [Results survey National Association for Homecare; on the effects of the transfer of the needs assessment.] Amersfoort: Terp.

Commissie Toezicht Uitvoeringsorganisatie (2001). Rol zorgkantoren in de thuiszorg. [The role of health insurance agencies in home care.] Amstelveen: CTU.

Degen JJEC \& Huijsman R (1999). Schakelen in de keten tussen vraag en aanbod: regionale indicatie-organen in de ouderenzorg. [Gearing in the chain between demand and supply: regional assessment agencies in care for the elderly.] Maarssen/Zoetermeer: Elsevier/De Tijdstroom/STIMO.

Dijkstra GJ (2001). De indicatiestelling voor verzorgingshuizen en verpleeghuizen. [Needs assessment for homes for the elderly and nursing homes.] Groningen: Noordelijk Centrum voor Gezondheidsvraagstukken (thesis).

Donker MCH (1996). Indicatiestelling in de care-sectoren: kwaliteitsbevordering of kostenbeheersing? [Needs assessment in the care-sectors: promotion of quality or cost control?] Kwaliteit \& Zorg; 4 (4): 159-166.

Gorter KA, Griffioen E, Hessels D \& Smit-Venhuizen MA (1989). Thuishulp gewogen: een onderzoek naar de behoefte van lichamelijk gehandicapte mensen aan hulp thuis. [Home care on balance: a study of the needs for care at home of physically disabled people.] Utrecht: Nederlands Instituut voor Maatschappelijk Werk Onderzoek.

Huijsman R (1990). Model van voorzieningen voor ouderen. [Model of facilities for the elderly.] Zeist: Kerckebosch BV (thesis). 
Hutten JBF \& Kerkstra A (2002). Home care is what people want. In: Van Rooij EHC, Droyan Kodner L, Rijsemus AH \& Schrijvers AJP (Ed.). Health and health care in the Netherlands: a critical self-assessment of Dutch experts in medical and health sciences. Maarssen: Elsevier Gezondheidszorg; p. 101-110.

Kerkstra A, Verheij RA, Foets M \& Van der Velden J (1990). Behoefte aan nazorg en verleende nazorg na ontslag uit het ziekenhuis. [Need for aftercare and provided aftercare following discharge from hospital.] Tijdschrift voor Sociale Gezondheidszorg; 68 (8): 346-354.

Ministerie van Volksgezondheid, Welzijn \& Sport (1997). Zorgindicatiebesluit (Besluit van 2 oktober 1997, houdende regels met betrekking tot het werkterrein, de samenstelling en werkwijze van indicatie-organen). [Care Needs Assessment Decree (White Paper of October, 2 1997, regarding field of activities, the formation, and the operation of Regional Needs Assessment Agencies).] Staatsblad van het Koninkrijk der Nederlanden. Den Haag: Sdu, 447.

Ministerie van Volksgezondheid, Welzijn \& Sport (1999). Brief d.d. 25 maart 1999 over Ontwikkelingen indicatiestelling 'nieuwe stijl'. [Letter of March, 251999 on developments new-style needs assessment.] Den Haag: Ministerie van Volksgezondheid, Welzijn \& Sport.

Ministerie van Volksgezondheid, Welzijn \& Sport (2000). Brief d.d. 31 mei 2000 over Indicatiestelling 'nieuwe stijl'. [Letter of May, 312000 on new-style needs assessment.] Den Haag: Ministerie van Volksgezondheid, Welzijn \& Sport.

Ministerie van Volksgezondheid, Welzijn \& Sport (2000). Brief d.d. 15 januari 2001 over Robuuste RIO's. [Letter of January, 152001 on robust regional assessment agencies.] Den Haag: Ministerie van Volksgezondheid, Welzijn \& Sport.

Ministerie van Volksgezondheid, Welzijn \& Sport (2001). Gedragsregels Ketenbenadering cluster Verpleging \& Verzorging. [Rules of conduct approach of the care chain in the nursing and caring sector.] Den Haag: Ministerie van Volksgezondheid, Welzijn \& Sport.

Nationale Raad voor de Volksgezondheid (1994). Indicatiestelling en zorg op maat: advies van de Nationale Raad voor de Volksgezondheid en het College voor Ziekenhuisvoorzieningen. [Needs assessment and customised care: recommendations by the National Council for Public Health and the Council for Hospital Facilities.] Zoetermeer: Nationale Raad voor de Volksgezondheid.

Schippers A (2001). Indicatiestelling voor wonen, zorg en welzijn. [Needs assessment for living, care and welfare.] In: Veldheer VC, Van den Nieuwenhuizen PJCM, Schoorl AHA, Sprinkhuizen AMM \& Stevens PGJJ (Ed.). Handboek Lokaal Sociaal Beleid. Den Haag: Elsevier Bedrijfsinformatie bv; p. D 7.1.1 - D 7.1.24. 
Schrijvers AJP (2001). RIO, het jongste kind groeit op; eindrapport van de evaluatie van het Zorgindicatiebesluit van 1998. [The assessment agency, the youngest child grows to maturity; final report on the evaluation of the Care Needs Assessment Decree of 1998.] Utrecht: Julius Centrum voor Huisartsgeneeskunde en Patiëntgebonden onderzoek.

Schrijvers AJP \& Heinsbroek NQM (1998). Veel op het spel: over het hoe en waarom van verbreding van geïntegreerde indicatiestelling voor mensen met een functiebeperking. [Much to lose: regarding the reason for expanding integrated needs assessment for people with a functional disability.] Utrecht: Stichting Dienstverleners Gehandicapten.

Schrijvers AJP \& Ravelli DP (2000). RIO, het jongste kind; tussenverslag van de evaluatie van het Zorgindicatiebesluit. [Regional assessment agency: the youngest child; preliminary report on the evaluation of the Care Needs Assessment Decree.] Utrecht: Juliuscentrum voor Huisartsgeneeskunde en Patiëntgebonden onderzoek.

SGBO (1999). Kosten van thuiszorg-indicaties; Een onderzoek naar de begrotingen van Regionale Indicatie-Organen. [Costs of needs assessments in home care; a study of the budgets of regional assessment agencies.] Den Haag: SGBO.

SGBO (2000). Werkwijze van Regionale Indicatie-Organen; Onderzoek onder 7 RIO's. [Working procedures of regional assessment agencies; research among 7 regional assessment agencies.] Den Haag: SGBO.

Slingerland P \& Van Amelsvoort F (1993). Thuiszorg bemiddeld: achtergronden, uitgangspunten en instrumenten voor een vraaggerichte benadering van intake en indicatiestelling. [Mediation on home care: backgrounds, points of departure and instruments for a demand directed approach of intake en needs assessment.] Utrecht: Nederlands Instituut voor Zorg en Welzijn.

STIMO (1997). Nieuwsbulletin; $n r .4$. [News Bulletin nr. 4.] Enschede: STIP.

STIMO (1998). Periodieke inventarisatie indicatie-organen: stand van zaken per 16 februari 1998. [Periodical inventarisation assessment agencies: state of affairs per February 16, 1998.] Zoetermeer: STIMO.

STIP (1999). Informatiebulletin; $n r .5$. [Information Bulletin, nr. 5.] Enschede: STIP.

STIP (1999). Periodieke inventarisatie indicatie-organen: de stand van zaken in augustus 1999. [Periodical inventarisation assessment agencies: state of affairs in August 1999.] Enschede: STIP.

STIP (2000). Informatiebulletin; $n r$. 1. [Information Bulletin, nr. 1.] Enschede: STIP.

STIP (2000). Periodieke inventarisatie indicatie-organen: de stand van zaken in mei 2000. [Periodical inventarisation assessment agencies: state of affairs in May 2000.] Enschede: STIP. 
Tweede Kamer der Staten-Generaal (1973-1974). Structuurnota Gezondheidszorg. [White Paper on the structure of healthcare.] Kamerstukken 13.012. Den Haag: Staatsuitgeverij.

Tweede Kamer der Staten-Generaal (1979-1980). Schets van de eerstelijns gezondheidszorg. Kamerstukken 16.066. 's-Gravenhage: Staatsuitgeverij.

Tweede Kamer der Staten-Generaal (1987-1988). Nota Ouderenbeleid: voortgangsrapportage 1982-1988. [White Paper on Policy for the Aged: report of progression 19821988.] Kamerstukken 20.539. Den Haag: Staatsuitgeverij.

Tweede Kamer der Staten-Generaal (1998-1999). Nota Zicht op Zorg: plan van aanpak modernisering AWBZ. [White Paper Vision on Care: planning the modernisation of the Exceptional Medical Expenses Act.] Kamerstukken 26.631 nr. 1. Den Haag: Staatsuitgeverij.

Tweede Kamer der Staten-Generaal (1999-2000). Planning en indicatie AWBZvoorzieningen. [Planning and assessment of facilities on behalf of the Exceptional Medical Expenses Act.] Kamerstukken 27.180 nr. 2. Den Haag: Sdu Uitgevers.

Vulto, M (1999). Indicatiestelling in de thuisverzorging; knelpuntenanalyse. [Needs assessment in home care; analysis of bottlenecks.] Utrecht: Vulto. 


\section{An evaluation of the new home care needs assessment policy in the Netherlands}




\begin{abstract}
The aim of the present study was to describe the realisation of the new-style needs assessment in the Netherlands and how it was evaluated. Furthermore, judgements about the new way of assessing (chronic) patients' needs with respect to home care are presented. Data were gathered by means of a postal survey. Of all assessment agencies, home care organisations and health insurers. The new-style needs assessment, as regulated by the Care Needs Assessment Decree, implies that home care needs should be objectively assessed independently of the availability of care supply and integrally with other types of (long-term) care. This study shows that all the organisational structures required to realise these goals are present. However, according to factual and evaluative data, many practical aspects of these structures appear to be deficient. The national assessment forms, an instrument for gaining objectivity, are judged impracticable by half of the assessment agencies. Authorisation arrangements threaten independent as well as comprehensive needs assessment. Whether the new-style needs assessment is evaluated positively or negatively depends upon the type of organisation under study. On the one hand, assessment agencies are positive about their achievements. On the other, home care organisations are generally negative about the functioning and advantages of the new style of needs assessment. Health insurers' opinions are in between those of assessment agencies and home care organisations.
\end{abstract}

\title{
Introduction
}

In the Netherlands, home care needs were assessed and such care was subsequently delivered by the same home care staff until 1998 (and still are in the UK and many other European countries) (Hutten \& Kerkstra, 1996, Parry-Jones \& Soulsby, 2001; Algera et al., 2002). For the purposes of the present paper 'needs assessment' is defined as the result of a formalised process of objectively determining the need for care, and subsequently prescribing adequate care according to type, content and extent (Nationale Raad voor de Volksgezondheid, 1994). In this context, the needs for care concern patients' health-related care deficits.

In the Netherlands, professional home care consists of care concerning instrumental activities of daily life (i.e. domestic care or home help), care concerning activities of daily living (i.e. physical or personal care), technical nursing care and psychosocial care, all delivered by professionals at the 
patient's home (Hutten \& Kerkstra, 1996). Since 1998, the assessment of home care needs (and also the assessment of needs for care in nursing and elderly homes) has been separated from the delivery of such care. These needs assessments are now undertaken by independent assessment agencies (called Regionale Indicatie Organen in Dutch). This profound change was introduced by the Care Needs Assessment Decree (Ministerie van Volksgezondheid, Welzijn \& Sport, 1997). In this paper, the present authors describe how the Care Needs Assessment Decree has been operationalised and how it is evaluated by the organisations involved. The Care Needs Assessment Decree describes some organisational aspects as well as the major objectives of the new style of needs assessment, where needs assessment has to be independent, objective and cpmprehensive.

The Care Needs Assessment Decree (Ministerie van Volksgezondheid, Welzijn \& Sport, 1997) prescribes that municipalities are responsible for establishing and maintaining the independent assessment agencies. In the year 2000, there were 85 assessment agencies, which encompass all the regions within the Netherlands. According to the Care Needs Assessment Decree, these assessment agencies are required to examine the patients' need for home care and long-term care, i.e. care provided by nursing homes or homes for elderly people. Furthermore, assessments for individual care budgets, a budget with which patients may purchase the allocated care themselves, belong to the obligatory domain of assessment agencies. Since 2000, the domain of the assessment agencies expanded to include other types of care, such as residential care for people with intellectual, physical or sensory disabilities, as well as housing and mobility arrangements for outpatients with physical disabilities (Algera et al., 2002). Mental healthcare will be added to the domain in 2003. In addition, optional assessment fields (e.g. various kinds of welfare) are allowed.

The assessment agencies have to be independent, in that the assessment of care eligibility should not be dependent on the supply available; for instance, the availability of home care should not interfere with the outcome of the actual needs assessment. With regard to home care, an exception is made for assessments of noncomplex home care needs (e.g. a need for limited domestic care or for eye drops to be administered). In those cases, assessment agencies are allowed to either perform these assessments themselves or to authorise the actual needs assessment to home care 
organisations (Ministerie van Volksgezondheid, Welzijn \& Sport, 1997).

In addition, the Care Needs Assessment Decree states that assessment agencies should assess patients' needs for home care and the abovementioned types of care integrally. For example, this implies that home care needs should no longer be assessed separately from the need for semiresidential care. Thus, innovative combinations of several types of care are made possible, while enhancing need-directed care provision. Previously, intake committees of home care organisations, nursing homes and homes for elderly people only made assessments related to their 'own' type of care and they did not take into account other possible care requirements (Dijkstra 2001; Algera et al., 2002).

Furthermore, according to the Care Needs Assessment Decree, assessments must be conducted objectively so that they are less dependent on the individual characteristics of the assessor or the patient (Ministerie van Volksgezondheid, Welzijn \& Sport, 1997). The government did not insist on the use of nationally developed assessment forms, but did recommend their use to enhance objectivity. This would promote equality for all patients in determining their care needs.

It is required that the result of the needs assessment is documented in an assessment report. The topics to be covered by the assessment report are also outlined in the Care Needs Assessment Decree. Assessment reports should specify, among other things, the type and amount of care needed, and the urgency with which the care is to be delivered.

Figure 4.1 Care chain from needing care to receiving it

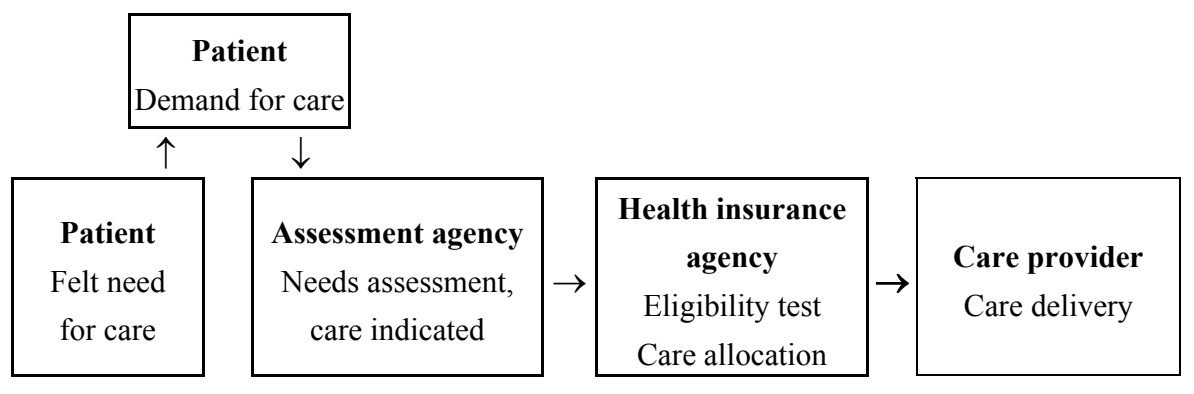


The government considers the new independent assessment agencies to be central to the so-called 'care chain' (Ministerie van Volksgezondheid, Welzijn \& Sport, 1997; Tweede Kamer der Staten-Generaal, 1999). The care chain describes the route patients have to follow in order to receive professional help for their needs for care. Figure 4.1 depicts this route.

After patients have made a request for care at the assessment agency's office, an assessor usually makes a home visit to determine the care needed (e.g. "You need to be washed five times a week"). The resulting assessment report is sent to the health insurance company. The insurer is responsible for judging whether or not the claim for care is legitimate, i.e. reimbursable by law. Subsequently, the health insurer confirms the care entitlement. Eventually, the care provider most eligible to deliver the allocated care starts giving care to patients, initially based on the assessment report.

The assessment of home care needs in the Netherlands is promoted as comprehensive and independent, and seems to be rather unique. However, striving for improved objectivity by using standardised assessment forms is done in other European countries as well (Hutten \& Kerkstra, 1996). Assessment of need for home care on the one hand and the delivery of such care on the other by separate organisations is usually not found in other countries, although in some, the general practitioner may be the assessor for home care (Hutten \& Kerkstra, 1996). Furthermore, comprehensibility of assessments is not seen in most other Western countries (Parry-Jones \& Soulsby, 2001). Therefore, it is interesting to share how the new-style needs assessment, particularly regarding home care, is realised in Dutch practice.

The assessment agencies have been in operation for some years now, and there is some descriptive research on how the new-style needs assessment is evaluated by assessment agencies themselves and by home care organisations as the organisation that has to deliver the care indicated by the assessment agencies. From this research, it appears that home care organisations tend to judge assessment agencies negatively because of bureaucracy, lack of uniformity and poor usability of assessment reports (Bureau voor Toegepaste Economische en Ruimtelijke Planning BV, 1999). Now that the assessment agencies have been established for a number of years, the present authors investigated how they, on the one hand, and home care organisations and health insurers, on the other, evaluate the new-style 
needs assessment, focusing on the field of home care. In particular, the authors studied how home care organisations, as primary users of the assessment agencies' reports, judge the usability of those reports.

The purpose of the present paper is to explain how the new style of needs assessment is realised in practice and how it is evaluated by relevant organisations. In doing so, the following research questions are posed:

1. In the Netherlands, is the needs assessment process realised in accordance with the main elements of the Care Needs Assessment Decree regarding the goals to be attained and the contents of the assessment report?

2. How is the new-style needs assessment for home care judged by assessment agencies, home care organisations and health insurers, in comparison to the former way of needs assessment?

3. According to home care organisations, how usable are the assessment reports produced by assessment agencies in practice?

4. Which organisational characteristics of assessment agencies and/or home care organisations may be related to home care organisations' judgements of assessment agencies?

Patients' judgements on the new style of needs assessment are included in other parts of the research project and will be reported elsewhere.

\section{Subjects and methods}

In May 2000, all 85 assessment agencies, all 114 home care organisations and all 31 health insurers in the Netherlands were approached with a written questionnaire. The response rate amongst these organisations has been high ( $92 \%, 81 \%$ and $74 \%$, respectively). Reasons for not responding were lack of time or lack of interest. Most questionnaires were completed by managers or members of staff. If answers on specific items were not given, or were unclear or inconsistent with scores on other items, the respondent was telephoned for clarification, thus reducing missing values and increasing the quality of the data. By doing so, virtually complete data sets of 78 assessment agencies, 92 home care organisations and 23 health insurers were obtained.

\section{Instruments}

Three questionnaires were developed, one for each type of organisation. If 
possible, items in the three questionnaires were formulated identically in order to allow comparisons between the participating organisations. Each questionnaire referred to the role the organisation plays in the procedures concerning the new-style needs assessment, such as activities performed by these organisations and the usability of assessment reports. Also, background information and evaluations of the new-style needs assessment were gathered by means of the surveys. The questionnaires were judged for content validity by experts in the respective fields.

\section{Statistical analyses}

All data were entered in the SPSS statistical computer program, and frequencies and percentages were computed. In addition, a judgement scale was constructed. The judgement scale was based on evaluations by home care organisations of the extent to which the new-style needs assessment was considered to have become more independent, objective and comprehensive, and to have led to more efficient, transparent, accessible assessment procedures, or to better correspondence between patients' care needs and subsequent assessment, all in comparison with the assessment 'old style'. This judgement scale had a Cronbach's alpha of 0.85 .

In almost half of the cases $(43 \%, n=40)$, a home care organisation dealt with only one assessment agency, in which case the opinion of the home care organisation could be attributed to that particular assessment agency. Judgements by home care organisations dealing with two or more assessment agencies were excluded from analysis. A $t$-test showed that the number of assessment agencies a home care organisation has to deal with has no influence on the direction of the judgement (positive or negative).

Then, by computing Pearson's correlations, characteristics of the 40 assessment agencies which significantly influenced home care organisations' judgements were detected while independent variables showing multicollinearity were excluded. Subsequently, these significant variables have been simultaneously entered in a regression analysis. Another regression analysis has been performed to find the significant characteristics of (all 92) home care organisations themselves which influenced their opinion about the new style of needs assessment. 


\section{Results}

Needs assessment in practice versus the Care Needs Assessment Decree

By establishing over 80 independent assessment agencies, the objective described in the Care Needs Assessment Decree (Ministerie van Volksgezondheid, Welzijn \& Sport, 1997) to obtain independence through separation of needs assessment from delivery of care has been realised. Most of the responding assessment agencies came into operation during the first half of 1998. Data collected from assessment agencies show that two out of three assessment agencies did not authorise the assessment of noncomplex home care needs (anymore) in 2000. Nevertheless, 9\% $(n=7)$ of the assessment agencies let the home care organisations perform these assessments, whereas another $24 \%(n=19)$ have arrangements with liaison nurses to assess home care needs in patients to be discharged from hospital. Conversely, three out of four home care organisations have stated they do not have anything to do with needs assessment anymore, while 24 home care organisations (26\%) are performing the noncomplex needs assessments.

According to the Care Needs Assessment Decree, some assessment fields are obligatory in order to facilitate the comprehensive needs assessment, the second goal to be attained. Table 4.1 shows all the obligatory fields to be fully covered by the assessment agencies under study. Authorising assessments to home care organisations does not exclude these assessments from the assessment agency's domain. During the survey, the number of compulsory fields of assessment has been enlarged, enriching the comprehensibility of the assessment with respect to expensive housing adjustments. This may be the reason that only $27 \%$ of the assessment agencies $(n=21)$ state that they are active in this field.

In addition to the obligatory assessment fields, there is a wide variety of other optional assessment fields for which assessment agencies may assess patients' need (see the 'Optional' section of Table 4.1). One-third to half of the assessment agencies reported they would expand their domain in near future in favour of outpatient facilities and inpatient care for people with physical, sensory or intellectual disability, respectively. 
Table 4.1 Domain of needs assessment by assessment agencies $(\mathrm{n}=78)^{*}$

\begin{tabular}{lcc}
\hline Domain of needs assessment & Number & Percentage \\
\hline Compulsory & 78 & 100 \\
Nursing home & 78 & 100 \\
Home for the elderly & & \\
Home care: & 78 & 100 \\
$\quad$ noncomplex needs & 78 & 100 \\
$\quad$ complex needs & 77 & 99 \\
Individual care budget & 21 & 27 \\
Expensive housing adjustments & & \\
& & 97 \\
Optional & 76 & 55 \\
Day care / night care & 43 & 41 \\
Sheltered home & 32 & 40 \\
Meals on wheels & 31 & 39 \\
Arousing public awareness & 30 & 37 \\
Other facilities for people with disabilities & 29 & 33 \\
Less-expensive housing adjustments & 26 & 24 \\
Nursing aids & 19 & \\
Supplementary public transport & & \\
\hline
\end{tabular}

* Multiple responses allowed

The third main goal of the new-style needs assessment concerns the objectivity of the assessment by making use of protocols. In the Care Needs Assessment Decree, the utilisation of national assessment forms, either on paper or electronically, is recommended. The results show that most assessment agencies appear to use the recommended assessment forms either entirely $(45 \%, n=35)$ or partially $(41 \%, n=32)$. Half of the assessing home care organisations do not use the national recommended assessment forms, but most of them $(62 \%, n=8)$ have based their own assessment forms on the national protocol, making some adjustments typical for the situation of that organisation.

The needs assessment process results in an assessment report; some details on the content of assessment reports are given in Table 4.2. In these reports, the type of care needed is always determined by the assessment agency, as is the frequency of care to be delivered. Most 
assessment agencies specify the duration of care to be delivered $(92 \%$, $\mathrm{n}=72)$ as well as the validity limit of the report $(91 \%, n=71)$. However, it appears that other specific topics referred to in the Care Needs Assessment Decree are not mentioned by every assessment agency (see Table 4.2). The less-frequently mentioned items concern the urgency with which care should be delivered, the expertise of the caregiver, a second-best option in case the care needed is not available, and margins within which the caregiver may expand the frequency or caring time per day or per week without the need for a reassessment by the assessment agency. By and large, authorised home care organisations' assessment reports contain the same elements as those by assessment agencies.

Table 4.2 Elements of assessment reports determined by assessment agencies $(\mathrm{n}=78)$ and authorised home care organisations $(\mathrm{n}=24)^{*}$

\begin{tabular}{|c|c|c|c|c|}
\hline \multirow[b]{2}{*}{ Element } & \multicolumn{2}{|c|}{ Assessment agency } & \multicolumn{2}{|c|}{$\begin{array}{c}\text { Authorised home care } \\
\text { organisation }\end{array}$} \\
\hline & Number & Percentage & Number & Percentage \\
\hline Type of care & 78 & 100 & 20 & 95 \\
\hline Frequency of care to be delivered & 77 & 99 & 19 & 91 \\
\hline Duration of care to be delivered & 72 & 92 & 20 & 95 \\
\hline Validity limit of assessment report & 71 & 91 & $* *$ & $* *$ \\
\hline Urgency & 69 & 89 & $* *$ & $* *$ \\
\hline Level of expertise of caregiver & 59 & 76 & 17 & 81 \\
\hline Second-best option & 48 & 62 & $* *$ & $* *$ \\
\hline $\begin{array}{l}\text { Margins of expanding frequency } \\
\text { or amount of care }\end{array}$ & 38 & 49 & $* *$ & $* *$ \\
\hline $\begin{array}{l}\text { * Multiple responses allowed } \\
\text { ** In the home care organisations' } \\
\text { those options seemed less releva } \\
\text { noncomplexity of the care n } \\
\text { organisations. }\end{array}$ & destionn & $\begin{array}{l}\text { not all th } \\
\text { the autho } \\
\text { assessed }\end{array}$ & $\begin{array}{l}\text { tions c } \\
\text { ion arr }\end{array}$ & $\begin{array}{l}\text { be selected; } \\
\text { ment and the } \\
\text { home care }\end{array}$ \\
\hline
\end{tabular}

\section{Judgements about the new style of needs assessment}

Table 4.3 contains the judgements by assessment agencies, home care organisations and health insurers regarding the realisation of the main goals of the new-style needs assessment. When comparing the new style of needs assessment with the former way of assessing needs by home care organisations, almost all (over 95\%) assessment agencies feel the assessment has become more independent, objective and 
comprehensive. As far as health insurer respondents could make comparisons, they agree with the opinions of assessment agencies, but to a lesser degree. However, on the topic of objectivity, a large proportion of the health insurers disagree with the respondents from assessment agencies. With regard to home care organisations, no distinct pattern emerged: the number of respondents agreeing with the statements, disagreeing, or not having a specific opinion are approximately equal.

Table 4.3 Judgements by assessment agencies $(n=78)$, home care organisations $(n=92)$ and health insurers $(n=23)$ about goal attainment according to Care Needs Assessment Decree

\begin{tabular}{|c|c|c|c|}
\hline Goal new-style needs assessment & $\begin{array}{l}\text { Assessment } \\
\text { agency }\end{array}$ & $\begin{array}{l}\text { Home care } \\
\text { organisation }\end{array}$ & $\begin{array}{l}\text { Health } \\
\text { insurer }\end{array}$ \\
\hline Assessment became more objective & & & $23 *$ \\
\hline (totally) agree & 95 & 31 & 36 \\
\hline neither agree nor disagree & 4 & 26 & 0 \\
\hline (totally) disagree & 1 & 42 & 41 \\
\hline Assessment became more independent & & & $13 *$ \\
\hline (totally) agree & 99 & 42 & 48 \\
\hline neither agree nor disagree & 0 & 26 & 17 \\
\hline (totally) disagree & 1 & 32 & 22 \\
\hline Assessment became more comprehensive & & & $22 *$ \\
\hline (totally) agree & 96 & 32 & 70 \\
\hline neither agree nor disagree & 1 & 29 & 0 \\
\hline (totally) disagree & 3 & 39 & 9 \\
\hline
\end{tabular}

Table 4.4 presents some opinions about other features of the new-style needs assessment. In the opinion of assessment agencies and health insurers who were able to compare both assessment styles, the correspondence between home care needs and the assessment of these needs has improved, as did the transparency of the assessment procedure. Interestingly, respondents employed by home care organisations strongly disagree with this viewpoint. The accessibility and efficiency of the assessment procedure have improved according to the assessment agencies, but home care organisations and health insurers seem to (strongly) disagree. Of note is the large percentage of 
respondents from assessment agencies not agreeing or disagreeing with the latter statements.

When considering the evaluations by assessment agencies and home care organisations, a certain pattern seems to emerge: the less confident assessment agencies are about the benefits of the new style of needs assessment, the more negative home care organisations show themselves to be regarding these aspects. In other words, negative attitudes by home care organisations seem to be confirmed by assessment agencies' lesspositive evaluations.

Table 4.4 Judgements by assessment agencies $(n=78)$, home care organisations $(n=92)$ and health insurers $(n=23)$ of newstyle needs assessment compared to the old style of needs assessment (in \%)

\begin{tabular}{|c|c|c|c|}
\hline Characteristic & $\begin{array}{l}\text { Assessment } \\
\text { agency }\end{array}$ & $\begin{array}{l}\text { Home care } \\
\text { organisation }\end{array}$ & $\begin{array}{l}\text { Health } \\
\text { insurer }\end{array}$ \\
\hline \multicolumn{4}{|l|}{ Better correspondence assessment and } \\
\hline & & & $52 *$ \\
\hline (totally) agree & 82 & 9 & 30 \\
\hline neither agree nor disagree & 17 & 22 & 4 \\
\hline (totally) disagree & 1 & 69 & 13 \\
\hline Assessment more transparent & & & $9 *$ \\
\hline (totally) agree & 67 & 15 & 59 \\
\hline neither agree nor disagree & 18 & 19 & 14 \\
\hline (totally) disagree & 15 & 66 & \\
\hline Accessibility assessment improved & & & $39 *$ \\
\hline (totally) agree & 47 & 9 & 17 \\
\hline neither agree nor disagree & 35 & 19 & 13 \\
\hline (totally) disagree & 18 & 72 & 30 \\
\hline Assessment more efficient & & & $50 *$ \\
\hline (totally) agree & 48 & 7 & 5 \\
\hline neither agree nor disagree & 46 & 13 & 15 \\
\hline (totally) disagree & 7 & 81 & 30 \\
\hline
\end{tabular}


The pattern of positive assessment agencies, negative home care organisations and health insurers somewhere in between also emerges when these organisations were asked about (dis)advantages of the newstyle needs assessment. Out of the 78 assessment agencies under study, $81 \%$ experience more advantages than disadvantages. The health insurers share this experience to a lesser extent $(48 \%, n=11)$. However, $38 \%(n=33)$ of the home care organisations experience more drawbacks than benefits. It is noteworthy that, in addition to their negative evaluation, one-quarter of all responding home care organisations do not see any gain from the new style of needs assessment at all. Furthermore, one-third of the health insurers do not express a specific opinion in this matter. Table 4.5 displays some drawbacks as experienced by assessment agencies, home care organisations and health insurers. Negative evaluation is mostly related to introductory difficulties, like computer problems and feeling uncomfortable about the new way the needs assessment is modelled. Because of the establishment of the assessment agencies, there is more bureaucracy and the presence of an extra link within the route for patients to pursue (see Figure 4.1). These objections were identified by home care organisations in a larger extent than health insurers. Interestingly, approximately one-quarter of the assessment agencies themselves reported these disadvantages. The feeling that complementary assessment is needed when starting the actual care by the home care organisation is especially recognised by home care organisations $(61 \%, \mathrm{n}=54)$, and interestingly, by almost $25 \%$ of the assessment agencies $(\mathrm{n}=18)$.

Table 4.5 Disadvantages of new-style needs assessment as judged by assessment agencies $(\mathrm{n}=78)$, home care organisations $(\mathrm{n}=92)$ and health insurers $(\mathrm{n}=23)(\text { in } \%)^{*}$

\begin{tabular}{lccc}
\hline Disadvantage & $\begin{array}{c}\text { Assessment } \\
\text { agency }\end{array}$ & $\begin{array}{c}\text { Home care } \\
\text { organisation }\end{array}$ & $\begin{array}{c}\text { Health } \\
\text { insurer }\end{array}$ \\
\hline Introductory problems & 58 & 66 & 78 \\
More bureaucracy & 22 & 92 & 61 \\
Extra link in patient's route & 28 & 72 & 30 \\
Complementary assessment needed & 24 & 61 & $* *$
\end{tabular}

* Multiple responses allowed

**Not asked 


\section{Usability of assessment reports}

It has already been reported that not all assessment agencies and authorised home care organisations make use of the national recommended assessment forms as an instrument for obtaining an objective needs assessment. Out of those that do $(n=67$ and $n=11$, respectively), $52 \%(n=35)$ and $73 \%(n=8)$ of the assessment agencies and authorised home care organisations evaluate them positively. Nevertheless, $48 \%$ and $27 \%$, respectively, of both types of assessing organisations find the national recommended assessment forms impractical for different reasons. The forms not being orderly, too extensive or open to multiple interpretations are some of the criticisms.

On average, the practicability of the assessment agencies' reports is evaluated by home care organisations as mediocre. While most assessment agencies $(87 \%, \mathrm{n}=68)$ think that they are producing usable (i.e. not too global) assessment reports, only $16 \%(n=14)$ of the home care organisations who have to work with these reports seem to agree. Furthermore, $13 \%(\mathrm{n}=11)$ of them regard the assessment agency's report as useless. Only about $20 \%(\mathrm{n}=19)$ of all responding home care organisations judge complementary assessment, generally, to be redundant. The others think that the assessment report is not practicable and/or that the period between the assessment and the actual care provision is too long, so that the home care needs may have changed in the meantime. Table 4.6 shows that the boundary conditions described in assessment reports, such as the validity limit of the assessment report, the margins and the indicated urgency, are found by home care organisations to be moderately to highly practicable, though.

Table 4.6 Home care organisations' evaluation of the usability of assessment agencies' reports $(\mathrm{n}=92)$

\begin{tabular}{lccc}
\hline Characteristic & High & $\begin{array}{c}\text { Evaluation (\%) } \\
\text { Moderate }\end{array}$ & Low \\
\hline $\begin{array}{l}\text { Practicability of the validity limit of the } \\
\text { assessment report }\end{array}$ & 40 & 47 & 14 \\
$\begin{array}{l}\text { Practicability of margins within the } \\
\text { assessment report }\end{array}$ & 53 & 32 & 15 \\
$\begin{array}{l}\text { Practicability of indicated urgency in the } \\
\text { assessment report }\end{array}$ & 35 & 42 & 24 \\
\hline
\end{tabular}


Characteristics of influence on home care organisations' judgements of new style of needs assessment

By computing Pearson's correlations between the characteristics of assessment agencies and the judgement scale for home care organisations, five significant independent variables have been identified (the direction of their correlation to a more positive evaluation is shown in brackets). The first four significant variables are: 'length of operational period of assessment agency' (longer); 'number of assessors (FTE)' (larger); 'number of assessment fields (magnitude of the assessment agency's domain)' (larger); and 'electronic exchangeability of assessment data between assessment agency and home care organisation' (possible). The fifth significant variable is 'presence of hardware/software problems in assessment agencies' (absent), but because of colinearity with other significant variables, this variable has been excluded from further analysis. Table 4.7 shows the computed correlations.

Table 4.7 Correlations between assessment agencies' characteristics and judgements by home care organisations and results of regression analysis $(\mathrm{n}=40)$

\begin{tabular}{|c|c|c|c|c|c|}
\hline \multirow[b]{2}{*}{$\begin{array}{l}\text { Assessment } \\
\text { agency's } \\
\text { characteristic }\end{array}$} & \multicolumn{2}{|c|}{$\begin{array}{l}\text { Correlation with } \\
\text { home care } \\
\text { organisation's score } \\
\text { on judgement scale }\end{array}$} & \multicolumn{3}{|c|}{$\begin{array}{c}\text { Regression } \\
\text { model }\end{array}$} \\
\hline & $\begin{array}{l}\text { Pearson's } \\
R\end{array}$ & $\begin{array}{l}P \text { - } \\
\text { value }\end{array}$ & $\begin{array}{l}\text { Unstandardised } \\
\text { coefficient }\end{array}$ & $\begin{array}{l}\text { Standardised } \\
\text { coefficient }\end{array}$ & $\begin{array}{l}P \text { - } \\
\text { value }\end{array}$ \\
\hline & & & Constant $=0.846$ & --- & 0.244 \\
\hline $\begin{array}{l}\text { Length of } \\
\text { operational } \\
\text { period } \\
\text { Number of }\end{array}$ & -0.311 & 0.026 & -0.06105 & -0.078 & 0.64 \\
\hline $\begin{array}{l}\text { assessors (FTE) } \\
\text { Number of }\end{array}$ & 0.291 & 0.036 & 0.009525 & 0.183 & 0.26 \\
\hline $\begin{array}{l}\text { assessment fields } \\
\text { Electronic } \\
\text { exchangeability } \\
\text { of data }\end{array}$ & 0.399 & 0.012 & 0.418 & 0.434 & 0.098 \\
\hline
\end{tabular}

Subsequently, the remaining four significant variables have been entered in a regression analysis (method Enter). The regression model built on the four independent variables proved to be significant $(P=0.012)$; the 
percentage of variance explained was $37.9 \%$. Out of the individual composing variables in the regression model, only the magnitude of the domain of the assessment agencies turned out to be significant $(P=0.011)$, i.e. in general, the more assessment fields an assessment agency integrates in assessing patients' care needs, the more positive the home care organisations' judgement of the assessment agency.

The comparable regression model built on the characteristics data of home care organisations has yielded no significant variables of home care organisations which can be related to their scores on the judgement scale.

\section{Discussion}

The present study suggests that, by and large, the new-style needs assessment is organised in accordance with what is regulated by law (the Care Needs Assessment Decree; Ministerie van Volksgezondheid, Welzijn \& Sport, 1997), and that all structures to attain the three main objectives of the new-style needs assessment - independent, comprehensive and objective needs assessment - seem to be present. However, the organisations involved hold different opinions about the new-style needs assessment and its practical consequences.

The first objective of the Care Needs Assessment Decree, independent needs assessment, seems to have been attained. By establishing over 80 regional assessment agencies, the assessment of home care needs is no longer an activity undertaken by care providers. This facilitates a needs assessment that is independent from the supply available and from the interests of care providers. However, with respect to noncomplex home care needs, the Care Needs Assessment Decree allowed for assessment agencies to give an authorisation to home care organisations to perform the assessment of this kind of need. The data show that about onequarter of the home care organisations are assessing noncomplex care needs, which is possibly threatening the independence of the assessment.

The second goal to be attained by the Care Needs Assessment Decree, the comprehensive needs assessment, also seems to be realised. Assessment agencies are carrying out needs assessments leading to home care, admission to a nursing home or a home for the elderly, or to 
individual care budgets. After the data collection was completed, the obligatory domain of assessment agencies was expanded and will continue to expand. Furthermore, there are a wide variety of optional assessment fields which may enhance comprehensive needs assessment. However, it is still unknown whether assessments actually have become more comprehensive.

By recommending the use of national assessment forms, the Care Needs Assessment Decree (Ministerie van Volksgezondheid, Welzijn \& Sport, 1997) promoted its third goal, i.e. the objectivity of the needs assessment. From this study, the present authors conclude that the complete or partial use of these forms appears to be reasonably widespread amongst assessment agencies as well as, though less so, amongst authorised home care organisations. The fact that assessment software is based on the national assessment protocol, but does not cover it completely, probably accounts for the relatively high score $(41 \%)$ on the partial use of these forms. About half of the authorised home care organisations were not using the recommended assessment forms, but this does not necessarily imply that they would not assess objectively. They just do not use a certain tool with which objectivity may be achieved.

In addition, the results show that a substantial proportion of the assessment agencies which do use the national recommended assessment forms find them impracticable. Moreover, only a minority of the home care organisations consider the product of assessment agencies, i.e. the assessment report, to be usable. A large majority of home care organisations (as well as about $25 \%$ of the assessment agencies themselves) feel complementary assessment is necessary when starting the delivery of care. Whether or not this is a negative evaluation of the assessment agency's work depends on the validity of the expectancy of the home care organisations. In other words, although the Care Needs Assessment Decree prescribes some specific elements of the assessment reports, it is not predetermined that the assessment report should be usable as a detailed care plan. However, it should be noted that home care organisations' respondents (i.e. managers and staff members) may not be in the best position to judge the practical usability of assessment forms nor the resulting reports because they are usually 
not the people working with these materials in practice. On the other hand, criticism of home helps or nurses about the usability of the assessment reports will reach their superiors.

As stated earlier, the independence of the needs assessment may be threatened by authorisation arrangements, since assessment and care provision then come together in one organisation, as before (Dijkstra, 2001; Algera et al., 2002). In addition, giving an authorisation may threaten the comprehensive needs assessment because assessors of home care organisations will not have the necessary skills to comprehensively assess needs.

Conditions for independent or comprehensive needs assessment will be hampered by authorisation arrangements. However, bureaucracy in assessing needs, a problem well recognised by home care organisations and health insurers, may be reduced because the care chain can be shortened for noncomplex home care needs.

The result of the assessment is not so much dependent on the patient's physical or psychological condition, but instead, focuses more on aspects such as living circumstances, which are hard to objectify (Dijkstra, 2001). Furthermore, Jörg (2002) found that how the assessor and the patient get along with each other to be an influential factor on the eventual assessment. As a consequence, the inter-rater reliability among assessors is questionable (Schrijvers, 2001; Jörg, 2002). Therefore, equality in handling comparable care demands is not brought about structurally. Moreover, in many cases, the assessment reports do not contain all elements required by the Care Needs Assessment Decree, leaving the care provider to fill in the gaps as considered convenient.

The evaluation by organisations dealing with the new-style needs assessment has given additional insight into the functioning of the assessment agencies. There is a hierarchy in judgements: the assessment agencies are more positive about the new-style needs assessment than the health insurers, who, in turn, appear to be less negative than home care organisations. Assessment agencies consider the new-style needs assessment to be more independent, more objective and more comprehensive than the 'old-style' assessment, i.e. care providers 
assessing patients' needs themselves. Furthermore, they hold the opinion that, in comparison with the former way of assessing home care needs, the new style of needs assessment yields a better correspondence between home care needs and assessment. The transparency, the accessibility and the efficiency all have improved according to assessment agencies, although the percentages of respondents agreeing nor disagreeing are noteworthy with regard to the two latter aspects.

The attitudes of assessment agencies and home care organisations may not be very surprising. Because assessment agencies have interests in evaluating their own work and reason for existence positively, and home care organisations probably have interests in trying to regain the authority of needs assessment, this may have strongly affected their responses. Of course, it may be possible that the realisation is as adequate as assessment agencies claim it to be or has as many shortcomings as home care organisations evaluate it to have. Possibly because of their strategically more neutral position, the opinions of the health insurers may be considered as closer to the actual functioning of the new-style needs assessment. If that is the case, it may be concluded that the assessment has become more independent and comprehensive, while the increase of objectivity is questionable. Furthermore, the assessment procedures have become more transparent, while they did not gain in efficiency or accessibility, according to health insurers.

Some negative opinions of assessment agencies, home care organisations and health insurers may stem from the tumultuous environment in which these organisations have to maintain themselves. They all have to constantly cope with new regulations, which impedes consolidation (Bakker, 2001; Schrijvers, 2001). In addition, it may be concluded that the home care organisations' criticism has barely changed over time, although the assessment agencies have increasingly matured in the meantime (Schrijvers, 2001). In 1999, the same objections of home care organisations to the new-style needs assessment were observed (Bureau voor Toegepaste Economische en Ruimtelijke Planning BV, 1999).

The result that the home care organisations' positive judgements may be correlated to the assessment agency's larger domain is remarkable. It is 
not easily explained why the home care organisations' attitude would become more positive if the assessment agency also assesses for other types of care not or only remotely related to home care. In addition, it was found that no characteristics of home care organisations themselves could be related to their opinion about the new-style needs assessment. Therefore, it may be concluded that, for policy makers, there are no specific attention areas located in either assessment agencies or home care organisations to improve the latters' judgements about the new procedures concerning the assessment for home care.

In the present paper, only evaluations of relevant organisations were included. Patients' perspectives on the new-style needs assessment were part of the research project as well, but results will be reported elsewhere.

The overall conclusion is that, in principle, the way the new style of needs assessment has been constructed in the Netherlands is conditionally adequate for independent, comprehensive and objective needs assessment in home care. This is more than can be observed regarding the needs-led assessment in Great-Britain (Parry-Jones \& Soulsby, 2001). However, in the Netherlands, the practical realisation of the new structures still needs to be refined. This will possibly improve the quality of the product of assessment agencies and smooth the route patients have to travel from presenting their care demand to receiving the allocated care.

\section{Acknowledgement}

This research project was funded by NWO-ZOB (Netherlands Organisation of Scientific Research, Research Programme on Care and Social Support for Chronically Ill Patients), the Netherlands. 


\section{References}

Algera M, Francke AL \& Van der Zee J (2002). Zorg-indicatiestelling 'nieuwe stijl' binnen de zorgketen: een literatuurstudie naar de haalbaarheid van de doelstellingen van de indicatiestelling 'nieuwe stijl' en de realisering van de zorgketen. ['Newstyle' needs assessment in the care chain; a study of the literature on the feasibility of the objectives of the 'new-style' needs assessment and realising the care chain.] Verpleegkunde, Nederlands-Vlaams Wetenschappelijk Tijdschrift voor verpleegkundigen; 17 (3): 140-151.

Bakker PF (2001). Periodieke inventarisatie indicatie-organen; stand van zaken augustus 2001 [Periodic inventory assessment agencies; the state of affairs in August 2001]. Enschede: Hoeksma, Homans \& Menting.

Bureau voor Toegepaste Economische en Ruimtelijke Planning BV (1999). Uitwerking enquête Landelijke Vereniging voor Thuiszorg: naar de effecten van de overheveling van de indicatiestelling. [Results survey National Association for Homecare; on the effects of the transfer of the needs assessment.] Amersfoort: Terp.

Dijkstra GJ (2001). De indicatiestelling voor verzorgingshuizen en verpleeghuizen. [Needs assessment for homes for the elderly and nursing homes.] Groningen: Noordelijk Centrum voor Gezondheidsvraagstukken (thesis).

Hutten JBF \& Kerkstra A (1996). Home care in Europe: a country-specific guide to its organization and financing. Aldershot: Ashgate Publishing Company.

Jörg F (2002). Objectivity in individual needs assessment for access to long-term care. Utrecht: University Utrecht (thesis).

Ministerie van Volksgezondheid, Welzijn \& Sport (1997). Zorgindicatiebesluit (Besluit van 2 oktober 1997, houdende regels met betrekking tot het werkterrein, de samenstelling en werkwijze van indicatie-organen). [Care Needs Assessment Decree (White Paper of October, 2 1997, regarding field of activities, the formation, and the operation of Regional Needs Assessment Agencies).] Staatsblad van het Koninkrijk der Nederlanden. Den Haag: Sdu, 447.

Nationale Raad voor de Volksgezondheid (1994). Indicatiestelling en zorg op maat: advies van de Nationale Raad voor de Volksgezondheid en het College voor Ziekenhuisvoorzieningen. [Needs assessment and customised care: recommendations by the National Council for Public Health and the Council for Hospital Facilities.] Zoetermeer: Nationale Raad voor de Volksgezondheid.

Parry-Jones B \& Soulsby J (2001). Needs-led assessment: the challenges and the reality. Health \& Social Care in the Community; 9 (6): 414-428. 
Schrijvers AJP (2001). RIO, het jongste kind groeit op; eindrapport van de evaluatie van het Zorgindicatiebesluit van 1998. [The assessment agency, the youngest child grows to maturity; final report on the evaluation of the Care Needs Assessment Decree of 1998.] Utrecht: Julius Centrum voor Huisartsgeneeskunde en Patiëntgebonden onderzoek.

Tweede Kamer der Staten-Generaal (1998-1999). Nota Zicht op Zorg: plan van aanpak modernisering AWBZ. [White Paper Vision on Care: planning the modernisation of the Exceptional Medical Expenses Act.] Kamerstukken 26.631 nr. 1. Den Haag: Staatsuitgeverij. 
The match between Dutch chronic patients' felt need and demand for home care and subsequent needs assessment

Algera M, Francke AL, Spreeuwenberg P, Kerkstra A \& Van der Zee J, Submitted 


\begin{abstract}
This paper provides insight into the match between Dutch chronic patients' felt need for care and their demand for home care on the one hand and the needed care as indicated by an assessment agency on the other. Factors influencing this match (characteristics of patients and assessment agencies) have also been studied. Data was collected by telephone survey from more than 400 chronic patients whose needs were assessed by an assessment agency. The background characteristics of assessment agencies were gathered by questionnaire. In addition, assessment reports were examined to gain insight into the home care needed according to the assessment agency.
\end{abstract}

Almost all patients appeared to be satisfied with the outcome of the needs assessment. However, in reality, the match between the patient's felt need for care and the care indicated by the agency is comparatively limited: a perfect match was recorded in about one-third of the cases. Additional analyses showed that the match between felt need and demand for home care was also imperfect. The match between the patient's demand for home care and the care indicated is much better. It is argued that the patient's demand for care is interpreted by needs assessors in terms of possible needed care, in which case the result of the needs assessment is already fixed at the time the patient presents a request to the agency. The importance of patient education in presenting a demand for home care is stressed.

Patient characteristics associated with the matches occurring were: younger age, not receiving professional home care already and patients themselves presenting their demand for home care at the assessment agency's office. Assessment agencies performing assessments of non-complex needs themselves and not authorising them to home care organisations and those using the national standardised assessment forms seem to yield a poorer match between felt need for care and care indicated.

Keywords: needs assessment, chronically ill, home care, the Netherlands

\title{
Introduction
}

Before 1998, Dutch home care organisations carried out the needs assessment themselves. However, the 'old style' needs assessment had been strongly criticised by representatives of Dutch patient organisations. In particular, the chronically sick and physically disabled and their 
representatives, claimed that they felt they were at a disadvantage when care providers assessed their home care needs. In the view of the critics, this often led to needs assessment being mainly determined by supply availability; consequently, the patient might receive either less care or not the specific care required. Further, it was argued that needs assessment procedures were not objective; procedures varied strongly from one home care organisation to another. The Dutch Council for the Disabled (Gehandicaptenraad) was among those calling for independent regional assessment agencies, that would not resort under the responsibility of home care organisations. This would ensure that the patient's felt need for care was paramount in the assessment of needs, and that such a need would no longer simply be determined by the possibilities or limitations of the home care organisations (Algera et al., 2002).

As a result of the criticism of the needs assessment procedure and the ensuing reports, a new-style needs assessment for both home care, and longterm residential care, was introduced in the Netherlands in 1998 (Schrijvers, 2001; Algera et al., 2002; Jörg, 2002). The 'new-style' needs assessment was regulated in law by the Care Needs Assessment Decree (Ministerie van Volksgezondheid, Welzijn \& Sport, 1997); see Box 5.1.

Box 5.1 New-style needs assessment according to the Care Needs Assessment Decree (Ministerie van Volksgezondheid, Welzijn \& Sport, 1997)

Organisation of new-style needs assessment

- establishment of independent regional assessment agencies ('Regionale IndicatieOrganen': RIO's) resorting under the responsibility of municipalities, covering the whole country;

- $\quad$ assessment of chronic and other patients' needs for various types of care: home care and long-term residential care (obligatory) and social welfare (optional);

- $\quad$ assessment of complex needs for care: only by assessment agencies; assessment of non-complex needs for care (e.g. administering eye drops or putting on support stockings): authorisation arrangements to home care organisation are allowed.

Three objectives of new-style needs assessment

- more independence than in the former way of needs assessment by assessing independently from the availability of care;

- more objectivity: to be reached by using uniform assessment protocols;

- comprehensiveness, to be obtained by taking into account various types of care; for instance, when a patient needs home care as well as a type of (semi-)residential care, the assessor integrates both types of care needs in the assessment procedure and assessment report. 
When the patient (or relatives/informal caregivers) is aware of a need for care, a demand for care may be formulated and presented to the assessment agency's office. The role of the assessor is to determine the patient's needs on an independent, objective, and integrated basis.

In an ideal situation, there would be a perfect match between the patient's felt care needs and the care indicated by the assessor and the home care eventually delivered. This paper looks at the first set of matching pairs in Figure 5.1, i.e. the match between chronic patient's felt need for care, the patient's demand for home care, and the care indicated by assessment agencies. In addition, we will study the influence of characteristics of chronically ill and of assessment agencies on this match.

'Need for care' means patient-felt need, arising from health-related deficits (cf Bradshaw, 1972). Patient's demand for home care may be defined as patient's expression of their felt need for care (Bradshaw's 'expressed need' (Bradshaw, 1972)), in this case expressed to an assessment agency. The 'care indicated' by an assessment agency is the result of a formalised process of determining the need for care and subsequently indicating the reasonable and adequate care with regard to the type and amount of care (Nationale Raad voor de Volksgezondheid, 1994). This parallels Bradshaw's 'normative or evaluated need' (Bradshaw, 1972).

In the Netherlands, professional home care includes IADL-care (i.e.: Instrumental Activities of Daily Life; also called domestic care or home help), ADL-care (i.e.: Activities of Daily Life; also called physical or personal care), technical nursing care, and psychosocial care, delivered by professionals at the patient's home (Hutten \& Kerkstra, 2002).

\section{Research questions}

To judge the new assessment procedures on its merits, and improve them if necessary, it is relevant to study whether the care indicated parallels the patients' felt need and demand for care. Although the patient's needs and demands should be the point of departure within the new-style needs assessment, no research has been reported yet on the match just mentioned. 
Figure 5.1 Research model: the matches between patient's felt need, care indicated, and home care delivered, and factors possibly influencing these matches

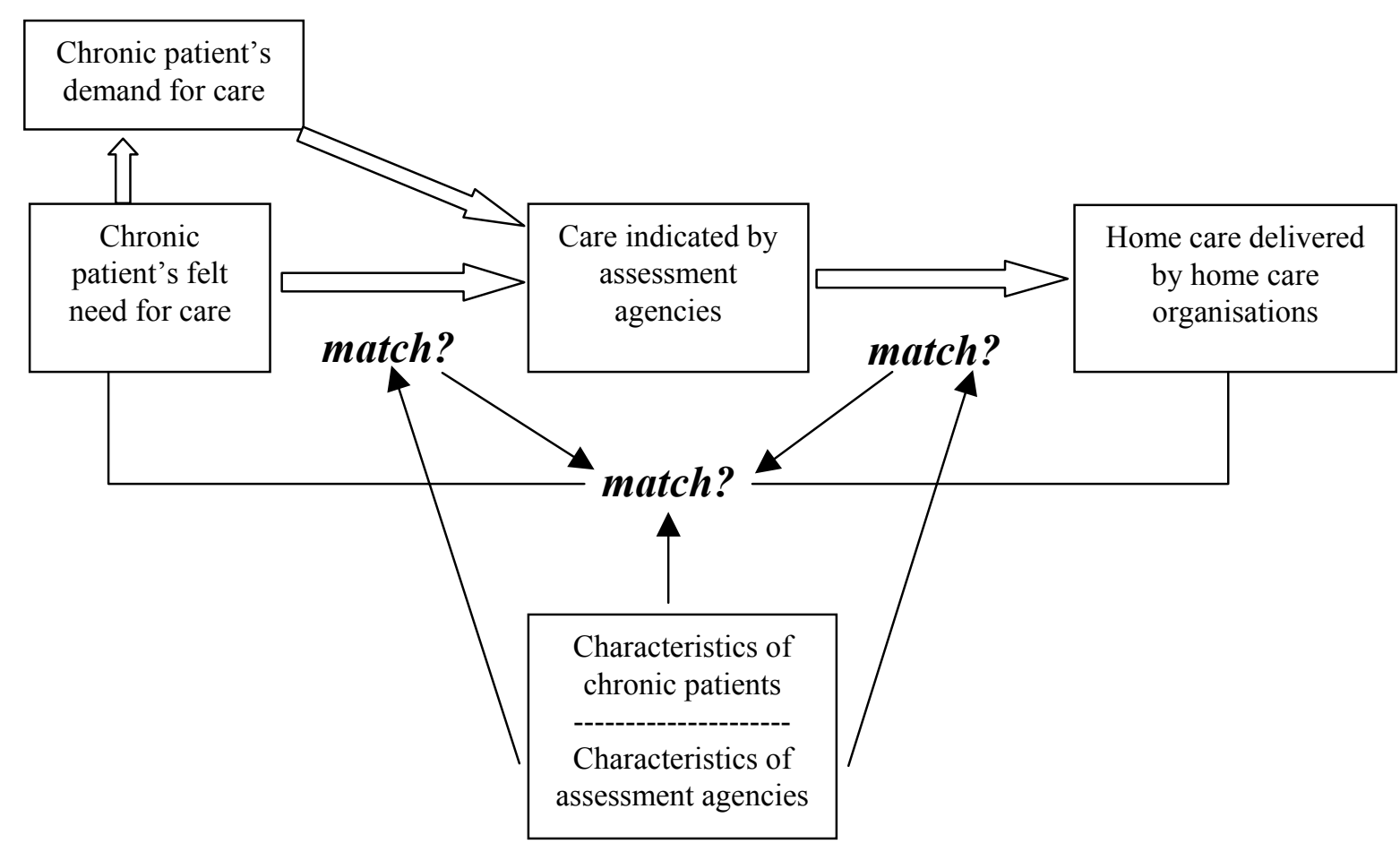


Accordingly, we address ourselves to the following research question:

1. To what extent does chronic patients' felt need for care match the care indicated by the assessment agency?

This first question encompasses the patient's opinion of the match as well as the actual match.

Since the match mentioned in research question 1 may be influenced by a (mis)match between the patient's felt need and demand for care or between the patient's demand for care and the care indicated, additional research questions were formulated:

2. To what extent does chronic patients' felt need for care match their demand for home care?

3. To what extent does chronic patients' demand for home care match the care indicated by the assessment agency?

In addition, insight into chronic patients' and assessment agencies' characteristics relating to better matches would be valuable; we therefore posed the next question:

4. What patient or assessment agencies' characteristics are related to the match between chronic patients' felt need, their demand for home care, and care indicated by the assessment agency?

\section{Expectations}

No literature could be identified considering characteristics influencing the match between felt care need and care indicated. A few studies on the match between felt need for care and home care delivered were found, but the results were contradictory (Algera et al., 2004). Assuming that factors influencing home care utilisation may, in part, be the same as those influencing the matches under study, the present authors were able to formulate some expectations. Patient-related characteristics may be classified as predisposing characteristics, enabling resources, and need factors (Andersen, 1995). Significant positive influence on the matches under study was expected from predisposing patient characteristics like younger age. Younger patients were supposed to be more critical as regards satisfying their reimbursable needs. One of the enabling resources is patients presenting the demand for care themselves to an assessment agency, assuming that the patients may better describe their felt needs than may 'significant others'. Further, it was hypothesised that patients suffering from 
comorbidity (need factor) would have a poorer match because of their usually more complex needs possibly leading to complex care indicated.

On the basis of a previous study (Algera et al., 2003), it was hypothesised that authorising assessments of non-complex home care needs to home care organisations would result in a poorer match between the patient's felt care need and the care indicated because of loss of needs assessment independence.

\section{Method}

Sample

Of 85 assessment agencies, 78 had participated in an previous part of the study (Algera et al., 2003). These assessment agencies were asked to make a random selection of chronically ill patients, who had presented a demand for home care at the assessment agency's office; of them, 49 were willing to cooperate in the current part of the study. Lack of time and staff or deficient data registration systems caused the other 29 assessment agencies to refrain from further participation. A t-test was performed to discover systematic differences between participating and non-participating assessment agencies; they were not found.

The patients selected had to meet the following inclusion criteria:

- they had suffered from a stroke, another chronic neurological disorder, chronic heart failure, diabetes mellitus, rheumatoid arthritis, and/or chronic disorders of the respiratory system;

- they were over 18 years of age;

- they were able to participate in a Dutch-language telephone interview;

- they had submitted an application for professional home care to the assessment agency;

- they were in receipt of a positive or negative decision on care allocation following needs assessment, noted in an assessment report; being on a waiting list was no exclusion criterion;

- they were in receipt of an assessment report made in the previous three months.

Not all assessment agencies were able to select patients by chronic disease criteria. A pilot among three assessment agencies showed that, on average, every third randomly selected patient met the disease criterion. In addition, 
in other research in the Netherlands (Van Campen et al., 1997; CarisVerhallen \& Kerkstra, 1998), the response rate among home care users, responding to a questionnaire, was approximately $30 \%$. It was calculated that about 4000 selected patients would suffice to be able to analyse data from 400 patients in the end. The number of 400 cases was based on poweranalyses. Actually, 3814 patients were selected, eventually yielding 402 patient data sets in the end.

Table 5.1 Characteristics of respondents $(n=402)$

\begin{tabular}{llc}
\hline Disease & Stroke & $16.4 \%$ \\
& Other neurological illness & $21.6 \%$ \\
& Chronic heart failure & $27.9 \%$ \\
& Diabetes mellitus & $15.9 \%$ \\
& Rheumatic disease & $39.1 \%$ \\
& Chronic respiratory disorder & $20.1 \%$ \\
& Other chronic disease & $19.9 \%$ \\
& Other non-chronic disease & $14.4 \%$ \\
& Comorbidity present & $54.5 \%$ \\
& & \\
Living arrangements & Alone & $43.0 \%$ \\
& With spouse & $52.0 \%$ \\
& With children/parents & $9.7 \%$ \\
& With fellow residents & $1.7 \%$ \\
& Temporarily admitted & $0.5 \%$ \\
& & \\
Highest education & Lower education & $46.5 \%$ \\
& Primary school & $31.8 \%$ \\
& Lower vocational & $14.7 \%$ \\
& Higher education & $48.3 \%$ \\
Secondary school & $22.4 \%$ \\
& Medium vocational & $15.7 \%$ \\
Higher vocational / university & $10.2 \%$ \\
& Missing & $5.2 \%$ \\
\hline
\end{tabular}

By way of the assessment agencies, an explanatory letter from the researcher, a consent form and a stamp-addressed envelope were sent to patients whose needs had been assessed. Of the 3814 patients selected by the assessment agencies, 1611 (42.2\%) patients returned their consent form. Of this group, 983 refrained from participation, mostly because of age, health, or lack of interest. No additional information on non-responders was available. Therefore, non-response analyses were impossible. Finally, 628 
(39.0\%) patients agreed to participate. Subsequently, 226 of these 628 patients were excluded because they did not meet the inclusion criteria after all. In the end, data sets for 402 of the 628 patients $(64.0 \%)$ were used in the analyses.

\section{Variables and measuring instruments}

Figure 5.2 holds an overview of the variables and the instruments used in this part of the study.

A structured telephone interview scheme was developed to collect data by telephone about patient characteristics and the patient's felt need for care and demand for home care, and their opinion about the match between their felt need for care and the care indicated by the assessment agency. As far as felt need for care was concerned, our interview scheme was based on a valid and reliable questionnaire by Kerkstra et al., (1990). The other items were selfdeveloped (see Figure 5.2).

The content validity of the structured interview scheme was tested in a meeting of experts $(\mathrm{n}=7)$ and in a separate meeting of chronically ill patients $(\mathrm{n}=6)$. The resulting adjusted version was tested among another 20 patients who had dealt with an assessment agency and who met the inclusion criteria. Their comments were integrated into the final version.

The number of patients per assessment agency varied from 2 to 22 (mean: 8.20, SD: 3.94).

Data on characteristics of assessment agencies and on how the assessment procedure was organised was collected by means of a self-developed questionnaire for assessment agencies, content validated by managers of assessment agencies and other experts.

\section{Data collection}

Patient data was gathered by experienced telephone interviewers from November 2000 through May 2001. On average, the interviews lasted about 20 minutes.

The questionnaire for the assessment agencies was distributed in May 2000 during a previous part of the study. The response among assessment 
agencies was $92 \%$. Main characteristics of assessment agencies were updated by means of a quick scan at the time the assessment agency started to select patients for the telephone interview.

Figure 5.2 Variables in relation to instruments used or way of data collection

\begin{tabular}{lllll}
\hline Variables & $\begin{array}{l}\text { Instruments used or way of data } \\
\text { collection }\end{array}$
\end{tabular}

Match between felt need for care and care indicated, as perceived by patients

Actual match between felt need for care and care indicated

Actual match between felt need for care and demand for care

Actual match between demand for care and care indicated

\section{Patient characteristics}

Predisposing characteristics

- age

- $\operatorname{sex}$

- patient's evaluation of house call for needs assessment (expertise of and contact with needs assessor)

Enabling resources

- having had previous experiences with home care

- patients presenting demand for care themselves

- actual match between felt need for care and care indicated
Self-developed item included in telephone interview scheme about patient's opinion

Comparison of need for care (items from Kerkstra et al. (1990) measuring IADL, ADL, technical nursing, and psychosocial needs included in telephone interview scheme) with care indicated according to assessment agencies' records (assessment reports)

Comparison of need for care with demand for care as included in telephone interview scheme and as noted in assessment reports Comparison of demand for care as included in telephone interview scheme and as noted in assessment report with care indicated according to assessment reports

Self-developed items included in telephone interview scheme

Self-developed item included in telephone interview scheme

Self-developed items included in telephone interview scheme

Algera et al. (this paper on match between felt need for care and care indicated) 
Figure 5.2 Continued I

\begin{tabular}{ll}
\hline Variables & $\begin{array}{l}\text { Instruments used or way of data } \\
\text { collection }\end{array}$ \\
\hline $\begin{array}{l}\text { Need factors } \\
\text { presence of comorbidity }\end{array}$ & $\begin{array}{l}\text { Self-developed item included in telephone } \\
\text { interview scheme }\end{array}$ \\
being admitted to hospital when \\
presenting demand for home care \\
already receiving professional home \\
care when presenting demand for home \\
care
\end{tabular}

In addition, specific items of the assessment reports of the participating patients were studied to disclose more specific data for determining the match between felt need for care, demand for home care, and care indicated. Of the 49 assessment agencies participating in this part of the study, 47 also joined the study of patients' assessment reports covering 387 patients. Assessment reports on 376 patients were reviewed; the remaining 11 patients did not give consent to study their records. 


\section{Analyses}

Based on the telephone interview and the study of patients' assessment reports, three matches could be calculated, i.e.:

- the match between the felt need for care and the care indicated (research question 1);

- the match between the felt need for care and the demand for home care (research question 2);

- the match between the demand for home care and the care indicated (research question 3).

Because 'demand for home care' was measured in two ways, i.e. during the telephone interview as well as by studying assessment reports (see Figure 5.2), the felt need for care and the care indicated could be linked in two ways to the demand for home care.

The felt need for care, the demand for home care presented at the assessment agency's office as well as the care indicated, were coded in IADL-care, ADL-care, technical nursing care, or psychosocial care as well as combinations of these types of home care.

Information about the patients' opinions on the felt need/care indicated match was derived by calculating frequencies and percentages of the patients' responses on interview items. To determine the actual matches (see above), cross-tabulations were produced. 'Perfect matches' were established when, for instance, type of care needed according to the patient was identical to the needs assessment. Discrepancies were distinguished as 'underindication' when, for instance, a combination of IADL- and ADL-care was needed in the patient's view, but only the need for IADL was recognised by the assessor. Other discrepancies might be that the demand for care was more restrictive than the care indicated ('over-indication'). A mismatch could be observed in cases in which a totally different type of care ('other') or no care at all was indicated (negative decision).

In addition, the relation between characteristics of patients and assessment agencies with the various matches was analysed (research question 4). First, multi-collinearity between the independent variables under study was determined. When a statistically significant correlation of $>0.70$ between two independent variables was detected, one of them was excluded. 
When analysing the factors of influence on the matches under study, here, the dependent variable was 'match' (a combination of 'perfect match' and 'over-indication'/'over-demand') or 'mismatch' (a combination of 'underindication'/'under-demand' and 'mismatch'). To study the relation between the dependent variables and a series of independent variables, logistic regression analysis seemed appropriate. Given the nature of the data there were three methodological aspects to incorporate into the statistical analyses. First, it was expected that nesting of the patients within assessment agencies was present. Secondly, the number of patients per assessment agency in this study varied strongly (see also Section Data collection). Thirdly because the independent variables were measured at two different levels (the patient's and the organisation's), statistical artefacts such as the ecological and atomistic fallacy had to be avoided. To deal with these three aspects adequately in one analysis a multi-level approach to (logistic) regression analysis was used. In literature (Snijders \& Bosker, 1999), a more elaborate discussion of why a multi-level approach for this kind of data is appropriate can be found. The software used was MLWIN. With regard to each match a series of theoretically relevant independent variables concerning the characteristics of patients and assessment agencies were entered into multivariate multi-level analyses simultaneously.

\section{Results}

Patients' opinions regarding the match between felt need for care and care indicated

The patients were asked whether or not they agreed with the care indicated by the assessor. Almost all patients $(87.7 \%)$ approved of the care indicated. A minority of the patients (12.3\%) disagreed, though, generally as regards the total number of hours of home care indicated for the patient's needs. In general, the type of home care as specified by the assessor was not subject to the patient's disagreement.

\section{Match between felt need for care and care indicated}

Next to the patient's subjective evaluation, felt need for care, as mentioned during the telephone interview and the care needed as determined by assessors, were compared. Overall, in $30.7 \%$ of the cases in which comparison was possible $(n=361)$, a perfect match between felt need for care and care indicated was observed. In some cases the care indicated exceeded the need for care uttered by the patients themselves (1.4\%). A much larger 
discrepancy existed in the other direction: in $57.3 \%$ of the cases fewer types of care were indicated by the assessor than needed in the patient's view. In approximately $10 \%$ of the cases, a completely different type of care was indicated or no care was indicated at all (see Table 5.2).

In addition, the felt need for care/care indicated match was analysed for specific types of home care (see Table 5.2). If the felt need for care exclusively concerned IADL-care $(\mathrm{n}=111)$, the need for care was assessed accordingly in most of the cases $(80.2 \%)$; with regard to this type of home care, the match under investigation is the best. If the patients reported needs in the field of IADL-care combined with ADL-care $(n=57)$, then in most cases $(73.7 \%)$ only one of those needs, generally the need for IADL-care, was recognised by the assessor. By and large, the same goes for felt needs for IADL-care combined with psychosocial care, and in cases in which the patient's felt need for IADL-care was combined with both ADL- and psychosocial care (see Table 5.2). In most of those cases, needs for care other than IADL were omitted by the assessor.

\section{Match between felt need for care and demand for home care}

Analogously to Table 5.2, the match between felt need for care and demand for home care was computed. During the telephone interview, the patients were asked what type of home care they had asked for at the assessment agency. As the demand for care was also noted in patient's assessment report, two interpretations of demand for care were available for comparison with the felt need.

As regards the felt need for care and the expressed demand for home care, both measured during the telephone interview, the overall perfect match in this respect was $34.6 \%(n=387)$. The match proved to be best for IADLneeds. In only a few cases $(1.3 \%)$, the number of types of care demanded exceeded the number of types of felt need for care. Most frequently, however, the patients could be observed to under-demand (62.3\%), with the implication that not all felt needs for care were expressed as a request for care. Generally, in most of those cases the demand was for IADL-care, whereas the underlying felt needs were more complex, combining IADLneeds with one or more other types of home care. In approximately $2 \%$ of the cases, a completely different type of care was demanded than could be expected on the basis of the patient's felt need for care (see Figure 5.3). 
Table 5.2 Degree of match (in \%) between felt need for care and care indicated by types of care

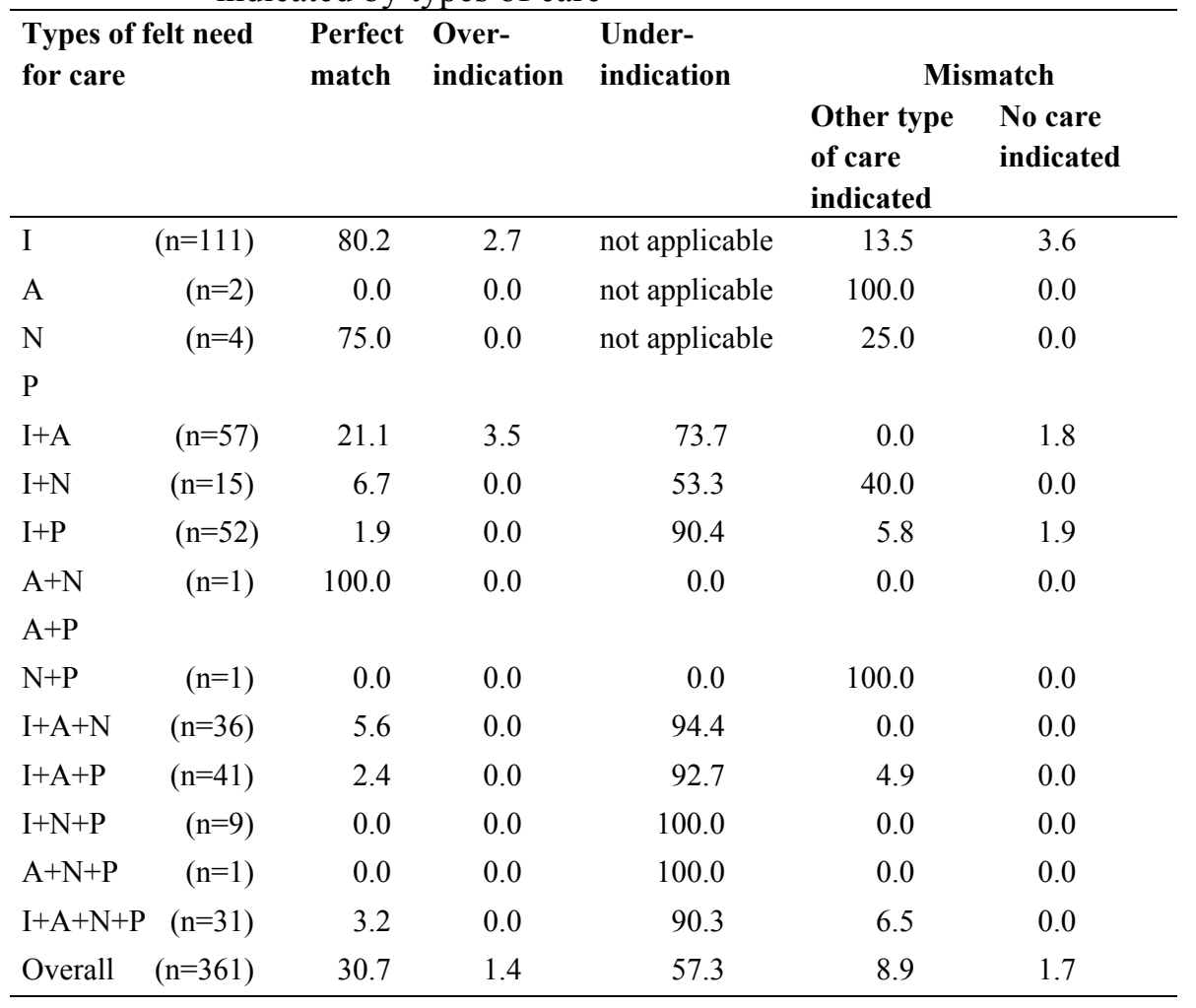

$\mathrm{A}=\mathrm{ADL}$-care, physical personal care

$\mathrm{N}=$ technical nursing care

$\mathrm{P}=$ psycho-social care

$\mathrm{I}=\mathrm{IADL}$-care, domestic care

The overall match $(n=336)$ between the patient's felt need for care, as expressed during the telephone interview, and the demand for home care, as noted in the patient's assessment report, was generally somewhat less perfect than was the match between felt need and demand for care both reported during the telephone interview. The mismatch percentage was the only one found to be much higher $(10.7 \%$ as against $1.8 \%$; see Figure 5.3$)$. In line with matches described before, it was found that in case of felt need for IADL-care in combination with needs for several other types of home care, under-demand could be observed, resulting in a demand for IADL-care alone. However, when, during the telephone interview, the patient mentioned 
a need for IADL-care in combination with a need for technical nursing care, a demand for ADL-care was often noted on the patient's assessment report.

With respect to demand for home care, it was interesting to investigate the extent to which the demand for home care, as indicated by the patient during the telephone interview, revealed an overlap with the demand for home care, as noted in the patient's assessment report. There appeared to be an overlap in $68.5 \%$ of the cases $(n=324$; not in Figure 5.3$)$. In $5.9 \%$ of the cases, the number of types of demanded care as noted in the assessment report was larger than reported by the patient during the telephone interview. Conversely, in almost $10 \%$ of the cases the patient's demand for a specific combination of types of care was only partly noted in the assessment report; this was particularly the case in demands for IADL-care in combination with ADL-care or technical nursing care. In $16 \%$ of the cases, both sources (telephone interview and assessment report) disagreed totally on the type of care requested.

\section{Match between demand for home care and care indicated}

As described in the previous section, the demand for home care was measured in two ways. As a consequence, the match between patient's demand for home care and the care indicated could be computed in two ways.

In two thirds $(66.9 \%)$ of the cases $(n=354)$, the demand for home care as specified by patients themselves during the telephone interview, was identical to the care indicated, as noted in the assessment report. A perfect match was particularly found in the case of the exclusive types of IADLcare; and, to a lesser extent, in ADL-care and technical nursing care. Overindication was seen in $7.6 \%$ of the cases: the care indicated added types of care to the demand for care. Under-indication could be observed in the combinations of IADL-care and ADL-care or technical nursing care, not favouring a specific type of care. The technical nursing care demand, according to the telephone interview, resulted in $38.9 \%$ of the cases in an assessed need for another type of care, mostly ADL-care. In one-sixth $(17.0 \%)$ of the cases, a completely different type of care was indicated or no care was indicated at all (see Figure 5.3). 
Figure 5.3 Degree of overall-matches (in \%)

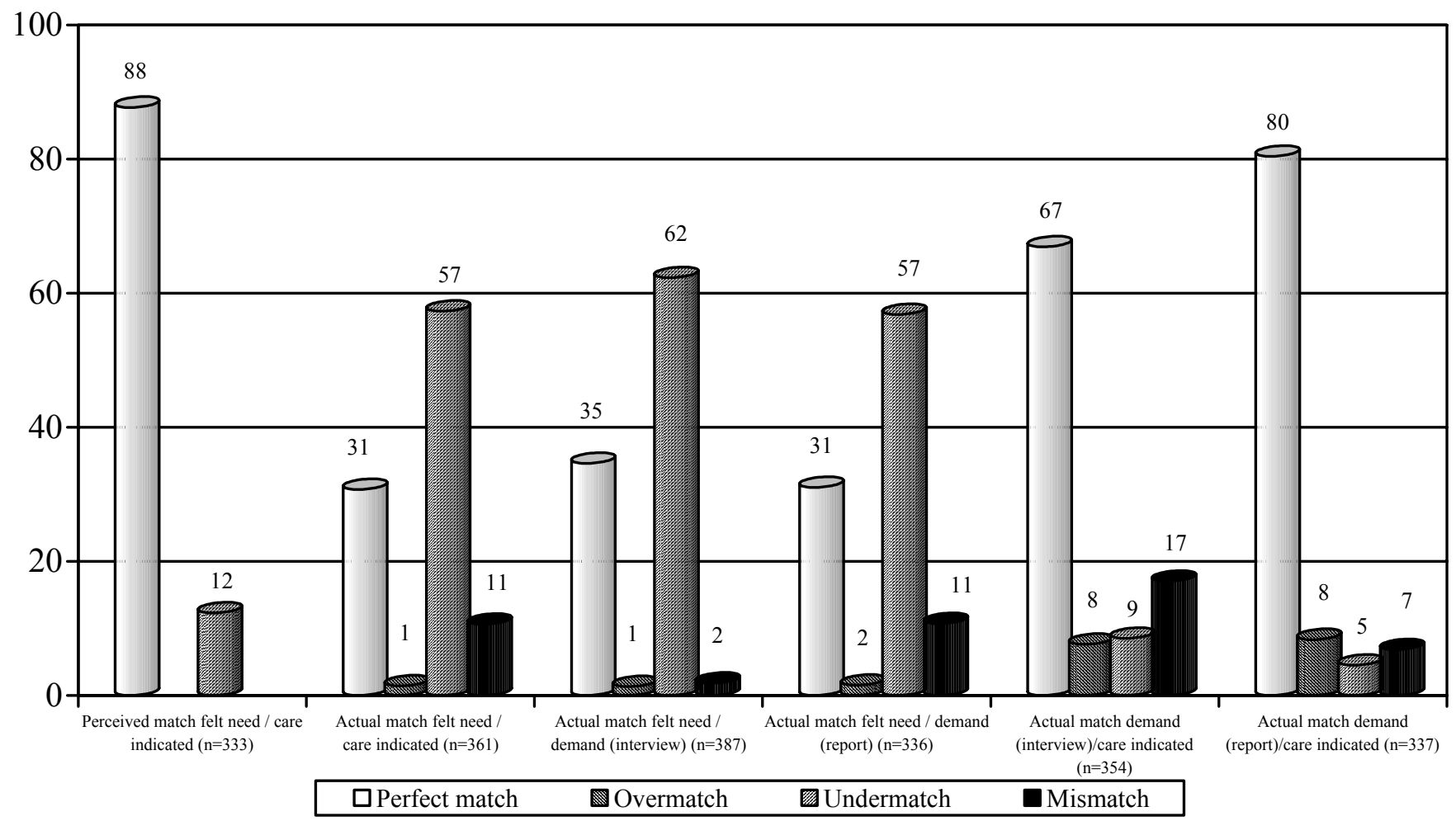


In $80.4 \%$ of the cases $(n=337)$, the demand for home care and the care indicated in the patient's assessment report were identical. Exclusive demands for IADL-care, ADL-care, or technical nursing care were almost always recognised by the assessor. The needs assessment included more types of care in $8.3 \%$ of the cases than the demand for care (over-indication; see Figure 5.3). In addition, under-indication was not frequently seen, relatively being the largest in the case of the demanded combination of IADL- and ADL-care according to the patient's assessment report. Mismatches could be observed in $6.8 \%$ of the cases.

\section{Patient and assessment agencies' characteristics related to matches}

In this study, characteristics of the chronic patients as well as characteristics of the assessment agencies were related to various matches as described before. Relevant characteristics of the patients and assessment agencies, possibly related to these matches, were entered into a multi-variate multilevel analysis (see Section Analyses).

Table 5.3 contains the results of all matches covered in this paper. Younger age (i.e.: being under 65) was a significant predictor of whether the patients believed that the care indicated by the assessor reflected their felt need adequately. If they held a positive opinion on the house call that the needs assessor had paid, the patients perceived a better match as well.

Younger age was also significantly predictive of an actual match between felt need for care and the care indicated. In addition, when the patients themselves applied for care at the assessment agency, or when the patients not already received professional home care, at the time of notifying the assessment agency, there was more frequently an actual match. In cases wherein the care indicated by the needs assessor encompassed more than one type of care (complex), a greater chance occurred that the care indicated would match patient's felt need for care. Finally, two assessment agencies' characteristics proved to be significant related to this match: the presence of authorisation arrangements for assessing non-complex needs for care to home care organisations (positive) and the use of national standardised assessment forms (negative).

Table 5.3 also contains the results of the other matches described. Younger age appeared to be, again, a significant predictor of a better match between 
felt care need and care demand, no matter how the latter was measured (telephone interview or assessment report). In addition, patients presenting their demand for care themselves had a better match between felt need for care and demand for care according to the assessment report.

With regard to the match between the demand for care as expressed during the telephone interview and the care indicated, non-complex felt needs for care were associated with a better match. In addition, patients not already receiving professional or informal home care at the time of notifying the assessment agency had a better chance for getting their demand form care recognised by the needs assessor. This was also the case if patients notified the assessment agency themselves. Finally, if the assessment agency had a larger domain of assessment fields and/or was one of the first to be established (before mid 1998), the match under study was significantly more often an adequate one. With respect to characteristics of patients or assessment agencies, already receiving professional home care at the moment of notifying the assessment agency and an assessment agency's longer period of being in operation appeared to be predictive of demand for care as noted in the assessment report paralleling the care indicated.

\section{Discussion \\ Discussion on match between felt need for care and care indicated}

In this paper, the question was posed as to whether chronic patient's felt need for care paralleled the care indicated by independent regional assessment agencies introduced in the Netherlands at the end of the 1990s. A large majority of the patients felt that it did. However, in view of all types of care the patients may need (IADL-care, ADL-care, technical nursing care, and psychosocial care and their combinations), the actual match appeared to be limited. In only about one-third of the cases did the need for care, as indicated by the assessment agencies, correspond fully with the need for care as felt by the patients. Perfect matches were most often found in the field of IADL-care exclusively (not in combination with other types of home care). In more than half of the cases, the care indicated included fewer types of care than the patients felt they needed. Generally, this related to situations in which the patients felt a need for IADL-care in combination with other types of home care, whereas the needs assessment resulted in IADL-care only. In those cases, the other types of care needed according to the patients themselves were not recognised by the assessors. In about ten percent of the 
cases, a completely different type of care was indicated or no care was indicated at all (negative decision by the assessment agency).

One reason for the care indicated not matching patient's felt needs may be that not all patient's felt needs are translated into demands for home care. Because patient's needs for care can be latent, the patients and needs assessors might disagree on what the patients may need as regards professional home care. Our study showed that in only about one-third of the cases did the felt need match the demand for care. In the literature too (Huijsman, 1990; Kerkstra et al., 1990; SGBO, 2000), it is noted that felt need for care does not always correspond with the demand for care. The patients may experience, for instance, a need for psychosocial care, but are unwilling to seek professional home care to meet this particular need. In other cases, informal care may be a substitute for professional care. Hence, patients seem to filter or prioritise their felt needs for care, before notifying the assessment agency. Therefore, when needs assessment would be strictly needs-led from patient's perspective, under-indication or mismatch might be expected a priori.

The extent to which a match between demand for care and care indicated was present seemed to depend on the person used as reference in formulating the demand for care: the patients themselves or the assessors. This conclusion was confirmed by the observation that an overlap between both sources of formulating patient's request for home care was much smaller than might be expected. In only two-thirds of the cases, the demand for home care in patient's view was identical to the assessor's, whereas, in theory, a $100 \%$ match may be expected. This observation may link to another plausible reason for the moderate felt need/care indicated match. This overall-match may be corrupted by deficient recording in the assessment report of patient's demand for home care. It may be argued that assessors probably unconsciously translate the demand for home care as expressed by the patients into terms amenable to assessment agencies and note this solution-directed interpretation in the assessment report as the actual request for home care by the patient. The assessors subsequently may assess needs and hence indicate the care needed, in terms of their interpretation of the patient's original demand for home care. If that was the case, then the outcome of the assessment is, to a large extent, already determined at the moment patients present their requests for home care 
Table 5.3 Results of multi-variate multi-level analyses on characteristics of patients and assessment agencies predicting actual matches between felt need for care, demand for home care, and care indicated and patients' perceived match

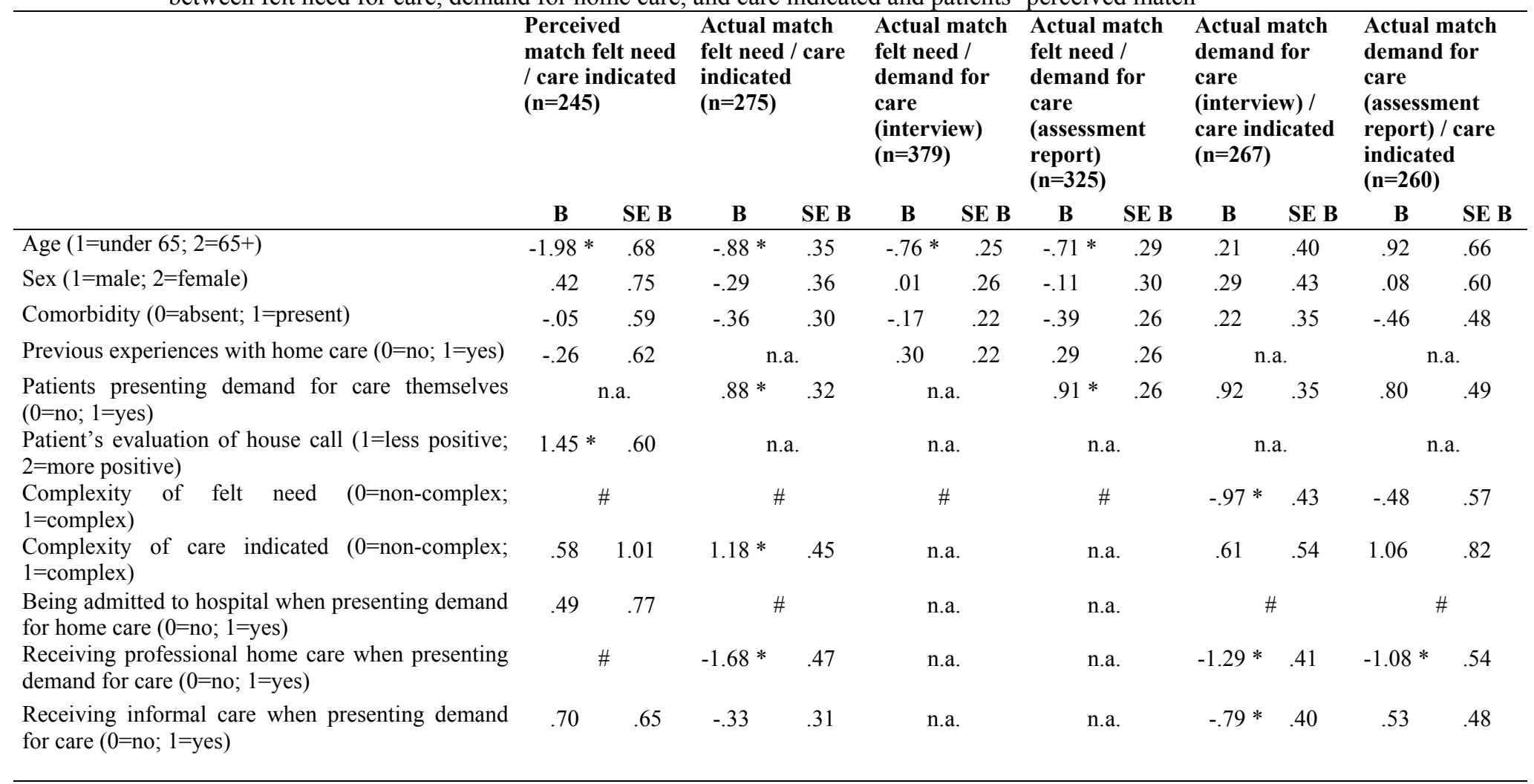


Table 5.3 Continued I

\begin{tabular}{|c|c|c|c|c|c|c|c|c|c|c|c|c|}
\hline & \multicolumn{2}{|c|}{$\begin{array}{l}\text { Perceived } \\
\text { match felt need } \\
\text { / care indicated } \\
(\mathbf{n}=245)\end{array}$} & \multicolumn{2}{|c|}{$\begin{array}{l}\text { Actual match } \\
\text { felt need / care } \\
\text { indicated } \\
(n=275)\end{array}$} & \multicolumn{2}{|c|}{$\begin{array}{l}\text { Actual match } \\
\text { felt need / } \\
\text { demand for } \\
\text { care } \\
\text { (interview) } \\
(n=379)\end{array}$} & \multicolumn{2}{|c|}{$\begin{array}{l}\text { Actual match } \\
\text { felt need / } \\
\text { demand for } \\
\text { care } \\
\text { (assessment } \\
\text { report) }(n=325)\end{array}$} & \multicolumn{2}{|c|}{$\begin{array}{l}\text { Actual match } \\
\text { demand for } \\
\text { care } \\
\text { (interview) / } \\
\text { care } \\
\text { indicated } \\
(n=267)\end{array}$} & \multicolumn{2}{|c|}{$\begin{array}{l}\text { Actual match } \\
\text { demand for } \\
\text { care } \\
\text { (assessment } \\
\text { report) / care } \\
\text { indicated } \\
(\mathrm{n}=260)\end{array}$} \\
\hline & B & SE B & B & SE B & B & SE B & B & SE B & B & SE B & B & SE B \\
\hline $\begin{array}{l}\text { Actual match between felt need for care and care } \\
\text { indicated }(0=\text { mismatch } / \text { partial; } 1=\text { perfect } / \text { more })\end{array}$ & 1.08 & .80 & \multicolumn{2}{|c|}{ n.a. } & \multicolumn{2}{|c|}{ n.a. } & & 1.a. & \multicolumn{2}{|c|}{ n.a. } & \multicolumn{2}{|c|}{ n.a. } \\
\hline Authorisation arrangements $(0=$ absent; $1=$ present $)$ & -.35 & .68 & $.79 *$ & .33 & & & .46 & .30 & -.50 & .40 & .44 & .59 \\
\hline $\begin{array}{l}\text { Use of assessment forms }(0=\text { no; } 1=\text { partial; } \\
2=\text { complete })\end{array}$ & -.43 & .41 & $-.39 *$ & .20 & & & -.14 & .18 & -.03 & .23 & -.56 & .36 \\
\hline $\begin{array}{l}\text { Number of assessment fields ( } 0=\text { less than } 10 \text {; } \\
1=\text { over } 10 \text { ) }\end{array}$ & -.21 & .61 & .33 & .32 & & & & a.a. & $1.63 *$ & .42 & -.04 & .54 \\
\hline Number of years of existence of assessment agency & .20 & .66 & .16 & .33 & & & -.19 & .29 & $-1.81 *$ & .45 & $-1.31 *$ & .67 \\
\hline $\begin{array}{l}\text { Having had to wait before being assessed ( } 0=\text { no; } \\
1=y e s)\end{array}$ & 1.17 & .68 & \multicolumn{2}{|c|}{ n.a. } & \multicolumn{2}{|c|}{ n.a. } & & 1.a. & \multicolumn{2}{|c|}{ n.a. } & \multicolumn{2}{|c|}{ n.a. } \\
\hline Waiting lists IADL-care $(0=$ absent; $1=$ present $)$ & .39 & .81 & -.18 & .48 & & & & 1.a. & -1.09 & .61 & .42 & .73 \\
\hline Waiting lists ADL-care $(0=$ absent; $1=$ present $)$ & .31 & .64 & -.08 & .33 & & & & 1.a. & 0.49 & .41 & .53 & .57 \\
\hline Constant & 3.07 & .43 & -.73 & .15 & -.60 & .11 & -.81 & .14 & 1.85 & .21 & 3.02 & .34 \\
\hline
\end{tabular}

* $\quad \mathrm{p}<.05$

n.a. Not applicable (theoretically not relevant)

\# Not to be included in analysis for statistical reasons (multi-collinearity or small number of observations) 
instead of as aresult of a house call or telephone call by the assessor. If so, the receptiveness of assessors for the real needs of the patients during the assessment procedure may be questioned, and, as a consequence, their independence, objectivity, and comprehensiveness: these being the objectives of the needs assessment 'new-style'. Other recent research (Dijkstra, 2001; Jörg, 2002) has already demonstrated that objectivity in needs assessment is a utopia.

\section{Discussion on characteristics influencing match}

Only a small number of patient characteristics appeared to contribute to the matches under study. As expected beforehand, the patients under the age of 65 had actually more often a match between their felt needs for care and the care indicated. In fact, younger patients also perceived such a match significantly more often. However, younger people's better actual match between felt need for care and care indicated proved not to be part of the explanation for their positive perception. Although, in health care research, satisfaction is often associated with older age (Sixma et al., 1998; CarisVerhallen, 1999), it is argued that younger patients are more assertive in getting what they want, especially considering care delivered at patients' homes. Possibly, younger patients feel stronger about gaining authority and autonomy in their own homes.

In addition, a partial match or a mismatch between felt need and care indicated might occur if the patient was already receiving professional home care at the moment the assessment agency was notified. When patients already receive professional home care, the assessor is likely to 'underindicate' yet unmet needs. This may be the case in reassessments, which usually take place once a year.

Furthermore, patients presenting the request for care themselves proved a significant association with the match under study. Possibly, these patients were better able to translate their felt need for care into a request for care. Another explanation may be, that 'significant others' presenting the request on behalf of the patient, consciously or unconsciously prioritise patient's felt need for care, in that not all needs are expressed to the assessment agency. In the previous section, we suggested that needs assessors may translate the demand for care already into terms of care to be indicated. Therefore, to the patients it would be crucial to make sure that the assessor adequately notices 
their demand for home care. Results point into the direction of younger patients, usually being more assertive and eloquent than older patients, and patients presenting the demand for care themselves to have therefore better matches. Still, assessors should assess patient's needs; the demand for care presented is merely to start the care chain by notifying the assessment agency. This inference implies that the needs assessment resulting in the care indicated should be needs-led rather than demand-driven.

A higher complexity of the care indicated could be significantly associated with a better felt need / care indicated match. Apparently, if the care indicated comprised just one type of care, in many cases IADL-care exclusively, the assessor probably did not recognise other types of care the patients themselves felt a need for. Indeed, in determining the degree of the matches (see Figure 5.3), under-indication occurred in over half of the cases.

At the start of the study, it was hypothesised that assessments of noncomplex needs for home care which were authorised to home care organisations would result in a worse match between felt need for care and care indicated because of a rationing of the home care available. However, authorisation arrangements proved to have a positive influence on the match under study. Since assessments of non-complex home care needs exceed by far those of complex needs, this result is rather invasive. Apparently, home care organisations do a better job in needs assessment and indicating care than do assessment agencies. The finding concerning the complexity of the care indicated positively influencing this match, also points into this direction. However, future research should strengthen our inference that assessment agencies might not be less capable of assessing non-complex needs.

The use of standardised assessment forms turned out to be not very helpful in achieving an adequate match between felt need for care and care indicated by the assessment agency. Although these forms were developed for gaining objectivity, concluding from our data they seem contra-productive. We expected these forms to be used as a checklist during the needs assessment, but in practice they may lead to stricter care indication, for instance by taking the possibilities of informal care more into account. The professional home care indicated to be delivered would be, by definition, less than what is required to meet the patient's felt needs. 
The two building blocks of the match under study are the felt need/demand for care match on the one hand and the patient's demand for care/care indicated match on the other. Because we could not enter both building blocks as independent variables into the analysis of the match between felt need and care indicated, we couldn't make assumptions about to the extent the latter is determined by the formers. However, the felt need / care demand match (irrespective of how care demand was measured) correlated much higher with the felt need / care indicated match than did the care demand / care indicated match. (Pearson: .752 respectively .835 versus .188).

Contrary to our expectations, suffering from multiple diseases simultaneously (comorbidity) was not related to any of the matches under study, neither did sex show significant influence on the matches described. Comorbidity usually is accompanied by more complex needs and probably more complex care indicated. Even though complexity of care indicated was positively associated with a better felt need / care indicated match, comorbidity still did not seem to be of importance in this respect. The presence of waiting lists for IADL-care and/or ADL-care appeared to be of no significant interest. Assessors apparently do not indicate a smaller number of types of care in case there are waiting lists. However, in this respect we might wonder whether or not the number of hours of care indicated would not have been minimised if the assessor has knowledge of waiting lists for home care in the area.

\section{Implications for practice}

Our research shows that assessment agencies addressing chronically ill's need for care should be extra alert in assessing the need for care in the following situations: patients being of older age, patients already receiving professional home care at the moment the assessment agency is notified and cases in which the demand for home care is not presented by patients themselves. In these situations, mismatches may occur. We also argued that assessors may not be as receptive to the patient's actual needs as might be expected. We therefore recommend specific training of needs assessors, especially their profession being in development. This additional training should make assessors aware of the apparent pitfalls in assessing chronically ill's needs. In doing so, needs assessors will become more patient-oriented in their approach. For instance, assessors may probe into the patient's needs a bit further or confront patients with their professional opinion. In patient's 
'negotiating' with needs assessors which care will be needed, the patients will (re)gain authority over the home care to be delivered to them. Probably this will result in a better match between patient's felt and requested need and the care indicated.

In addition, on the side of the patients, educating and preparing them how to adequately present their demand for home care, would probably be profitable for (chronic) patients and would possibly lead to a better felt need / care indicated match as well. In some regions in the Netherlands an 'advisor for the elderly' already helps the patients in this respect. Still, we argue that needs assessors should be capable of assess needs and indicate care in an objective and independent way.

\section{Methodological issues and restrictions of the study}

Analysis of the patient's perspective on the match between their felt need for care and the care indicated showed almost all patients satisfied with the outcome of the needs assessment. The well-known validity problem of measuring patient satisfaction, generally resulting in highly to very highly satisfied patients (Sixma et al., 1998), might have interfered here.

The sample in this study resembles the assessment agencies' population as regards sex and type of chronic disease, but not with regard to age, in that the mean age of our sample was much lower (PricewaterhouseCoopers/Nivel, 2002; Van Campen \& Van Gameren, 2003). This will possibly be related to the fact that most patients unwilling to participate in the study reported old age as the reason.

From other studies (Sixma et al., 1998; Schrijvers, 2001) it became clear, that if patients are dissatisfied at all with the care delivered, it usually concerns the number of hours of care indicated by the assessment agency, not so much the type of care. This result is confirmed in our study, analysing the patient's perceived match between felt need for care and care indicated. In this study, no data about the actual matches regarding the amount of care could be gathered because the present authors deemed it impossible for patients to estimate the number of hours of care they might need. Future research could make an effort to specify patient's estimate of the number of hours needed to alleviate the felt need for care (especially when domestic 
care is considered) so that the match of patient's estimate of the number of hours and the assessor's professional opinion could be computed.

The retrospective design of this study made patient selection procedures complex. However, it is possible that some mismatches may be attributed to the time elapsed between the needs assessment and the date the telephone interview was held. For instance, the patients were asked to report their felt needs for care, scoring on a structured needs-list, no matter whether they received professional or informal help to address these needs. As in twothirds of the cases home care was being delivered at the time of the telephone interview, it is possible that some needs for care were already reduced, resulting in an apparent mismatch. By separating the moment of measuring the felt needs for care and the needs assessment and/or receiving the allocated care possibly more reliable matches would have been produced. A prospective study design might facilitate this. However, since chronic patients' needs are usually rather stable, we argue that our retrospective design sufficed.

\section{Acknowledgement}

This research project was funded by NWO-ZOB (Zorg, Opvang en Begeleiding; Netherlands Organisation of Scientific Research, programme Care and Support), the Netherlands. 


\section{References}

Algera M, Francke AL \& Van der Zee J (2002). Zorg-indicatiestelling 'nieuwe stijl' binnen de zorgketen: een literatuurstudie naar de haalbaarheid van de doelstellingen van de indicatiestelling 'nieuwe stijl' en de realisering van de zorgketen. ['New-style' needs assessment in the care chain; a study of the literature on the feasibility of the objectives of the 'new-style' needs assessment and realising the care chain.] Verpleegkunde, Nederlands-Vlaams Wetenschappelijk Tijdschrift voor verpleegkundigen; 17 (3): 140151.

Algera M, Francke AL, Kerkstra A \& Van der Zee J (2003). An evaluation of the new home care needs assessment policy in the Netherlands. Health and Social Care in the Community; 11 (3): 232-241.

Algera M, Francke AL, Kerkstra A \& Van der Zee J (2004). Home care needs of patients with long-term conditions: literature review. Journal of Advanced Nursing; 46 (4) 417-429.

Andersen RM (1995). Revisiting the behavior model and access to medical care: does it matter? Journal of Health and Social Behavior; 36: 1-10.

Bradshaw J (1972). A taxonomy of social need. In: MacLachlan G (Ed.). Problems and progress in medical care. Oxford: University Press; p. 69-82.

Caris-Verhallen WMCM (1999). Nurse-patient communication in elderly care; an observation study into verbal and nonverbal communication in nursing practice. Utrecht: Nivel/University Utrecht (thesis).

Caris-Verhallen W \& Kerkstra A (1998). Cliënten op de wachtlijst voor een verpleeghuis of verzorgingshuis en hun ervaring met de continuiteit van zorg. [Patients on a waiting list for a nursing home or a home for the elderly and their experience with the continuity of care.] Utrecht: Nivel.

Dijkstra GJ (2001). De indicatiestelling voor verzorgingshuizen en verpleeghuizen. [Needs assessment for homes for the elderly and nursing homes.] Groningen: Noordelijk Centrum voor Gezondheidsvraagstukken (thesis).

Huijsman R (1990). Model van voorzieningen voor ouderen. [Model of facilities for the elderly.] Zeist: Kerckebosch BV (thesis).

Hutten JBF \& Kerkstra A (2002). Home care is what people want. In: Van Rooij EHC, Droyan Kodner L, Rijsemus AH \& Schrijvers AJP (Ed.). Health and health care in the Netherlands: a critical self-assessment of Dutch experts in medical and health sciences. Maarssen: Elsevier Gezondheidszorg; p. 101-110.

Jörg F (2002). Objectivity in individual needs assessment for access to long-term care. Utrecht: University Utrecht (thesis). 
Kerkstra A, Verheij RA, Foets M \& Van der Velden J (1990). Behoefte aan nazorg en verleende nazorg na ontslag uit het ziekenhuis. [Need for aftercare and provided aftercare following discharge from hospital.] Tijdschrift voor Sociale Gezondheidszorg; 68 (8): 346-354.

Ministerie van Volksgezondheid, Welzijn \& Sport (1997). Zorgindicatiebesluit (Besluit van 2 oktober 1997, houdende regels met betrekking tot het werkterrein, de samenstelling en werkwijze van indicatie-organen). [Care Needs Assessment Decree (White Paper of October, 2 1997, regarding field of activities, the formation, and the operation of Regional Needs Assessment Agencies).] Staatsblad van het Koninkrijk der Nederlanden. Den Haag: Sdu, 447.

Nationale Raad voor de Volksgezondheid (1994). Indicatiestelling en zorg op maat: advies van de Nationale Raad voor de Volksgezondheid en het College voor Ziekenhuisvoorzieningen. [Needs assessment and customised care: recommendations by the National Council for Public Health and the Council for Hospital Facilities.] Zoetermeer: Nationale Raad voor de Volksgezondheid.

PricewaterhouseCoopers/Nivel (2002). Benchmarkonderzoek 2000 verscherpt inzicht in prestaties en bedrijfsvoering thuiszorginstellingen: resultaten benchmarkonderzoek op serctor-niveau. Eindrapport. [Benchmark project 2000 gives more insight into achievements and management of home care organisations: results of a benchmark study on the level of the sector. Final report.] Almere/Utrecht: PricewaterhouseCoopers /Nivel.

Schrijvers AJP (2001). RIO, het jongste kind groeit op; eindrapport van de evaluatie van het Zorgindicatiebesluit van 1998. [The assessment agency, the youngest child grows to maturity; final report on the evaluation of the Care Needs Assessment Decree of 1998.] Utrecht: Julius Centrum voor Huisartsgeneeskunde en Patiëntgebonden onderzoek.

SGBO (2000). Werkwijze van Regionale Indicatie-Organen; Onderzoek onder 7 RIO's. [Working procedures of regional assessment agencies; research among 7 regional assessment agencies.] Den Haag: SGBO.

Sixma HJ, Kerssens JJ, Van Campen C \& Peters L (1998). Quality of care from the patients' perspective: from theoretical concept to a new measuring instrument. Health Expectations; 1: 82-95.

Snijders TAB \& Bosker RS (1999). Multi-level analysis: an introduction to basic and advanced multi-level modeling. London: Sage Publications.

Van Campen C, Sixma HJ, Kerssens JJ \& Peters L (1997). Assessing non-institutionalised asthma and COPD patients' priorities and perceptions of quality of health care: the development of the QUOTE-CNSLD instrument. Journal of Asthma; 34: 531-538.

Van Campen C \& Van Gameren E (2003). Vragen om hulp; vraagmodel verpleging en verzorging. [Asking for help; model for demand in nursing and caring.] Den Haag: Sociaal en Cultureel Planbureau. 
Care indicated and home care delivered: do they match in Dutch chronic patients?

Algera M, Francke AL, Spreeuwenberg P, Kerkstra A \& Van der Zee J

Submitted 


\begin{abstract}
This paper provides insight into the match between Dutch chronic patients' needed care as indicated by assessment agencies and the care delivered by home care organisations, regarding type and amount of care. Factors influencing this match are also studied, i.e.: characteristics of patients, assessment agencies, and home care organisations.
\end{abstract}

Data on more than 400 chronic patients, whose needs were assessed by an assessment agency, was collected by means of a telephone survey. The background characteristics of assessment agencies and home care organisations were gathered by means of a questionnaire. Match in type and amount of care indicated and delivered was determined by comparing assessment agencies' reports with home care organisations' records. Patients' opinions about the match were also canvassed.

A large majority of the patients held the opinion that the professional home care delivered paralleled the care indicated. However, in reality, the care indicated / care delivered match was frequently less than adequate. In approximately one-third of the cases only some of the indicated types were delivered or a mismatch could be observed, whereas in one-fifth of the cases a smaller number of hours of care was delivered compared to what was indicated by the assessment agency.

Male patients, those with non-complex care indicated by the assessment agency, and cases in which an actual preceding match between felt need for care and care indicated occurred, had a better care indicated / delivered match, both actually as in patients' perception. It was not possible to detect significant influence of characteristics on the match concerning the amount of care. In addition, no characteristics of assessment agencies or home care organisations could be associated with either of the matches studied in this paper.

Keywords: needs assessment, home care, chronically ill, the Netherlands 
Figure 6.1 Research model: the matches between patient's felt need and demand for care, care indicated, and home care delivered, and factors possibly influencing these matches

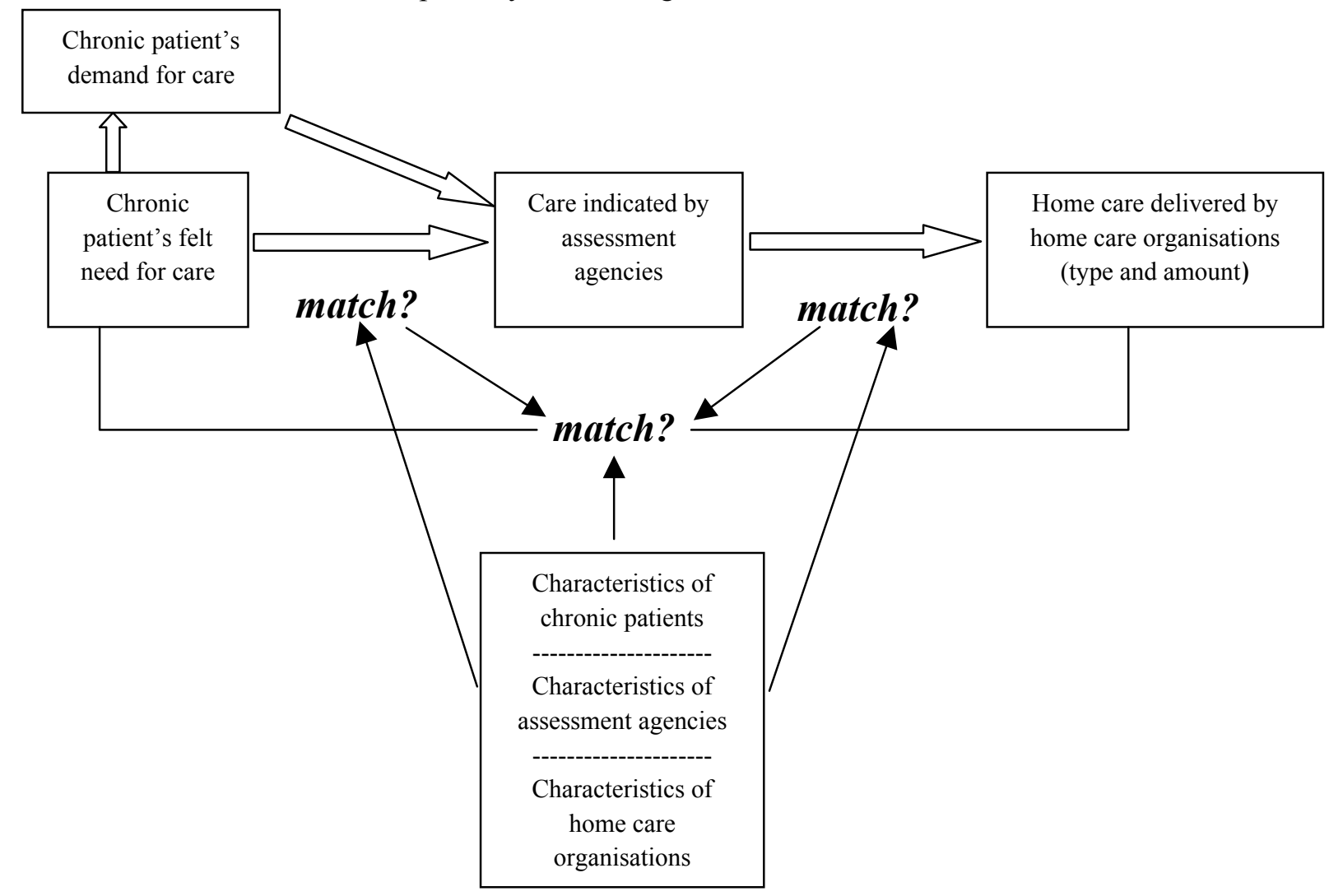




\section{Introduction}

In most Western countries, increasing attention has been paid to the match between care needs and care delivered. Usually, needs assessment, and the subsequent indication of the type and amount of care needed, links delivery of care to felt need for it. Not only should the care indicated reflect the patient's need, subsequently the care indicated should be delivered as well. Only two subsequent adequate matches would lead to a proper match between felt need and care indicated. Figure 6.1 displays these matches. In the chain of needing/demanding, indicating, and delivering care, several links can be observed, each of them determining the strength of the whole care chain. This figure also shows that there may be characteristics of assessment agencies and home care organisations as well as characteristics of chronic patients that might influence the matches.

Box 6.1 New-style needs assessment according to the Care Needs Assessment Decree (Ministerie van Volksgezondheid, Welzijn \& Sport, 1997)

Organisation of new-style needs assessment

- establishment of independent regional assessment agencies ('Regionale IndicatieOrganen': RIO's) resorting under the responsibility of municipalities, covering the whole country;

- $\quad$ assessment of chronic and other patients' needs for various types of care: home care and long-term residential care (obligatory) and social welfare (optional);

- assessment of complex needs for care: only by assessment agencies; assessment of noncomplex needs for care (e.g. administering eye drops or putting on support stockings): authorisation arrangements to home care organisation are allowed.

Three objectives of new-style needs assessment

- more independence than in the former way of needs assessment by assessing independently from the availability of care;

- more objectivity: to be reached by using uniform assessment protocols;

- comprehensiveness, to be obtained by taking into account various types of care; for instance, when a patient needs home care as well as a type of (semi-)residential care, the assessor integrates both types of care needs in the assessment procedure and assessment report.

In order to attain better matches within the care chain, in 1998, the Dutch government initiated a new-style needs assessment approach to be implemented by independent regional assessment agencies. The new-style needs assessment was regulated by law in the Care Needs Assessment Decree (Ministerie van Volksgezondheid, Welzijn \& Sport, 1997). Its 
organisation and objectives are presented in Box 6.1.

'Need for care' is taken to mean a patient's felt need in respect of healthrelated deficits (Bradshaw, 1972). Patient's demand for home care may be defined as patient's expression of the felt need for care (Bradshaw (1972): 'expressed need'), in this case, to an assessment agency. The 'care indicated' is the result of a formalised process of determining the need for care and subsequently indicating the reasonable and adequate care in respect of type, content, and amount of care (Nationale Raad voor de Volksgezondheid, 1994). This parallels Bradshaw's 'normative or evaluated need'. The care indicated by an assessment agency is described in the agency's assessment report. The home care delivered relates to the type and amount of care the home care organisation provides to the chronic patient. In the Netherlands, professional home care consists of IADL-care (i.e. care concerning instrumental activities of daily life; also called domestic care or home help), ADL-care (i.e. care concerning activities of daily life; also called physical or personal care), technical nursing care, and psychosocial care, delivered by professionals at the patient's home (Hutten \& Kerkstra, 2002).

\section{Research questions}

In a broad research project, all the above-mentioned matches (see Figure 6.1) are being studied in a group of chronic patients. The match between the patient's felt need for care and the care indicated by the assessment agency appeared to be rather poor (Algera et al., 2004b). This makes it even more relevant to investigate whether other matches displayed in Figure 6.1 are poor as well.

In this paper, the emphasis is on chronic patients' results on the care indicated / home care delivered match. This match is operationalised in three ways:

a. patient opinions regarding their care indicated / professional home care delivered match;

b. the actual match regarding type of care as indicated and delivered, based on record study;

c. the actual match regarding the number of hours of care as indicated and delivered, also based on record study. 
The following research questions will be addressed:

1. To what extent does chronic patients' care indicated by the assessment agency match with the care delivered by home care organisations in respect of type and amount of care, and how do patients themselves judge this match?

2. What characteristics of patients, assessment agencies, and home care organisations are related to this match?

\section{Expectations}

The present authors expected several characteristics of chronic patients, assessment agencies, and home care organisations to influence the care indicated / professional home care delivered match.

Patient characteristics may be classified as predisposing characteristics, enabling resources, and need factors (Andersen, 1995). Influence was expected with regard to several characteristics:

- complexity of the felt need for care or complexity of care indicated (need factor); in the case of complex care needed or indicated, as is often seen in patients suffering from various diseases simultaneously (comorbidity), a poorer match may be observed. Where the assessor does not recognise all needs, the home care organisation has to fill in the occurring gaps. Where the patient's complex needs were recognised by the assessor, the home care organisation may not be able to meet the care indicated. Then, the match between indicated and delivered home care would be inadequate as well. Younger age is another characteristic expected to be positively associated with the matches under study: younger patients are supposed to be better able to express themselves and more assertive in getting the indication for care and/or delivery of home care that they want;

- living arrangements (predisposing characteristic); informal care delivered to patients not living alone may be falsely taken into account in the care indicated; then, the home care organisation has to fill in the occurring gaps;

- previous matches within the care chain (enabling resource); a better match will probably evoke better subsequent matches.

The actual match involved is one concerning the professionalism of two organisations: assessment agencies and home care organisations. Therefore, their features were included in our study as well. 
Relevant assessment agency's characteristics in this regard were expected to be:

- whether or not assessment agencies have authorised home care organisations to assess non-complex care needs; in case both needs assessment and delivery of care are concentrated in the home care organisation, a better fit between care indicated and home care delivered may emerge because the needs assessment is already performed in the light of the availability of care;

- whether or not assessment agencies use national assessment forms in which the objectives of new-style needs assessment are assimilated; when the assessment agency uses the national assessment forms, possibly all the relevant details essential to home care organisations are present in the assessment report; a better match may then be expected;

- the extent of detail in the assessment report; possibly, more detailed assessment reports would help home care organisations to start their initial care to the patients, yielding a better match.

Characteristics of home care organisations, which were expected to influence the matches at hand, were:

- shortage of personnel; when there is an apparent lack of personnel in the home care organisation, care, as indicated by the assessment agency in terms of the number of hours, may not be delivered to the chronic patient, who, in turn, will be confronted with mismatch between the care indicated and the home care delivered;

- usability of the assessment report: if the home care organisation judges this report to be impracticable, it has, once again, to fill in the resulting gaps, leading to less independence, and a worse match between care indicated and home care delivered;

- presence of waiting lists (according to the assessment agency); a delay in delivering the care indicated may be observed when the home care organisation is not able to provide the care indicated instantaneously and a mismatch may therefore occur.

\section{Method}

\section{Sample}

Of 85 assessment agencies, 78 had participated in an earlier part of the study (Algera et al., 2003). These assessment agencies were asked to make a random selection of chronically ill patients, who had submitted a request for 
home care to the assessment agency's office; among them, 49 were willing to co-operate in the current phase of the study. Lack of time and staff or deficient data registration systems caused the other 29 assessment agencies to abstain from further participation. A $t$-test was performed to discover systematic differences between participating and non-participating assessment agencies; they were not found.

The patients selected had to meet the following inclusion criteria:

- they had suffered from a stroke, another chronic neurological disorder, chronic heart failure, diabetes mellitus, rheumatoid arthritis, and/or chronic disorders of the respiratory system;

- they were over 18 years of age;

- they were able to participate in a Dutch-language telephone interview;

- they had submitted an application for professional home care to the assessment agency;

- they were in receipt of a positive or negative decision on care allocation following needs assessment, noted in an assessment report; being on a waiting list was no exclusion criterion;

- they were in receipt of an assessment report made in the previous three months.

Not all assessment agencies were able to select patients on chronic disease criteria. A pilot among three assessment agencies showed that, on average, every third randomly selected patient met the disease criterion. In addition, in other research in the Netherlands (Van Campen et al., 1997; CarisVerhallen \& Kerkstra, 1998), the response rate among home care users, responding to a questionnaire, was approximately $30 \%$. It was calculated that about 4000 selected patients would be required to provide a final data sample of 400 patients. The number of 400 cases was based on poweranalyses. Actually, 3814 patients were selected, eventually yielding 402 patient data sets in the end.

An explanatory letter from the researcher, a consent form and a stampaddressed envelope were sent via the assessment agencies to the patients whose needs had been assessed. Of the 3814 patients selected by the assessment agencies, $1611(42.2 \%)$ patients returned their consent form. Of this group, 983 refrained from participation, mostly because of age, health, or lack of interest. No additional information on non-responders was 
available. Therefore, non-response analyses were impossible. Finally, 628 (39.0\%) patients agreed to participate. Subsequently, 226 of these 628 patients were excluded because they did not meet the inclusion criteria after all. In the end, data sets for 402 of the 628 patients $(64.0 \%)$ were used in the analyses.

Table 6.1 Characteristics of respondents $(\mathrm{n}=402)$

\begin{tabular}{|c|c|c|}
\hline \multirow[t]{9}{*}{ Disease } & Stroke & $16.4 \%$ \\
\hline & Other neurological illness & $21.6 \%$ \\
\hline & Chronic heart failure & $27.9 \%$ \\
\hline & Diabetes mellitus & $15.9 \%$ \\
\hline & Rheumatic disease & $39.1 \%$ \\
\hline & Chronic respiratory disorder & $20.1 \%$ \\
\hline & Other chronic disease & $19.9 \%$ \\
\hline & Other non-chronic disease & $14.4 \%$ \\
\hline & Comorbidity present & $46.8 \%$ \\
\hline \multirow[t]{5}{*}{ Living arrangements } & Alone & $43.0 \%$ \\
\hline & With spouse & $52.0 \%$ \\
\hline & With children/parents & $9.7 \%$ \\
\hline & With fellow residents & $1.7 \%$ \\
\hline & Temporarily admitted & $0.5 \%$ \\
\hline \multirow[t]{8}{*}{ Highest education } & Lower education & $46.5 \%$ \\
\hline & Primary school & $31.8 \%$ \\
\hline & Lower vocational & $14.7 \%$ \\
\hline & Higher education & $48.3 \%$ \\
\hline & Secondary school & $22.4 \%$ \\
\hline & Medium vocational & $15.7 \%$ \\
\hline & Higher vocational / university & $10.2 \%$ \\
\hline & Missing & $5.2 \%$ \\
\hline
\end{tabular}

Table 6.1 contains some characteristics of the respondents. The mean age of the respondents was 67 (SD: 14), three out of four were women. About half of the respondents suffered from various diseases simultaneously (comorbidity), the proportion of respondents suffering from rheumatoid 
arthritis was the largest. Telephone interviews with the patients themselves were possible in $85 \%$ of the cases, in other cases spouses or other informal caregivers were interviewed on the patient's behalf.

\section{Variables and measuring instruments}

Figure 6.2 gives an overview of the variables and the instruments used in this part of the study.

Figure 6.2 Variables in relation to instruments used or way of data collection

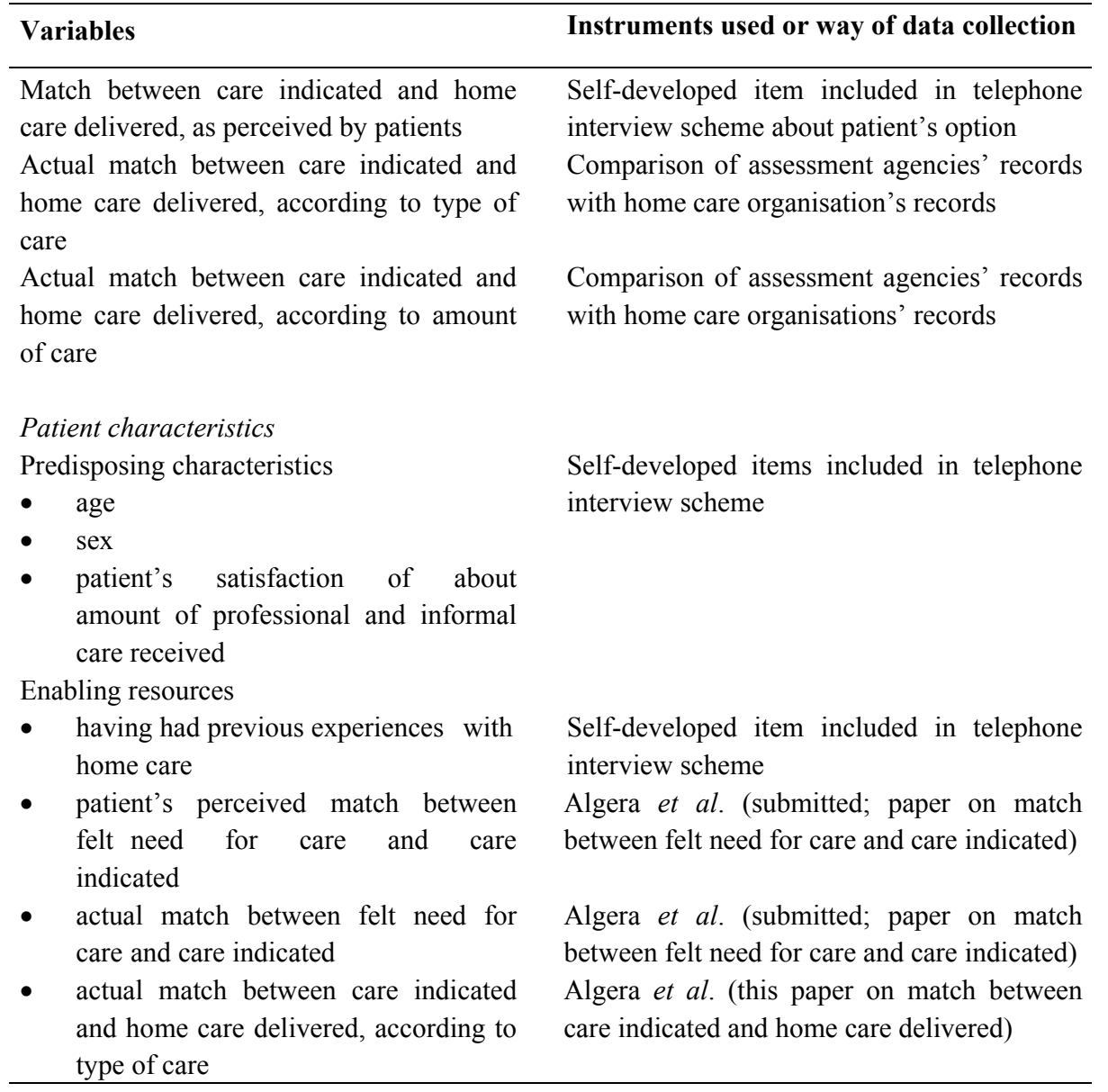


Figure 6.2 Continued I

\begin{tabular}{|c|c|}
\hline Variables & Instruments used or way of data collection \\
\hline $\begin{array}{l}\text { Need factors } \\
\text { - } \quad \text { presence of comorbidity } \\
\text { - } \quad \text { receiving additional informal care } \\
\text { - } \quad \text { complexity of care indicated by } \\
\text { assessment agencies } \\
\text { - complexity of felt need for care }\end{array}$ & $\begin{array}{l}\text { Self-developed item } \\
\text { Self-developed item } \\
\text { Assessment agencies' reports } \\
\text { Based on Kerkstra et al. (1990): items } \\
\text { measuring IADL, ADL, technical nursing, } \\
\text { and psychosocial needs included in telephone } \\
\text { interview scheme }\end{array}$ \\
\hline $\begin{array}{l}\text { Characteristics of assessment agencies } \\
\text { - } \text { period of being in operation } \\
\text { - } \text { authorisation of assessments non- } \\
\text { complex home care needs to home } \\
\text { care organisations } \\
\text { - working with a standardised set of } \\
\text { assessment forms } \\
\text { - } \text { number of assessment fields } \\
\text { level of detail of assessment report } \\
\text { patients having had to wait before } \\
\text { being assessed }\end{array}$ & $\begin{array}{l}\text { Self-developed items included in } \\
\text { questionnaire for assessment agencies }\end{array}$ \\
\hline $\begin{array}{l}\text { Characteristics of home care organisations } \\
\text { - lack of staff } \\
\text { - } \quad \text { usability of assessment reports } \\
\text { - } \quad \text { waiting lists IADL-care and/or ADL- } \\
\text { care }\end{array}$ & $\begin{array}{l}\text { Self-developed items included in } \\
\text { questionnaire for home care organisations }\end{array}$ \\
\hline
\end{tabular}

A structured telephone interview scheme was constructed to gather data by telephone about, among others, patient characteristics and the patient's perspective on the match between the care indicated by the assessment agency and the professional home care delivered. All of these items were self-developed (see Figure 6.2). Home care delivery, according to the home care organisation's records, was measured about a year after the telephone interview. In the time elapsed, in many cases professional home care started.

The content validity of the structured interview scheme was tested in a meeting of experts in the field of assessment agencies, home care organisations, and health insurers $(n=7)$ and in a separate meeting of 
chronically ill patients $(n=6)$. The resulting adjusted version was tested among another 20 patients who had dealt with an assessment agency and who met the inclusion criteria. Their comments were integrated into the final version.

Data on characteristics of assessment agencies and on how the assessment procedure was organised, was collected by means of a questionnaire for assessment agencies, content validated by managers of assessment agencies and other experts.

Data on characteristics of home care organisations, on what part home care organisations played in handling waiting lists, and on opinions about the quality of the reports of assessment agencies, were also collected by means of a self-developed questionnaire for home care organisations, content validated by managers of home care organisations and other experts.

\section{Data collection}

Patient data was gathered by experienced telephone interviewers from November 2000 through May 2001. On average, the interviews lasted about 20 minutes.

The questionnaires for assessment agencies and home care organisations were distributed in May 2000. The response was $92 \%$ and $81 \%$, respectively. Main characteristics of assessment agencies were updated by means of a quick scan at the time the assessment agency started to select the patients for the telephone interview.

In addition, specific items of the assessment reports as well as home care organisations' records of participating patients were studied to disclose more specific data about the care indicated and the home care eventually delivered. Of the 49 assessment agencies participating in this part of the study, 47 also joined the study of the patients' assessment reports covering 387 patients. Assessment reports concerning 376 patients were reviewed; the remaining 11 patients did not give consent for their files to be studied.

All but two home care organisations agreed to participate in this part of the study (number of patients lost =19). However, not all chronic patients involved in our study could be traced by the home care organisation (number of patients lost $=27$ ). Another 19 patients were still waiting for care. As 
mentioned before, 11 patients did not give permission to study their files. In the end, data on type and amount of home care delivered was gathered for 326 of the 402 involved chronic patients (81\%). However, being put on a waiting list or having received a negative care allocation on behalf of the assessment agency led to infer in even more cases whether or not a (mis)match had occurred $(\mathrm{n}=349)$.

The number of patients per assessment agency varied from 2 to 22 (mean: 8.20, SD: 3.94), whereas the number of patients per home care organisation varied from 1 to 27 (mean: 6.70, SD: 6.08).

\section{Analyses}

The care indicated by the assessment agency as well as the professional home care delivered were coded in IADL-care, ADL-care, technical nursing care, or psychosocial care as well as combinations of these types of home care.

Opinions on the care indicated / care delivered match were derived by calculating frequencies and percentages of patients' responses on questionnaire items.

The actual match between the care indicated and the home care delivered (see research question 1) was determined by comparison of the types of care and the amount of care indicated or delivered, respectively. 'Perfect matches' were established when type of care delivered by the home care organisation was identical to the needed care according to the assessment agency. Cases in which the delivery of care exceeded the care indicated, were coded as 'overdelivery'. In addition, discrepancies were distinguished as 'underdelivery' when, for instance, a combination of IADL- and ADLcare was needed according to the assessment agency, but only IADL-care was delivered by the home care organisation. Furthermore, being put on a waiting list was coded as 'mismatch' as were cases in which a totally different type of care was delivered from that indicated. The types of care in which matches/mismatches were observed were discovered by making cross-tabulations. Calculation of the match in amount of care only seemed meaningful, when the match in type of care was perfect because receiving the appropriate number of hours of care according to the assessment report, but of an incongruent type of care was considered irrelevant. 
In answering research question 2, first multi-collinearity between the independent variables under study was determined. When a statistically significant correlation of $>0.70$ between two independent variables was detected, one of them was excluded.

When analysing the factors of influence on the matches under study, here, the dependent variable was 'match' (a combination of 'perfect match' and 'overdelivery') or 'mismatch' (a combination of 'underdelivery' and 'mismatch'). Logistic regression analysis was deemed appropriate in studying the relation between the dependent variables and a series of independent variables. Given the nature of the data, there were three methodological aspects to be incorporated into the statistical analyses. First, it was expected that there was a nesting of patients within assessment agencies. Secondly, the number of patients per assessment agency in this study varied strongly (see also Section Data collection). Thirdly because the independent variables were measured at two different levels (the patient's and the organisation's), statistical artefacts such as the ecological and atomistic fallacy had to be avoided. To deal with these three aspects adequately in one analysis, a multi-level approach to (logistic) regression analysis was used. In the literature (Snijders \& Bosker, 1999), a more elaborate discussion can be found on why a multi-level approach for this kind of data is appropriate. The software used was MLWIN. With regard to each match a series of theoretically relevant independent variables concerning the characteristics of patients, assessment agencies, and home care organisations were entered into multi-variate multi-level analyses simultaneously.

\section{Results}

Patients' opinions regarding match between care indicated and professional home care delivered

The patients were asked whether or not they thought that the care delivered by the home care organisation matched with the care indicated by the assessment agency. By far the most patients (89.0\%) believed that there was such a match. Most of the patients who stated that there was not an adequate match, reported receiving fewer hours of the adequate type of home care than was indicated by the assessment agency.

In addition, irrespective of a care indicated / home care delivered match, 
every sixth patient in this study believed that the home care was not delivered at an acceptable term, whereas an approximately equal number of patients objected to the care providers not being skilled enough or to the large number of different home care professionals visiting the patient.

As many as almost one-third of the respondents were not able to answer the question about the care indicated / delivered match, mainly because they had not received care yet at the time of the telephone interview. Most of these patients did not know how long they would have to wait to receive their home care.

\section{Actual match between care indicated and professional home care delivered regarding type of care}

Types of care indicated by assessment agencies and types of care delivered by home care organisations were compared (see Table 6.2).

In $58.0 \%$ of the cases in which a comparison was possible ( $\mathrm{n}=338)$, a perfect match between the care indicated and the home care delivered by the home care organisation could be observed. A perfect match was most present concerning IADL-care: in three-quarters $(74.8 \%)$ of the cases in which just IADL-care was needed according to the assessment agency, the home care organisation also delivered just IADL-care.

Overdelivery could be observed in mainly the exclusive types of ADL-care or technical nursing care; in those cases not only was the ADL-care or technical nursing care delivered (in accordance with the assessment report), but also some other types of home care. Overdelivery was seen in $8.9 \%$ of the cases.

Underdelivery was present in $8.6 \%$ of the cases and was most frequently located in care indicated concerning IADL/ADL-care or ADL/technical nursing care.

When the delivery of care did not at all match with what was indicated by the assessment agency, this mostly concerned ADL-care; a totally different type of care was delivered, usually IADL-care or technical nursing care. In about eleven percent of the cases in which IADL-care, ADL-care, or technical nursing care was indicated exclusively, or the combination 
IADL/ADL was indicated, no care was delivered at all. In those cases, results show that this could be attributed to waiting lists. Both of the latter categories combined resulted in $24.5 \%$ of the cases showing a total mismatch.

Table 6.2 Degree of actual match (in \%) between care indicated and professional home care delivered regarding type of care

\begin{tabular}{|c|c|c|c|c|c|c|}
\hline \multirow{2}{*}{\multicolumn{2}{|c|}{$\begin{array}{l}\text { Types of care } \\
\text { indicated }\end{array}$}} & \multirow[t]{2}{*}{$\begin{array}{l}\text { Perfect } \\
\text { match }\end{array}$} & \multirow[t]{2}{*}{$\begin{array}{l}\text { Over- } \\
\text { delivery }\end{array}$} & \multirow[t]{2}{*}{$\begin{array}{l}\text { Under- } \\
\text { delivery }\end{array}$} & \multicolumn{2}{|c|}{ Mismatch } \\
\hline & & & & & $\begin{array}{l}\text { Other type } \\
\text { of care } \\
\text { delivered } \\
\end{array}$ & $\begin{array}{c}\text { No professional } \\
\text { care delivered } \\
\text { at all } \\
\end{array}$ \\
\hline I & $(n=202)$ & 74.8 & 5.9 & not applicable & 5.0 & 14.4 \\
\hline A & $(n=51)$ & 35.3 & 15.7 & not applicable & 39.2 & 9.8 \\
\hline $\mathrm{N}$ & $(n=24)$ & 58.3 & 16.7 & not applicable & 16.7 & 8.3 \\
\hline $\mathrm{P}$ & $(n=3)$ & 33.3 & 0.0 & not applicable & 66.7 & 0.0 \\
\hline $\mathrm{I}+\mathrm{A}$ & $(n=25)$ & 28.0 & 8.0 & 52.0 & 4.0 & 8.0 \\
\hline $\mathrm{I}+\mathrm{N}$ & $(n=3)$ & 0.0 & 100.0 & 0.0 & 0.0 & 0.0 \\
\hline $\mathrm{I}+\mathrm{P}$ & $(n=2)$ & 50.0 & 0.0 & 50.0 & 0.0 & 0.0 \\
\hline $\mathrm{A}+\mathrm{N}$ & $(n=13)$ & 15.4 & 7.7 & 76.9 & 0.0 & 0.0 \\
\hline $\mathrm{A}+\mathrm{P}$ & $(n=3)$ & 0.0 & 0.0 & 00.0 & 0.0 & 0.0 \\
\hline \multicolumn{7}{|l|}{$\mathrm{N}+\mathrm{P}$} \\
\hline $\mathrm{I}+\mathrm{A}+\mathrm{N}$ & $(n=3)$ & 33.3 & 0.0 & 66.7 & 0.0 & 0.0 \\
\hline $\mathrm{I}+\mathrm{A}+\mathrm{P}$ & $(n=3)$ & 33.3 & 0.0 & 66.7 & 0.0 & 0.0 \\
\hline \multicolumn{7}{|l|}{$\mathrm{I}+\mathrm{N}+\mathrm{P}$} \\
\hline \multicolumn{7}{|c|}{$\mathrm{A}+\mathrm{N}+\mathrm{P}$} \\
\hline \multicolumn{7}{|c|}{$\mathrm{I}+\mathrm{A}+\mathrm{N}+\mathrm{P}$} \\
\hline Other & $(n=8)$ & 0.0 & 0.0 & 0.0 & 100.0 & 0.0 \\
\hline Overall & $(n=338)$ & 58.0 & 8.9 & 8.6 & 13.3 & $11.2 *$ \\
\hline $\begin{array}{ll}\mathrm{I}= & \mathrm{IA} \\
\mathrm{A}= & \mathrm{AD} \\
\mathrm{N}= & \text { tec } \\
\mathrm{P}= & \mathrm{psy} \\
* & \mathrm{Th} \\
& \text { on }\end{array}$ & $\begin{array}{l}\text { DL-care, } \mathrm{d} \\
\text { L-care, ph } \\
\text { hnical nurs } \\
\text { chosocial } \\
\text { fact that } \\
\text { waiting lis } \\
\text { ment of s } \\
\text { pondents }\end{array}$ & $\begin{array}{l}\text { estic care } \\
\text { ical perso } \\
\text { g care } \\
\text { e } \\
\text { s percenta } \\
\text { (almost } \\
\text { dy: at the } \\
\text { e on som }\end{array}$ & $\begin{array}{l}\text { care } \\
(11.2 \%) \mathrm{i} \\
\text { ird) prese } \\
\text { oment of } \\
\text { aiting list }\end{array}$ & $\begin{array}{l}\text { nuch smaller tha } \\
\text { ed earlier in the } \\
\text { the telephone ir } \\
\text { the moment o }\end{array}$ & $\begin{array}{l}\text { the percenta } \\
\text { aper can be } \\
\text { rview almo }\end{array}$ & $\begin{array}{l}\text { ge of respondents } \\
\text { attributed to the } \\
\text { st a third of the } \\
\text { idy most of them }\end{array}$ \\
\hline
\end{tabular}



regarding number of hours of care

The number of hours of care indicated by assessment agencies and the amount of care delivered by home care organisations were also compared, but only in cases wherein the proper type of care was delivered in accordance with the assessment report $(n=204$; see Table 6.3).

In two thirds $(69.7 \%)$ of the cases in which IADL-care was indicated, the number of hours of care indicated by the assessment agency was identical to what was delivered by the home care organisation. Over all combinations of types of home care, the percentage of perfect match was $61.3 \%$.

Table 6.3 Degree of actual match (in \%) between care indicated and professional home care delivered regarding number of hours of care

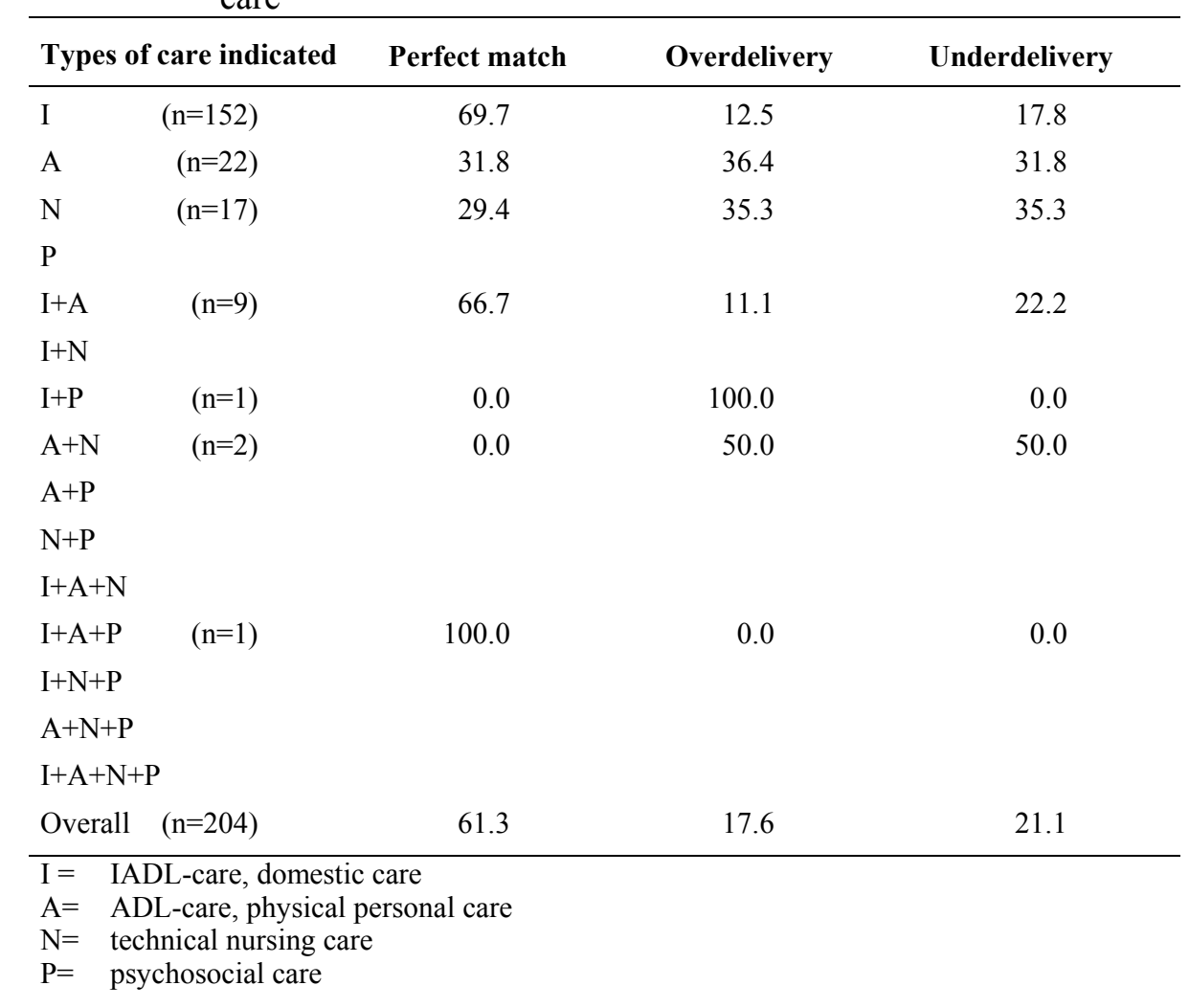


Table 6.4 Results of multi-variate multi-level analyses on characteristics of patients, assessment agencies, and home care organisations explaining the match between care indicated and professional home care delivered regarding patients' opinions, actual type of care and actual amount of care

\begin{tabular}{|c|c|c|c|c|c|c|}
\hline & \multicolumn{2}{|c|}{$\begin{array}{c}\text { Perceived match } \\
\text { care indicated / } \\
\text { home care delivered } \\
(\mathrm{n}=\mathbf{2 3 2})\end{array}$} & \multicolumn{2}{|c|}{$\begin{array}{c}\text { Actual match } \\
\text { indicated type of care / } \\
\text { home care delivered } \\
(n=225)\end{array}$} & \multicolumn{2}{|c|}{$\begin{array}{c}\text { Actual match } \\
\text { indicated amount of home } \\
\text { care /care delivered } \\
(\mathrm{n}=129)\end{array}$} \\
\hline & B & SE B & B & SE B & B & SE B \\
\hline Age $(1=$ under $65 ; 2=65+)$ & -.56 & .52 & -.08 & .35 & .11 & .51 \\
\hline Sex $(1=$ male; $2=$ female $)$ & $2.36 *$ & .87 & $-.85 *$ & .40 & -.19 & .54 \\
\hline Comorbidity $(0=$ absent; $1=$ present $)$ & .64 & .50 & .19 & .33 & 1.02 & .55 \\
\hline Previous experiences with home care $(0=$ no; $1=$ yes $)$ & -.53 & .50 & \multicolumn{2}{|c|}{ n.a. } & \multicolumn{2}{|c|}{ n.a. } \\
\hline $\begin{array}{l}\text { Patient's satisfaction with amount of professional and } \\
\text { informal home care received }(0=\text { no; } 1=\text { reasonable; } 2=y e s)\end{array}$ & $1.89 *$ & .38 & \multicolumn{2}{|c|}{ n.a. } & \multicolumn{2}{|c|}{ n.a. } \\
\hline Complexity of felt need $(0=$ non-complex; $1=$ complex $)$ & \multicolumn{2}{|c|}{ \# } & \multicolumn{2}{|c|}{ \# } & \multicolumn{2}{|c|}{ \# } \\
\hline Complexity of care indicated $(0=$ non-complex; $1=$ complex $)$ & $-1.99 *$ & .64 & $-2.49 *$ & .51 & -1.30 & .89 \\
\hline Having received additional informal care at all $(0=$ no; $1=$ yes $)$ & -.42 & .63 & .28 & .36 & -.32 & .58 \\
\hline $\begin{array}{l}\text { Perceived match between felt need for care and care indicated } \\
(0=\text { no; } 1=\text { yes })\end{array}$ & \multicolumn{2}{|c|}{ \# } & \multicolumn{2}{|c|}{ n.a. } & \multicolumn{2}{|c|}{ n.a. } \\
\hline $\begin{array}{l}\text { Actual match between felt need for care and care indicated } \\
(0=\text { mismatch } / \text { partial; } 1=\text { perfect } / \text { more })\end{array}$ & $2.13 *$ & 67 & $.87 *$ & .36 & -.30 & .48 \\
\hline
\end{tabular}




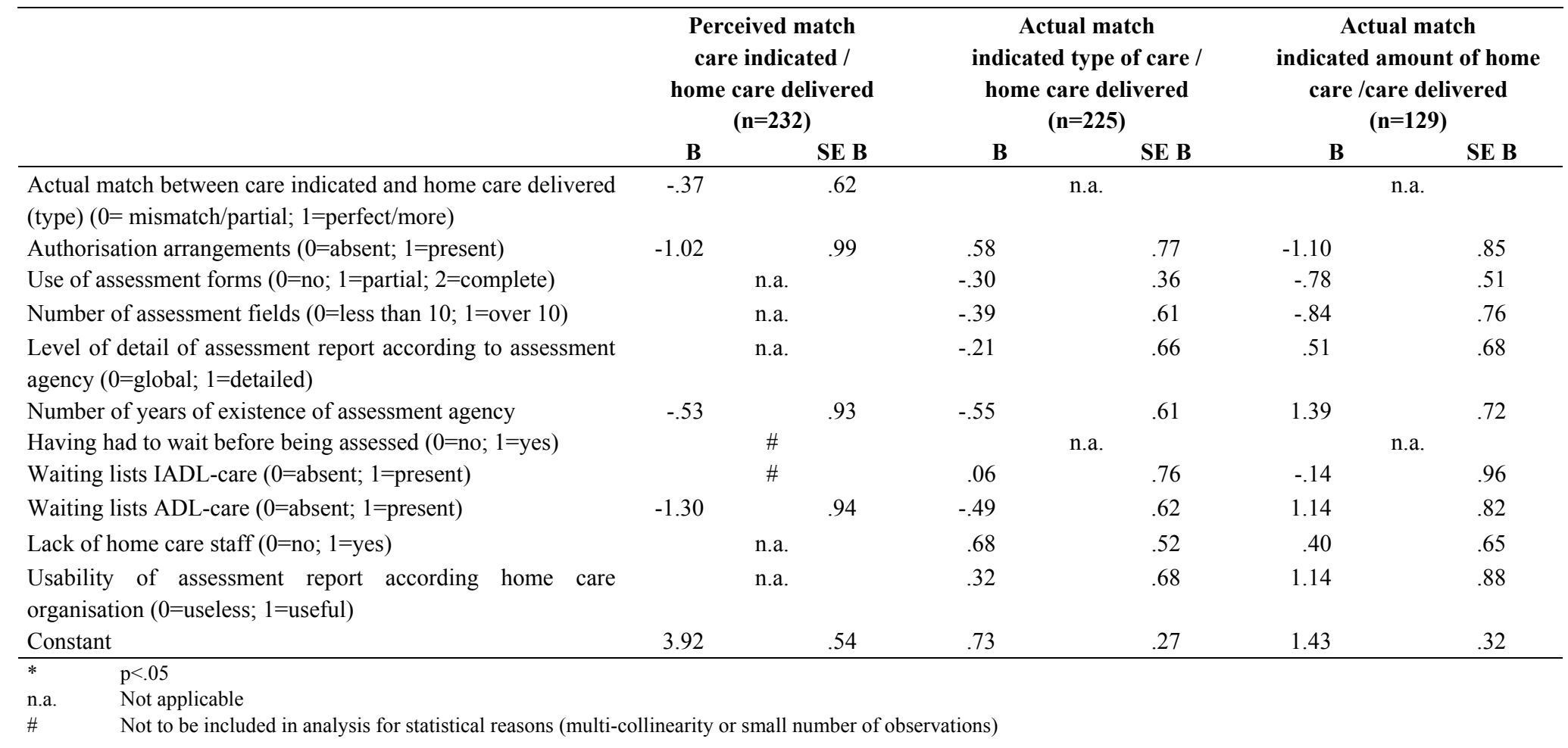


Overdelivery in number of hours of care could be observed in $17.6 \%$ of the cases. Especially in the exclusive types of just ADL-care or technical nursing care overdelivery was measured in the amount of care. Conversely, the overall underdelivery was $21.1 \%$. Mainly in cases in which an exclusive type of home care was needed according to the assessment agency, a smaller amount of home care delivered compared to the assessment report could be noted.

\section{Patients', assessment agencies' and home care organisations' characteristics related to matches}

The patients significantly held more positive opinions about the care indicated / professional home care delivered match when they were male. In addition, when their care indicated was less complex, they more often perceived such a match. If they had an actual match between their felt need and the care indicated by the assessment agency, they perceived a better match under study. This was also the case if the patients thought positively about the amount of professional and informal home care delivered (see Table 6.4).

As regards the actual care indicated / home care delivered match with respect to type of care, three factors proved to be predictive of the occurrence of a match. First, in general, the care indicated was indeed actually delivered by a home care organisation to men rather than to women. Secondly, if the assessor indicated just one type of care, the chance a match would occur increased. Finally, an adequate felt need for care / care indicated match proved to be a predictor of the occurrence of a care indicated / home care delivered match (see Table 6.4).

In analysing the match between the number of hours indicated by the assessment agency and delivered by the home care organisation, no characteristics of patients, assessment agencies, or home care organisations were significantly related to a match regarding the amount of care indicated and delivered (see Table 6.4). 


\section{Discussion}

Discussion on match between care indicated and professional home care delivered

This paper describes the match between the care indicated by assessment agencies and the care delivered by home care organisations. This match was measured in three ways: a) the patients' opinions regarding the match between care indicated and home care delivered; b) the actual match regarding type of care; and c) the actual match regarding amount of care, the latter two based on record study. Comparison of the assessment agencies' report with the home care organisations' records showed that in about three out of five cases, a perfect match on type of home care or amount of care could be observed. Moreover, when the percentages of a perfect match are added to the percentages of overdelivery, the type and amount of home care delivered appeared to match or even exceed the care indicated in approximately two out of three cases (type) and four out of five cases (amount). As to type of home care, a distinction can also be made between underdelivery (about ten percent) and mismatch (about a quarter of the cases) (see Figure 6.3). Mismatch emerged when a totally different type of care was delivered from what was indicated or when the patients did not receive care at all, mainly because of waiting lists.

Figure 6.3 - Degree of overall-matches (in \%)

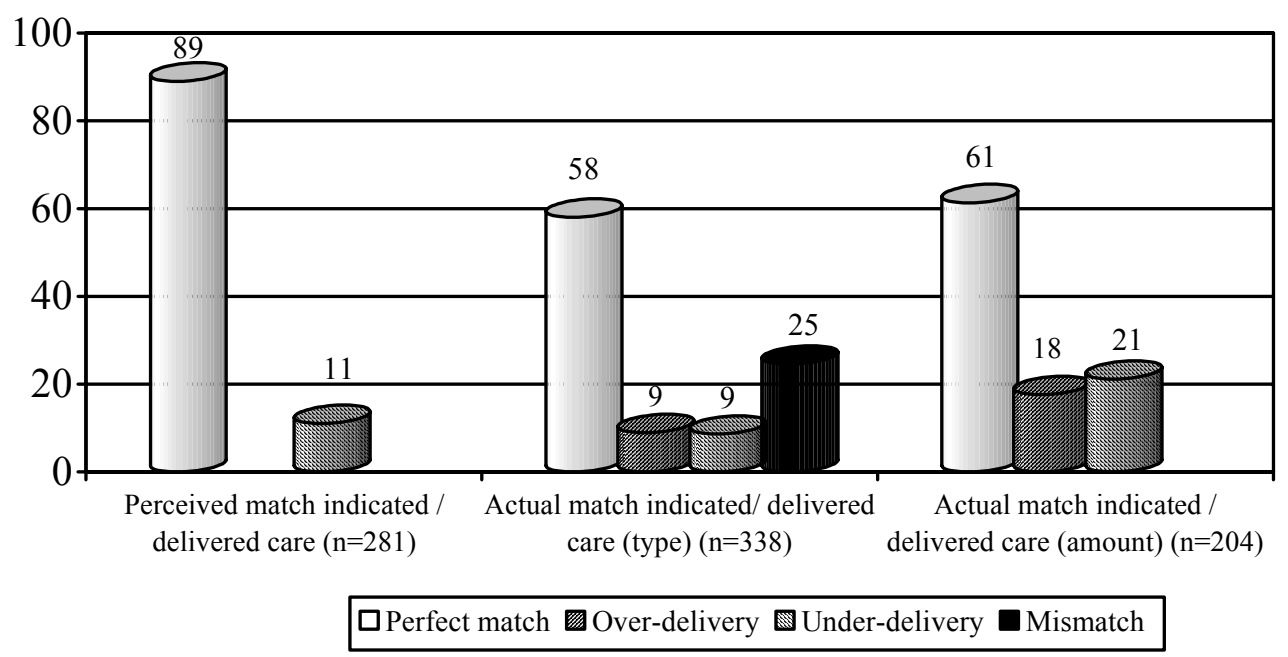


In about one-third or one-fifth of the cases respectively, the type or the amount of care was not delivered in accordance with the assessment report (underdelivery or mismatch). This finding is in line with other research in this field in the Netherlands (Schrijvers et al., 2001), particularly regarding the amount of care. In our study, about one-fifth of the patients were confronted with underdelivery in hours of care. As, in this regard, the present authors only analysed cases if the type of home care delivered matched the care indicated by the assessment agency, no patients on waiting lists (11\%) were included. Therefore, our finding of $20 \%$ underdelivery in amount of care is, in fact, an underestimate.

As mentioned in the Introduction section, before the assessment agencies were established, home care organisations assessed the patient's needs. Criticisms by the patient movement were directed at home care organisations' tendency to minimise those needs in order to serve as much patients within the constraints of money and available staff. In contrast, our study showed that nowadays almost one out of five (17.6\%) patients received a larger number of hours of care from home care organisations than was indicated to be needed by the assessment agency. Conversely, a comparable proportion $(21.1 \%)$ of the patients was confronted with underdelivery in amount of care. In some of the cases, the home care organisation may have increased respectively decreased the number of hours of care to be delivered, due to changed circumstances in health condition or altered availability of informal care. Still, in general, these findings suggest that non-equitable allocation of scarce care - one of the initial reasons for the Care Needs Assessment Decree - yet remains after the introduction of the new assessment procedures.

The fact that the care indicated / home care delivered match is rather moderate (about 60\%) does not allow us to conclude that the new-style needs assessment is not functioning properly. This match only describes part of the route the patients have to cover from presenting their felt need for care, through needs assessment, to receiving the allocated care (see Figure 6.1). However, the match regarding the preceding part of this route (felt need versus care indicated) appeared to be poor (Algera et al., 2004b). In approximately one-third of the cases, a perfect match in care needed according to the patients themselves and assessors could be observed. More frequently (over half of the cases) under-indication could be observed in that 
only the need for IADL-care was usually recognised by the assessor, while the patients themselves felt needs in the field of IADL-care in combination with other types of home care. Another paper (Algera et al., 2004c) will discuss the extent to which a match between patient's felt need and home care delivered exists.

Considering assessment agencies' and home care organisations' worries about the match between care indicated and home care delivered, the actual match appeared not to be as bad as was expected, based on their views. In another part of this research project, respondents of many assessment agencies $(69 \%)$ and home care organisations (84\%) have reported observing bottlenecks in the match under study. Bottlenecks were mainly located in underdelivery of care: fewer hours of care were delivered when compared to the assessment report. Moreover, waiting lists for home care were judged to be a major reason for mismatch. Compared with these rather negative views, the actual matches according to type and amount of care may be considered as rather favourable.

Notwithstanding the (relatively) moderate actual match deriving from the study of records, most patients perceived an adequate match between the care indicated and the home care delivered. Apparently, patient's opinion about the match at hand was not completely determined by whether or not an actual match had occurred (see also next section). Other factors might also play a role, such as general satisfaction with home care received - seen in most satisfaction-research (e.g. Caris-Verhallen, 1999).

In a previous part of this study (Algera et al., 2002), it was concluded that all the conditions for reaching the objectives of the new-style needs assessment - more independence, objectivity, and comprehensiveness of needs assessment and indicating care - were present in practice. However, this being so, it appears to be no guarantee for an adequate care indicated / home care delivered match. Other factors may be of influence here (see next section). The present study shows that the complexity of patient's felt need and of the care indicated may be the main factors of the match in amount and type of care, respectively.

\section{Discussion on characteristics influencing match}

Results show that, in general, men seem to be better provided with care 
according to the assessment report than are women. Despite the societal development in sharing domestic and caring tasks, home care organisations still seem to benefit men more than women in this respect. Patients do not always seem to be equal in home care organisations. In contrast, men tend to have more unmet (I)ADL-needs (Scholte op Reimer, 1999). It is argued that this might be due to men not seeking help. It seems that when men actually do seek help by asking assessment agencies to recognise their needs, they are better off than are women.

Although the presence of comorbidity appeared not to be significantly influential on the matches under study, the possibly inherent complexity of care indicated did. If the assessment report indicated an exclusive type of care (i.e. not combined with other types of care), a better actual match occurred. This is in line with our expectations. In part, this result may be evoked by probability: the more complex the care indicated by the assessor, the more chance that the home care organisation does not recognise or cannot deliver that specific combination of types of care. Another explanation may be the possibility that the home care organisation judges the assessment report in these cases to be too generous, especially in the light of scarcity of care and personnel. If that was the case, then despite possible independent needs assessment, still the delivery of care is supply-oriented and not needs-led.

Finally, the adequacy of the match between the felt need for care and the care indicated proved to be influential with regard to the subsequent match between care indicated and home care delivered. Apparently, an adequate needs-led assessment is a proper onset for home care organisations realising the care indicated.

With respect to the patient's perceived care indicated / delivered match the same characteristics leading to such an actual match are predictors of the patient's perception of the match under study. However, remarkably enough, the adequacy of the actual match itself was no predictor of the patient's perception of this match. Once again, perception was not directly linked to reality, as we already expected analysing the degree of perceived and actual matches. In addition, if the patients were satisfied about the amount of home care (either professionally or informally) they received, patient's perception of the match between care indicated and professional home care delivered 
improved. Additional analyses suggested that the efforts of informal caregivers might bear considerable responsibility in this (Algera et al., 2004c). Patient's opinion seems to be that an adequate care indicated / delivered match may only partly be attributed to home care organisations delivering professional home care. The part informal care generally plays in care giving appeared substantial. The sum of professional and informal home care delivered may have led to the high percentage of satisfied patients.

With regard to the match in numbers of hours of care, no characteristics predicted such a match significantly. Probably, influence of individual characteristics was diminished because the care indicated / delivered match according to type of care was made conditional for the one according to amount of care.

Living alone and its supposed non-availability of informal care, appeared not to influence the match in amount of indicated/delivered home care. This finding is in contrast with literature on home care utilisation (Riemsma et al., 1998; Scholte op Reimer, 1999), in that living alone is associated with intensified consumption of home care. Younger patients appeared not to have an advantage over older patients, although we expected that to be the case. Younger patients were supposed to be more eloquent and assertive in getting the indication and/or home care that they wanted, but this hypothesis was not supported by our data. Other patient characteristics, which influence the intensity of home care use (Algera et al., 2004a), could not be significantly associated with the match in numbers of indicated and delivered hours of home care as well.

In our study, the influence of characteristics of assessment agencies and home care organisations appeared to be absent. The present authors expected, for instance, the use of national assessment forms and presence of authorisation arrangements to be of positive influence on the match between care indicated and home care delivered. Circumstantial aspects like waiting lists and shortage of home care personnel were supposed to block the match between the patient's care indicated and the home care delivered to them. However, apparently no characteristic of assessment agencies and home care organisations determined the actual or the perceived match in type and amount of care specifically. 


\section{Restrictions of the study}

Some of the restrictions of this study are related to lack of co-operation of some of the patients, assessment agencies, and home care organisations. First, this is due to the fact that not all of the assessment agencies wanted to participate in this part of the study. However, comparison on relevant characteristics of participating and non-participating assessment agencies did not give rise to an assumption of systematic differences and therefore of biased results. Second because two records per patient from different organisations (assessment reports and home care organisation's records) were related to one other, one deficient record is enough for the deletion of the whole case. Finally, many patients, selected by the assessment agencies, refused to participate in the study. Reasons for not entering the study were old age, poor health condition, and no interest. Yet another substantial part of the selected patients did not give any reason at all. Possibly, the group of non-participants differs significantly from the group of respondents, for instance with regard to age and severity of the chronic illness. Because of the anonymity of the respondents, this could not be analysed any further.

In the Analyses section, the problem of nesting of data within assessment agencies was considered. The multi-level analyses took this nesting problem into account. However, it may be argued, that nesting of patients within the home care organisations is present as well. The higher level included in our analyses could, therefore, also be the home care organisations instead of the assessment agencies. Additional analyses in this respect pointed to a considerable overlap in factors being statistical influential on the matches under study, though. Moreover, we argue that the procedure of patient selection via the assessment agencies as well as the focus of our study, aiming at the assessment agencies, justifies the choice of nesting patient data within the assessment agencies.

\section{Conclusion}

Although record study showed that the care indicated / home care delivered match is moderate, and assessment agencies and home care organisations report in high percentages observing incongruity in this regard, the chronic patients themselves still generally report satisfaction with the way in which the assessment report is put into practise by the home care organisation. When the patients seem satisfied irrespective of the actual match, the question arises, as to whether it will be worth the assessment agencies' and 
home care organisations' while to try improving the match between care indicated and the home care subsequently delivered. Although pragmatism may inhibit such initiatives, reasoning from the patient's perspective on ameliorating the actual match, it will be inevitable.

\section{Acknowledgement}

This research project was funded by NWO-ZOB (Zorg, Opvang en Begeleiding; Netherlands Organisation of Scientific Research, programme Care and Support), the Netherlands. 


\section{References}

Algera M, Francke AL \& Van der Zee J (2002). Zorg-indicatiestelling 'nieuwe stijl' binnen de zorgketen: een literatuurstudie naar de haalbaarheid van de doelstellingen van de indicatiestelling 'nieuwe stijl' en de realisering van de zorgketen. ['New-style' needs assessment in the care chain; a study of the literature on the feasibility of the objectives of the 'new-style' needs assessment and realising the care chain.] Verpleegkunde, Nederlands-Vlaams Wetenschappelijk Tijdschrift voor verpleegkundigen; 17 (3): 140151.

Algera M, Francke AL, Kerkstra A \& Van der Zee J (2003). An evaluation of the new home care needs assessment policy in the Netherlands. Health and Social Care in the Community; 11 (3): 232-241.

Algera M, Francke AL, Kerkstra A \& Van der Zee J (2004). Home care needs of patients with long-term conditions: literature review. Journal of Advanced Nursing; 46 (4): 417-429.

Algera M, Francke AL, Spreeuwenberg P, Kerkstra A \& Van der Zee J (2004). The match between Dutch chronic patients' felt need and demand for home care and subsequent needs assessment. Submitted.

Algera M, Francke AL, Spreeuwenberg P \& Van der Zee J (2004). The match between Dutch chronic patients' felt need and home care delivered and its determinants. Submitted.

Andersen RM (1995). Revisiting the behavior model and access to medical care: does it matter? Journal of Health and Social Behavior; $36: 1-10$.

Bradshaw J (1972). A taxonomy of social need. In: MacLachlan G (Ed.). Problems and progress in medical care. Oxford: University Press; p. 69-82.

Caris-Verhallen WMCM (1999). Nurse-patient communication in elderly care; an observation study into verbal and nonverbal communication in nursing practice. Utrecht: Nivel/University Utrecht (thesis).

Caris-Verhallen W \& Kerkstra A (1998). Cliënten op de wachtlijst voor een verpleeghuis of verzorgingshuis en hun ervaring met de continuiteit van zorg. [Patients on a waiting list for a nursing home or a home for the elderly and their experience with the continuity of care.] Utrecht: Nivel.

Hutten JBF \& Kerkstra A (2002). Home care is what people want. In: Van Rooij EHC, Droyan Kodner L, Rijsemus AH \& Schrijvers AJP (Ed.). Health and health care in the Netherlands: a critical self-assessment of Dutch experts in medical and health sciences. Maarssen: Elsevier Gezondheidszorg; p. 101-110.

Kerkstra A, Verheij RA, Foets M \& Van der Velden J (1990). Behoefte aan nazorg en verleende nazorg na ontslag uit het ziekenhuis. [Need for aftercare and provided aftercare following discharge from hospital.] Tijdschrift voor Sociale Gezondheidszorg; 68 (8): 346-354. 
Ministerie van Volksgezondheid, Welzijn \& Sport (1997). Zorgindicatiebesluit (Besluit van 2 oktober 1997, houdende regels met betrekking tot het werkterrein, de samenstelling en werkwijze van indicatie-organen). [Care Needs Assessment Decree (White Paper of October, 2 1997, regarding field of activities, the formation, and the operation of Regional Needs Assessment Agencies).] Staatsblad van het Koninkrijk der Nederlanden. Den Haag: Sdu, 447.

Nationale Raad voor de Volksgezondheid (1994). Indicatiestelling en zorg op maat: advies van de Nationale Raad voor de Volksgezondheid en het College voor Ziekenhuisvoorzieningen. [Needs assessment and customised care: recommendations by the National Council for Public Health and the Council for Hospital Facilities.] Zoetermeer: Nationale Raad voor de Volksgezondheid.

Riemsma RP, Klein G, Taal E, Rasker JJ, Houtman PM, Van Paassen HC \& Wiegman O (1998). The supply of and demand for informal and professional care for patients with rheumatoid arthritis. Scandinavian Journal of Rheumatology; 27: 7-15.

Scholte op Reimer WJM (1999). Long-term care after stroke: studies on care utilisation, quality of care and burden of caregiving. Amsterdam: University of Amsterdam (thesis).

Schrijvers AJP (2001). RIO, het jongste kind groeit op; eindrapport van de evaluatie van het Zorgindicatiebesluit van 1998. [The assessment agency, the youngest child grows to maturity; final report on the evaluation of the Care Needs Assessment Decree of 1998.] Utrecht: Julius Centrum voor Huisartsgeneeskunde en Patiëntgebonden onderzoek.

Snijders TAB \& Bosker RS (1999). Multi-level analysis: an introduction to basic and advanced multi-level modeling. London: Sage Publications.

Van Campen C, Sixma HJ, Kerssens JJ \& Peters L (1997). Assessing non-institutionalised asthma and COPD patients' priorities and perceptions of quality of health care: the development of the QUOTE-CNSLD instrument. Journal of Asthma; 34: 531-538. 


\section{The match between Dutch chronic patients' 7 felt need and home care delivered and its}




\begin{abstract}
Objectives This paper provides insight into the match between Dutch chronic patients' felt need for care and the home care delivered. Home care may be delivered professionally by home care organisations or informally by spouses or other relatives. Considering the needs assessment as an intermediary link between needing and receiving professional home care, the match between felt need and care indicated on the one hand and between care indicated and professional home care delivered on the other are taken into account. In addition, factors influencing the felt need for care / professional home care delivered match are studied, viz. characteristics of patients, assessment agencies, and home care organisations.
\end{abstract}

Method Data from more than 400 chronic patients, whose needs were assessed by an assessment agency, were collected by means of a telephone survey. The background characteristics of assessment agencies and home care organisations were gathered by means of a questionnaire. Actual match between felt need/demand for care and home care delivered was determined by comparing the type of home care delivered as noted in home care organisations' records with the felt need / demand for care as described by the patients during the telephone interview. In addition, the patients were asked for their views on the match and for their views on the role informal care plays in this match.

Results Results show that when patients receive home care matching their felt need for it, informal care rather than professional home care may be held accountable for it. With respect to the delivery of home care by professionals, only one-third of the patients received home care exactly matching their felt needs. In approximately half of the cases the professional home care received met only part of the patients' felt needs.

No significant influence of characteristics of assessment agencies and home care organisations was found on the felt need/demand for care / professional home care delivered match. However, both actual and patients' perceived felt need / demand for professional home care delivered match appear to be significantly determined by the two component matches in the process of obtaining professional home care: a) the match between felt need/demand for home care and the care indicated by an assessment agency and b) the match between the care indicated and professional home care delivered. 
Conclusion Needs assessment and care indication by assessment agencies appear to be a crucial phase in the process of obtaining professional home care to meet the patients' felt need or demand for it, both in real terms and in the patients' perception.

Keywords needs assessment, home care, chronic illness, the Netherlands

\section{Summary}

What is already known about this topic:

- needs assessment does not always match the patient's felt need for care

- professional home care delivery does not always match the patient's care indicated

What this paper adds:

- professional home care delivery does not always match the patient's felt need for care

- needs assessment and care indication by assessment agencies are a crucial phase in the process of obtaining professional home care to meet the patients' felt need or demand for it, both in real terms and in patients' perception

- quantitative demonstration of the worth of informal care in meeting the patients' felt need

\section{Introduction}

Today, care providers and policy makers emphasise the fact that care delivered has to correspond with the patients' need for care. Patient rights, integrated care, lack of funds, cost cutting, and the substitution of home care for institutionalised care, particularly for the chronically sick, demand a proper match. In principle, needs assessment, in the sense of a formalised process of determining the need for care and subsequently indicating the reasonable and adequate care regarding type and amount of care (Nationale Raad voor de Volksgezondheid, 1994), has to be the link between felt need for care and delivery of care. Home care organisations, however, are said to base their needs assessment on availability of care facilities rather than patient's felt needs. Therefore, in 1998, the Dutch government initiated a new-style needs assessment to be performed by independent regional assessment agencies. The new-style needs assessment was to be organised pursuant to the Care Needs Assessment Decree (Ministerie van Volksgezondheid, Welzijn \& Sport, 1997). Its organisation and objectives 
are presented in Box 7.1.

Box 7.1 New-style needs assessment according to the Care Needs Assessment Decree (Ministerie van Volksgezondheid, Welzijn \& Sport, 1997)

Organisation of new-style needs assessment

- establishment of independent regional assessment agencies ('Regionale IndicatieOrganen': RIO's) resorting under the responsibility of municipalities, covering the whole country;

- assessment of chronic and other patients' needs for various types of care: home care and long-term residential care (obligatory) and social welfare (optional);

- assessment of complex needs for care: only by assessment agencies; assessment of noncomplex needs for care (e.g. administering eye drops or putting on support stockings): authorisation arrangements to home care organisation are allowed.

Three objectives of new-style needs assessment

- more independence than in the former way of needs assessment by assessing independently from the availability of care;

- more objectivity: to be reached by using uniform assessment protocols;

- comprehensiveness, to be obtained by taking into account various types of care; for instance, when a patient needs home care as well as a type of (semi-)residential care, the assessor integrates both types of care needs in the assessment procedure and assessment report.

If the main objectives of new-style needs assessment could be achieved, the needs assessment would become needs-led instead of supply-oriented, as had been the case in the past. This would imply a better fit between the patient's felt needs for care, what assessment agencies indicate the care to be needed, and the care (home) care organisations deliver (Algera et al., 2002). The matches in the chain among need/demand, indication and delivery are shown in Figure 7.1. The diagram also points to characteristics of assessment agencies, home care organisations, and chronic patients that might influence these matches.

The new-style needs assessment was expected to lead to better matches between

a. patients' felt need for care and the care indicated;

b. the care indicated and the home care actually delivered; and therefore

c. patients' felt need for care and the home care delivered. 
Figure 7.1 Research model: the matches between patient's felt need and demand for care, care indicated and home care delivered, and factors possibly influencing these matches

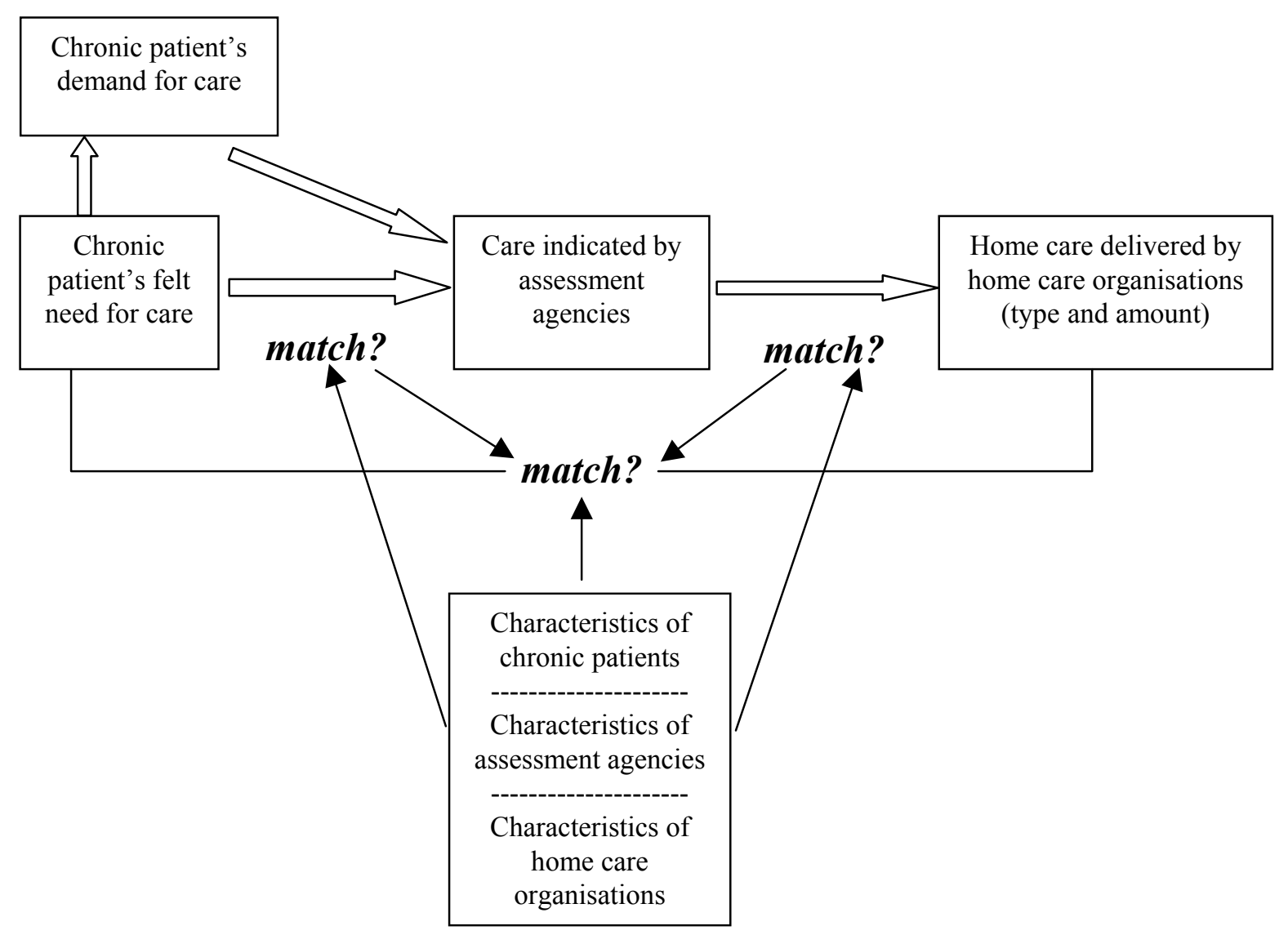


By 'need for care' the present authors mean a patient's felt need with regard to health related deficits. For the purposes of this paper, the patient's demand for home care is defined as the patient's expression of the felt need for care (Bradshaw (1972): 'expressed need'), in this case toward an assessment agency. The 'care indicated' by an assessment agency is the result of the needs assessment, which is described in the agency's assessment report. The home care delivered concerns the type and amount of care the home care organisation provides to the chronic patient. Professional home care should complement the informal home care provided by the patient's partner or 'significant others' in the patient's environment. In the Netherlands, professional home care includes IADL-care (i.e. care relating to instrumental activities of daily life; also called domestic care or home help), ADL-care (i.e. care relating to activities of daily life; also called physical or personal care), technical nursing care, and psychosocial care, delivered by professionals at the patient's home (Hutten \& Kerkstra, 2002).

\section{Research questions}

In a broad research project the matches mentioned above (see Figure 7.1) are being studied in a group of chronic patients. The match between the patient's felt need for care and the care indicated by the assessment agency appeared to be rather poor (Algera et al., 2004a). The match between the care indicated and the professional home care delivered proved to be substantially better (Algera et al., 2004b).

In this paper, the focus is on the match between the patient's felt need and demand for care on the one hand and the home care delivered, taking the linking pin of care indicated into account. This match is operationalised in three ways:

a. patients' opinions on the match between felt need and home care delivered;

b. the actual match between patient felt need and type of home care delivered;

c. the actual match between the patient's demand and home care delivered, as demand is not always the same as felt need (Huijsman, 1990; Kerkstra et al., 1990; SGBO, 2000; Algera et al., 2004a).

Since the 'type of home care delivered' was determined first by what the patients themselves said they had received, either professionally or 
informally, and, second, by what was recorded in the home care organisations' records, additional matches could be computed. Furthermore, where appropriate, a distinction between professional and informal home care is made.

The following research questions will be addressed:

1. To what extent does chronic patients' felt need for care match the home care delivered?

2. To what extent does chronic patients' demand for care match the home care delivered?

3. What characteristics of patients, home care organisations, and assessment agencies are related to these matches?

Finally, it seemed relevant to study the influence of the submatches on the felt need/demand for care / received home care match, since matches incorporating needs assessment and care indicated are seen as an intermediary link in the chain from need to reception. The sub-matches comprise the match between felt need/demand for care and care indicated on the one hand and the match between the care indicated and professional home care delivered on the other.

4. To what extent do the submatches concerning needs assessment and care indicated influence the match between felt need and professional home care delivered?

\section{Expectations}

The present authors expected several characteristics of chronic patients, home care organisations, and assessment agencies to influence the extent of the match between the patient's felt need and demand for care and the professional home care delivered.

Patient characteristics may be classified as need factors, predisposing characteristics and enabling resources (Andersen, 1995). Influence was expected with regard to the following:

- complexity of felt need for care of care indicated (need factor); in case of complex needs for care or care indicated, as is often seen in patients suffering from various diseases simultaneously (comorbidity), a poorer match was expected because in those cases not all needs may be recognised by the assessor or they may not be satisfied by the home care organisation; 
- age (predisposing characteristic); younger patients were expected to be more eloquent and assertive, which may give them a better chance of an adequate match;

- having had previous experiences with professional home care (enabling resource); if patients had already received home care in the past, their evaluation of that period of care may influence their current perception.

As regards the home care organisations, some of the following factors were expected to influence the match between felt need or demand for care and professional home care delivered:

- shortage of staff; where there is a shortage of staff in the home care organisation, the hours indicated by the assessment agency may not be delivered to the chronic patient, who, in turn, will face a mismatch between felt need and delivery of professional home care;

- waiting lists; a delay in delivering the care indicated may be observed when the home care organisation is not able to provide the care indicated momentarily and therefore felt needs will not be satisfied.

Some of the assessment agency's characteristics, expected to influence the match between felt need and demand for care and professional home care delivered were:

- when assessment agencies have authorised home care organisations to assess non-complex needs for care; where both needs assessment and delivery are concentrated in the home care organisation, a worse fit between felt need and care delivered may result from rationing the available home care;

- when assessment agencies use national assessment forms in which the objectives of the new-style needs assessment are assimilated; where the assessment agency uses these forms, the relevant details essential for home care organisations will be present in the assessment report, which may positively influence the match at hand;

- the level of detail in the assessment report; more detailed assessment reports would help home care organisations to start their initial care to the patients.

Finally, adequate matches between (a) felt need or demand for care and the care indicated and (b) care indicated and professional home care delivered was expected to be conditional upon achieving the match between felt need 
and home professional care delivered.

\section{Method}

Of 85 assessment agencies, 78 had participated in a previous part of the study (Algera et al., 2003). These assessment agencies were asked to randomly select chronically ill patients, who had presented a demand for home care at the assessment agency's office; of them, 49 were willing to cooperate in the current part of the study. Lack of time and staff or deficient data registration systems caused the other 29 assessment agencies to refrain from further participation. The patients selected had to meet the following inclusion criteria:

- they had suffered from a stroke, another chronic neurological disorder, chronic heart failure, diabetes mellitus, rheumatoid arthritis, and/or chronic disorders of the respiratory system;

- they were over 18 years of age;

- they were able to participate in a Dutch-language telephone interview;

- they had submitted an application for professional home care to the assessment agency;

- they were in receipt of a positive or negative decision on care allocation following needs assessment, noted in an assessment report; being on a waiting list was no exclusion criterion;

- they were in receipt of an assessment report made in the previous three months.

Not all assessment agencies were able to select patients by chronic disease criteria. A pilot project among three assessment agencies showed that, on average, every third randomly selected patient met the disease criterion. In addition, in other research in the Netherlands (Van Campen et al., 1997; Caris-Verhallen \& Kerkstra, 1998), the response rate among home care users, responding to a questionnaire, was approximately $30 \%$. It was computed that about 4000 selected patients would be needed to provide final data for analysis from 400 patients. The number of 400 cases was based on power-analyses. In the event, 3814 patients were selected, eventually yielding 402 patient data sets.

By way of the assessment agencies, an explanatory letter from the researcher, a consent form and a stamp-addressed envelope were sent to the patients whose needs had been assessed. Of the 3814 patients selected by the 
assessment agencies, 1611 (42.2\%) patients returned their consent form. Of this group, 983 refrained from participation, mostly because of age, health, or lack of interest. No additional information on non-responders was available. Therefore, non-response analyses were impossible. Finally, 628 $(39.0 \%)$ patients agreed to participate. Subsequently, 226 of these 628 patients were excluded because they did not meet the inclusion criteria after all. In the end, data sets for 402 of the 628 patients $(64.0 \%)$ were used in the analyses.

Table 7.1 Characteristics of respondents $(\mathrm{n}=402)$

\begin{tabular}{|c|c|c|}
\hline \multirow[t]{9}{*}{ Disease } & Stroke & $16.4 \%$ \\
\hline & Other neurological illness & $21.6 \%$ \\
\hline & Chronic heart failure & $27.9 \%$ \\
\hline & Diabetes mellitus & $15.9 \%$ \\
\hline & Rheumatic disease & $39.1 \%$ \\
\hline & Chronic respiratory disorder & $20.1 \%$ \\
\hline & Other chronic disease & $19.9 \%$ \\
\hline & Other non-chronic disease & $14.4 \%$ \\
\hline & Comorbidity present & $46.8 \%$ \\
\hline \multirow[t]{5}{*}{ Living arrangements } & Alone & $43.0 \%$ \\
\hline & With spouse & $52.0 \%$ \\
\hline & With children/parents & $9.7 \%$ \\
\hline & With fellow residents & $1.7 \%$ \\
\hline & Temporarily admitted & $0.5 \%$ \\
\hline \multirow[t]{8}{*}{ Highest education } & Lower education & $46.5 \%$ \\
\hline & Primary school & $31.8 \%$ \\
\hline & Lower vocational & $14.7 \%$ \\
\hline & Higher education & $48.3 \%$ \\
\hline & Secondary school & $22.4 \%$ \\
\hline & Medium vocational & $15.7 \%$ \\
\hline & Higher vocational / university & $10.2 \%$ \\
\hline & Missing & $5.2 \%$ \\
\hline
\end{tabular}

Table 7.1 contains some characteristics of the respondents. The mean age of the respondents was 67 (SD: 14); three out of four were women. About half of the respondents suffered from various diseases simultaneously 
(comorbidity), the proportion of respondents suffering from rheumatoid arthritis was the largest. Telephone interviews with the patients themselves were possible in $85 \%$ of the cases, in other cases spouses or other informal caregivers were interviewed on the patient's behalf.

\section{Variables and measuring instruments}

Figure 7.2 holds an overview of the variables and the instruments used in this part of the study.

A structured telephone interview scheme was constructed to gather data by telephone about patient characteristics and patient satisfaction on several care related aspects. In addition, their felt need and their demand for care were identified during the telephone interview as well as information according to themselves about who provided for the home care they received either professionally or informally. Finally, their opinion on the match between the felt need and professional home care delivered was solicited. As far as felt need was concerned, our interview scheme was based on a valid and reliable questionnaire by Kerkstra et al. (1990). The other items were self-developed (see Figure 7.2). Home care delivery according to the home care organisation's records was measured about a year after the telephone interview. In the time elapsed, in many cases professional home care was started.

The content validity of the structured interview scheme was tested in a meeting of experts in the field of assessment agencies, home care organisations, and health insurers $(n=7)$ and in a separate meeting of chronically ill patients $(n=6)$. The resulting adjusted version was tested among another 20 patients who had dealt with an assessment agency and who met the inclusion criteria. Their comments were integrated into the final version.

Data on characteristics of assessment agencies and on how the assessment procedure was organised were collected by means of a self-developed questionnaire for assessment agencies, content validated by managers of assessment agencies and other experts. 
Figure 7.2 Variables in relation to instruments used or way of data collection

\begin{tabular}{|c|c|}
\hline Variables & $\begin{array}{l}\text { Instruments used or way of data } \\
\text { collection }\end{array}$ \\
\hline $\begin{array}{l}\text { Match between felt need for care and home } \\
\text { care delivered, as perceived by patients }\end{array}$ & $\begin{array}{l}\text { Self-developed item included in } \\
\text { telephone interview scheme about } \\
\text { patient's opinion }\end{array}$ \\
\hline $\begin{array}{l}\text { Actual match between felt need for care and } \\
\text { home care delivered }\end{array}$ & $\begin{array}{l}\text { Comparison of need for care (items from } \\
\text { Kerkstra et al. (1990) measuring IADL, } \\
\text { ADL, technical nursing, and } \\
\text { psychosocial needs included in telephone } \\
\text { interview scheme) with home care } \\
\text { organisations' records }\end{array}$ \\
\hline $\begin{array}{l}\text { Actual match between demand for care and } \\
\text { home care delivered }\end{array}$ & $\begin{array}{l}\text { Comparison of demand for care included } \\
\text { in telephone interview scheme with } \\
\text { home care organisations' records }\end{array}$ \\
\hline $\begin{array}{l}\text { Match between felt need and professional } \\
\text { home care delivered from patient's } \\
\text { perspective }\end{array}$ & $\begin{array}{l}\text { Comparison of need for care with } \\
\text { professional home care delivered, both } \\
\text { included in telephone interview scheme }\end{array}$ \\
\hline $\begin{array}{l}\text { Match between felt need and professional } \\
\text { and informal home care delivered from } \\
\text { patient's perspective }\end{array}$ & $\begin{array}{l}\text { Comparison of need for care with } \\
\text { professional and informal home care } \\
\text { delivered, both included in telephone } \\
\text { interview scheme }\end{array}$ \\
\hline Patient characteristics & \\
\hline $\begin{array}{l}\text { Predisposing characteristics } \\
\text { - age } \\
\text { - sex } \\
\text { - patient's satisfaction of about } \\
\text { amount of professional and } \\
\text { informal care received }\end{array}$ & $\begin{array}{l}\text { Self-developed items included in } \\
\text { telephone interview scheme }\end{array}$ \\
\hline $\begin{array}{l}\text { Enabling resources } \\
\text { - having had previous experiences with } \\
\text { professional home care } \\
\text { patient's perceived match between } \\
\text { felt need for care and care indicated } \\
\text { actual match between felt need for } \\
\text { care and care indicated } \\
\text { actual match between demand for care. } \\
\text { and care indicated }\end{array}$ & $\begin{array}{l}\text { Self-developed item included } \\
\text { telephone interview scheme } \\
\text { Algera } \text { et al. }(2004 \mathrm{a}) \\
\text { Algera et al. }(2004 \mathrm{a}) \\
\text { Algera et al. }(2004 \mathrm{a})\end{array}$ \\
\hline
\end{tabular}


Figure 7.2 Continued I

\begin{tabular}{|c|c|}
\hline Variables & $\begin{array}{l}\text { Instruments used or way of data } \\
\text { collection }\end{array}$ \\
\hline $\begin{array}{l}\text { - patient's perceived match between care } \\
\text { indicated and home care delivered } \\
\text { - actual match between care indicated } \\
\text { and home care delivered } \\
\text { - actual match between felt need for } \\
\text { care and home care delivered }\end{array}$ & $\begin{array}{l}\text { Algera et al. }(2004 \mathrm{~b}) \\
\text { Algera et al. }(2004 \mathrm{~b}) \\
\text { Algera et al. (this paper on match } \\
\text { between felt need for care and home care } \\
\text { delivered) }\end{array}$ \\
\hline $\begin{array}{l}\text { Need factors } \\
\text { - } \text { presence of comorbidity } \\
\text { - } \quad \text { receiving additional informal care } \\
\text { - } \quad \begin{array}{l}\text { complexity of care indicated by } \\
\text { assessment agencies }\end{array} \\
\text { - } \quad \text { complexity of felt need for care }\end{array}$ & $\begin{array}{l}\text { Self-developed item included in } \\
\text { telephone interview scheme } \\
\text { Self-developed item included in } \\
\text { telephone interview scheme } \\
\text { Assessment agencies' reports } \\
\text { Based on Kerkstra et al. (1990): items } \\
\text { measuring IADL, ADL, technical } \\
\text { nursing, and psychosocial needs included } \\
\text { in telephone interview scheme }\end{array}$ \\
\hline $\begin{array}{l}\text { Characteristics of assessment agencies } \\
\text { - period of being in operation } \\
\text { - } \quad \text { authorisation of assessments non- } \\
\text { complex home care needs to home } \\
\text { care organisations } \\
\text { - } \text { working with a standardised set of } \\
\text { assessment forms } \\
\text { - number of assessment fields } \\
\text { - level of detail of assessment report } \\
\text { - patients having had to wait before } \\
\text { being assessed }\end{array}$ & $\begin{array}{l}\text { Self-developed items included in } \\
\text { questionnaire for assessment agencies }\end{array}$ \\
\hline $\begin{array}{l}\text { Characteristics of home care organisations } \\
\text { - lack of staff } \\
\text { - usability of assessment reports } \\
\text { - } \quad \text { waiting lists IADL-care and/or ADL- } \\
\text { care }\end{array}$ & $\begin{array}{l}\text { Self-developed items included in } \\
\text { questionnaire for home care organisations }\end{array}$ \\
\hline
\end{tabular}


Data on characteristics of home care organisations, on the part they played in handling waiting lists, and on opinions about the quality of the reports of assessment agencies, were also collected by means of a self-developed questionnaire for home care organisations, content validated by managers of home care organisations and other experts.

\section{Data collection}

Patient data were collected by experienced telephone interviewers from November 2000 through May 2001. On average, interviews lasted about 20 minutes.

The questionnaires for assessment agencies and home care organisations were distributed in May 2000. The response was $92 \%$ and $81 \%$, respectively. The main characteristics of assessment agencies were updated by means of a quick scan at the time the assessment agency started to select the patients for the telephone interview.

In addition, specific items of home care organisations' records of the participating patients were studied to discover more specific data on home care eventually delivered.

All but two organisations agreed to participate in this part of the study (number of patients lost $=19$ ). However, not all chronic patients involved in our study could be traced by the home care organisation (number of patients lost $=27$ ). Another 19 patients were still waiting for care and 11 patients did not give consent for the use of their records. Finally, data on type and amount of professional home care delivered were collected for 326 of the 402 chronic patients involved (81\%). However, being put on a waiting list or having received a negative care allocation on behalf of the assessment agency led to infer in even more cases whether or not a (mis)match had occurred $(n=360)$.

The number of patients per home care organisation varied from 1 to 27 (mean: 6.70, SD: 6.08).

\section{Analyses}

The patients' felt need and demand for care and the care eventually delivered by the home care organisation or by informal caregivers was coded as 
IADL-care, ADL-care, technical nursing care, or psychosocial care as well as combinations of these.

The actual match between felt need or demand for care and home care delivered (see research questions 1 and 2) was determined by the comparison of what was mentioned by the patients themselves with what had been noted by the home care organisation ${ }^{1}$. The type of professional and/or informal home care delivered was also ascertained during the telephone interview. 'Perfect matches' were established when the type of home care delivered was identical to the patient's felt need or demand for care. Cases in which the delivery of care exceeded the felt need or demand for care were coded as 'overdelivery'. 'Underdelivery' was recorded when the patient requested, for instance, the combination of IADL- and ADL-care, but only received IADLcare. Being put on a waiting list was coded as a 'mismatch' as were cases in which a totally different type of care was delivered to that judged necessary by the patients themselves. The types of care in which the above-mentioned degrees of match were determined, were discovered by making crosstabulations.

To answer research questions 3 and 4, multi-collinearity among the independent variables was first determined. When a statistically significant correlation of $>0.70$ between two independent variables was detected, one of them was excluded.

When analysing the factors of influence on the matches under study, the dependent variable was 'match' (a combination of 'perfect match' and 'overdelivery') or 'mismatch' (a combination of 'underdelivery' and 'mismatch'). To study the relation between the dependent variables and a series of independent variables, logistic regression analysis seemed appropriate. Given the nature of the data, three methodological aspects had to be incorporated into the statistical analyses. First, it was expected that there would be a nesting of patients within home care organisations. Secondly, the number of patients per home care organisation in this study

\footnotetext{
1 'Demand for care' was measured in two ways: during the telephone interview and in the assessment report. For the purposes of this paper, results proved to be comparable. The number of cases was larger concerning demand for care measured during the telephone interview; therefore this measure was chosen for the analysis in this paper.
} 
varied greatly (see also Data collection section). Thirdly because the independent variables were measured at two different levels (the patient's and the organisation's), statistical artefacts such as the ecological and atomistic fallacy had to be avoided. To deal adequately with these three aspects in one analysis, a multi-level approach to (logistic) regression analysis was used. In the literature (Snijders \& Bosker, 1999), a more elaborate discussion can be found of why a multi-level approach for this kind of data is appropriate. The software used was MLWIN. With regard to each match a series of theoretically relevant independent variables concerning the characteristics of patients, assessment agencies, and home care organisations were entered into multi-variate multi-level analyses simultaneously.

As regards question 4, matches between felt need, demand for care, care indicated, and type of professional home care delivered (see Figure 7.1) were entered into multi-level analyses as independent variables with the match between felt need for care and professional home care delivered as the dependent variable.

\section{Results}

Patients' opinions on the match between felt need for care and home care delivered

The patients were asked whether they thought that the home care delivered corresponded, in general, with their felt need for care. Three-quarters of the patients $(75.0 \%)$ were of the opinion that there was such a match. Two-thirds of this positively judging group stated that only professional home care staff met their felt needs; the others were served by either informal home carers or by a combination of informal home carers and professional home care staff. In $11.3 \%$ of all cases, the patients experienced an acceptable, though not perfect match, between felt needs and care delivered. One out of seven patients $(13.7 \%)$ said that there was barely any or no correspondence between their felt need for care and the home care delivered.

Match between patients' felt need for care and professional home care delivered

Felt need mentioned by patients during the telephone interview and home care delivered by home care organisations, according to their records, were compared (see Table 7.2) 
In $32.2 \%$ of the cases in which a comparison was possible $(\mathrm{n}=357)$, a perfect match between the patient's felt need for care and the professional home care delivered could be verified. A perfect match was most often achieved in IADL-care: in almost three-quarters of the cases, in which only IADL-care was needed in the view of the patients themselves, the home care organisation also exclusively delivered it.

Table 7.2 Type of match (in \%) between felt need for care and professional home care delivered, regarding type of care

\begin{tabular}{|c|c|c|c|c|c|c|}
\hline \multicolumn{2}{|c|}{ Felt need for care } & \multirow[t]{2}{*}{$\begin{array}{l}\text { Perfect } \\
\text { match }\end{array}$} & \multirow[t]{2}{*}{$\begin{array}{c}\text { Over- } \\
\text { delivery }\end{array}$} & \multirow[t]{2}{*}{$\begin{array}{l}\text { Under- } \\
\text { delivery }\end{array}$} & \multicolumn{2}{|c|}{ Mismatch } \\
\hline & & & & & $\begin{array}{c}\text { Other } \\
\text { type of } \\
\text { care } \\
\text { delivered }\end{array}$ & $\begin{array}{c}\text { No } \\
\text { professional } \\
\text { care } \\
\text { delivered } \\
\end{array}$ \\
\hline I & $(n=109)$ & 74.3 & 2.8 & not applicable & 8.3 & 14.7 \\
\hline $\mathrm{A}$ & $(n=2)$ & 50.0 & 0.0 & not applicable & 50.0 & 0.0 \\
\hline $\mathrm{N}$ & $(n=5)$ & 60.0 & 40.0 & not applicable & 0.0 & 0.0 \\
\hline \multicolumn{7}{|l|}{$\mathrm{P}$} \\
\hline $\mathrm{I}+\mathrm{A}$ & $(n=60)$ & 23.3 & 3.3 & 51.7 & 3.3 & 18.3 \\
\hline $\mathrm{I}+\mathrm{N}$ & $(n=16)$ & 0.0 & 6.3 & 62.5 & 12.5 & 18.8 \\
\hline $\mathrm{I}+\mathrm{P}$ & $(n=46)$ & 17.4 & 0.0 & 67.4 & 8.7 & 6.5 \\
\hline $\mathrm{A}+\mathrm{N}$ & $(n=1)$ & 0.0 & 0.0 & 100.0 & 0.0 & 0.0 \\
\hline \multicolumn{7}{|l|}{$\mathrm{A}+\mathrm{P}$} \\
\hline $\mathrm{N}+\mathrm{P}$ & $(n=1)$ & 0.0 & 0.0 & 0.0 & 100.0 & 0.0 \\
\hline $\mathrm{I}+\mathrm{A}+\mathrm{N}$ & $(n=38)$ & 15.8 & 2.6 & 73.7 & 0.0 & 7.9 \\
\hline $\mathrm{I}+\mathrm{A}+\mathrm{P}$ & $(n=39)$ & 5.1 & 0.0 & 74.4 & 10.3 & 10.3 \\
\hline $\mathrm{I}+\mathrm{N}+\mathrm{P}$ & $(n=9)$ & 0.0 & 0.0 & 100.0 & 0.0 & 0.0 \\
\hline $\mathrm{A}+\mathrm{N}+\mathrm{P}$ & $(n=1)$ & 0.0 & 0.0 & 100.0 & 0.0 & 0.0 \\
\hline $\mathrm{I}+\mathrm{A}+\mathrm{N}+\mathrm{P}$ & $(n=30)$ & 0.0 & 0.0 & 100.0 & 0.0 & 0.0 \\
\hline Overall & $(n=357)$ & 32.2 & 2.5 & 47.6 & 6.4 & 11.2 \\
\hline
\end{tabular}

$\mathrm{I}=$ IADL-care, domestic care

$\mathrm{A}=$ ADL-care, physical personal care

$\mathrm{N}=$ technical nursing care

$\mathrm{P}=$ psychosocial care

Overdelivery was rarely observed: in only $2.5 \%$ of the cases more types of care were delivered than what patient's felt needs led to believe. In contrast, underdelivery was present in $47.6 \%$ of the cases and most frequently occurred in cases where patients felt more complex (i.e. multiple) care 
needs. Looking at types of felt need for care which occurred more than 25 times, underdelivery was found most often in the combination of IADL/ADL-care, as well as in combination with technical nursing care and/or psychosocial care. In such cases, most frequently it was only IADLcare that was delivered and other types were left out.

A mismatch occurred in about one fifth of the cases: up to six percent of the patients received a totally different type of professional care and in up to about eleven percent of the cases, no professional care was delivered at all.

\section{Other matches}

By analogy to Table 7.2, other matches were computed. They were:

- the match between demand for home care (as expressed by the patients during the telephone interview) and professional home care delivered (according to home care organisations' records);

- the match between felt need for care and just professional home care delivered according to the patients themselves (telephone interview);

- the match between felt need for care and professional as well as informal home care delivered according to the patients themselves (telephone interview).

Figure 7.3 shows that a perfect match could be observed in about $58 \%$ of the cases in which comparisons could be made $(n=349)$ as regards the demand/delivered match. This is almost twice as much as the felt need for care / professional home care delivered match. Underdelivery was mostly seen in respect of the need for the combination of IADL- and ADL-care. Overall, there was underdelivery in about one tenth of the cases, whereas overdelivery occurred in about an equal percentage of the cases. Mismatches occurred in almost a quarter of the cases $(22.7 \%)$ and were dispersed equally over deliveries of a completely different type of care, compared with the demand for it and the failure to deliver any care. In greater detail, in onethird of the cases, a totally different type of care was delivered in response to the ADL-care demand presented to the assessment agency.

The patients were asked to distinguish between home care delivered by professionals with that from informal caregivers. These types of home care were compared to patient's initial felt need $(n=398)$. A large discrepancy was observed between the resulting matches. A perfect match in the 
Figure 7.3 Degree of overall-matches (in \%)

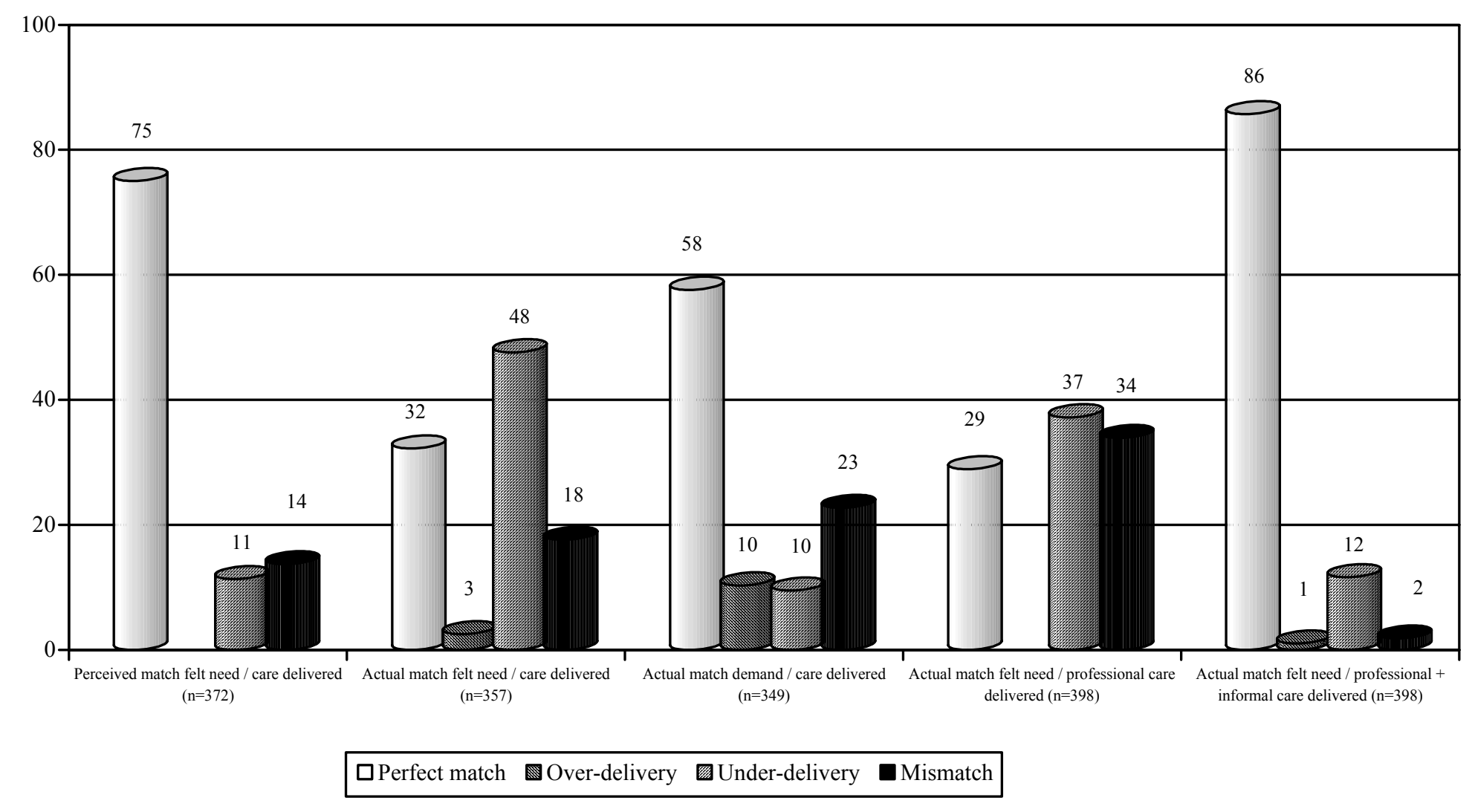


Table 7.3 Results of multi-variate multi-level analyses on characteristics of patients, assessment agencies, and home care organisations explaining perfect matches between felt need/demand for care and professional home care delivered regarding type of care, based on patients' views and record study

\begin{tabular}{|c|c|c|c|c|c|c|}
\hline & \multicolumn{2}{|c|}{$\begin{array}{c}\text { Perceived match felt need / } \\
\text { professional home care } \\
\text { delivered }(n=191)\end{array}$} & \multicolumn{2}{|c|}{$\begin{array}{c}\text { Actual match felt need / } \\
\text { professional home care } \\
\text { delivered }(n=225)\end{array}$} & \multicolumn{2}{|c|}{$\begin{array}{l}\text { Actual match demand / } \\
\text { professional home care } \\
\text { delivered }(n=219)\end{array}$} \\
\hline & & & & & & SE B \\
\hline Age $(1=$ under $65 ; 2=65+)$ & -.00 & .06 & .02 & .59 & .19 & .36 \\
\hline Sex $(1=$ male; $2=$ female $)$ & -.10 & .07 & .55 & .64 & -.51 & .39 \\
\hline Comorbidity $(0=$ absent; $1=$ present $)$ & .02 & .06 & -.35 & .56 & .03 & .32 \\
\hline Previous experiences with home care $(0=$ no; $1=$ yes $)$ & -.00 & .06 & \multicolumn{2}{|c|}{ n.a. } & \multicolumn{2}{|c|}{ n.a. } \\
\hline $\begin{array}{l}\text { Patient's satisfaction with amount of professional and informal } \\
\text { home care received ( } 0=\text { no; } 1=\text { reasonable; } 2=\text { yes) }\end{array}$ & $.32 *$ & .06 & \multicolumn{2}{|c|}{ n.a. } & \multicolumn{2}{|c|}{ n.a. } \\
\hline Complexity of felt need $(0=$ non-complex; $1=$ complex $)$ & \multicolumn{2}{|c|}{ \# } & \multicolumn{2}{|c|}{ \# } & -.42 & .36 \\
\hline Complexity of care indicated $(0=$ non-complex; $1=$ complex $)$ & $.20 *$ & .08 & -1.99 & 1.03 & -.30 & .46 \\
\hline $\begin{array}{l}\text { Having received additional informal care at all } \\
(0=\text { no; } 1=\text { yes })\end{array}$ & -.13 & .07 & -.95 & .59 & .02 & .37 \\
\hline $\begin{array}{l}\text { Patient's perceived match between felt need and care indicated } \\
(0=\text { no; } 1=\text { yes })\end{array}$ & $.21 *$ & .10 & \multicolumn{2}{|c|}{ n.a. } & \multicolumn{2}{|c|}{ n.a. } \\
\hline $\begin{array}{l}\text { Actual match between felt need and care indicated } \\
(0=\text { mismatch } / \text { partial; } 1=\text { perfect } / \text { more })\end{array}$ & .04 & .07 & $3.65 *$ & .67 & \multicolumn{2}{|c|}{ n.a. } \\
\hline $\begin{array}{l}\text { Match demand for care (patient's perspective) and care } \\
\text { indicated }(0=\text { mismatch } / \text { partial; } 1=\text { perfect } / \text { more })\end{array}$ & \multicolumn{2}{|c|}{ n.a. } & \multicolumn{2}{|c|}{ n.a. } & \multirow[t]{2}{*}{$1.29 *$} & .40 \\
\hline $\begin{array}{l}\text { Patient's perceived match between care indicated and type of } \\
\text { professional home care delivered }(0=\text { no; } 1=\text { yes })\end{array}$ & $.70 *$ & .10 & & & & \\
\hline
\end{tabular}


Table 7.3 Continued I

\begin{tabular}{|c|c|c|c|c|c|c|}
\hline & \multicolumn{2}{|c|}{$\begin{array}{l}\text { Perceived match felt need / } \\
\text { professional home care } \\
\text { delivered }(n=191)\end{array}$} & \multicolumn{2}{|c|}{$\begin{array}{l}\text { Actual match felt need / } \\
\text { professional home care } \\
\text { delivered }(\mathbf{n}=\mathbf{2 2 5})\end{array}$} & \multicolumn{2}{|c|}{$\begin{array}{c}\text { Actual match demand } / \\
\text { professional home care } \\
\text { delivered }(n=219)\end{array}$} \\
\hline & B & SE B & B & SE B & B & SE B \\
\hline $\begin{array}{l}\text { Actual match between care indicated and type of professional } \\
\text { home care delivered ( } 0=\text { mismatch/partial; } 1=\text { perfect } / \text { more) }\end{array}$ & .05 & .07 & $3.11 *$ & .78 & & \\
\hline $\begin{array}{l}\text { Actual match between felt need for care and professional home } \\
\text { care delivered }(0=\text { mismatch } / \text { partial; } 1=\text { perfect } / \text { more })\end{array}$ & .08 & .07 & & & & \\
\hline Authorisation arrangements $(0=$ absent; $1=$ present $)$ & -.02 & .07 & .60 & .78 & 1.01 & .53 \\
\hline Use of assessment forms $(0=$ no; $1=$ partial; $2=$ complete $)$ & \multicolumn{2}{|c|}{ n.a. } & .16 & .45 & .18 & .24 \\
\hline Number of assessment fields $(0=$ less than $10 ; 1=$ over 10$)$ & \multicolumn{2}{|c|}{ n.a. } & .49 & .71 & .42 & .42 \\
\hline $\begin{array}{l}\text { Level of detail of assessment report according to assessment } \\
\text { agency }(0=\text { global; } 1=\text { detailed })\end{array}$ & \multicolumn{2}{|c|}{ n.a. } & .06 & .69 & -.10 & .45 \\
\hline Number of years of existence of assessment agency & -.01 & .06 & -.19 & .66 & -.74 & .44 \\
\hline Having had to wait before being assessed $(0=$ no; $1=y e s)$ & -.01 & .06 & \multicolumn{2}{|c|}{ n.a. } & \multicolumn{2}{|c|}{ n.a. } \\
\hline Waiting lists IADL-care $(0=$ absent; $1=$ present $)$ & .02 & .08 & -.26 & .97 & .03 & .54 \\
\hline Waiting lists ADL-care $(0=$ absent; $1=$ present $)$ & .03 & .06 & .94 & .78 & -.65 & .44 \\
\hline Lack of home care staff $(0=$ no; $1=$ yes $)$ & \multicolumn{2}{|c|}{ n.a. } & -.29 & .64 & .08 & .39 \\
\hline $\begin{array}{l}\text { Usability of assessment report according home care } \\
\text { organisation ( } 0=\text { useless; } 1=\text { useful })\end{array}$ & \multicolumn{2}{|c|}{ n.a. } & 1.34 & .93 & .86 & .49 \\
\hline Constant & 2.80 & .03 & -1.44 & .32 & .74 & .18 \\
\hline
\end{tabular}

* $\mathrm{p}<05$

n.a. Not applicable (theoretically not relevant)

\# $\quad$ Not to be included in analysis for statistical reasons (multi-collinearity or small number of observations) 
reception of professional care only was found in less than one-third of the cases $(28.9 \%)$ whereas, almost $86 \%$ of the patients felt their needs were met with the addition of informal care from partners and relatives (see Figure 7.3). This discrepancy seems to illustrate the importance of the informal home care in meeting the patients' felt needs. According to the patients, in one-third of the cases (33.9\%), professional home care did not satisfy the patient's felt need (mismatch) because no care was delivered at all.

When analysing these matches in greater detail, generally speaking there is a resemblance with the match between felt need and professional care delivered (see previous section). When looking at all matches, a perfect match is mostly found in IADL-care. Underdelivery is generally found in the combination of the more complex types of care: IADL-care and ADL-care and technical nursing care, be it combined with psychosocial care or not. Overdelivery is a rare phenomenon in practice.

\section{Patient, assessment agency, and home care organisation characteristics related to matches}

Table 7.3 holds an overview of most of the characteristics that were expected to have significant influence.

The patients seemed to perceive a match between felt need and professional care delivered match more often, when their evaluation of the amount of professional and informal home care was more positive. If complex care was indicated, the patients perceived a better match. Finally, if the patients felt the care indicated paralleled their need for it or, in their perception, professional home care delivered fitted the care indicated, they also tended to perceive a match between felt need for care and home care delivered.

Similarly, the actual felt need/professional care delivered match was significantly associated with the two other matches in the process for obtaining home care (see Figure 7.1): the match of the felt need/care indicated on the one hand and the match of care indicated/professional care delivered on the other.

The actual match between demand for care and care indicated appeared to be significantly influential with respect to the actual match between demand for care and professional care delivered. 


\section{Discussion}

Discussion on matches between felt need for care and home care delivered

Three-quarters of the patients asked, said there was a match between their felt need for care and the home care delivered. However, an actual match, derived by comparing the patient's initial felt need for care (retrieved in a telephone interview) and the professional home care delivered according to home care organisations' records could only be observed in one-third of the cases. Therefore, the authors of this paper conclude that the patients' perception of the match under study depends only partly on the actual match in professional home care delivery. Informal care seems to play a crucial role here, albeit an ambiguous one. When asking the patients who was responsible for the match between felt need and home care delivered, twothirds attributed the match solely to professional home care delivery. Judging by this, the role of informal care seemed limited. However, when asking the patients of whom they received a specific type of care, less than one-third of them said their felt needs were met by professional home caregivers alone, whereas $86 \%$ of the chronic patients mentioned receiving help from professionals as well as informal home caregivers. As regards the enormous increase in felt needs met, when informal care giving is added, it appears that the role of informal caregivers in meeting the chronic patient's felt need is of great importance. Apparently, chronic patients themselves tend to downsize the importance of informal care giving when asked for their judgement on the match between felt need and care delivered. This hardly seems right, when one takes into account the very considerable amount of informal caregiver assistance. So although informal caregivers are very helpful in meeting the patient's felt needs, patients themselves seem to look on meeting needs as a largely professional activity and tend to take the role of informal caregivers for granted.

The proportion of informal care in satisfying the patient's felt need is substantial, though understandable because assessment agencies have to take the possibilities and the impossibilities of informal carers into account in determining the type (and amount) of care they indicate in the assessment report. Accordingly it is known beforehand that in many cases professional home care will not be sufficient to meet the patient's need.

The patients' views about the match between felt need and care delivered are rather positive ( $75 \%$ of the patients), though less so than as regards the two 
component matches within the process of receiving home care: a) the felt need /care indicated match $(87 \%)$ and $b)$ the care indicated / care delivered match (89\%) (see Figure 7.1; Algera et al. 2004a, 2004b). However, since these are submatches, both are conditional in achieving an adequate overallmatch. Both figures should therefore be multiplied in predicting the perceived overall-match. By multiplying both percentages of the component matches $(89 \%$ times $87 \%)$, the percentage of the patients with the overall need/delivered match approaches 75 . Still, an explanation for the smaller overall percentage may be self-evident: the longer a sequence to be evaluated, in this case the process from needing home care to receiving it, the more chance there is that complications may occur along the way, leading to a less positive evaluation. One of those complications was expected to be the existence of waiting lists in home care. Our study, however, did not show an influence of waiting lists on the perceived match (see next section).

When comparing the match between the patient's felt need for care and professional home care delivered with the match between the patient's demand and professional home care delivered, the percentage of actual match is about twice as great in the latter case. Patients probably do not seek professional help for all their felt needs, but may prioritise them (Algera et al., 2004a).

Underdelivery of professional home care, i.e. failure to deliver all needed or required care by patients, can be observed in varying percentages. Here, the tension between needs-led or demand-oriented home care delivery and the professionalism of home care staff is made visible. The discrepancy between needing/demanding and receiving professional home care may be attributed to a difference of insight between the patients themselves and assessment agencies or home care organisations about the legitimacy of needing professional home care instead of informal care. Nevertheless, the occasional non-availability of home care may be responsible for underdelivery or even mismatch (delivering no care at all or a completely different type of care). In contrast, in some cases overdelivery is observed. Discarding the possibility of home care organisations having a surplus of care to be delivered, causing inequitable delivery, overdelivery may be caused by patients' underestimating their felt need for care or overestimating the endurance of 
informal carers. Assessment agencies are supposed to correct chronic patients' limited insight in this respect.

\section{Discussion on characteristics influencing matches}

Hardly any characteristic of chronic patients, assessment agencies or home care organisations could be significantly related to a better felt need/demand for home care / professional home care delivered match, either actually or perceived. The fact that just a few patient related factors could be identified has the implication that assessment agencies do not need to focus on specific groups among chronic patients. In addition, implementing different procedures in needs assessment, indication of care or delivery of home care would not have had effect on our sample directly.

However, results show that having an adequate felt need/care indicated match or having an adequate care indicated / professional care delivered match, is predictive of an adequate match between felt need or demand for home care and professional home care delivered. In other words: if adequacy is achieved in the separate links of the process chain in obtaining home care, the chance that the overall-match will occur increases. This appears to be the case with regard to the actual matches as well as the patients' perceived matches. With regard to these component matches some characteristics of the patients (age, presenting the demand for care themselves, already receiving some professional and/or informal care, complexity of need or care indicated) and assessment agencies (authorisation arrangements, the use of national assessment forms, the number of assessment fields, its length of being in operation) did show significant influence (Algera et al., 2004a, 2004b). The influence of patient and assessment agency characteristics on the match between felt need for care and professional home care delivered seems to be indirect through its component matches.

In summary, the two component matches in the process of obtaining home care, both encompassing the phase of needs assessment and care indication, turn out to be of influence on the matches, either actual or perceived, discussed in this paper. The authors conclude therefore that the needs assessment and care indication appear to be crucial in the process of obtaining home care. The objective of the operation to modernise the Exceptional Medical Expenses Act by making the needs assessment the linking pin between need for and supply of care would seem to be achieved. 
The fact that it was not possible to disclose significant associations regarding waiting lists and lack of home care staff was surprising because when conducting this study, practical and political emphasis was laid on reducing long waiting lists. Also, the level of detail of the assessment report (canvassed in both assessment agencies and home care organisations) did not seem to matter as regards the matches under study.

\section{Restrictions of the study}

In this study, the type of home care delivered was retrieved during a telephone interview as well as by screening home care organisations' records. The telephone interview was conducted at a maximum of three months after the patient's needs were assessed by the assessment agency. In many cases (about one-third), the patients had not yet received professional home care at the time of the telephone interview. As the study of the records took place about a year after the telephone interview, in the mean time many patients had actually received (some) home care. The comparability of the two sources is therefore somewhat limited, as are the respective matches.

As a result of the time elapsing between the telephone interview and the study of the records, the influence of waiting lists in home care is obscured to some degree. Although one-third of the patients were still on a waiting list three months after the needs assessment (the approximate time of the telephone interview), waiting lists do not seem to be of influence on the actual matches.

In studies of the records, which depend on the accuracy of what is recorded, the authors had to rely on the validity of home care organisation records. Not in all cases there was absolute certainty about whether the home care delivered according to the home care organisation was the care ensuing from the needs expressed during the telephone interview. Home care organisations' occasionally deficient recording of dates or type of care delivered made adequate retrieval of patient related data questionable in some cases.

In many cases, professional home care had already started at the time the patients were asked about their felt needs. It was impossible to measure the extent to which the initial needs were expressed by then, or whether the patients had convalesced in the meantime. It was also possible that informal 
care had been successfully organised, resulting in a smaller role for the home care organisation in complementing the informal care. In these cases, a mismatch between patient's felt needs and care delivered by a home care organisation should be expected beforehand and should be welcomed because it may demonstrate that professional home care delivery is needs-led and demand-driven.

Finally, In the Analysis section, consideration was given to the problem of the nesting of data within home care organisations. The multi-level analyses took this nesting problem into account. However, it may be argued, that nesting of patients within the assessment agencies is also present. The higher level included in our analyses could, therefore, also be the assessment agencies instead of the home care organisations. Additional analyses in this respect pointed to a considerable overlap in factors, which are of statistical influential on the matches under study. We argue that this, along with the theoretical consideration that for the matches under study the importance of possible nesting within home care organisations exceeds that of within assessment agencies, justified our choice of the highest level in these multilevel analyses.

\section{Acknowledgement}

This research project was funded by NWO-ZOB (Zorg, Opvang en Begeleiding; Netherlands Organisation of Scientific Research, programme Care and Support), the Netherlands. 


\section{References}

Algera M, Francke AL \& Van der Zee J (2002). Zorg-indicatiestelling 'nieuwe stijl' binnen de zorgketen: een literatuurstudie naar de haalbaarheid van de doelstellingen van de indicatiestelling 'nieuwe stijl' en de realisering van de zorgketen. ['New-style' needs assessment in the care chain; a study of the literature on the feasibility of the objectives of the 'new-style' needs assessment and realising the care chain.] Verpleegkunde, Nederlands-Vlaams Wetenschappelijk Tijdschrift voor verpleegkundigen; 17 (3): 140151.

Algera M, Francke AL, Kerkstra A \& Van der Zee J (2003). An evaluation of the new home care needs assessment policy in the Netherlands. Health and Social Care in the Community; 11 (3): 232-241.

Algera M, Francke AL, Spreeuwenberg P, Kerkstra A \& Van der Zee J (2004). The match between Dutch chronic patients' felt need and demand for home care and subsequent needs assessment. Submitted.

Algera M, Francke AL, Spreeuwenberg P, Kerkstra A \& Van der Zee J (2004). Care indicated and home care delivered: do they match in Dutch chronic patients? Submitted.

Andersen RM (1995). Revisiting the behavior model and access to medical care: does it matter? Journal of Health and Social Behavior; 36:1-10.

Bradshaw J (1972). A taxonomy of social need. In: MacLachlan G (Ed.). Problems and progress in medical care. Oxford: University Press; p. 69-82.

Caris-Verhallen W \& Kerkstra A (1998). Cliënten op de wachtlijst voor een verpleeghuis of verzorgingshuis en hun ervaring met de continuiteit van zorg. [Patients on a waiting list for a nursing home or a home for the elderly and their experience with the continuity of care.] Utrecht: Nivel.

Huijsman R (1990). Model van voorzieningen voor ouderen. [Model of facilities for the elderly.] Zeist: Kerckebosch BV (thesis).

Hutten JBF \& Kerkstra A (2002). Home care is what people want. In: Van Rooij EHC, Droyan Kodner L, Rijsemus AH \& Schrijvers AJP (Ed.). Health and health care in the Netherlands: a critical self-assessment of Dutch experts in medical and health sciences. Maarssen: Elsevier Gezondheidszorg; p. 101-110.

Kerkstra A, Verheij RA, Foets M \& Van der Velden J (1990). Behoefte aan nazorg en verleende nazorg na ontslag uit het ziekenhuis. [Need for aftercare and provided aftercare following discharge from hospital.] Tijdschrift voor Sociale Gezondheidszorg; 68 (8): 346-354. 
Ministerie van Volksgezondheid, Welzijn \& Sport (1997). Zorgindicatiebesluit (Besluit van 2 oktober 1997, houdende regels met betrekking tot het werkterrein, de samenstelling en werkwijze van indicatie-organen). [Care Needs Assessment Decree (White Paper of October, 2 1997, regarding field of activities, the formation, and the operation of Regional Needs Assessment Agencies).] Staatsblad van het Koninkrijk der Nederlanden. Den Haag: Sdu, 447.

Nationale Raad voor de Volksgezondheid (1994). Indicatiestelling en zorg op maat: advies van de Nationale Raad voor de Volksgezondheid en het College voor Ziekenhuisvoorzieningen. [Needs assessment and customised care: recommendations by the National Council for Public Health and the Council for Hospital Facilities.] Zoetermeer: Nationale Raad voor de Volksgezondheid.

SGBO (2000). Werkwijze van Regionale Indicatie-Organen; Onderzoek onder 7 RIO's. [Working procedures of regional assessment agencies; research among 7 regional assessment agencies.] Den Haag: SGBO.

Snijders TAB \& Bosker RS (1999). Multi-level analysis: an introduction to basic and advanced multi-level modeling. London: Sage Publications.

Van Campen C, Sixma HJ, Kerssens JJ \& Peters L (1997). Assessing non-institutionalised asthma and COPD patients' priorities and perceptions of quality of health care: the development of the QUOTE-CNSLD instrument. Journal of Asthma; 34: 531-538. 


\section{Summary}

Recent decades have seen considerable focus on the issue of matching the care delivered with the need for care. This Ph.D. thesis sets out to examine this match, specifically in relation to the chronically ill who require home care.

One reason for the increased focus of attention by Western politicians and policymakers on the match between the felt need for care of the chronically ill and the home care or an other type of care delivered, is the rapid population ageing and associated growth of the number of chronically ill in both absolute and relative terms. Because this group typically relies heavily on healthcare services, a shift in emphasis took place in favour of providing care in the home, rather than in an inpatient setting, in order to make the care sustainably affordable. This was also seen as satisfying a preference of patients for home-based care. An additional consideration is that care users, now increasingly vocal, demand greater say in healthcare and expect home care or an other type of care to be matched to their needs.

The needs assessment, which is the process of professionally determining the need for care of a patient and subsequently indicating adequate care according to type and extent of care, was, in the case of home care, formerly conducted by the home care organisations themselves. Patient organisations (such as the former Gehandicaptenraad) objected to needs assessment by the home care organisations, because it was thought that particularly the chronically ill were often indicated less care than needed, or the wrong type of care, on account of their usually more complex care needs. This tendency to minimise the care indicated was attributed to the influence of a shortage in home care resources: by rationing the care available, a greater number of people could be reached. Critics claimed that the needs assessors were under-indicating care in anticipation of the lack of resources, and that the capacity of the care supply was central to the decision-making, rather than the patient's need for care.

In order to address these developments and criticisms, the Health Ministry initiated a new style of needs assessment with the 1997 Care Needs Assessment Decree. The new-style needs assessment was designed to 
contribute towards improved matching of the care delivered to the patient's real need for care. The needs assessment was to be conducted in a way that was independent of the care supply situation and the interests of the home care organisations. It was also to be performed objectively, by making the process uniform (using a national protocol). In addition, it was decided that an integrated approach to needs assessment should be adopted, which means that all a patient's care needs within the framework of the Exceptional Medical Expenses Act $(A W B Z)$ and part of the Facilities for the Handicapped Act $(W V G)$ should be assessed in a single procedure (a one-stop-shop concept). This new assessment procedure was to be undertaken by regional assessment agencies (in Dutch: RIO's). In 1998 some 80 of these assessment agencies were established, and together these covered all regions in the Netherlands. The Care Needs Assessment Decree also determined that the assessment agencies could authorise the home care organisations to conduct needs assessments for non-complex need for care. In the case of complex need for care, however, the needs assessment was to remain the responsibility of the assessment agencies.

Chapter 2 contains a review of literature examining factors which influence the match between need for care and the professional home care delivered to the chronically ill. The review shows that despite the focus on matching care delivered with need for care, scarcely any scientific research has been conducted on factors which impact on this match. It was assumed that factors which influence the match between need for care and the professional home care delivered to the chronically ill are, by and large, similar to factors impacting on home care use. Based on this assumption, the literature review was expanded to include studies concerning the latter factors as well. From literature it becomes clear that the groups that make relatively the most use of professional home care are elderly, women, sufferers from various chronic disorders simultaneously (co-morbidity), patients experiencing functional impairment in daily life and/or having recently received intramural care. The characteristics of the healthcare system appear to have scarcely any influence on home care use. No studies at all have been found on the possible influence of the needs assessment on home care use.

Despite the lack of scientific basis for establishing factors of influence on the match between need for care and professional care delivered, a new-style needs assessment procedure was nevertheless implemented in the 
Netherlands in 1997. The main aim was to realise an independent, objective and comprehensive assessment procedure. The assessment agencies became a link within the care chain. This chain consisted of the following links: patient, assessment agency, health insurance agency and care provider. The patient experiences a need for care, and expresses this as a demand for care, which he or she presents to the assessment agency. The assessment agency indicates which type and how much care is required to meet the patient's care needs. The health insurance agency subsequently determines whether the patient is entitled to the care indicated (eligibility test) and allocates the care indicated. Finally, the care provider delivers the allocated care.

Chapter 3 explores the feasibility of the objectives of the new-style needs assessment and the realisation of the care chain, based on a review of the literature. This review discloses possible threats to the realisation of the objectives, including: transfer of authorisation from the assessment agencies to the home care organisations for conducting certain needs assessments; and the diversity among the assessment agencies in terms of organisation and contents of the assessment reports. The performance of the care chain, as described above may be negatively influenced by shifts of responsibilities among the actors concerned. Besides, the role of the health insurance agencies would appear to be unclear.

The literature review also demonstrates that no representative research had yet been conducted on the extent to which the various links within the care chain fit together. Although the patient is supposed to be central to the new style of needs assessment, the patient is far from central to much of the research conducted to date.

Chapter 4 presents research on how the assessment agencies themselves, home care organisations and health insurance agencies rate the new-style needs assessment. The findings show that all organisational structures designed to realise the objectives of the new-style needs assessment are in place. At the same time, the research data reveal that the realisation of these structures in practice appears to be deficient. The standard assessment forms are judged impracticable by half of the home care organisations. Authorisation arrangements for non-complex care needs are thought to jeopardise the independence as well as the comprehensive character of needs assessment. 
Whether the new-style needs assessment is evaluated positively or negatively depends on the type of organisation under study. In the year 2000, assessment agencies are positive about what they have achieved since being set up. By contrast, home care organisations are generally negative about the functioning and supposed advantages of the new style of needs assessment. Health insurance agencies' opinions are somewhere between those of assessment agencies and home care organisations.

After examining how the organisations within the care chain rate the newstyle assessment procedure, it was important to investigate how well the home care delivered matches the patients' felt need for care, as well as examine the role played by the care indicated by the assessment agencies. In addition to record study, the perspective of chronically ill home care users on this match within the care chain is central in Chapters 5 through 7. The match between felt need for care and home care delivered was subdivided into two submatches:

(1) The match between the chronically ill patient's felt need for care and the care indicated by the assessment agency (or in the case of authorisation: by the home care organisation);

(2) The match between the care indicated and the care ultimately delivered by the home care organisation, in terms of type and amount.

Other aspects examined are: (3) the match between the felt need for care and the demand for care of the chronically ill, (4) the match between the demand for care and the care indicated, (5) the match between the demand for care and the professional home care ultimately delivered and (6) the match between the felt need for care and the type of home care received according to the respondents themselves, while distinguishing between professional home care and informal care.

For the purpose of this study, a telephone survey was conducted among 402 patients concerning their felt need for care, their opinion on the matches described above and which type of professional home care or informal care they received. The biographical characteristics of these patients were also collected. In addition, the assessment reports made by the assessment agencies relating to these patients were reviewed, as were their home care records, in order to ascertain the type and extent of the care indicated as well as the professional home care ultimately delivered. By canvassing the 
opinions of patients and reviewing their records as well, it was possible to establish both the perceived and the actual matches.

Chapter 5 examines the match between felt need for care of the chronically ill and the care indicated by the assessment agencies. It also investigates how the felt need for care matched the patient's demand for care and how the demand for care matched the care indicated by the assessment agencies. Although the vast majority of patients are positive about the match between their felt needs and the care indicated, a review of their records shows otherwise about actual care. A comparison between what patients reported as their felt need for care during a telephone interview and what the assessment report subsequently describes as the care indicated, leads to the conclusion that there is no actual matching in two thirds of the cases. The majority of these involve 'under-indication', which means that fewer types of care are indicated than might have been expected on the basis of the care needs expressed by the patient.

The match between felt need for care and the patient's demand for care, as presented (according to the patient) to the assessment agency also proves deficient. Apparently, the chronically ill do not request professional help for every felt need. This may partly explain why the match between the felt need for care and the care indicated, and by extension the professional home care ultimately delivered, has been found imperfect.

The match between the demand for care and the care indicated has been determined in two ways: firstly, the care indicated is compared with what the patients themselves said the demand for care was during the telephone interview, and secondly with what is recorded in the assessment report as the patient's demand for care. These two demands for care should be identical per patient, of course; however, this is true in only two thirds of the cases. Furthermore, the match between the demand for care recorded in the assessment report and the care indicated proves better than the match between the demand for care as expressed during the interview and the care indicated ( $80 \%$ versus $67 \%$ ). Possibly, this does mean that the needs assessor already interprets the demand for care in the light of the care to be indicated, and he/she subsequently records that interpretation of the demand for care on the assessment forms, as though it were the patient's original demand for care. If that is the case, the crux in the care chain is not the needs assessment 
by the assessment agency, but the moment when the patient formulates the demand for care.

With regard to patient characteristics, it appears that age and the individual who presents the demand for care to the assessment agency are of influence on the matches under study: if patients are aged under 65 and place their application for care themselves, the match is better. In addition, there is a better actual match between felt need for care and care indicated when there is greater complexity of the care indicated and if other home care products are not already being received.

Two characteristics of the assessment agencies, which both affect the essential objectives of the new-style needs assessment are also of influence. Firstly, authorisation is positively related to a better match between felt need for care and the care indicated. Secondly, the use of the standard assessment forms shows a negative effect on this match.

Central to Chapter 6 is the next match within the care chain: the match between the care indicated and the professional home care ultimately delivered. This match was divided into a match according to type of home care and the amount of home care. Again, almost all chronically ill patients report an adequate match, whereas the record study shows that the actual match is often deficient. In about one third of cases not all types of care indicated are delivered by the home care organisation. In addition, it appears that when the indicated type of care actually is delivered, the indicated number of hours is not honoured in a quarter of the cases.

There is a better actual match (based on record study) for men and for patients who are indicated non-complex care by the assessment agencies than for their counterparts. In addition, a good actual match between a patient's felt need for care and care indicated by the assessment agency has a significantly positive impact on the studied actual match between care indicated and the type of professional home care delivered. The same characteristics are of influence with regard to the patients' experience of this match according to type of care. In addition, the opinions of patients about this match are more positive when they find the total amount of care (professional and informal) to be sufficient. 
The characteristics of chronically ill patients show no significant influence on the match between the number of hours of care indicated and the amount of care professionally provided.

None of the matches under study appear to be linked significantly to the characteristics of the assessment agencies or home care organisations.

Chapter 7 deals with the match between felt need for care and the home care delivered, encompassing the entire care chain. Almost half the patients surveyed receive less care from the home care organisation than is indicated by the assessment agency. About one to five patients receive care completely mismatching their felt need or receive no care at all. Only in one third of cases this match is adequate. Nonetheless, patients appear to be satisfied with the extent to which their felt need for care was met. Further analyses show, however, that in many cases it was chiefly informal care that enabled satisfactory matching between felt need for care and home care, rather than the professional home care itself. This confirms the importance of informal care in meeting the care needs of the chronically ill in a quantitative sense. The relatively minor contribution of the home care organisations is understandable, though. After all, the assessment report should take the efforts of informal care into account. The needs assessment actually does not indicate what care a patient needs, but what professional home care is needed in addition to what can be provided by informal carers.

In relation to this match too, no significant influence by the characteristics of assessment agencies or home care organisations can be established. Nor does the influence of patient characteristics prove to be statistically significant for the actual match. Factors that do exert a positive influence on patient perception of this match are greater complexity of the care indicated and a positive judgement on the total amount of care received (both professional and informal).

However, both submatches - the one between felt need for care and care indicated and that between care indicated and the professional home care provided - have a significant impact on the match between felt need for care and care provided. This is the case both with actual matching and that perceived by the patients. Because both submatches involve the needs 
assessment, this finding underlines the crucial role of the needs assessment within the care chain.

This dissertation begins with a general overview in Chapter 1, of the main research findings. It is to be read as an extended summary of the work, with the subsequent chapters as reference works containing greater detail. In addition, this chapter contains a synthesis of the matches in the care chain, which are described in greater detail in the subsequent chapters. It appears that only one sixth of all patients has reason to be fully satisfied: their felt need for care is fully reflected in the type of care indicated, and the care indicated is fully honoured by the home care organisation in terms of type and amount of care. At the same time, as much as three quarters of the patients express satisfaction about the match between their felt need for care and the care delivered. To a significant extent, this satisfaction would appear to be attributable to the provision of informal care.

Chapter 1 also shows that the scant available care is not distributed equally among patients. Looking at the entire care chain, one out of ten patients do not receive enough types of home care from the home care organisation, based on the care indicated. In addition, for one out of five patients, there is a shortfall in the number of hours of care received compared to the number stated in the assessment report. In contrast, one out of thirteen patients receive more types of professional home care than indicated, whereas one out of seven is accorded more hours of professional home care of the indicated type, than stated in the assessment report. It appears that some patients are advantaged at the expense of others, not counting the cases where home care organisations believe the assessment report should be corrected, perhaps because of a change in care needs due to a time lag between needs assessment and the start of care. The rationing method never deserved a recommendation, since it obscures the gap between care needs and care supply, but it seems not to work in practice in any case.

In addition to presenting the major research findings, this chapter also deals with the scientific value and methodological limitations of the research. Unravelling the matches within the care chain and giving insight into the factors of influence on the matches under study using various resources (surveys, telephone interviews and record study) is considered valuable. Also the fact that a mayor part of the study has taken the perspective of 
patients into account - by canvassing patients' opinions as well as conducting record study to determine to which extent patients were confronted with adequate or inadequate matches - has proved to be a worthwhile addition to other research.

Finally, a good deal of attention is paid to the practical and political implications of the findings of this study. An important point in this respect is the recommendation that through measures such as care leave and increased facilities for respite care, provision for informal carers should be monitored and expanded, since informal care has proved crucial in meeting the felt need for care of chronically ill home care users. An adequate match between patient's felt need for care and the care indicated appears to be jeopardised by the use of standard assessment forms, which are now not merely recommended, but have been made compulsory by the Health Ministry. However, because the assessment forms have since been updated, it is not possible to make any assertion about the influence of the new set of forms on the matches under study.

In order to ensure a good match between the chronically ill's felt need for care and the needs assessment, it can be recommended on the basis of this research that more use should be made of the possibility to transfer authorisation of the needs assessment of non-complex demands for home care to the home care organisations. By creating protocols for the needs assessment procedure, the independence and objectivity of the needs assessment by the authorised home care organisations can be ensured, preventing the identified threat from authorisation. If the intake staff of a home care organisation suspect that the care needs are more complex than authorised for, and proceed to involve the assessment agency, the comprehensive nature of the needs assessment will remain intact. The fact that authorisation does not influence the other matches under study in the statistical analyses leads to the conclusion that authorisation does not impact either positively or negatively on actual or perceived matches. Consequently, considerations relating to efficiency, patient-friendliness and reducing bureaucracy should lead to the transfer of needs assessment for specific, clearly defined types of demands for home care to the home care organisations. 


\section{Samenvatting}

De afgelopen decennia is er veel aandacht geweest voor de aansluiting tussen zorgbehoeften en verleende zorg. Dit proefschrift richt zich op deze aansluiting en wel voor chronisch zieken, die thuiszorg nodig hebben.

Eén van de redenen waarom de aansluiting tussen zorgbehoeften van chronisch zieken en verleende professionele (thuis)zorg ruime aandacht kreeg van Westerse politici en beleidsmakers, is de toenemende vergrijzing en de daaraan inherente absolute en procentuele groei van het aantal chronisch zieken, die doorgaans een zwaar beroep doen op de gezondheidszorg. Om dat betaalbaar te houden, zou de zorg bij voorkeur thuis verleend moeten worden in plaats van in een intramurale instelling. Ook door cliënten zelf zou aan zorg thuis over het algemeen de voorkeur gegeven worden. Verder eisen zorggebruikers ten gevolge van een groter wordende mondigheid meer inspraak in de zorg en verwachten zij dat de (thuis)zorg aansluit bij hun behoeften.

De indicatiestelling, dat is het op professionele wijze in kaart brengen van de zorgbehoeften van een cliënt en het bepalen van de aard en omvang van de zorg die nodig is om aan die zorgbehoeften tegemoet te komen, lag voor wat betreft de thuiszorg vanouds in handen van de thuiszorgorganisaties zelf. Patiëntenorganisaties (zoals de voormalige Gehandicaptenraad) kwamen hiertegen in het geweer, omdat men van oordeel was dat juist chronisch zieken, vanwege hun vaak complexere zorgbehoeften, vaak minder zorg geïndiceerd kregen dan nodig was of een verkeerd type zorg. Deze minimalisering van de geïndiceerde zorg zou worden ingegeven door schaarste in de thuiszorg. Wanneer iedereen een beetje minder zorg zou krijgen dan eigenlijk nodig was, zouden meer cliënten geholpen kunnen worden (kaasschaafmethode). De kritiek luidde dat er al bij de indicatiestelling beknibbeld werd met het oog op de beperkte beschikbaarheid van zorg en dat dus niet de werkelijke zorgbehoeften van een cliënt centraal stonden, maar de mogelijkheden van het zorgaanbod.

Om aan al deze ontwikkelingen en kritiek tegemoet te komen, initieerde het Ministerie van Volksgezondheid, Welzijn \& Sport een nieuwe manier van indicatiestelling krachtens het Zorgindicatiebesluit van 1997. De nieuwe 
indicatiestelling zou ertoe moeten bijdragen dat de uiteindelijk verleende professionele zorg beter afgestemd zou zijn op de werkelijke zorgbehoeften van cliënten. De indicatiestelling zou onafhankelijk van het zorgaanbod en de belangen van de thuiszorgorganisaties gestalte moeten krijgen. Daarnaast zou de indicatiestelling objectief moeten zijn door het uniformeren van de indicatiestelling (door middel van een landelijk protocol). Ook moest de indicatiestelling integraal zijn, zodat alle zorgbehoeften van een cliënt binnen het kader van de Algemene Wet Bijzondere Ziektekosten (AWBZ) en een deel van de Wet Voorzieningen Gehandicapten (WVG) met één en dezelfde indicatiestelling bestreken zou worden (één loket-gedachte). Deze nieuwe indicatieprocedure zou moeten worden vormgegeven door Regionale Indicatie Organen, de RIO's. In 1998 werden er ongeveer 80 RIO's opgericht, die met elkaar heel Nederland bestreken. Het Zorgindicatiebesluit bepaalde ook dat de uitvoering van de indicatiestelling voor niet-complexe zorgbehoeften door het RIO aan de thuiszorgorganisatie gemandateerd mocht worden. De indicatiestelling bij complexe zorgbehoeften zou echter steeds de verantwoordelijkheid blijven van het RIO.

In Hoofdstuk 2 wordt een literatuurstudie beschreven naar de factoren die van invloed zijn op de aansluiting tussen zorgbehoeften en verleende professionele thuiszorg aan chronisch zieken. Ondanks de belangstelling die de aansluiting tussen zorgbehoeften en verleende zorg geniet, blijkt er nog nauwelijks wetenschappelijk onderzoek gedaan te zijn naar factoren die die aansluiting beïnvloeden. Onder de premisse dat de factoren van invloed op de aansluiting tussen zorgbehoeften van chronisch zieken en verleende professionele thuiszorg min of meer dezelfde zouden zijn als die van invloed op thuiszorggebruik, werd de literatuurstudie in die richting verbreed. Uit de literatuur komt naar voren dat over het algemeen ouderen, vrouwen, zij die lijden aan verscheidene chronische ziekten tegelijkertijd (co-morbiditeit), die functionele beperkingen kennen in het dagelijks leven en/of die recentelijk intramurale zorg hebben gekregen, meer gebruik maken van professionele thuiszorg. Kenmerken van het gezondheidszorgsysteem blijken nauwelijks van invloed op thuiszorggebruik. Over de eventuele invloed van de indicatiestelling op thuiszorggebruik werd in het geheel geen literatuur gevonden.

Ondanks het gebrek aan wetenschappelijke basis voor factoren van invloed op de aansluiting tussen zorgbehoeften en verleende professionele zorg, werd in Nederland in 1997 toch een indicatiestelling 'nieuwe stijl' opgezet. 
Hoofddoel daarvan was het realiseren van een onafhankelijke, objectieve en integrale indicatiestelling. De RIO's werden tot een schakel binnen de zorgketen gemaakt. Die zorgketen bestond uit de volgende schakels: cliënt, RIO, zorgkantoor en zorgaanbieder. De cliënt ervaart een zorgbehoefte en verwoordt deze in een zorgvraag, waarmee hij naar het RIO gaat. Het RIO indiceert welke en hoeveel zorg nodig is om aan de zorgbehoeften van de cliënt te voldoen. Het zorgkantoor bepaalt vervolgens of de cliënt recht heeft op de geïndiceerde zorg (rechtmatigheidstoets) en wijst de zorg toe. De zorgaanbieder verleent vervolgens de toegewezen zorg.

In Hoofdstuk 3 wordt de haalbaarheid van de doestellingen van de indicatiestelling 'nieuwe stijl' en de realisering van de zorgketen aan de hand van een literatuurstudie beschreven. Mogelijke bedreigingen van de realisering van de doelstellingen zijn: het mandateren door de RIO's van thuiszorgorganisaties om de indicatiestelling voor bepaalde zorgbehoeften uit te voeren en de diversiteit van de RIO's in organisatie en in de inhoud van de indicatiebesluiten. Het functioneren van de zorgketen, zoals in de vorige alinea beschreven, kan mogelijk nadelig beïnvloed worden door geconstateerde taakverschuivingen tussen de betrokken actoren, waarbij de rol van het zorgkantoor diffuus is.

Uit de literatuurstudie blijkt tevens dat er nog geen representatief onderzoek verricht was naar in hoeverre de verschillende schakels binnen de zorgketen op elkaar aansluiten. Hoewel de cliënt uitgangspunt van de indicatiestelling 'nieuwe stijl' moet zijn, blijkt het cliëntenperspectief in veel reeds verricht onderzoek te ontbreken.

Hoofdstuk 4 betreft een onderzoek naar hoe RIO's zelf, thuiszorgorganisaties en zorgkantoren de indicatiestelling 'nieuwe stijl' beoordelen. De resultaten van het onderzoek geven aan dat alle organisatiestructuren om de doelstellingen van de indicatiestelling 'nieuwe stijl' in potentie te realiseren, aanwezig zijn. Toch blijkt uit de onderzoeksgegevens, dat de praktische invulling van deze organisatiestructuren nog te wensen over laat. De standaard indicatieformulieren blijken door de helft van de thuiszorgorganisaties als onwerkbaar beoordeeld te worden. Mandatering van de indicatiestelling voor niet-complexe zorgbehoeften lijkt de onafhankelijkheid en de integraliteit van de indicatiestelling te schaden. 
Het oordeel over de indicatiestelling 'nieuwe stijl' hangt af van wie ondervraagd wordt. RIO's zijn in het jaar 2000 vrij positief over wat ze sinds hun oprichting bereikt hebben. Thuiszorgorganisaties daarentegen zijn over het algemeen negatief over het functioneren en de voordelen van de nieuwe indicatieprocedure. Zorgkantoren zitten met hun mening ergens tussen de RIO's en thuiszorgorganisaties in.

Nadat onderzocht was hoe organisaties binnen de zorgketen de indicatiestelling 'nieuwe stijl' evalueerden, was ook van belang om te onderzoeken hoe adequaat de aansluiting tussen de ervaren zorgbehoeften van cliënten en de verleende professionele thuiszorg is en welke rol de door de RIO's geïndiceerde zorg daarin speelt. Het cliëntenperspectief van chronisch zieke thuiszorggebruikers op deze aansluiting binnen de zorgketen staat - naast dossieronderzoek - centraal in de hoofdstukken 5 tot en met 7. De aansluiting tussen ervaren zorgbehoeften en verleende professionele thuiszorg werd opgedeeld in twee deelaansluitingen:

(1) de aansluiting tussen ervaren zorgbehoeften van de chronisch zieke cliënt en de geïndiceerde zorg door het RIO (of in geval van mandatering: door de thuiszorgorganisatie);

(2) de aansluiting tussen de geïndiceerde zorg en de uiteindelijk verleende zorg door de thuiszorgorganisatie, naar aard en omvang.

Verder zijn nog onderzocht:

(3) de aansluiting tussen ervaren zorgbehoefte en zorgvraag van chronisch zieken;

(4) de aansluiting tussen de zorgvraag en de geïndiceerde zorg;

(5) de aansluiting tussen de zorgvraag en de uiteindelijk verleende professionele thuiszorg en

(6) de aansluiting tussen ervaren zorgbehoefte en de aard van de gekregen thuiszorg volgens opgave van de respondent zelf, met daarin een onderscheid naar professionele thuiszorg en mantelzorg.

Voor deze studie zijn 402 cliënten telefonisch ondervraagd over hun ervaren zorgbehoeften, hun mening over de genoemde aansluitingen en welke professionele thuiszorg dan wel mantelzorg men kreeg. Ook zijn biografische kenmerken van deze cliënten verzameld. Bovendien zijn hun indicatiebesluiten van het RIO en hun thuiszorgdossiers geraadpleegd om te bepalen wat de aard en omvang van de geïndiceerde en de uiteindelijk verleende professionele thuiszorg was. Door te vragen naar meningen van 
cliënten en bovendien dossieronderzoek te doen, kon achterhaald worden hoe de gepercipieerde dan wel de feitelijke aansluitingen waren.

Hoofdstuk 5 behandelt de aansluiting tussen ervaren zorgbehoeften van chronisch zieken en de geïndiceerde zorg door het RIO. Ook is onderzocht wat de aansluiting is tussen de ervaren zorgbehoeften en de zorgvraag van de cliënt en tussen de zorgvraag en de geïndiceerde zorg door het RIO. Hoewel het overgrote deel van de cliënten van oordeel is dat de aansluiting tussen hun ervaren zorgbehoeften en de geïndiceerde zorg goed is, is dat feitelijk beschouwd (op grond van dossieronderzoek) niet het geval. Uit vergelijking tussen wat cliënten tijdens het telefonisch interview als ervaren zorgbehoeften aangaven en wat er volgens het indicatiebesluit geïndiceerd is, kan afgeleid worden dat er in twee derde van de gevallen géén sprake is van een feitelijke aansluiting. In het gros van deze gevallen is er sprake van 'onder-indicatie', dat wil zeggen dat er minder typen zorg geïndiceerd worden dan wat op geleide van de door de cliënt aangegeven zorgbehoeften verwacht mag worden.

De aansluiting tussen ervaren zorgbehoeften en zorgvraag van de cliënt, zoals die (volgens de cliënt) is voorgelegd aan een RIO, blijkt ook matig. Blijkbaar vragen chronisch zieken niet voor elke ervaren zorgbehoefte professionele hulp. Dit kan één van de verklaringen zijn waarom de aansluiting tussen ervaren zorgbehoeften en de geïndiceerde zorg, en in het verlengde daarvan de uiteindelijk verleende thuiszorg, niet perfect is.

De aansluiting tussen de zorgvraag en de geïndiceerde zorg is op twee manieren bepaald: ten eerste is de geïndiceerde zorg vergeleken met wat de cliënt zelf tijdens het telefonische interview zei dat zijn zorgvraag geweest was en ten tweede met wat in het indicatiebesluit als zorgvraag genoteerd werd. Deze twee zorgvragen zouden per cliënt uiteraard identiek moeten zijn, maar stemden in slechts twee derde van de gevallen overeen. Bovendien blijkt de aansluiting tussen de in het indicatiebesluit genoteerde zorgvraag en de geïndiceerde zorg beter te zijn dan de aansluiting tussen de zorgvraag zoals vermeld tijdens het interview en de geïndiceerde zorg $(80 \%$ versus $67 \%$ ). Wellicht interpreteert de indicatie-adviseur de zorgvraag al in termen van te indiceren zorg en noteert die interpretatie van de zorgvraag in de indicatieformulieren als zijnde de oorspronkelijke zorgvraag van de cliënt. Als dat het geval zou zijn, dan zou de crux in de zorgketen niet bij de 
indicatiestelling door het RIO liggen, maar al bij het formuleren van de zorgvraag door de cliënt.

Wat betreft kenmerken van cliënten, blijken leeftijd en degene die de zorgvraag aanmeldt bij het RIO van invloed op de beschreven aansluitingen: als cliënten jonger dan 65 jaar zijn of zelf hun zorgvraag bij het RIO aanmelden, is de aansluiting beter. Verder wordt een goede feitelijke aansluiting tussen ervaren zorgbehoeften en geïndiceerde zorg bepaald door een grotere mate van complexiteit van de geïndiceerde zorg en het nog niet reeds ontvangen van andere thuiszorgproducten.

Twee RIO-kenmerken, die allebei het wezen van de doelstellingen van de indicatiestelling 'nieuwe stijl' raken, blijken eveneens van invloed. Ten eerste blijkt mandatering positief gerelateerd te zijn aan een betere aansluiting en ten tweede blijkt het gebruik van de standaard indicatieformulieren de aansluiting negatief te beïnvloeden.

In Hoofdstuk 6 staat de volgende aansluiting in de zorgketen centraal: de aansluiting tussen geïndiceerde zorg en uiteindelijk verleende professionele thuiszorg. Deze aansluiting werd opgedeeld in een aansluiting naar type thuiszorg en naar de hoeveelheid ervan. Opnieuw percipiëren bijna alle chronisch zieke cliënten een adequate aansluiting, terwijl de feitelijke aansluiting op grond van dossieronderzoek lang niet altijd goed blijkt. In ongeveer een derde van de gevallen worden niet alle typen geïndiceerde zorg door de thuiszorgorganisatie verleend. Daarnaast blijkt, als wel het geïndiceerde type zorg wordt verleend, in een kwart van de gevallen niet het geïndiceerde aantal uren zorg verleend te worden.

Mannen en cliënten die niet-complexe zorg geïndiceerd krijgen door het RIO, blijken feitelijk (op basis van dossieronderzoek) een betere aansluiting te hebben dan hun tegenhangers. Bovendien blijkt een goede feitelijke aansluiting tussen ervaren zorgbehoeften van de cliënt en de geïndiceerde zorg door het RIO significant van invloed op een goede feitelijke aansluiting tussen de geïndiceerde zorg en het uiteindelijk verleende type professionele zorg. Wat betreft de door cliënten gepercipieerde aansluiting naar type zorg blijken precies dezelfde kenmerken van invloed. Daarnaast is het oordeel van cliënten over deze aansluiting positiever als zij vinden dat de totale hoeveelheid zorg (professioneel en mantelzorg) voldoende is. 
Er kan geen significante invloed van kenmerken van chronisch zieke cliënten op de aansluiting tussen het geïndiceerde aantal uren en de omvang van de uiteindelijk verleende professionele zorg aangetoond worden.

Geen van de onderhavige aansluitingen blijkt wezenlijk af te hangen van kenmerken van RIO's of van thuiszorgorganisaties.

Het onderwerp van Hoofdstuk 7 betreft de aansluiting tussen ervaren zorgbehoeften en verleende thuiszorg en omspant daarmee de hele zorgketen. Bijna de helft van de cliënten krijgt minder zorg van de thuiszorgorganisatie dan is geïndiceerd door het RIO. Eén op de vijf cliënten krijgt een type zorg dat helemaal niet aansluit bij de door hen ervaren zorgbehoeften of krijgt überhaupt geen zorg. In slechts een derde van de gevallen blijkt de aansluiting adequaat. Toch blijken cliënten over het algemeen tevreden te zijn over de mate waarin aan hun ervaren zorgbehoeften tegemoet wordt gekomen. Nadere analysen tonen echter aan dat het in veel gevallen vooral de mantelzorg is die een goede aansluiting tussen ervaren zorgbehoeften en verleende thuiszorg bewerkstelligt en niet zozeer de professionele thuiszorg. Hoewel dit het belang van de mantelzorg in de bevrediging van de zorgbehoeften van chronisch zieken nu ook kwantitatief bevestigt, is de relatief geringe bijdrage van de thuiszorgorganisaties daarin verklaarbaar. Immers, in het indicatiebesluit is de inzet van de mantelzorg verdisconteerd. Wel beschouwd wordt in het indicatiebesluit niet aangegeven welke zorg een cliënt nodig heeft, maar welke professionele thuiszorg deze nodig heeft in aanvulling op wat mantelzorgers kunnen bieden.

Ook met betrekking tot deze aansluiting kan geen significante invloed van kenmerken van RIO's of thuiszorgorganisaties vastgesteld worden. Op de feitelijke aansluiting blijkt de invloed van de gemeten cliëntkenmerken ook niet statistisch significant. Op een positievere perceptie van cliënten op deze aansluiting zijn een grotere complexiteit van de geïndiceerde zorg en een positief oordeel over de totale hoeveelheid ontvangen (professionele en mantel-) zorg van invloed.

Ondanks het geringe aantal significante kenmerken zijn wel de beide deelaansluitingen - die tussen ervaren zorgbehoeften en geïndiceerde zorg en die tussen geïndiceerde zorg en uiteindelijk verleende professionele thuiszorg - 
significant te relateren aan de aansluiting tussen ervaren zorgbehoeften en verleende zorg. Dit is zowel bij de feitelijke aansluitingen het geval als bij de door cliënten gepercipieerde aansluitingen. Omdat beide deelaansluitingen de indicatiestelling betreffen, onderstreept deze bevinding de cruciale rol van de indicatiestelling binnen de zorgketen.

Dit proefschrift begint met een algemeen hoofdstuk, Hoofdstuk 1, dat een overzicht van de belangrijkste resultaten van dit onderzoek bevat. Het is te lezen als een uitgebreide samenvatting, waarbij de daaropvolgende hoofdstukken als een soort naslagwerk voor verdere details beschouwd kunnen worden. Bovendien wordt in dit hoofdstuk een synthese gegeven van de onderzochte aansluitingen binnen de zorgketen, die in de daarop volgende hoofdstukken gefragmenteerd beschreven worden. Het blijkt dat slechts een zesde van alle cliënten reden heeft om volledig tevreden te zijn: hun ervaren zorgbehoeften zijn volledig te herkennen in de aard van de geïndiceerde zorg, terwijl die geïndiceerde zorg volledig naar aard en omvang door de thuiszorgorganisatie is gehonoreerd. Toch blijkt maar liefst driekwart van de cliënten tevreden over de aansluiting tussen hun ervaren zorgbehoeften en de uiteindelijk verleende zorg. Voor een belangrijk deel lijkt deze tevredenheid aan de inzet van mantelzorg toegeschreven te kunnen worden.

Ook blijkt in dit hoofdstuk dat de schaarse zorg niet gelijkelijk over cliënten wordt verdeeld. Over de hele zorgketen heen bekeken, ontvangt één op de tien cliënten te weinig typen thuiszorg van de thuiszorgorganisatie in vergelijking met diens geïndiceerde zorg, terwijl het aantal ontvangen uren zorg bij één op de vijf cliënten achterblijft bij het aantal uren vermeld in het indicatiebesluit. Daartegenover staat echter dat één op de dertien cliënten méér typen zorg ontvangt dan geïndiceerd, terwijl één op de zeven cliënten meer uren professionele thuiszorg ontvangt van het geïndiceerde type dan aangegeven in het indicatiebesluit. De gevallen waarin thuiszorgorganisaties van mening zijn dat het indicatiebesluit gecorrigeerd moest worden vanwege bijvoorbeeld veranderde zorgbehoeften ten gevolge van het tijdsverloop tussen indicatiestelling en start van de zorgverlening daargelaten, lijkt een deel van de cliënten bevoordeeld te worden ten koste van een ander deel. De kaasschaafmethode verdiende al geen aanbeveling, omdat de zorgkloof tussen zorgbehoeften en zorgaanbod dan diffuus blijft, maar hij blijkt in de praktijk ook nog eens niet te werken. 
In dit hoofdstuk wordt naast bij de belangrijkste onderzoeksresultaten ook stil gestaan bij de wetenschappelijke waarde en de methodologische beperkingen van dit onderzoek. Het met behulp van diverse bronnen (vragenlijstonderzoek, telefonische interviews en dossieronderzoek) determineren van de aansluitingen binnen de zorgketen en welke factoren van invloed zijn op die aansluitingen, wordt als belangrijkste waarde beschouwd. Ook het feit dat een belangrijk deel van het onderzoek het cliëntenperspectief belicht (door zowel te vragen naar de meningen van cliënten als door dossieronderzoek te bepalen in hoeverre men met inadequate aansluitingen geconfronteerd wordt) vormt een waardevolle aanvulling op ander onderzoek.

Tenslotte wordt uitgebreid ingegaan op de implicaties voor de praktijk en de politiek van dit onderzoek. Belangrijk punt hierbij is de aanbeveling om via maatregelen als zorgverlof en meer faciliteiten voor respijtzorg de mogelijkheden van mantelzorgers te bewaken en uit te bouwen, omdat de inzet van deze informele zorgverleners cruciaal blijkt in het voldoen aan de ervaren zorgbehoeften van chronisch zieke thuiszorggebruikers. De aansluiting tussen ervaren zorgbehoeften en geïndiceerde zorg blijkt bedreigd te worden door het gebruik van de standaard indicatieformulieren, waarvan het gebruik sinds kort niet meer slechts aanbevolen wordt, maar door VWS verplicht is gesteld. Omdat het een inmiddels aangepaste set indicatieformulieren betreft, kan echter geen uitspraak gedaan worden over de invloed van de huidige set formulieren op de aansluitingen.

In het belang van een indicatiestelling die goed aansluit op de ervaren zorgbehoeften van chronisch zieken, verdient het op grond van dit onderzoek aanbeveling meer gebruik te maken van de mogelijkheid om de indicatiestelling van niet-complexe zorgvragen te mandateren aan thuiszorgorganisaties. Door protocolisering van de indicatiestelling zou de onafhankelijkheid en objectiviteit van de indicatiestelling door de gemandateerde thuiszorgorganisaties gewaarborgd kunnen worden, zodat de gesignaleerde bedreiging daarvan door mandatering voorkómen wordt. Als de intaker van zo'n thuiszorgorganisatie bij vermoeden van complexere zorgbehoeften alsnog het RIO inschakelt, kan ook de integraliteit van de indicatiestelling overeind blijven. Het feit dat mandatering bij de andere aansluitingen in de statistische analysen er niet toe blijkt te doen, geeft aanleiding te concluderen dat mandatering op die feitelijke en gepercipieerde 
aansluitingen voordelig noch nadelig uitwerkt. In dat geval zouden overwegingen van efficiëntie, cliëntvriendelijkheid en ontbureaucratisering de doorslag kunnen geven de indicatiestelling van bepaalde, nauw omschreven typen zorgvragen over te laten aan thuiszorgorganisaties. 


\section{Reference list}

Adam SGM \& Hutten JBF (2001).The Netherlands. In: (Philp I Ed.). Family Care of Older People in Europe. Amsterdam/Berlin/Oxford/Tokyo/Washington DC: IOS Press; p. 135160.

Adams CE \& Kramer S (1996). Home health resource utilization: Health Maintenance Organization versus fee-for-service subscribers. Journal of Nursing Administration; 6: 20-27.

Algera M, Francke AL \& Van der Zee J (2002). Zorg-indicatiestelling 'nieuwe stijl' binnen de zorgketen: een literatuurstudie naar de haalbaarheid van de doelstellingen van de indicatiestelling 'nieuwe stijl' en de realisering van de zorgketen. ['New-style' needs assessment in the care chain; a study of the literature on the feasibility of the objectives of the 'new-style' needs assessment and realising the care chain.] Verpleegkunde, Nederlands-Vlaams Wetenschappelijk Tijdschrift voor verpleegkundigen; 17 (3): 140151.

Algera M, Francke AL, Kerkstra A \& Van der Zee J (2003). An evaluation of the new home care needs assessment policy in the Netherlands. Health \& Social Care in the Community; 11 (3): 232-241.

Algera M, Francke AL, Kerkstra A \& Van der Zee J (2004). Home care needs of patients with long-term conditions: literature review. Journal of Advanced Nursing; 46 (4): 417-429.

Algera M, Francke AL, Spreeuwenberg P, Kerkstra A \& Van der Zee J (2004). The match between Dutch chronic patients' felt need and demand for home care and subsequent needs assessment. Submitted.

Algera M, Francke AL, Spreeuwenberg P, Kerkstra A \& Van der Zee J (2004). Care indicated and home care delivered: do they match in Dutch chronic patients? Submitted.

Algera M, Francke AL, Spreeuwenberg P \& Van der Zee J (2004). The match between Dutch chronic patients' felt need and home care delivered and its determinants. Submitted.

Andersen RM (1995). Revisiting the Behavioral Model and access to medical care: does it matter? Journal of Health and Social Behavior; 36: 1-10.

Andersen R \& Newman JF (1973). Societal and individual determinants of medical care utilization in the United States. The Milbank Memorial Fund Quarterly Health and Society; 51: 95-124.

Bakker PF (2001). Periodieke inventarisatie indicatie-organen: stand van zaken augustus 2001. [Periodic inventory assessment agencies: the state of affairs in August 2001.] Enschede: Hoeksma, Homans \& Menting. 
Beemsterboer WGM (2000). De ratio van de RIO's: meerwaarde van onafhankelijke, objectieve en integrale indicatiestelling. [The ratio of the regional assessment agencies: the extra worth of independent, objective, and comprehensive needs assessment.] Tijdschrift voor Gezondheidswetenschappen; 78 (4): 238-243.

Bellemakers C (1995). Patiënt en indicatiestelling. [Patient and needs assessment.] NRV Magazine; 2 (1): 9.

Bradshaw J (1972). A taxonomy of social need. In: MacLachlan G (Ed.). Problems and progress in medical care. Oxford: University Press; p. 69-82.

Breed Indicatie Overleg (1997). Modelprotocol geïntegreerde indicatiestelling voor het terrein van wonen, welzijn en zorg. [Model protocol for integrated needs assessment in the area of living, welfare and care.] Gouda: BIO.

Bull MJ (1994). Use of formal community services by elders and their family caregivers 2 weeks following hospital discharge. Journal of Advanced Nursing; 19: 503-508.

Bureau voor Toegepaste Economische en Ruimtelijke Planning BV (1999). Uitwerking enquête Landelijke Vereniging voor Thuiszorg: naar de effecten van de overheveling van de indicatiestelling. [Results survey National Association for Homecare; on the effects of the transfer of the needs assessment.] Amersfoort: Terp.

Caris-Verhallen WMCM (1999). Nurse-patient communication in elderly care: an observation study into verbal and nonverbal communication in nursing practice. Utrecht: Nivel/University Utrecht (thesis).

Caris-Verhallen W \& Kerkstra A (1998). Cliënten op de wachtlijst voor een verpleeghuis of verzorgingshuis en hun ervaring met de continuiteit van zorg. [Patients on a waiting list for a nursing home or a home for the elderly and their experience with the continuity of care.] Utrecht: Nivel.

Centraal Bureau voor de Statistiek (2003). Statistisch jaarboek. [Statistical yearbook.] Voorburg/Heerlen: CBS.

Centraal Bureau voor de Statistiek (2003). Vademecum gezondheidstatistieken. [Vademecum health statistics.] Den Haag: CBS.

Coulton C \& Frost AK (1982). Use of social and health services by the elderly. Journal of Health and Social Behavior; 23: 330-339.

Commissie Toezicht Uitvoeringsorganisatie (2001). Rol zorgkantoren in de thuiszorg. [The role of health insurance agencies in home care.] Amstelveen: CTU.

Degen JJEC \& Huijsman R (1999). Schakelen in de keten tussen vraag en aanbod: regionale indicatie-organen in de ouderenzorg. [Gearing in the chain between demand and supply: regional assessment agencies in care for the elderly.] Maarssen/Zoetermeer: Elsevier/De Tijdstroom/STIMO.

De Haan R, Limburg M, Van der Meulen J \& Van den Bos GAM (1993). Use of health care services after stroke. Quality in Health Care; 2: 222-227. 
Dickersin K (1990). Existence of publication bias and risk factors for its occurrence. Journal of the American Medical Association; 263: 1385-1389.

Dijkstra GJ (2001). De indicatiestelling voor verzorgingshuizen en verpleeghuizen. [Needs assessment for homes for the elderly and nursing homes.] Groningen: Noordelijk Centrum voor Gezondheidsvraagstukken (thesis).

Donker MCH (1996). Indicatiestelling in de care-sectoren: kwaliteitsbevordering of kostenbeheersing? [Needs assessment in the care-sectors: promotion of quality or cost control?] Kwaliteit \& Zorg; 4 (4): 159-166.

Ettner SL \& Weissman J (1994). Utilization of formal and informal home care by AIDS patients in Boston: a comparison of intravenous drug users and homosexual males. Medical Care; 32: 459-470.

Evashwick C, Rowe G, Diehr P \& Branch L (1984). Factors explaining the use of health care services by the elderly. Health Services Research; 19: 357-382.

Fleishman JA (1997). Utilization of home care among people with HIV infection. Health Services Research; 32: 155-175.

Freiman MP \& Breen N (1997). The use of home care by cancer patients: a multi-variate analysis. Home Health Care Services Quarterly; 16: 3-19.

Gorter KA, Griffioen E, Hessels D \& Smit-Venhuizen MA (1989). Thuishulp gewogen: een onderzoek naar de behoefte van lichamelijk gehandicapte mensen aan hulp thuis. [Home care on balance: a study of the needs for care at home of physically disabled people.] Utrecht: Nederlands Instituut voor Maatschappelijk Werk Onderzoek.

Health Insurance Association of America (1999). Source Book of Health Insurance Data. Washington DC: HIAA.

Holtkamp CCM (2002). Effects of the Resident Assessment Instrument on quality of care and quality of life in nursing homes. Utrecht: Nivel (thesis).

Huijsman R (1990). Model van voorzieningen voor ouderen. [Model of facilities for the elderly.] Zeist: Kerckebosch BV (thesis).

Hutten JBF \& Kerkstra A (1996). Home care in Europe: a country-specific guide to its organization and financing. Aldershot: Ashgate Publishing Company.

Hutten JBF \& Kerkstra A (2002). Home care is what people want. In: Van Rooij EHC, Droyan Kodner L, Rijsemus AH \& Schrijvers AJP (Ed.). Health and health care in the Netherlands: a critical self-assessment of Dutch experts in medical and health sciences. Maarssen: Elsevier Gezondheidszorg; p. 101-110.

Jedeloo S (2002). Quality of needs assessment and the provision of assistive devices and services for people with a functional disability. Utrecht: Universiteit Utrecht (thesis).

Jörg F (2002). Objectivity in individual needs assessment for access to long-term care. Utrecht: University Utrecht (thesis). 
Joung IMA, Kunst AE, Van Imhoff E \& Mackenbach JP (2001). Sociaal-demografische variabelen toekomstige gezondheid. Effecten op gezondheid en gebruik van gezondheidszorgvoorzieningen 1996-2015. [Social-demographic variables future health. Effects on health and use of healthcare facilities 1996-2015.] Tijdschrift voor Gezondheidswetenschappen; 1: 21-26.

Kane RL, Finch M, Chen Q, Blewett L, Burns R \& Moskowitz M (1994). Post-hospital home health care for Medicare patients. Health Care Financing Review; 16: 131-153.

Katz MH, Cunningham WE, Mor V, Andersen RM, Kellogg T, Zierler S, Crystal SC, Stein MD, Cylar K, Bozzette SA \& Shapiro MF (2000). Prevalence and predictors of unmet need for supportive services among HIV-infected persons: impact of case management. Medical Care; 38: 58-69.

Kempen GIJM \& Suurmeijer ThPBM (1991). Professional home care for the elderly: an application of the Andersen-Newman model in the Netherlands. Social Science \& Medicine; 33: 1081-1089.

Kenney GM (1993). How access to long-term care affects home health transfers. Journal of Health Politics, Policy and Law; 18: 937-965.

Kerkstra A, Verheij RA, Foets M \& Van der Velden J (1990). Behoefte aan nazorg en verleende nazorg na ontslag uit het ziekenhuis. [Need for aftercare and provided aftercare following discharge from hospital.] Tijdschrift voor Sociale Gezondheidszorg; 68 (8): 346-354.

Kerkstra A \& Vorst-Thijssen T (1991). Factors related to the use of community nursing services in the Netherlands. Journal of Advanced Nursing; 16: 47-54.

London AS, Fleishman JA, Goldman DP, McCaffrey DF, Bozzette SA, Shapiro MF \& Leibowitz AA (2001). Use of unpaid and paid home care services among people with HIV infection in the USA. AIDS Care; 13: 99-121.

Ministerie van Volksgezondheid, Welzijn \& Sport (1997). Zorgindicatiebesluit (Besluit van 2 oktober 1997, houdende regels met betrekking tot het werkterrein, de samenstelling en werkwijze van indicatie-organen). [Care Needs Assessment Decree (White Paper of October, 2 1997, regarding field of activities, the formation, and the operation of Regional Needs Assessment Agencies).] Staatsblad van het Koninkrijk der Nederlanden. Den Haag: Sdu, 447.

Ministerie van Volksgezondheid, Welzijn \& Sport (1999). Brief d.d. 25 maart 1999 over Ontwikkelingen indicatiestelling 'nieuwe stijl'. [Letter of March, 251999 on developments new-style needs assessment.] Den Haag: Ministerie van Volksgezondheid, Welzijn \& Sport.

Ministerie van Volksgezondheid, Welzijn \& Sport (2000). Brief d.d. 31 mei 2000 over Indicatiestelling 'nieuwe stijl'. [Letter of May, 312000 on new-style needs assessment.] Den Haag: Ministerie van Volksgezondheid, Welzijn \& Sport. 
Ministerie van Volksgezondheid, Welzijn \& Sport (2000). Brief d.d. 15 januari 2001 over Robuuste RIO's. [Letter of January, 152001 on robust regional assessment agencies.] Den Haag: Ministerie van Volksgezondheid, Welzijn \& Sport.

Ministerie van Volksgezondheid, Welzijn \& Sport (2001). Gedragsregels Ketenbenadering cluster Verpleging \& Verzorging. [Rules of conduct approach of the care chain in the nursing and caring sector.] Den Haag: Ministerie van Volksgezondheid, Welzijn \& Sport.

Ministerie van Volksgezondheid, Welzijn \& Sport (2004). Op weg naar een bestendig stelsel voor langdurige zorg en maatschappelijke ondersteuning. [Heading towards a longlasting system for long-term care and societal support.] Den Haag: Ministerie van Volksgezondheid, Welzijn \& Sport.

Mor V, Allen SM, Siegel K \& Houts P (1992). Determinants of need and unmet need among cancer patients residing at home. Health Services Research; 27: 337-360.

Nationale Raad voor de Volksgezondheid (1994). Indicatiestelling en zorg op maat: advies van de Nationale Raad voor de Volksgezondheid en het College voor Ziekenhuisvoorzieningen. [Needs assessment and customised care: recommendations by the National Council for Public Health and the Council for Hospital Facilities.] Zoetermeer: Nationale Raad voor de Volksgezondheid.

Parry-Jones B \& Soulsby J (2001). Needs-led assessment: the challenges and the reality. Health and Social Care in the Community; 9 (6): 414-428.

Philp I (2001). Family Care of Older People in Europe. Amsterdam/Berlin/Oxford/Tokyo/ Washington DC: IOS Press.

PricewaterhouseCoopers/Nivel (2002). Benchmarkonderzoek 2000 verscherpt inzicht in prestaties en bedrijfsvoering thuiszorginstellingen: resultaten benchmarkonderzoek op serctor-niveau. Eindrapport. [Benchmark project 2000 gives more insight into achievements and management of home care organisations: results of a benchmark study on the level of the sector. Final report.] Almere/Utrecht: PricewaterhouseCoopers /Nivel.

Riemsma RP, Klein G, Taal E, Rasker JJ, Houtman PM, Van Paassen HC \& Wiegman O (1998). The supply of and demand for informal and professional care for patients with rheumatoid arthritis. Scandinavian Journal of Rheumatology; 27: 7-15.

Rijken PM \& Spreeuwenberg P (2004). Patiëntenpanel Chronisch Zieken. Kerngegevens Zorg 2003. [Patient Panel Chronically Ill. Core data Care 2003.] Utrecht: Nivel.

Schippers A (2001). Indicatiestelling voor wonen, zorg en welzijn. [Needs assessment for living, care and welfare.] In: Veldheer VC, Van den Nieuwenhuizen PJCM, Schoorl AHA, Sprinkhuizen AMM \& Stevens PGJJ (Ed.). Handboek Lokaal Sociaal Beleid. Den Haag: Elsevier Bedrijfsinformatie bv; p. D 7.1.1 - D 7.1.24.

Scholte op Reimer WJM (1999). Long-term care after stroke: studies on care utilisation, quality of care and burden of caregiving. Amsterdam: University of Amsterdam (thesis). 
Schrijvers AJP (2001). RIO, het jongste kind groeit op; eindrapport van de evaluatie van het Zorgindicatiebesluit van 1998. [The assessment agency, the youngest child grows to maturity; final report on the evaluation of the Care Needs Assessment Decree of 1998.] Utrecht: Julius Centrum voor Huisartsgeneeskunde en Patiëntgebonden onderzoek.

Schrijvers AJP \& Heinsbroek NQM (1998). Veel op het spel: over het hoe en waarom van verbreding van geïntegreerde indicatiestelling voor mensen met een functiebeperking. [Much to lose: regarding the reason for expanding integrated needs assessment for people with a functional disability.] Utrecht: Stichting Dienstverleners Gehandicapten.

Schrijvers AJP \& Ravelli DP (2000). RIO, het jongste kind; tussenverslag van de evaluatie van het Zorgindicatiebesluit. [Regional assessment agency: the youngest child; preliminary report on the evaluation of the Care Needs Assessment Decree.] Utrecht: Juliuscentrum voor Huisartsgeneeskunde en Patiëntgebonden onderzoek.

SGBO (1999). Kosten van thuiszorg-indicaties; Een onderzoek naar de begrotingen van Regionale Indicatie-Organen. [Costs of needs assessments in home care; a study of the budgets of regional assessment agencies.] Den Haag: SGBO.

SGBO (2000). Werkwijze van Regionale Indicatie-Organen; Onderzoek onder 7 RIO's. [Working procedures of regional assessment agencies; research among 7 regional assessment agencies.] Den Haag: SGBO.

Shaughnessy PW, Schlenker RE \& Hittle DF (1994). Home health care outcomes under capitated and fee-for-service payment. Health Care Financing Review; 16: 187-222.

Sixma HJ, Kerssens JJ, Van Campen C \& Peters L (1998). Quality of care from the patients' perspective: from theoretical concept to a new measuring instrument. Health Expectations; 1: 82-95.

Slingerland P \& Van Amelsvoort F (1993). Thuiszorg bemiddeld: achtergronden, uitgangspunten en instrumenten voor een vraaggerichte benadering van intake en indicatiestelling. [Mediation on home care: backgrounds, points of departure and instruments for a demand directed approach of intake en needs assessment.] Utrecht: Nederlands Instituut voor Zorg en Welzijn.

Snijders TAB \& Bosker RS (1999). Multi-level analysis: an introduction to basic and advanced multi-level modeling. London: Sage Publications.

Sociaal Economische Raad (1999). Gezondheidszorg in het licht van de toekomstige vergrijzing. [Healthcare in the light of the future ageing.] Den Haag: Sdu.

Sommers LS, Marton KI, Barbaccia JC \& Randolph J (2000). Physician, nurse, and social worker collaboration in primary care for chronically ill seniors. Archives of Internal Medicine; 160: 1825-1833.

Steel K, Leff B \& Vaitovas B (1998). A home care annotated bibliography. Journal of the American Geriatrics Society; 46: 898-909.

STIMO (1997). Nieuwsbulletin; $n r .4$. [News Bulletin nr. 4.] Enschede: STIP. 
STIMO (1998). Periodieke inventarisatie indicatie-organen: stand van zaken per 16 februari 1998. [Periodical inventarisation assessment agencies: state of affairs per February 16, 1998.] Zoetermeer: STIMO.

STIP (1999). Informatiebulletin; $n r .5$. [Information Bulletin, nr. 5.] Enschede: STIP.

STIP (1999). Periodieke inventarisatie indicatie-organen: de stand van zaken in augustus 1999. [Periodical inventarisation assessment agencies: state of affairs in August 1999.] Enschede: STIP.

STIP (2000). Informatiebulletin; $n r$. 1. [Information Bulletin, nr. 1.] Enschede: STIP.

STIP (2000). Periodieke inventarisatie indicatie-organen: de stand van zaken in mei 2000. [Periodical inventarisation assessment agencies: state of affairs in May 2000.] Enschede: STIP.

Tennstedt S, McKinlay J \& Kasten L (1994). Unmet need among disabled elders: a problem in access to community long-term care? Social Science \& Medicine; 38: 915-924.

Tweede Kamer der Staten-Generaal (1973-1974). Structuurnota Gezondheidszorg. [White Paper on the structure of healthcare.] Kamerstukken 13.012. Den Haag: Staatsuitgeverij.

Tweede Kamer der Staten-Generaal. (1979-1980). Schets van de eerstelijns gezondheidszorg. [Draft of the primary healthcare.] Kamerstukken 16.066. Den Haag: Staatsuitgeverij.

Tweede Kamer der Staten-Generaal (1987-1988). Nota Ouderenbeleid: voortgangsrapportage 1982-1988. [White Paper on Policy for the Aged: report of progression 19821988.] Kamerstukken 20.539. Den Haag: Staatsuitgeverij.

Tweede Kamer der Staten-Generaal (1998-1999). Nota Zicht op Zorg: plan van aanpak modernisering AWBZ. [White Paper Vision on Care: planning the modernisation of the Exceptional Medical Expenses Act.] Kamerstukken 26.631 nr. 1. Den Haag: Staatsuitgeverij.

Tweede Kamer der Staten-Generaal (1999-2000). Planning en indicatie AWBZvoorzieningen. [Planning and assessment of facilities on behalf of the Exceptional Medical Expenses Act.] Kamerstukken 27.180 nr. 2. Den Haag: Sdu Uitgevers.

Tweede Kamer der Staten-Generaal (2000-2001). Kamerstukken 26.631 nr.10. [White Paper.] Den Haag: Sdu Uitgevers.

Tweede Kamer der Staten-Generaal (2000-2001). Kamerstukken 26.631 nr.12. [White Paper.] Den Haag: Sdu Uitgevers.

Tweede Kamer der Staten-Generaal (2001-2002). Kamerstukken 26.631 nr.22. [White Paper.] Den Haag: Sdu Uitgevers.

Tweede Kamer der Staten-Generaal (2002-2003). Kamerstukken 26.631 nr.46. [White Paper.] Den Haag: Sdu Uitgevers.

Van Campen C, Sixma HJ, Kerssens JJ \& Peters L (1997). Assessing non-institutionalised asthma and COPD patients' priorities and perceptions of quality of health care: the development of the QUOTE-CNSLD instrument. Journal of Asthma; 34: 531-538. 
Van Campen C \& Van Gameren E (2003). Vragen om hulp; vraagmodel verpleging en verzorging. [Asking for help; model for demand in nursing and caring.] Den Haag: Sociaal en Cultureel Planbureau.

Van den Bos GAM (1989). Zorgen van en voor chronisch zieken. [Concerns of and caring for the chronically ill.] Utrecht: Bohn, Scheltema \& Holkema.

Van der Windt W, Calsbeek H, Talma H \& Hingstman L (2003). Feiten over verpleegkundige en verzorgende beroepen in Nederland 2003. [Facts on nursing and caring professions in the Netherlands 2003.] Maarssen/Utrecht: Elsevier gezondheidszorg / Landelijk Expertisecentrum Verpleging \& Verzorging.

Van Oers (2002). Gezondheid op koers?: Volksgezondheid Toekomst Verkenning 2002. [Health on track?: Exploration of future health of the population 2002.] Bilthoven/Houten: Rijksinstituut voor Volksgezondheid en Milieu / Bohn Stafleu Van Loghum.

Vulto, M (1999). Indicatiestelling in de thuisverzorging; knelpuntenanalyse. [Needs assessment in home care; analysis of bottlenecks.] Utrecht: Vulto. 


\section{Dankwoord}

Het schrijven van een dankwoord dóét iets met een promovendus.

Natuurlijk is het heerlijk om de laatste pagina's van je 'levenswerk' vol te schrijven, de laatste stuiptrekkingen vóór De Drukker, de eindstreep dan eindelijk echt in zicht. Maar als je sommige epilogen leest, lijkt het wel of de auteur de hele wereld wil bedanken voor het bijdragen aan de afronding van de dissertatie. Respondenten worden halve helden vanwege hun participatie in het onderzoek, ouders worden ondanks leerplicht en studiebeurs bedankt voor de mogelijkheden die ze hun kind gaven. Dank is verschuldigd aan het sociale netwerk voor de bróódnodige ontspanning en aan het gezin voor het begrip en geduld en met de excuses dat de promovendus hen de voorbije jaren verwaarloosd heeft en dat dat vanaf nu allemaal anders gaat worden. (Co-) promotoren worden opeens 'lief', met collega's van de afdeling is zoveel lol beleefd...

Of zou het zijn dat de promovendus het als een bevrijding ervaart nu eens een niet-wetenschappelijk verantwoorde, meer persoonlijke tekst te mogen schrijven? Eindelijk geen begeleiders die net een andere invalshoek voor ogen hadden, eindelijk geen tijdschriftredactie die het stuk niet echt goed begrepen heeft, maar die toch bepaalt hoe jouw inspanningen wereldkundig gemaakt worden (en bijvoorbeeld een titel na de drukproeven verandert tot een niet-lading dekkende). Er zijn universiteiten waar het dankwoord, als het ook maar iets informeler wordt, als een inlegvel aan de thesis moet worden toegevoegd, niet geschikt om integraal in het boekje te worden opgenomen.

Een dankwoord heeft iets weg van een speech van een kersverse bruidegom aan het eind van een bruiloft. Trouwens, de hele promotiedag vertoont grote gelijkenis met een trouwpartij: een plechtigheid met toga's en de pappa's en mamma's, getuigen (paranimfen) die een erebaantje vervullen, een receptie, een etentje en een feestje, cadeaus en een korte vakantie...

Ben ik dan niet dankbaar voor de begeleiding die ik professioneel kreeg? Jazeker wel, zonder dat was de inhoud van dit proefschrift beslist anders geweest en in een flink deel van de gevallen minder gedegen. Dus Anneke, Jouke en Ada, bedankt voor jullie inbreng en kritische blik! 
Anneke Francke, co-promotor en directe begeleider, wat heb jij eindeloos veel concepten gelezen en van commentaar voorzien. Heel bijzonder heb ik altijd gevonden onze afspraak al vanaf het begin, dat ik jouw commentaar gewoon terzijde zou schuiven als ik het niet ermee eens was. Slechts een enkele maal was je heel pertinent en vond je ècht dat ik iets moest aanpassen, ook al zag ik dat zelf (nog) niet zo. Overigens heb ik volgens mij van die vrijheid maar weinig gebruikt gemaakt, omdat je commentaar doorgaans gewoon bijdroeg aan de kwaliteit van het geschrevene. Op persoonlijk vlak konden we goed overweg en dat is erg van belang als je zo'n lange tijd met elkaar gaat optrekken. Wat dat betreft bewaar ik ook goede herinneringen aan ons tochtje naar Brussel, waar we beurtelings college gaven aan de Vrije Universiteit aldaar. Kinderen, relaties en hoe we in het leven staan passeerden de revue. Je zei eens dat menig promovendus het wel eens over de hoge schoenen loopt en hij of zij dan in tranen uitbarst. $\mathrm{Nu}$ heb ik er geen traan om gelaten, maar de enige keer dat het er echt op aankwam, was jij de enige die aan mij vroeg, hoe ik me nu in die situatie voelde. Die steun als persoon heb ik zeer gewaardeerd! Het enige echte verschil van mening door al die jaren heen was ieders kijk op planningen: ik chronisch te optimistisch, jij voortdurend pessimistisch (in mijn ogen) dan wel realistisch (in jouw ogen). Zo aan het eind van het traject geef ik toe: jij had vaker gelijk...

Jouke van der Zee, directeur van het Nivel, je was mijn enige promotor. Op een ontmoetingsdag voor promovendi (ja, die bestaat) binnen de onderzoeksschool CaRe werd daarover een beetje smalend gedaan: "maar eentje?" Ik heb dat nooit als bezwaarlijk ervaren. Je rol was het promotietraject op afstand te monitoren. Soms had jij als enige van het 'team' een helicopterview, waarvoor de anderen net iets te dicht op de data zaten. Je invloed op het eindproduct is dan ook niet onaanzienlijk, hoewel veelal niet direct aanwijsbaar. Toch had je op bepaalde momenten ook een scherp oog voor details; zo vlooide je na of al mijn referenties in de tekst wel terugkwamen in de literatuurlijst. Je humor-in-bijzinnen kon ik wel waarderen. Tenslotte vind ik het ook wel erg leuk dat je als hoogleraar verbonden bent aan de Universiteit Maastricht. Dit heeft namelijk als gevolg dat ik dáár promoveer, terwijl daar ook mijn wetenschappelijke wieg stond, qua studie en werk. 
Ada Kerkstra, destijds hoofd van de onderzoeksafdeling waartoe het themagebied Verpleging \& Verzorging behoort binnen het Nivel, jij had soms ideeën waarin ik mij helemaal niet kon vinden, maar aan de andere kant waren er ook jouw suggesties die mijn ogen deden fonkelen. Over één ding waren we het in alle omstandigheden als 'oprjochte Frysen' eens: Harlingen is een erg leuk stadje. Ik werd er geboren, jij wilt er doodgaan. Het laatste stuk van het promotietraject heb je niet meer meegekregen, omdat je vier jaar lang de wereld wilde 'omzeilen'.

Daarnaast hebben mij op het professionele vlak nog tal van mensen bijgestaan. Gerard Blad, Eefje Lenders en Richard van Aalst assisteerden mij bij het nauwgezette werk van de verzending van al die verschillende vragenlijsten en voerden de data consciëntieus in. De mensen van de enquêtekamer onder leiding van Irma Hermans en Anneke Kaper namen ruim 400 telefonische interviews af op een wijze die respectvol en integer genoemd kan worden. Al die verhalen die chronisch zieken graag kwijt willen, maar die, voor het onderzoek tenminste, niet ter zake doen... Peter Spreeuwenberg, dé MLA-man van het Nivel, heeft heel wat multi-level analyses gedaan en overgedaan en overgedaan. Zeker gezien zijn werklast was het toch bijzonder dat hij zei dat hij het kon waarderen als hij analyses moest overdoen: "dan wordt er tenminste over nagedacht", zei hij. Herma van den Brink heeft er hard aan getrokken de lay-out van het proefschrift te optimaliseren. Voor het uiterlijk van het boekje tekenden Ronald en Matthijs Beil: het werd een plaatje! Allen veel dank voor het werk achter de schermen, maar stuk voor stuk cruciaal voor een gedegen eindproduct.

En toen lag er een proefschrift, het resultaat van jaren lang schrijven en schaven. Eigenlijk vormt de totstandkoming van het boekje één lange reeks van selecties: welke vragen neem ik wel op in de vragenlijsten en welke niet, welke resultaten rapporteer ik wel en wat niet meer, wat laat ik in de Overview wel terugkomen en wat moet afvallen, wat haal ik wel aan en wat niet in het lekenpraatje? Wellicht ben ik iets te ver doorgeschoten in mijn globalisering van de onderzoeksresultaten, wanneer ik denk vijf jaar onderzoek naar de Regionale Indicatie Organen te kunnen samenvatten in slechts één woord: RIO-lering. Het is aan de lezer aan deze synthese al dan niet een negatieve connotatie te hechten. 
Toch wil ik zeker niet onverschillig lijken met het oog op de belangenloze medewerking van al die respondenten binnen de verschillende delen van het onderzoek. Zij mogen in dit dankwoord zeker niet onvermeld blijven! Bijna alle RIO-directeuren vulden een vragenlijst in en velen selecteerden a-select hun cliënten voor een ander deel van mijn onderzoek en dat in een tijd dat de RIO's toch al onderzoeksmoe werden. Ook directeuren van thuiszorgorganisaties kregen van mij een dikke vragenlijst evenals medewerkers van de zorgkantoren. Later volgde nog dossieronderzoek bij RIO's en thuiszorgorganisaties en opnieuw deed ik een beroep op hun medewerking. Uiteraard ook dank aan die ruim 400 chronisch zieken, die hoewel veelal op gevorderde leeftijd en zorgbehoeftig, toch al die vragen wilden beantwoorden en daarmee onder andere inzicht gaven in hoe aansluitingen tussen zorgbehoeften, geïndiceerde zorg en geleverde thuiszorg door hen ervaren werden.

En ben ik dan niet dankbaar voor alle steun en belangstelling die ik van mijn sociale netwerk kreeg: (schoon)ouders, familie en vrienden? O zeker wel, al was het alleen maar om me met beide benen op de grond te laten staan. Velen waren geïnteresseerd in mijn vorderingen met mijn 'werkstuk', 'scriptie' of 'proefwerk'. Zo bezien wordt mijn openbare verdediging niet meer dan een 'mondelinge overhoring'!

Hierboven schamperde ik weliswaar over de lol die promovendi vaak zeggen te hebben met hun ganggenoten op het werk, maar de werksfeer is natuurlijk wel van wezenlijk belang. Zonder prettige en amicale contacten wordt het promoveren wel een erg solistische bezigheid. Wat dat betreft heb ik mij bij het Nivel altijd als een vis in het water gevoeld. Kamer- en jaargenoten, researchmedewerkers, medewerkers van secretariaten en de administratie, leden van de werkgroep Kwaliteit, en zeker de bibliotheekmedewerkers (dit begint al aardig op de hele Nivel-wereld te lijken...) droegen bij aan het werkplezier.

$\mathrm{Na}$ verloop van tijd sprong ik over naar een ander vissenkom: Cliënt \& Kwaliteit, een bureau dat de kwaliteit van AWBZ-zorg onderzoekt op grond van wat cliënten zèlf aangaven belangrijk te vinden wat betreft de kwaliteit van zorg (het cliëntenperspectief). Met het thuiszorgonderzoek als mijn eigen winkeltje en in de informele sfeer die kleinschaligheid vaak met zich meebrengt, voel ik mij zeer gezegend! 
Mijn beide paranimfen, Diederik van Romondt en Thorbald van Hall, staan mij geestelijk bij op het moment suprème. Diek, het was voor mij vanzelfsprekend dat jij naast mij zou staan. Ik kan me geen gebeurtenis van enige importantie in de laatste vijftien jaar herinneren waarbij jij en Anneke niet aanwezig waren. Thorbald, jij volgde de aansporing die in de titel 'doctorandus' besloten ligt ('hij die nog promoveren moet') al eerder op. Samen met anderen hebben we de laatste jaren menige beleidskwestie moeten verdedigen, dus déze verdediging moet ook wel gaan lukken.

En dan 'trechtert' het dankwoord zich tot de privé-sfeer: Renate, Jorik en Nynke. Zeker de laatste paar jaren heeft het schrijven en schaven veel tijd geroofd, niet alleen mijn tijd, ook onze tijd. Voor het snel promoveren zou je niet de zorg voor terminale familieleden op je moeten willen nemen, je zou geen verbouwingen aan je huis moeten willen, je zou geen vrijwilligerswerk moeten willen doen, geen andere baan aannemen, geen gezin moeten hebben, geen sociale contacten, dus eigenlijk geen leven moeten hebben... Gelukkig forceerden de eenzame perioden in de caravan, midden in een weiland, slechts door een kabelhaspel voor de laptop verbonden met de buitenwereld, acceleraties in het schrijfproces.

Lieve Renate (ja, $z i j$ wel), ik heb lang zitten nadenken over wat jouw rol al deze jaren in dit kader is geweest. Ik denk dat je grootste kracht, zeker de laatste drie jaren, erin bestond - naast je andere kwaliteiten - dat je hard aan de bel trok als mijn werklust te ver ging. Remmend, dat wel en daardoor soms storend, maar wel gezond voor ons gezin en mijzelf. Jorik en Nynke, gelukkig gaan jullie nog bijtijds naar bed en zijn jullie echte buitenkinderen. Dat creëerde heel wat gestolen ogenblikken. Zeer graag laat ik jullie ervoor verantwoordelijk zijn dat mijn gevoel 'straks' zeeën van tijd over te houden, misplaatst blijkt te zijn. En Jorik: het is geen kinderboek geworden...

Als laatste ben ik de Eerste dankbaar, Jezus Christus, de Bron van echte Kennis en Wijsheid. Zonder Hem is geen ding geworden dat geworden is, ook dit proefschrift niet. 


\section{Curriculum vitae}

Marco Algera was born in 1967, in Harlingen, the Netherlands.

After having graduated from high school (1986), he studied to become an all-round nurse (bachelor-degree), during which he created his own research project. In 1990 he graduated on 'organisational change in nursing practice'. At the Maastricht University, he studied Nursing Science (master), both the primary process and managerial track, from which he graduated cum laude (1993) on the topic 'resistance to organisational change in nursing practice'. In part during his study at the Nursing Science Department, he also worked at that same Department as well as at the Department for Medical Psychology, as an alternative to military service. From 1993 till 1994 he investigated amongst others the effects of implementing an organisational structure called 'primary nursing' in a technocratic hospital. During this period, he was also an assistant lecturer and gave many training sessions in social skills and the methodology in social sciences as well.

Employed by the National Association for Home Care (Bunnik), he performed in 1995 statistical analyses differentiating between two classification systems for home care and analysed their predictive validity.

From 1996-1997, Marco was a consultant at KPMG Healthcare, conducting research in workload and marketing.

After that, he returned to scientific research again, investigating the shifts in activities from medical staff to nursing staff at the institute Research voor Beleid in Leiden (1997-1998).

At Nivel - Netherlands institute for health services research in Utrecht Marco organised the evaluation study of the Patients Complaints Act and studied the patient satisfaction about the complaint procedures in Dutch healthcare organisations (1999). The next research project at Nivel was the Ph.D.-project resulting in this thesis (1999-2002). Meanwhile he was a quality officer at Nivel.

He contributed to several handbooks about resistance to change and electronic patient records and for several years he was a free lance author for a nursing journal. Privately, he conducted research on co-parenthood and Personal Care Budgets.

Since 2003, Marco Algera is manager of quality of care projects in home care at Cliënt \& Kwaliteit in Utrecht, taking the patients' perspective as the central point of focus. 
Marco Algera is geboren in 1967 in Harlingen.

$\mathrm{Na}$ het VWO doorlopen te hebben (1986), studeerde hij aan de HBO-V waarbij hij een eigen onderzoeksproject opzette. In 1990 studeerde hij af op het onderwerp 'organisatieverandering in de verpleegkundige praktijk'.

Aan de Universiteit Maastricht studeerde hij vervolgens Verplegingswetenschap, zowel de richting 'primair proces' als 'beleid en beheer'. In 1993 studeerde hij cum laude af; het onderwerp was 'weerstand tegen organisatieverandering in de verpleegkundige praktijk'.

Gedeeltelijk tijdens zijn studie verrichtte hij zijn vervangende dienstplicht aan zijn 'eigen' vakgroep Verplegingswetenschap en was ook verbonden aan de vakgroep Medische Psychologie. Van 1993 tot 1995 verrichtte hij daar onder meer een onderzoek naar de effecten van de implementatie van Integrerende Verpleegkunde in een taakgericht ziekenhuis. Gedurende deze periode was hij ook docent en gaf daarnaast verscheidene trainingen op het gebied van de sociale wetenschap en sociale vaardigheden.

In 1995 verrichtte hij voor de Landelijke Vereniging voor Thuiszorg (Bunnik) statistische analyses naar het onderscheid tussen twee thuiszorgclassificatiesystemen en analyseerde hij de predictieve validiteit ervan.

Van 1996 tot 1997 was Marco organisatieadviseur bij KPMG Gezondheidszorg en deed daar werklast- en marketingonderzoek.

In 1997 keerde hij weer terug naar het wetenschappelijk onderzoek, en onderzocht de taakverschuiving van arts naar verpleegkundige in opdracht van Research voor Beleid te Leiden.

Op het Nivel (Utrecht) organiseerde hij het evaluatie-onderzoek van de Wet Klachtrecht Cliënten Zorgsector en onderzocht hij de cliënttevredenheid over de klachtenprocedure in de Nederlandse gezondheidszorg (1999). Het volgende onderzoeksproject op het Nivel was het promotie-onderzoek waarvan dit proefschrift het resultaat is $(1999-2002)$. Ondertussen was Marco ook kwaliteitsfunctionaris op het Nivel.

Hij droeg bij aan een paar handboeken over weerstand tegen organisatieverandering en elektronische zorgdossiers en schreef een aantal jaren free lance voor het Tijdschrift voor Verpleegkundigen (TVZ). Privé deed hij nog onderzoek naar co-ouderschap en naar Persoonsgebonden Budgetten.

Marco Algera is sinds 2003 projectleider Thuiszorg bij Cliënt \& Kwaliteit te Utrecht, waarbij in het onderzoek naar de kwaliteit van (thuis)zorg het cliëntenperspectief uitgangspunt is. 